\title{
MEASURING THE QUALITY OF PERSONAL CARE IN PROSTATE CANCER RADIOTHERAPY
}

by

Kimberley Anne Foley

A thesis submitted to the Department of Public Health Sciences

in conformity with the requirements for

the degree of Doctor of Philosophy

\author{
Queen's University \\ Kingston, Ontario, Canada
}

(December, 2017)

Copyright @ Kimberley Anne Foley, 2017 


\begin{abstract}
Background: Quality of care includes both technical and non-technical elements of care (personal care).

We previously developed a questionnaire to assess the quality of personal care in prostate cancer radiotherapy. The objectives of this thesis were: 1) to determine which elements of personal care were most important to patients; 2) to develop a method of integrating ratings of importance and ratings of quality to identify elements of care that should become targets for quality improvement; 3 ) to describe the quality of personal care and identify the elements of care that should be targeted for quality improvement.
\end{abstract}

Methods: We surveyed 108 patients undergoing radiotherapy for localized prostate cancer. Patients completed a self-administered questionnaire and rated both the importance and the quality of their care for each of the 143 elements. The importance and the quality of each element was measured by the percentage of respondents who rated it "very important" and "very good", respectively. Different methods for identifying elements to target for quality improvement were developed and compared.

Results: The percentage of elements rated "very important" and "very good" varied from patient to patient. Aspects of care deemed important to most patients were: the perceived competence of their caregivers, the empathy and respectfulness of their caregivers, and the adequacy of information sharing. Patients assigned their lowest quality ratings to elements relating to the treatment environment and comprehensiveness of services, but they also rated these elements as relatively unimportant. We developed three methods of identifying priorities for quality improvement and found that incorporating importance ratings with quality ratings identified different priorities than quality ratings alone. One method was theoretically superior since the ratings for importance and quality were linked for each individual. Elements of care relating to communication of information about the disease and its treatment were identified as the highest priorities for improvement. 
Conclusions: We have developed indicators for measuring the quality of personal care in prostate cancer radiotherapy. We have shown that it is possible to measure the quality of personal care in routine practice and we developed a method for identifying priorities for quality improvement. 


\section{Co-Authorship}

The manuscripts presented in this thesis were written by Kimberley A Foley in collaboration with her supervisors, William J Mackillop, Patti A Groome, and additional co-authors. Financial support for this work was provided by the Canadian Institutes for Health Research (ADC 83510), Prostate Cancer Fight Foundation - Ride for Dad, and the Queen's University Terry Fox Training Program in Transdisciplinary Cancer Research in Partnership with CIHR.

Chapter 3 - Manuscript 1: What Aspects of Personal Care are Most Important to Patients Undergoing Radiation Therapy for Prostate Cancer? This manuscript is presented in the format published in the International Journal of Radiation Oncology*Biology*Physics in 2016. (Full citation: Foley KA, Feldman-Stewart D, Groome PA, Brundage MD, McArdle S, Wallace D, Yingwei P, Mackillop WJ. What Aspects of Personal Care Are Most Important to Patients Undergoing Radiation Therapy for Prostate Cancer? Int J Radiat Oncol • Biol • Phys 2016;94:280-8.) (Supplemental materials are included in Appendix B and additional results not included in the original manuscript are presented in Appendix C.) Data collection was conducted by Kimberley Foley with assistance from David Wallace. Data analysis, interpretation of the results and writing of the manuscript was done by Kimberley Foley with supervision from Deb Feldman-Stewart, Patti Groome and William Mackillop with additional input from Michael Brundage, Siobhan McArdle, David Wallace and Yingwei Peng.

\section{Chapter 4 - Manuscript 2: Development and Comparison of Methods to Identify Priorities for} Improvement of the Quality of Personal Care in Patients Undergoing Radiotherapy for Prostate Cancer This manuscript is formatted for submission to the International Journal for Quality in Healthcare. (Supplemental materials are included in Appendix D.) Data collection was conducted by Kimberley Foley. Data analysis, interpretation of the results and writing of the manuscript was done by Kimberley 
Foley with supervision from Patti Groome and William Mackillop with additional input from Yingwei Peng, Deb Feldman-Stewart and Michael Brundage.

Chapter 5 - Manuscript 3: Measuring the Quality of Personal Care in Patients Undergoing Radiotherapy for Prostate Cancer. This manuscript is presented in the format published in Clinical Oncology in 2017. (Full citation: Foley KA, et al, Measuring the Quality of Personal Care in Patients Undergoing Radiotherapy for Prostate Cancer, Clinical Oncology (2017), https:// doi.org/10.1016/j.clon.2017.09.004) (Supplemental materials are included in Appendix E and additional results not included in the original manuscript are presented in Appendix F.) Data collection was conducted by Kimberley Foley. Data analysis, interpretation of the results and writing of the manuscript was done by Kimberley Foley with supervision from Patti Groome and William Mackillop with additional input from Deb Feldman-Stewart, Michael Brundage, Jonathan Foley, and Siobhan McArdle. 


\section{Acknowledgements}

Acknowledging everyone who has contributed to my education and the development of this thesis is a daunting task. This truly feels like it has been a team effort and I fear my words will not adequately convey the immense gratitude I feel to everyone who has supported me...

First, I must thank my supervisors, Dr. William Mackillop and Dr. Patti Groome. Bill, thank you for agreeing to meet with a young elementary school teacher years ago....and for every opportunity you have given me since that day. I have greatly valued your expert guidance and support and your patience and encouragement to think in more depth. Patti, you have always encouraged me to consider a different perspective. Thank you for your interest in this project and for developing my skills as an epidemiologist! Patti and Bill, you have both been supportive and understanding of the "non-thesis" aspects of my life and always able to see beyond what others would consider barriers to completion. Nothing has seemed insurmountable with your guidance and encouragement.

To my committee members, Dr. Deb Feldman-Stewart and Dr. Michael Brundage, thank you both for bringing unique perspectives to my work and always being available to me whenever I needed additional guidance and input.

Thank you to the numerous graduate students who have supported me over the years, beginning with my MSc. In particular, I wish to acknowledge my original PhD cohort of Atif, Colleen S, Alex and Afshin, and also Lyndsay, Colleen W and Ally who have been a tremendous source of support. Lyndsay, I feel like you deserve a special mention - without you there would no doubt be a stack of questionnaires somewhere I lost track of... thank you for your keen attention to detail and also for our whine \& wine dates!!

I have been fortunate to be part of such a wonderful department. Thank you to the faculty, staff and students in the Department of Public Health Sciences (formerly Community Health and Epidemiology). Numerous professors have contributed to my education and learning, and I am grateful to 
you all for your support and input. I am also appreciative of the administrative support over the years from Lee, Kat, Gerri, Erin, Tim and Sue.

Thank you to the faculty, staff and students at Cancer Care and Epidemiology - to Jenn, Bev, Brenda, Patti's student group and the members of my "pod", past and present, and especially to Lyndsay, Dave, Dan, Tina, Sarah and Weidong for all your support and for making my trips to the office truly enjoyable!

An incredible team of radiation therapists made this study possible. Thank you Siobhan McArdle, Mary Westerland, Michelle Freedman, Anne McNamee, Jim Gooding, Denise Littlejohn, and Heather Watters for your help with data collection. The genitourinary oncology group at CCSEO was also instrumental, in particular, Drs. Khaled Zaza, Maria Kalyvas, Aamer Mahmud, Carey Shenfield, and Michael Brundage. Funding for this project came from the Prostate Cancer Fight Foundation - Ride for Dad, and the Canadian Institutes for Health Research (ADC 83510) and personal funding from the Queen's University Terry Fox Training Program in Transdisciplinary Cancer Research in Partnership with CIHR, with support and encouragement from Lois Mulligan and administrative support from Mark Andrews.

To the many patients who contributed to this work, I am grateful for your time and effort in sharing your experiences, especially at such a difficult and stressful time in your lives. It was both a challenge and an honour to try to and accurately share your opinions so carefully expressed to me in the questionnaire. Thank you.

To my parents and siblings - thank you for all your support... both practical and emotional! Thank you for the warm meals, free accommodations, constant encouragement, and for patiently listening to the ongoing trials and tribulations of a PhD student.

Jonathan, starting my $\mathrm{PhD}$ literally a few days after you completed yours seemed straightforward at the time. I had seen your ups and downs and was convinced I "knew better" and wouldn't run into the same difficulties. Thank you for not laughing at me (too loudly) when I was SO wrong and for patiently 
listening to me talk about my project for hours on end. This process has definitely achieved the goal I wanted when I returned to school from teaching - our dinner table conversations are never boring or repetitive! Thank you for constantly reminding me to celebrate the small victories - clearly from a voice of experience. I look forward to navigating the two $\mathrm{PhD}$ family life... and am thrilled to have you by my side!

And finally, to Hanna. You have made completing my $\mathrm{PhD}$ a much more challenging task than I expected, and I wouldn't change it for anything. Thank you for keeping me grounded in what really matters, for reminding me of the immense joy short trips to the park can bring, and for keeping my focus on the "bigger picture". Sorry to turn you into a child with two $\mathrm{PhD}$ parents... but we can only hope that will do you more good than harm! Know that we will support you in whatever career you ultimately choose - but really, wouldn't it be nice to have a third family member with a framed first author paper in the house?? 


\section{Table of Contents}

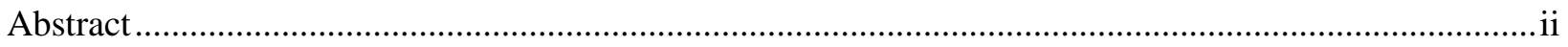

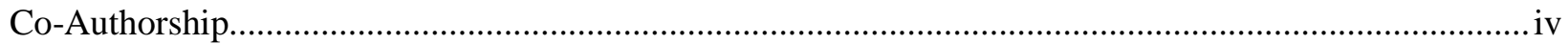

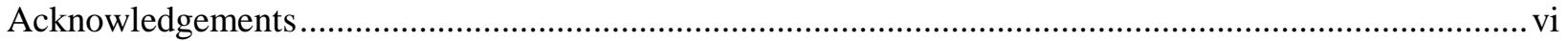

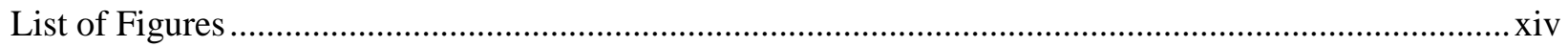

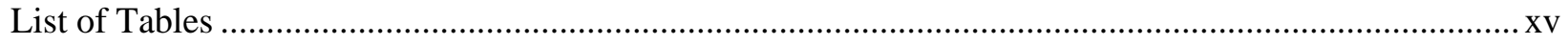

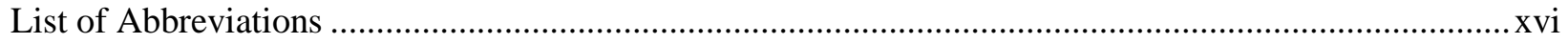

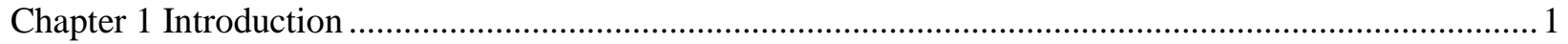

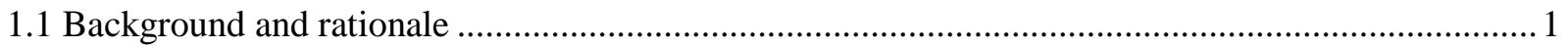

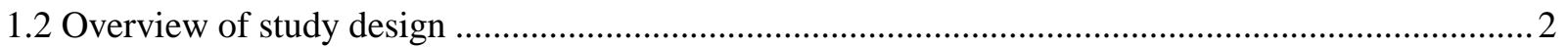

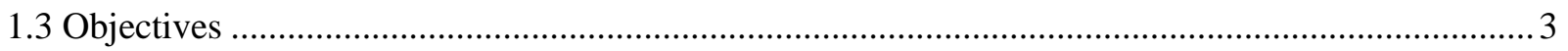

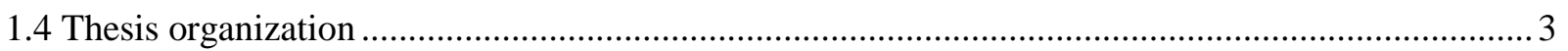

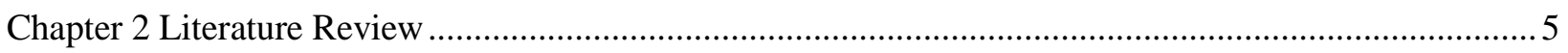

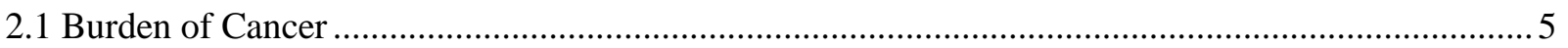

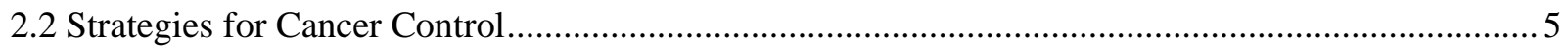

2.2.1 The Role of Treatment in Cancer Control................................................................................ 6

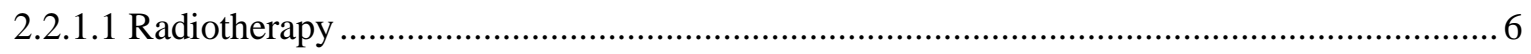

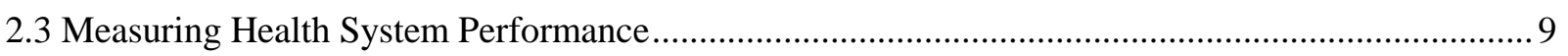

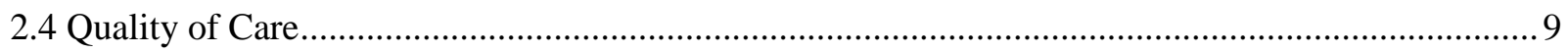

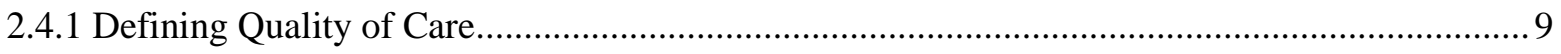

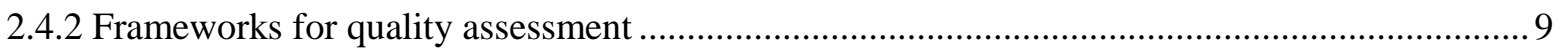

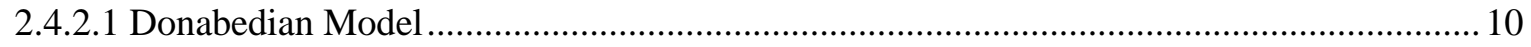

2.4.2.2 Organization for Economic Cooperation and Development Health Care Quality Indicators

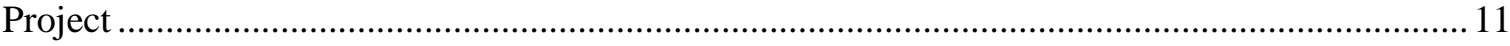

2.4.2.3 Canadian Institute for Health Information Health Indicator Framework ............................ 12

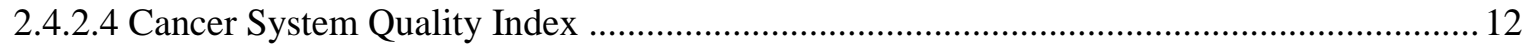

2.5 Evaluating Quality of Care within Healthcare Institutions .......................................................... 13

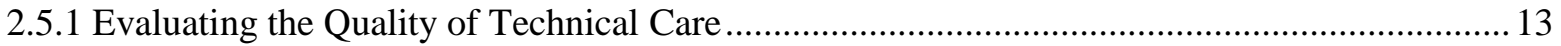

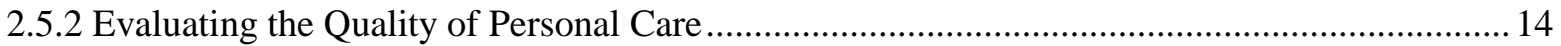

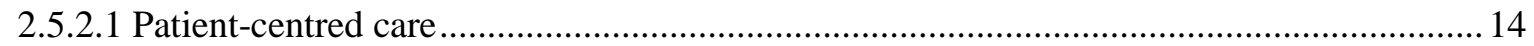

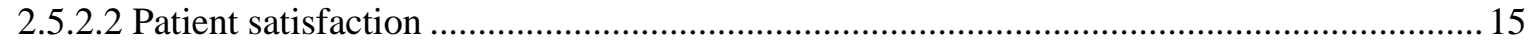

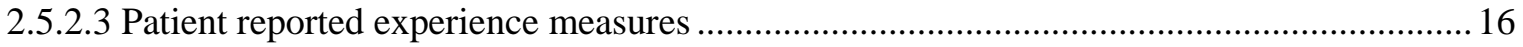

2.5.3 Evaluating quality of care in a specific context ..................................................................... 17 


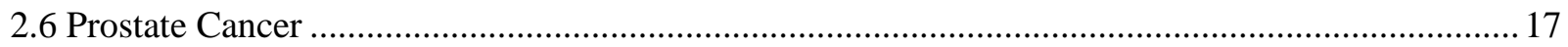

2.6.1 The Use of Radiotherapy as a Treatment for Early-Stage Prostate Cancer .............................. 19

2.6.1.1 Previous Research in the Quality of Technical Care in Radiotherapy ..............................20

2.6.1.2 Previous Research in the Quality of Personal Care in Radiotherapy .................................21

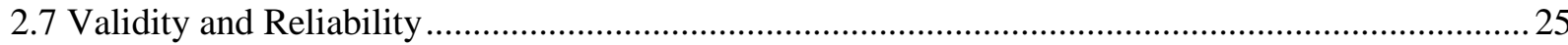

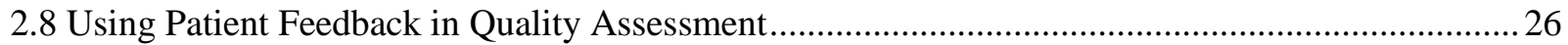

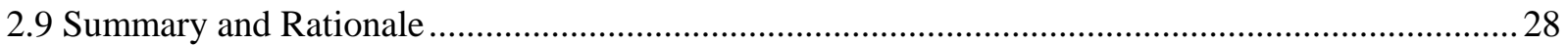

Chapter 3 What Aspects of Personal Care Are Most Important to Patients Undergoing Radiation Therapy

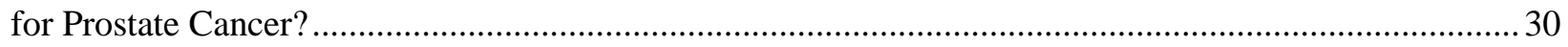

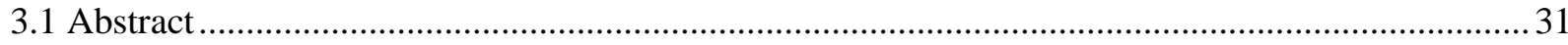

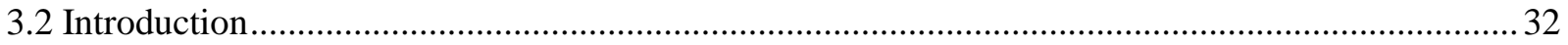

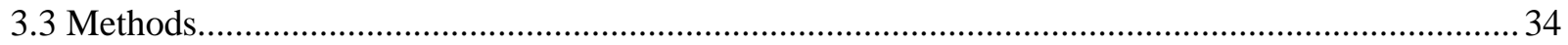

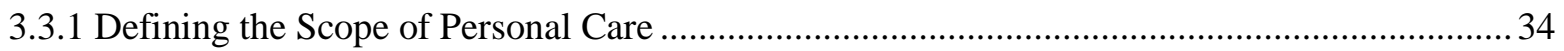

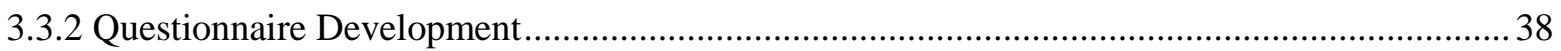

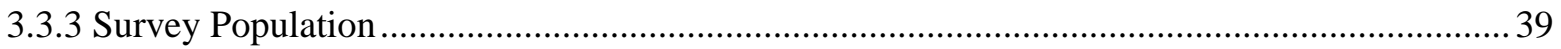

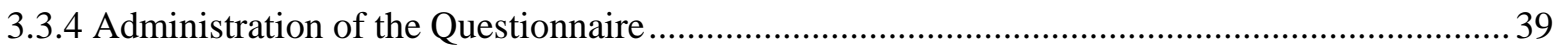

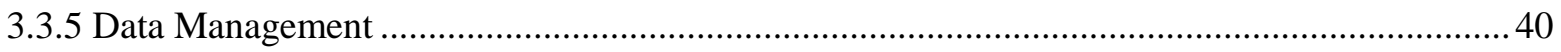

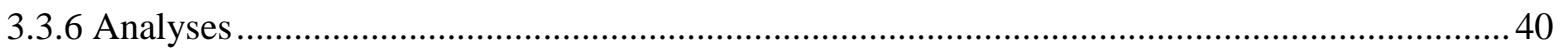

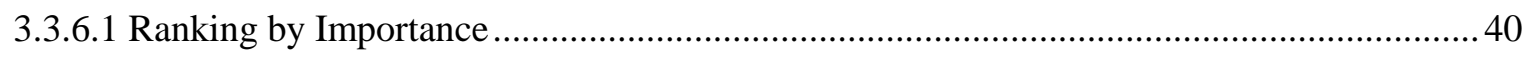

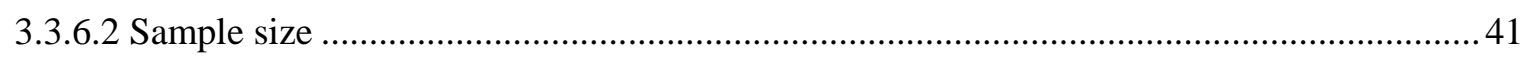

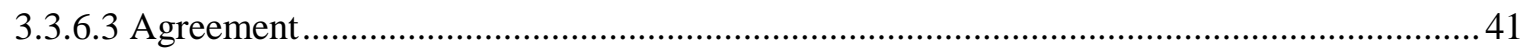

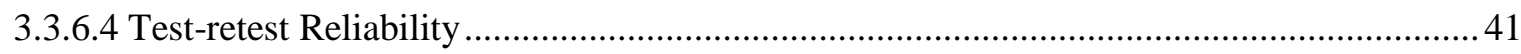

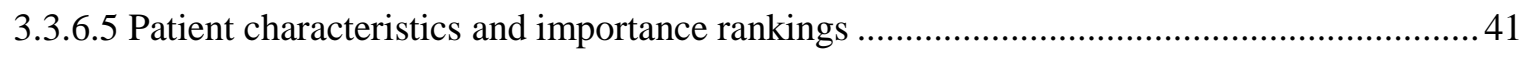

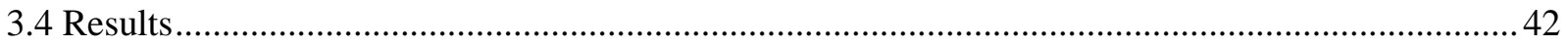

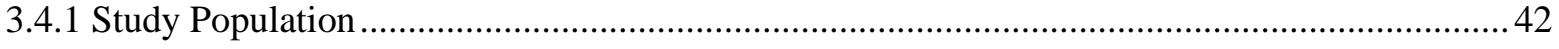

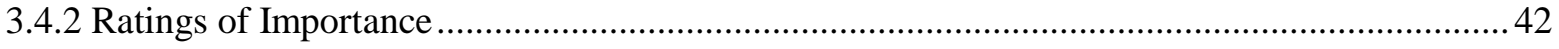

3.4.3 Agreement on Ratings of Importance …......................................................................... 45

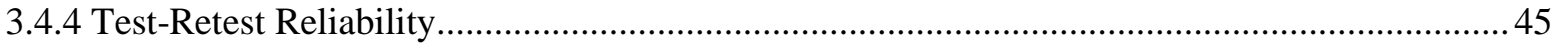

3.4.5 Relationship between patient characteristics and ratings of importance .................................. 46

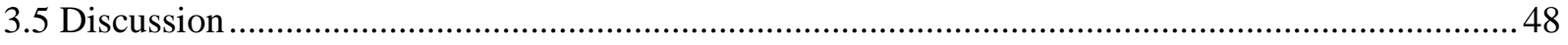

Chapter 4 Development and Comparison of Methods to Identify Priorities for Improvement of the Quality of Personal Care in Patients Undergoing Radiotherapy for Prostate Cancer ...........................................51

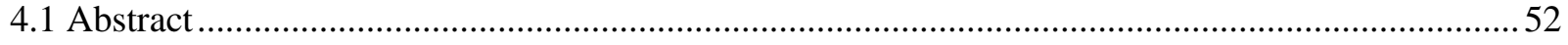

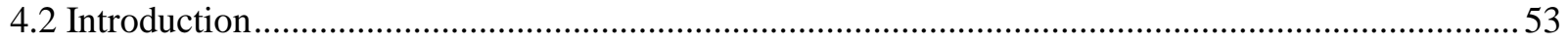




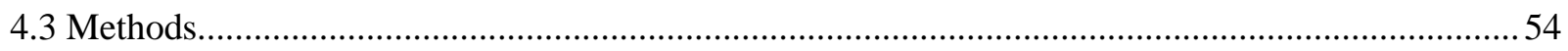

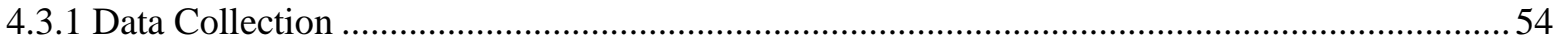

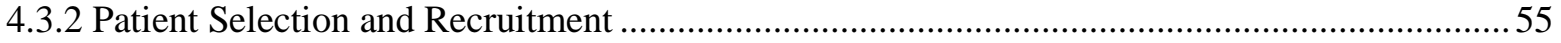

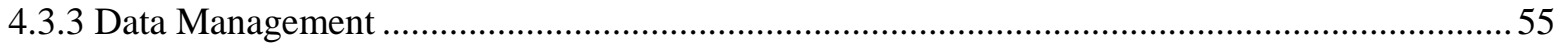

4.3.4 Identifying Priorities for Quality Improvement ..................................................................56

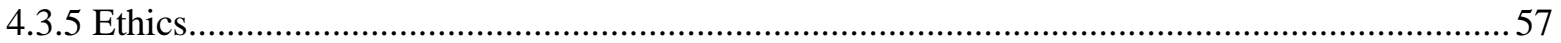

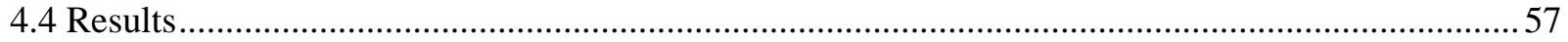

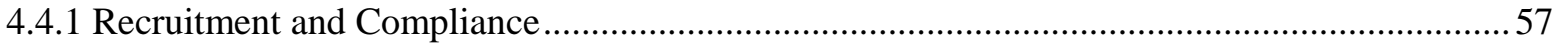

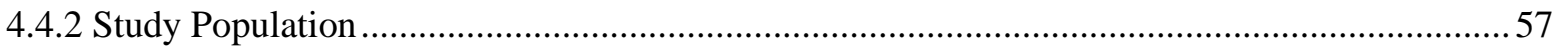

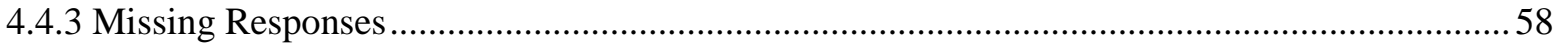

4.4.4 Identifying Priorities for Quality Improvement .................................................................58

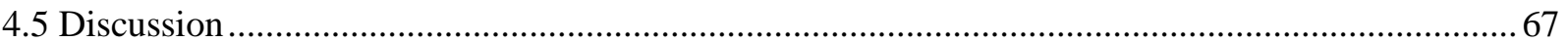

Chapter 5 Measuring the Quality of Personal Care in Patients Undergoing Radiotherapy for Prostate

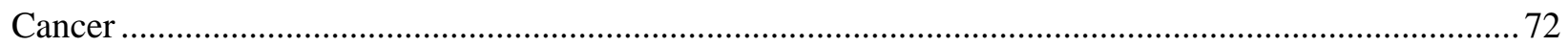

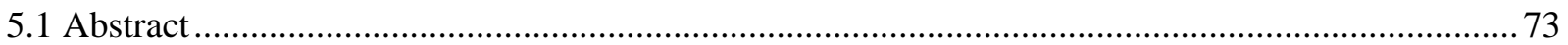

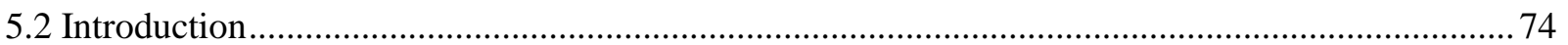

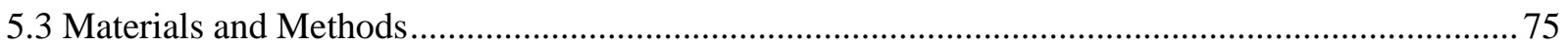

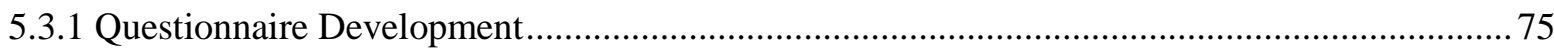

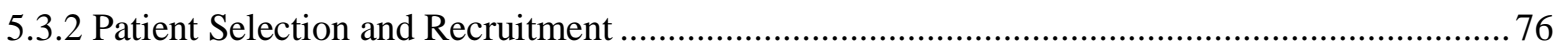

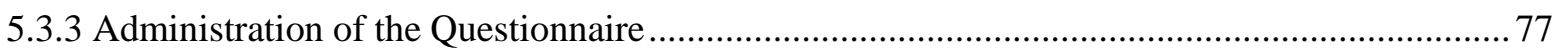

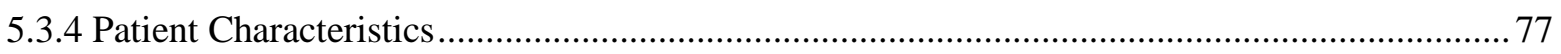

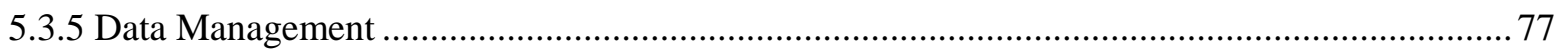

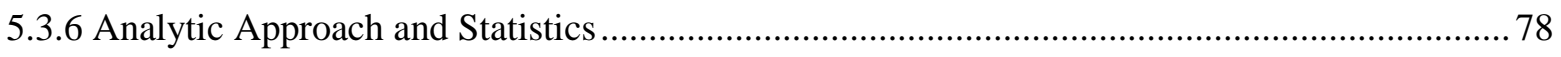

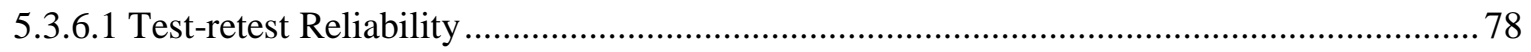

5.3.6.2 Describing the Overall Quality of Personal Care................................................................ 78

5.3.6.3 Identifying Priorities for Quality Improvement ............................................................. 78

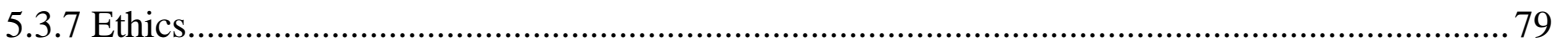

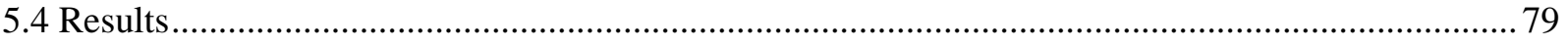

5.4.1 Recruitment, Consent and Completion Rates …..................................................................... 79

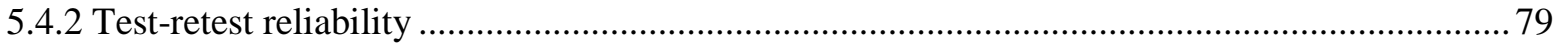

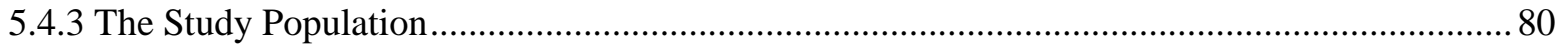

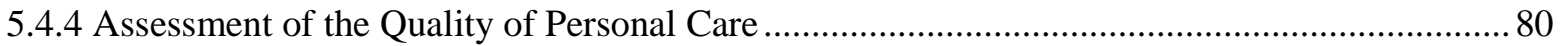

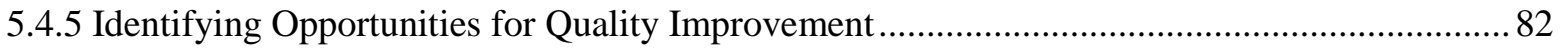

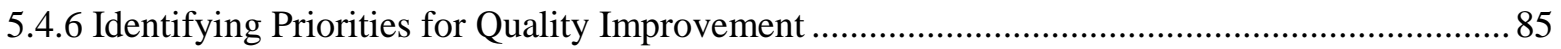


5.5 Discussion .88

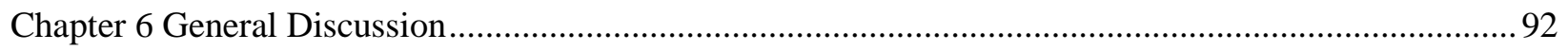

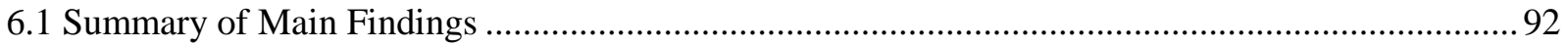

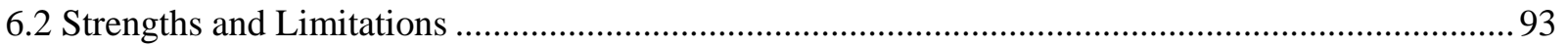

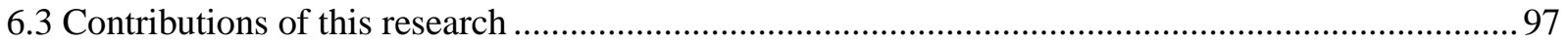

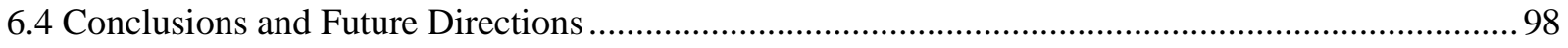

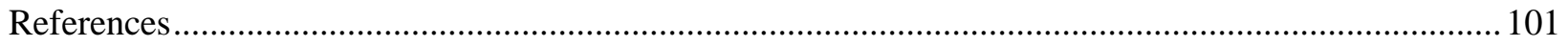

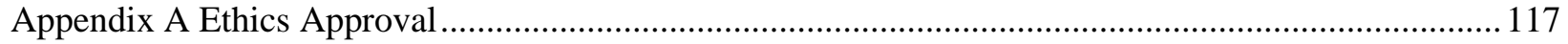

Appendix B E-Supplement for the manuscript titled, "What Aspects of Personal Care Are Most Important to Patients Undergoing Radiation Therapy for Prostate Cancer?" ........................................................... 120

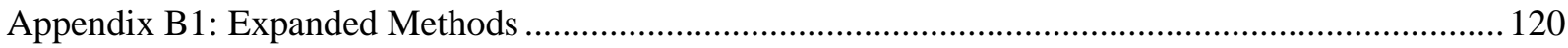

Appendix B2: Source references used to identify elements and aspects of the quality of personal care relevant to patients undergoing radiation therapy for prostate cancer ................................................ 128

Appendix B3: Time to completion, Response Rate by Module and Completeness of Responses ........ 132 Appendix C Additional results for the manuscript titled, "What Aspects of Personal Care Are Most Important to Patients Undergoing Radiation Therapy for Prostate Cancer?" .......................................... 144

Appendix C1: Additional rationale for our sample size calculation ............................................... 144

Appendix C2: Comparing ages between responders and non-responders ....................................... 144

Appendix C3: Assumptions of Generalized Estimating Equations ................................................ 145

Appendix C4: Timing of module 1 in relation to the diagnosis......................................................... 146

Appendix D E-Supplement for the manuscript titled, "Development and Comparison of Methods to Identify Priorities for Improvement of the Quality of Personal Care in Patients Undergoing Radiotherapy

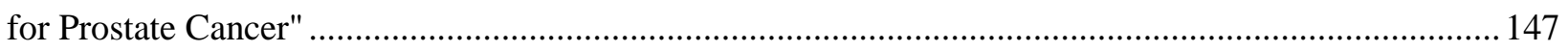

Appendix D1: Missing Responses and Sensitivity Analyses......................................................... 147

Appendix D2: Assumptions of Generalized Estimating Equations …............................................... 147

Appendix D3: The full ranking of priorities for quality improvement identified by each method....... 150

Appendix D4: Comparing the percentage of elements of care identified as priorities for improvement

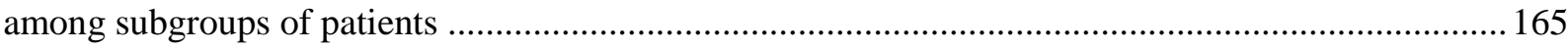

Appendix E E-Supplement for the manucript titled, "Measuring the Quality of Personal Care in Patients

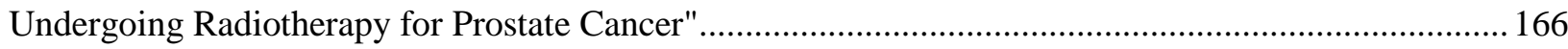

Appendix F Additional results for the manuscript titled, "Measuring the Quality of Personal Care in

Patients Undergoing Radiotherapy for Prostate Cancer" ........................................................................ 193

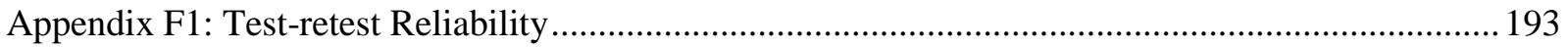

Appendix F2: Percentage of elements rated "very good" over time................................................... 193 
Appendix F3: Sensitivity analyses for ranking methods and missing data...................................... 193

Appendix F4: Assumptions of Generalized Estimating Equations ................................................. 194 


\section{List of Figures}

Figure 2-1: Levels of care where quality can be assessed ................................................................ 10

Figure 2-2: Sample page of the self-administered questionnaire ...........................................................23

Figure 2-3 Framework for Health Services Research ..................................................................2

Figure 3-1: Identifying elements of the quality of personal care relevant to radiotherapy for prostate

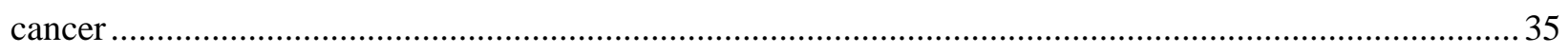

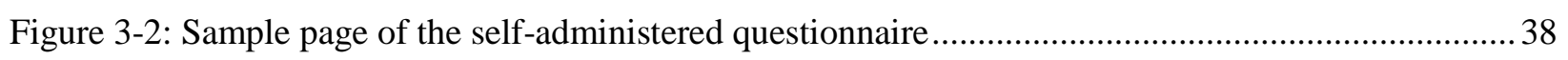

Figure 3-3: Comparison of the importance of aspects of personal care ..................................................45

Figure 3-4: Relationship between patient characteristics and ratings of importance................................48

Figure 4-1: Sample page of the self-administered questionnaire ...........................................................55

Figure 4-2: Rank correlation between results of the three methods..................................................... 60

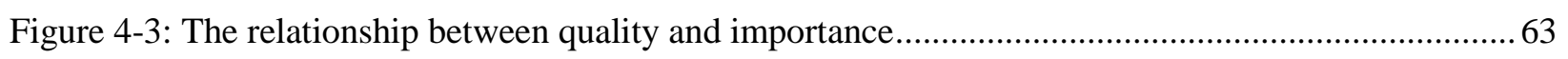

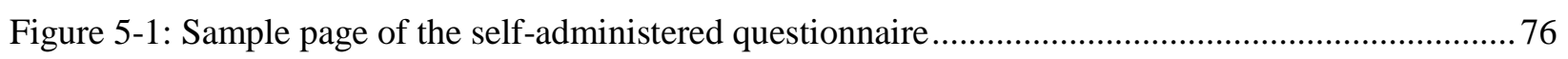

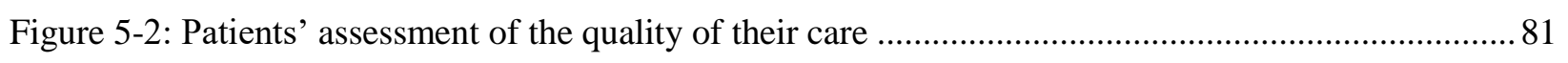

Figure 5-3: The relationship between quality and importance ............................................................ 86 


\section{List of Tables}

Table 2-1: Selected elements from the conceptual framework for OECD Health Care Quality Indicator

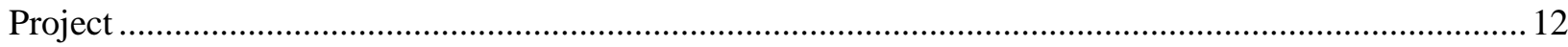

Table 3-1: Aspects and sample elements of the quality of personal care ….............................................36

Table 3-2: Highest and lowest ranked elements of care by percentage of patients rating each one "very important"

Table 4-1: Comparison of the three methods based on their ability to discriminate between top priorities

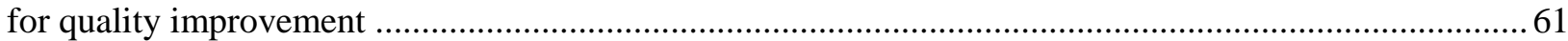

Table 4-2: The top elements of care identified by each method for identifying targets for quality improvement

Table 5-1: Quality ranking of the elements of care based on the percentage of patients rating each element

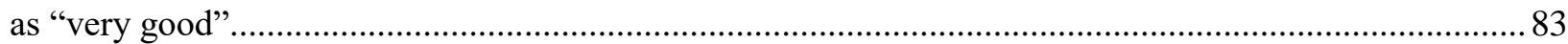

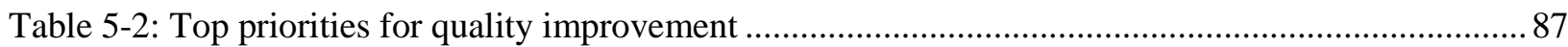




\section{List of Abbreviations}

3D-CRT 3-Dimensional Conformal Radiotherapy

CCSEO Cancer Centre of Southeastern Ontario

CIHI Canadian Institute for Health Information

CSQI Cancer System Quality Index

DRE Digital rectal examination

GEE Generalized Estimating Equations

Gy Gray

IGRT Image-guided Radiotherapy

IMRT Intensity-modulated Radiotherapy

IQR Interquartile range

MCAR Missing completely at random

OECD Organization for Economic Cooperation and Development

PREM Patient Reported Experience Measure

PSA Prostate-Specific Antigen

RAND Research and Development Corporation

WHO World Health Organization 


\section{Chapter 1}

\section{Introduction}

\subsection{Background and rationale}

Delivering a high quality of care to patients is a priority for any health care system.

Quality of care is defined by the Institute of Medicine as "the degree to which health services for individuals and populations increase the likelihood of desired health outcomes and are consistent with current professional knowledge" (1). Before care delivered to patients can be improved, the current quality of care must be evaluated, and areas in need of improvement identified.

Assessment of quality of care is complex as quality consists of both technical and non-technical elements of care (2), the latter referred to as "personal care". Comprehensive assessments of quality must include an assessment of both technical and personal care.

Our research group previously conducted a study to assess the quality of technical care in prostate cancer radiotherapy $(3,4)$. The current study assessed the quality of personal care to complement our previous work and ensure a comprehensive assessment of quality. Although health care providers are the best judges of the quality of technical care, they are not the best judges of the quality of personal care (5). To attain a high quality of personal care, it is not sufficient to simply deliver the care to patients. It must be delivered in a manner that is consistent with patients' values and wishes and they must perceive the care provided as acceptable and adequate. Therefore, the best judge of the quality of personal care is the patient $(5,6)$.

Our literature search found no appropriate, comprehensive tools to assess the quality of personal care in the context of prostate cancer radiotherapy. We addressed this gap by designing our own questionnaire, which formed the basis of my MSc Thesis (7). The questionnaire consisted of 143 elements of care organized within the 10 aspects of personal care: 'patient centeredness', 'empathy and respectfulness of caregivers', 'competence of caregivers', 'adequacy 
of information sharing', 'accessibility of caregivers', 'continuity of care', 'comprehensiveness of care', 'acceptability of the treatment environment', 'privacy' and 'convenience'. The questionnaire was organized into three modules corresponding to specific time points in the patient care continuum.

In order to accurately describe quality of care from the patient's perspective we need to make sure we are collecting data on the aspects of care that are important to patients $(8,9)$. Furthermore, to ensure the data collected is useful in quality improvement, we need to synthesize and present it in a way that allows us to identify clear priorities for quality improvement $(10,11)$.

\subsection{Overview of study design}

We conducted a cross-sectional study at the Cancer Centre of Southeastern Ontario in Kingston, Canada to collect information on the quality of personal care in patients starting curative radiotherapy for prostate cancer between May 2011 and August 2014. Patients were provided with each module of the questionnaire at appropriate time points during their care. For each element of care, patients were asked "How important is this to you" and "How good was your care in this regard"? Ratings of importance were provided on a 4-point scale (not important, somewhat important, important, very important) and ratings of quality were provided on a 5-point scale (very poor, poor, okay, good, very good). Beginning in May 2012, patients were invited to participate in a test-retest study. Additional details about the patients' cancer and treatment were obtained by medical chart review. 


\subsection{Objectives}

This $\mathrm{PhD}$ thesis addressed three main objectives:

1) To determine which elements of personal care were most important to patients undergoing radiotherapy for prostate cancer

2) To develop a method of integrating ratings of importance and ratings of quality to identify elements of care that should become targets for quality improvement

3) To describe the quality of personal care delivered to patients undergoing radiotherapy for prostate cancer in routine practice and to identify the elements of personal care that should be targeted for quality improvement

\subsection{Thesis organization}

This thesis is written as a manuscript-based thesis consisting of six chapters and six appendices. Chapter 2 contains a literature review including a definition of quality of care, frameworks for quality assessment, an overview of prostate cancer management, and an overview of previous work done in the area of assessing the quality of personal care. Three manuscripts follow the literature review. The first manuscript describes the aspects of care most important to patients undergoing radiotherapy for prostate cancer. As it was published in an American journal, the terminology used throughout this chapter is "radiation therapy" instead of radiotherapy as written elsewhere in the thesis. This manuscript addresses the first objective of this $\mathrm{PhD}$ thesis but also includes relevant background information from my Master's thesis as it addressed the following objective from my MSc: To define the scope of personal care and create a comprehensive list of the elements of personal care that are pertinent to patients who undergo radiation therapy for prostate cancer. The second manuscript describes and compares different methods for identifying targets for quality improvement, addressing objective 2 of this $\mathrm{PhD}$ 
thesis. This manuscript is formatted for submission to the International Journal for Quality in Healthcare. The third manuscript describes the quality of personal care delivered to patients undergoing radiotherapy for prostate cancer and identifies the elements of personal care that should be targeted for quality improvement, addressing objective 3 . The third manuscript identifies the priorities for improvement using one of the methods described in manuscript two, but it should be noted that the name of the method changed between manuscript 2 and 3 (this change was in name only, the method itself remains the same). In manuscript 2 , the method is referred to as "individual priority-based method" to be in line with the names of the other two methods, but in manuscript 3, for simplicity we call it "importance/quality analysis". This third manuscript was published in Clinical Oncology and therefore uses British spelling. Chapter 6 provides a general discussion of the overall strengths and limitations of this work and provides an overview of the next steps. The appendices include the ethics approval, the e-supplements for each manuscript, and additional results not published in the original manuscripts or esupplements. 


\section{Chapter 2}

\section{Literature Review}

\subsection{Burden of Cancer}

Cancer is the second leading cause of death worldwide with 8.7 million deaths in 2015 (12). The incidence of cancer is increasing; between 2005 and 2015 the incidence of cancer increased by $33 \%$ mainly due to an aging population and an increasing population size. In 2015 there were 17.5 million incident cancer cases, with large differences in the odds of being diagnosed with cancer depending on the country of origin (12).

In Canada, cancer is the leading cause of both death and premature mortality. In 2017, it is estimated that 206200 people will be diagnosed with cancer and that 80800 deaths will be attributed to a cancer diagnosis. The risk of developing cancer increases with age and in 2017 an estimated $89 \%$ of new cancers will be in people over the age of 50 , and $45 \%$ in people over the age of 70. Individuals over the age of 65 are the fastest-growing age group in Canada, therefore the incidence and mortality due to cancer are expected to increase (13).

Cancer puts a strain on the health care system due to the resources required to diagnose, treat and manage this group of diseases. Cancer control strategies must be developed and implemented in order to prevent premature mortality and to ensure the health care system can meet the increasing needs of individuals in Canada and worldwide.

\subsection{Strategies for Cancer Control}

To reduce the burden of cancer, the World Health Organization (WHO) has recommended all countries adopt a national cancer control policy. Specifically, they recommend implementing a cancer control strategy that addresses prevention, early detection, screening, treatment and palliative care (14). In Canada, The Canadian Partnership Against Cancer has 
developed such a strategy, which was recently updated for 2017-2022 and clearly describes an action plan for reducing the burden of cancer on Canadians (15). Ideally, we would control the burden of cancer solely through prevention. For some cancers, prevention or screening for precursors of the cancer is a feasible strategy for controlling disease. In other cases, this may not be possible, in which case treatment takes on a critical role in reducing the burden of cancer.

\subsubsection{The Role of Treatment in Cancer Control}

Treatment is an essential component of any cancer control strategy. Treatment has a variety of roles, including curing cancer, prolonging life, and alleviating symptoms (16). Various treatments for cancer are available, including surgery, radiotherapy, chemotherapy, immunotherapy and hormone therapy. The specific treatment choice depends on the type of cancer, its stage, and the ultimate goal of treatment. The WHO acknowledges that treatment involves more components than cancer management, in that it also encompasses non-technical elements such as psychosocial support for patients and families (16).

\subsubsection{Radiotherapy}

Radiotherapy is a key treatment modality as it is recommended in the treatment of approximately $42 \%$ of patients with cancer (17). Radiotherapy involves using radiation such as xrays, gamma rays and charged particles to destroy cancer cells. Radiation works by damaging DNA, either directly, or indirectly by the creation of free radicals (18). Radiation damages normal cells in addition to cancer cells, but normal cells are better at repairing the damage caused by radiation treatment (19).

Techniques include external-beam radiotherapy, as well as brachytherapy. External beam radiotherapy is most often delivered by photon beams. Linear accelerators are the machines that provide the photon beams. Radiation doses are measured in gray (Gy), which is a unit representing the amount of radiation absorbed by $1 \mathrm{~kg}$ of tissue (18). External beam radiotherapy 
can be delivered by 3-D conformal radiation (3D-CRT) or intensity-modulated radiation therapy (IMRT) with or without image-guidance. 3D-CRT delivers radiation using static treatment beams to precise targets generated by the radiation oncologist by contouring volumes on 3-D images captured in the planning phase, taking into account the size, shape and location of the tumour and the surrounding organs $(18,20)$. IMRT is a technique that allows for modification of the intensity of radiation beams during a treatment session, meaning that the dose of radiation given to the tumour and to surrounding tissues can be further separated by conforming the dose more precisely to the target volumes. The way 3D-CRT and IMRT are planned differs slightly. In 3DCRT, the radiation oncologist will often choose the number and angles of the radiation beams and the radiation dose will be calculated accordingly. In contrast, with IMRT, the radiation oncologist will specify the dose to the tumour and the maximum desired dose to surrounding tissues, and complex computer algorithms will determine the direction, intensity, and shielding of the treatment beams required to meet the prescription constraints (18). Image-guided radiation therapy (IGRT) means that additional imaging scans are obtained during the course of treatment, allowing comparison with the planning imaging. These comparisons ensure that the patient is positioned properly for treatment, and also allow changes in the treatment plan to be considered if patient anatomy changes over the course of therapy. Brachytherapy is "short-distance" radiotherapy, which involves placing radioactive sources internally in or near the tumour. Brachytherapy can be permanent or temporary. Permanent brachytherapy is a type of low-doserate treatment where continuous low-dose-rate radiation is provided over time and the radioactive seeds are not removed even after the radiation dose has been delivered. Temporary brachytherapy means that the radioactive source and the catheter used for its delivery are removed after treatment. Temporary brachytherapy can be delivered as either low-dose-rate or high-dose-rate in one or more sessions and involves the placement of radioactive sources in or close to the tumour, followed by their removal at the end of each session of treatment. In the case of permanently implanted seeds, the radioactive isotopes gradually decay over time and give off radiation to 
nearby cells. Compared to external beam radiotherapy, brachytherapy may allow for higher doses of radiation to be delivered to the tumour with less damage to normal body tissues. Brachytherapy can also be given in addition to a course of external-beam radiotherapy to "boost" the radiation given to the tumour (18).

All of these radiotherapy techniques aim to deliver a targeted radiation dose to the tumour while minimizing damage to surrounding (healthy) tissues (21). In addition to factors such as the dose and a patient's general health, the side effects experienced by patients will be related to the area(s) of the body irradiated. Therefore, many of the side effects from radiation are specific to the location/type of the cancer and some areas of the body are more susceptible to damage from radiation. Radiotherapy can cause both acute side effects (early, during the course of treatment) and chronic side effects (late, months or years after treatment) (18).

Radiotherapy may be given with the intention of curing the cancer (curative radiotherapy) or to decrease symptoms caused by the cancer and hopefully prolong life (palliative radiotherapy). Additionally, it may be given in addition to other treatments such as surgery (neoadjuvant if administered prior to surgery, or adjuvant if administered afterwards).

Radiotherapy is given as daily treatment over several weeks. The dose and number of treatments will vary depending on the treatment intent and type of tumour (18). A single dose of treatment is referred to as a fraction, and typically patients are given one fraction per day. By providing the total dose in fractions, this minimizes damage to normal body tissues and may increase the damage to cancer cells by exposing them to radiation at a point in the cell cycle when they are most susceptible to DNA damage (18).

Administration of any treatment must be done in an optimal manner in order to obtain optimal results. However, our capacity to improve the care delivered to patients will be limited based on the current technology available, the state of professional knowledge and other factors such as cost. We need to measure the current performance of this aspect of the health care system 
and compare it to what is potentially achievable in order to identify and improve upon areas that are not functioning optimally (22).

\subsection{Measuring Health System Performance}

The performance of the health care system is measured in terms of accessibility, quality and efficiency. Accessibility means that patients receive the necessary care when it is needed. Quality means that the health care system provides the appropriate care, delivered in the correct way. Efficiency looks at whether the cost and resources used to deliver the care achieve an optimum balance with respect to the accessibility and quality of services (22). We can evaluate each of these components separately to identify areas requiring improvement and target interventions and policy to those specific areas. In this project, the focus is on the measurement of quality of care within a very specific disease and treatment context.

\subsection{Quality of Care}

\subsubsection{Defining Quality of Care}

Delivering a high quality of care to patients is a priority for any health care system. Quality of care is defined by the Institute of Medicine as "the degree to which health services for individuals and populations increase the likelihood of desired health outcomes and are consistent with current professional knowledge"(1). This is a very broad definition and useful in a general context, but a more specific definition is helpful for quality assessment.

\subsubsection{Frameworks for quality assessment}

Many frameworks exist to define quality of care and to identify specific quality indicators for use in quality assessment (23). All such frameworks build upon work initially done by Avedis Donabedian. 


\subsubsection{Donabedian Model}

Avedis Donabedian was a groundbreaking researcher in the area of quality of care who developed a framework for assessing quality (2). This framework has been described as a "bullseye" with the health care practitioners in the center representing the fundamental pre-requisite to the provision of high quality patient care. Beginning with the center and moving outwards, there are several levels of care where quality can be assessed: the care provided by health care providers (subdivided into technical and interpersonal care), the care provided by health care institutions (including amenities such as privacy and comfort), the care implemented by the patient (patient compliance) and the care provided by the community (2). As one moves outward from the center the components build on each other. This framework is shown in Figure 2-1.

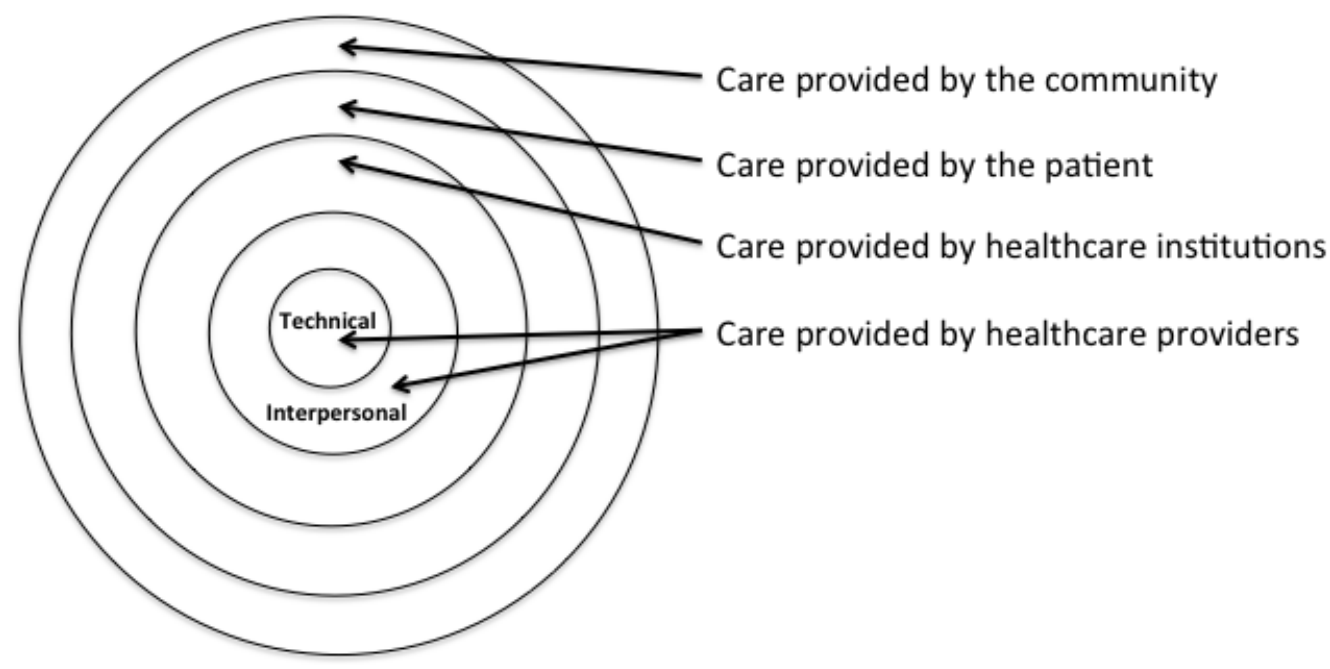

\section{Figure 2-1: Levels of care where quality can be assessed (adapted from Donabedian (2))}

Within each level of this framework, we can identify indicators of care representing one of three domains: structure, process or outcome. Structure refers to the types and number of staff resources or the physical layout of the institution in which care is provided. Process refers to the way that care is delivered, which includes both technical and non-technical elements of care. Outcomes are the result of care. The quality of technical care will affect outcomes such as 
survival, whereas the quality of non-technical elements of care is likely to affect outcomes such as patient satisfaction or quality of life. By identifying and resolving any deficiencies in structures or processes of care, we can improve patient outcomes (24). Process measures are often the most useful in quality assessments as they are usually more sensitive measures and have the greatest potential to be targeted for future intervention (25).

Building upon the work done by Donabedian, several other frameworks have been developed for use in assessing quality of care. Three frameworks will be described here as examples: a global framework, a Canadian framework and one relevant to the Ontario Cancer system. All of these frameworks follow the same principles as the Donabedian framework; they define dimensions of quality that should be included in quality assessment and then identify indicators relevant to each dimension.

\subsubsection{Organization for Economic Cooperation and Development Health Care Quality Indicators} Project

This project was designed to develop a set of indicators for use in comparing the quality of health care across Organization for Economic Cooperation and Development (OECD) countries. The OECD framework distinguishes between health and health care, but it is the performance of the health care system that is of relevance here. It is a broad framework, but the relevant portion describes a matrix examining health care performance by health care needs. In assessing the quality of health care it focuses on effectiveness, safety and responsiveness/patient centeredness as the relevant dimensions of care. Health care needs include general elements which can be mapped onto the trajectory of patient cancer care: prevention, treatment or "getting better", survivorship or "living with illness/disability" and palliative care or "coping with end-oflife" (see Table 2-1). Indicators can then be mapped to each position in the matrix (26). The section particularly relevant to this thesis would be the indicators within the "responsiveness/patient-centeredness" and "treatment" box. 
Table 2-1: Selected elements from the conceptual framework for OECD Health Care Quality Indicator Project (adapted from $(26,27)$ )

\begin{tabular}{|l|l|l|l|}
\hline \multirow{2}{*}{ Healthcare needs } & \multicolumn{3}{|c|}{ Quality of Health Care } \\
\cline { 2 - 4 } & Effectiveness & Safety & $\begin{array}{l}\text { Responsiveness / } \\
\text { Patient-Centeredness }\end{array}$ \\
\hline $\begin{array}{l}\text { Primary prevention } \\
\text { (Screening) }\end{array}$ & & & \\
\hline $\begin{array}{l}\text { Getting Better } \\
\text { (Treatment) }\end{array}$ & & & \\
\hline $\begin{array}{l}\text { Living with illness or } \\
\text { disability } \\
\text { (Survivorship) }\end{array}$ & & & \\
\hline $\begin{array}{l}\text { Coping with end-of-life } \\
\text { (Palliative Care) }\end{array}$ & & & \\
\hline
\end{tabular}

\subsubsection{Canadian Institute for Health Information Health Indicator Framework}

The Canadian Institute for Health Information (CIHI) developed a performance measurement framework. Again, it is a broad framework, but indicators for measuring health system performance are related to acceptability, accessibility, appropriateness, competence, continuity, effectiveness, efficiency, and safety (28). The CIHI indicator relevant to this project falls under "acceptability: patient satisfaction (and quality rating of services received)" (29). This framework is useful on a national level for identifying indicators to use in quality assessment and for making comparisons between countries, but it is too broad to be useful in the specific context of this thesis work.

\subsubsection{Cancer System Quality Index}

The Cancer System Quality Index (CSQI) is a quality improvement tool used by the Cancer Quality Council of Ontario. This council is an "arms-length" advisory group associated with Cancer Care Ontario. The CSQI uses seven dimensions of quality: safe, effective, accessible, responsive (patient-centered), equitable, integrated and efficient. Indicators are mapped to these dimensions across the trajectory of patient cancer care including prevention, screening, diagnosis, 
treatment, recovery and end of life (30). Indicators relevant to this thesis would fall within "responsive/patient centeredness" and "treatment". In particular, there is a measure for patient experience with outpatient cancer care, using composite indicators based on data from the Ambulatory Oncology Patient Satisfaction Survey (31). Although this is useful on a programmatic level to monitor progress, and could be helpful as a screening tool to identify areas that should be examined further, it can be challenging to use composite indicators to identify specific areas to target for improvement (32).

Additional frameworks have been described in comprehensive reviews $(33,34)$. Although all of these frameworks provide an overview of ways to assess health system performance and quality of care, they are too broad to be useful within the specific context of this thesis project. In order to accurately assess quality, a clear and specific definition is required, and specific quality indicators must be identified.

The Donabedian framework was used for this project as it clearly defines care within a health care institution to include amenities of care, as well as care provided by health care providers (which includes technical and interpersonal aspects of care). For our purposes, for the care provided by healthcare institutions, we have grouped together the two non-technical aspects of care (amenities of care and interpersonal aspects of care) and we refer to it as "personal care". In order to have a comprehensive assessment of quality and to maximize patient outcomes, it is essential to assess both technical and personal care and to identify areas in need of improvement.

\subsection{Evaluating Quality of Care within Healthcare Institutions}

\subsubsection{Evaluating the Quality of Technical Care}

Providing high quality 'technical care' means that the patient receives the tests, procedures, and services that are needed and that they are provided appropriately (35). Health care professionals are the best judges of the quality of technical care provided to patients (36). 
The quality of technical care has been studied extensively and many quality indicators have been identified $(26,37,38)$. These indicators can be applied to data abstracted from patient medical records in order to assess the quality of care. Examples of this type of study are The American Patterns of Care studies in cancer radiotherapy (39).

\subsubsection{Evaluating the Quality of Personal Care}

In contrast to assessing the quality of technical care, health care providers are not the best judges of the quality of personal care (5). To attain a high quality of personal care, it is not sufficient to simply deliver the care to patients. It must be delivered in a manner that is consistent with patients' values and wishes and patients must perceive the care provided as acceptable and adequate (40). Therefore, the patient is the best judge of the quality of personal care $(5,6,41,42)$.

Measuring and improving the quality of personal care has been made a priority in recent years $(43,44)$ and there is increased interest in developing approaches to measure the cancer patient experience (45-47). It has been defined and evaluated in many different ways, including assessments of "patient-centred care", "patient satisfaction" and through the use of "patient reported experience measures". Each is briefly described below.

\subsubsection{Patient-centred care}

Patient-centred care means that the care provided is in accordance with patient's needs and wishes and that patients are actively involved in their care $(48,49)$. A variety of tools and instruments are available to assess the quality of patient-centred care $(50,51)$. Guidelines for the delivery of "person-centred care" now exist, emphasizing the importance of patient engagement in care (52). Indicators were recently developed to measure the quality of patient-centered care in oncology using a modified Delphi process (53), building upon previous work (48). These indicators cover domains of communication, physical support, psychosocial care, after-care and organization of care (53). It has been pointed out that these domains relate to aspects of provision 
of information (54), which are essential components for the delivery of person-centered care, but this may not cover all aspects of "personal care" as we have defined it.

A comprehensive description of instruments available to assess the quality of patientcentered cancer care is available in a systematic review published in 2014 (41) with additional instruments reported in more recent reviews $(45,55)$. Research in this field is in an early phase and it is not yet known how measuring the patient experience leads to improvements in the delivery of patient-centred care (45).

\subsubsection{Patient satisfaction}

Patient satisfaction questionnaires have traditionally been used to try to assess quality of care from the patient's perspective (56-58). However, patient satisfaction has not been shown to be a valid indicator of quality (59). Patient satisfaction is affected by patients' expectations prior to treatment, which can influence their perceptions of care (5). Satisfaction is also related to individual patient characteristics such as race/ethnicity, age, education level and marital status $(5,60)$. Measures of patient satisfaction are often abstract in nature, and patient satisfaction questionnaires commonly report high, undifferentiated levels of satisfaction (59), making it difficult to identify targets for improvement. Although the relationship between quality of care and patient satisfaction is not clearly defined (61), satisfaction remains an important concept in quality measurement. High patient satisfaction has been shown to be related to patient compliance with treatment (62), which may affect treatment outcomes (63). Furthermore, patient satisfaction has traditionally been regarded as an essential component of quality assurance in the health care system and is an expected outcome of quality care $(41,62)$.

Recent comprehensive reviews of specific patient satisfaction measures used to assess the cancer patient experience have been published $(45,55)$. The conclusions of both of these reviews highlights the need for additional work in this area to further develop, validate and implement measures of patient experience (45) and to ensure the content of any patient questionnaire 
designed for this purpose addresses all aspects of care that may be important to cancer patients receiving care in an outpatient setting (55).

\subsubsection{Patient reported experience measures}

More recently, in an attempt to combat the problems reported in the patient satisfaction literature, questionnaires have been developed that focus on asking patients to rate and/or report on their experiences with specific aspects of care instead of indicating their satisfaction $(5,41,59)$. Patient reported experience measures (PREMs) gather information about patient perspectives on care, are increasingly being used in quality improvement activities $(11,40,46,64)$ and their importance is increasingly being acknowledged (65). The Picker series of questionnaires are examples of these types (66). The Picker questionnaires ask patients to report whether certain events occurred during their experience with the health care system. It has been suggested that asking detailed questions about specific aspects of a patient's experience may be more useful for monitoring care than collecting information on satisfaction, and these results could be used to identify specific areas where care could be improved (67). The Picker Instruments were developed in consultation with patients and incorporate questions addressing eight dimensions of patient-centred care. Although the importance of selected elements of care was considered in the development of these instruments, the final questionnaire asks for patients to report their care experience only and does not collect information about the importance of each element of care to individual patients.

In the Netherlands, Booij et al have developed a Consumer Quality Index Cancer Care questionnaire. They wished to develop a generic questionnaire applicable for all cancer patients and made the assumption that patient experiences with cancer care were not specific to the tumour site. They aimed to identify the aspects of care important to cancer patients and describe the experience of patients with respect to the quality of care received. The authors noted that to keep the number of elements of care on their questionnaire to a reasonable size, they did not 
include specific elements that would be applicable to only subgroups of patients, and acknowledged this as a potential limitation of their questionnaire (68).

Additional PREMs are described and reported in reviews conducted in 2015 (55), 2016 (45) and 2017 (46). The authors point out that data about the cancer patient experience are not collected in a routine and systematic way at this time (45), and further work is needed to determine the relationship between patient experiences and outcomes (55).

An alternate strategy was recently used where patient complaints about care were examined in order to identify priorities for quality improvement. Unsurprisingly, this approach identified personal aspects of care as the ones most in need of improvement from the patient perspective as opposed to technical elements of care (69).

This highlights that methods used to assess quality of care from the patient's perspective are diverse, and that no single method has been identified as best $(60,70)$.

\subsubsection{Evaluating quality of care in a specific context}

Measuring quality of care is complex and quality indicators must be specific in order to effectively identify targets for quality improvement. Therefore, it may be beneficial to focus on assessing quality within a particular context. Our research group has focused on assessing quality of care in the context of prostate cancer radiotherapy.

\subsection{Prostate Cancer}

Prostate cancer is the fourth most common cancer worldwide with 1.6 million cases and 366000 deaths in 2015 (12). Incidence greatly varies between countries and up to a 25-fold difference has been reported. Australia/New Zealand and North America have the highest agestandardized incidence rates, whereas Asia and Africa have the lowest. Much of the difference in incidence rates is likely attributable to widespread PSA testing in westernized countries (71). In Canada, prostate cancer is the most common cancer among men. There is a large variation in the 
incidence of prostate cancer among provinces in Canada, which may reflect variation in screening rates (13). Although mortality from prostate cancer in Canada has been declining since 2001, it is still the third cause of cancer death in men and 4100 Canadian men are expected to die of prostate cancer in 2017 (13).

There are no known modifiable risk factors for prostate cancer at this time. The main risk factors for prostate cancer are age, race and family history $(72,73)$. Other genetic, hormonal, behavioural and lifestyle risk factors have been explored (72-75), but further confirmatory studies are required to determine their role in the etiology of prostate cancer. Prostate cancer is rarely diagnosed prior to age $50(73,74)$, and in Canada, it is most often diagnosed between ages 60 and 69 (13).

In the absence of known modifiable risk factors for this disease, we cannot reduce the burden of prostate cancer through primary prevention; therefore treatment has a critical role in reducing the burden of prostate cancer. Early detection of the cancer through screening is possible and may improve the outcomes of treatment by identifying cases at a time when cure is possible. Screening is done by Prostate-Specific Antigen (PSA) testing and digital rectal examinations (DRE). PSA is a protein naturally produced by the prostate gland to assist in nourishing sperm and it is normally found in low levels in the blood. Because prostate cancer cells secrete large amounts of PSA, high levels in blood may indicate the presence of prostate cancer. PSA levels may also be elevated as a result of benign prostatic hyperplasia or prostatitis however, so it is a non-specific test and additional tests, including a biopsy of the prostate, are required to diagnose prostate cancer. Although it is often done, routine screening using PSA testing is not currently recommended in Canada (76) and widespread PSA testing has led to concerns about overdiagnosis and overtreatment of this disease (77).

At diagnosis, patients are assessed to determine the stage of their cancer. Early-stage prostate cancer patients are grouped into one of three risk categories based on prognostic factors which include PSA level, clinical T stage and grade. Along with determining the prognosis of the 
patient, the risk category helps to identify the possible treatment options open to the patient (78). Current standard treatment options for early-stage prostate cancer include surgery and radiotherapy. Active surveillance of the cancer is also an option for early stage disease, where treatment is delayed and patients are regularly monitored until progression of the cancer is detectible through either a change in prostate volume or change in grade $(77,79)$. Currently there is no consensus on the best treatment option for men with early stage prostate cancer (80).

\subsubsection{The Use of Radiotherapy as a Treatment for Early-Stage Prostate Cancer}

Radiotherapy for prostate cancer consists of 3D-CRT, IMRT or brachytherapy (81). During the period of time we conducted our study, standard radiotherapy approaches were as follows: low-risk patients received single-phase IMRT photon therapy of $70 \mathrm{~Gy} / 35$ fractions to the prostate and proximal seminal vesicles. A $0.8 \mathrm{~cm}$ margin was used for planning treatment volume. Intermediate-risk patients underwent the same technique, but received 76 Gy / 38 fractions. High-risk patients received treatment in two phases - 46 Gy / 23 fractions to the prostate and pelvic nodes followed by IMRT boost of $30 \mathrm{~Gy} / 15$ fractions to the prostate and proximal seminal vesicles. High-risk patients also received 2 years of adjuvant hormonal therapy, which was usually initiated within 30 days of the start of hormone treatment. Standard approaches for radiotherapy delivery and adjuvant hormone treatment have changed since the initiation of our study. Active surveillance is now the recommended strategy for men with lowrisk disease, and it may be an appropriate strategy for some intermediate-risk patients as well. Ongoing PSA tests, DREs and biopsies are recommended to monitor the progression of cancer and determine when to consider active treatment (79). Current clinical guidelines recommend delivery of dose-escalated IMRT and also now recommend brachytherapy and/or hormone therapy (either neoadjuvant or adjuvant), depending on the specific risk group of the patient $(82,83)$. 
As mentioned previously, there are possible side effects of radiation treatment. The likelihood of developing side effects depends on many factors including the patient's general health and the amount of radiation delivered to normal tissues. Acute side effects from radiotherapy for prostate cancer include urinary problems, bowel problems, fatigue, sexual problems, local skin reactions and local hair loss. Acute side effects typically improve shortly after treatment concludes. Long term side effects may develop months to years after the receipt of radiotherapy and include urinary problems, bowel problems, sexual difficulties, lymphedema, and hip and bone problems (20).

Approximately 53\% of prostate cancer patients should receive radiotherapy in their lifetime (17). However, these utilization rates are based on both curative and palliative treatments. Approximately $36 \%$ of patients should receive radiotherapy within a year of diagnosis (17). Patients who receive radiotherapy instead of surgery as a treatment for their prostate cancer are typically older, with more co-morbidities than patients who receive surgery (84) however both of these treatments are considered to be effective (85).

Cancer treatments such as radiotherapy are processes that lend themselves to monitoring, evaluation and intervention. Additionally, aspects of the methods used to assess quality in this context could be applied to study quality of care in other cancer contexts.

\subsubsection{Previous Research in the Quality of Technical Care in Radiotherapy}

In the United States, the RAND (Research and Development) Corporation used a consensus method to develop a set of technical quality indicators for prostate cancer radiotherapy. They started with a comprehensive literature search to identify candidate indicators of quality of care, and then conducted focus groups and interviews with experts. They then used a modified Delphi process to develop a final list of indicators (86). These indicators were then applied to data abstracted from patient medical records to evaluate the quality of care delivered to patients (8789). 
In Canada, Health Services Researchers at Queen's University used a similar method to develop a set of Canadian quality indicators for prostate cancer radiotherapy. A literature search identified an initial list of 57 candidate indicators. A modified Delphi process undertaken with an expert panel reduced this list to 15 quality indicators (3). These indicators were subsequently used in a National Patterns of Care Study to assess the quality of technical care provided to patients undergoing radiotherapy for prostate cancer. They found that although compliance on many quality indicators was high, there were opportunities for improvement, and there was variation in quality of care delivered between centres (4).

\subsubsection{Previous Research in the Quality of Personal Care in Radiotherapy}

To complement the work done to assess the quality of technical care $(3,4)$ and ensure a comprehensive assessment of quality, we must also assess the quality of personal care. As previously described, radiotherapy for prostate cancer involves daily attendance at a cancer centre for approximately seven weeks. During these seven weeks, patients visit the cancer centre for a designated appointment time, interacting with a team of radiation therapists who deliver the daily treatment. The intensity and frequency of contact between patients, the cancer centre, and their health care providers makes radiotherapy an excellent context for assessing the quality of personal care. Additionally, improvements in the quality of personal care delivered to patients may have a greater impact in this context due to the degree of contact patients have with both the health care system and their health care providers.

At the initiation of this project we did not find any published reports of an instrument specifically designed to comprehensively measure the quality of personal care of patients undergoing radiotherapy for prostate cancer (7). At that time, there were two questionnaires that we felt were relevant, but they were not deemed appropriate for assessing the quality of personal care in prostate cancer radiotherapy since they did not specifically address prostate cancer (90) and/or they had a narrow focus and only related to a particular point in time (91), thereby not 
meeting our requirement that quality indicators need to be comprehensive and context-specific. We set out to define the scope of personal care and to create a comprehensive list of the elements of personal care that are pertinent to patients who undergo radiation therapy for prostate cancer. This developmental work formed the basis of my MSc thesis (7) and a description of that work forms part of the content of the published manuscript that is Chapter 3 of this thesis. As a brief summary of that work, we began by identifying the domains of the quality of personal care: 'patient centeredness', 'empathy and respectfulness of caregivers', 'competence of caregivers', 'adequacy of information sharing', 'accessibility of caregivers', 'continuity of care', 'comprehensiveness of care', 'acceptability of the treatment environment', 'privacy' and 'convenience' by adapting and refining domains referred to in the literature $(90,92-95)$. We then searched the literature to identify items relevant to each domain by identifying items from surveys used to assess quality of care (96-98), patient satisfaction (93,99-106), patient needs assessments (107-113) as well as publications describing the development of quality indicators for cancer care (86,87,114-116). We supplemented the initial item list by seeking input from health care professionals and patients. The items were initially mapped to each step in the patient care continuum to identify gaps and redundancies. The items were then incorporated into a questionnaire consisting of 3 modules corresponding to appropriate time points in the patient care continuum.

Our questionnaire contains 143 items across 10 domains of personal care. For each item, patients are asked to rate the quality of that aspect of their care (using a 5-point scale from very poor to very good) and rate the item's importance (using a 4-point scale from not important to very important) (see Figure 2-2). As part of the MSc thesis, the questionnaire was pilot tested on a small group of patients and the results indicated that patients were willing to complete it and did so without difficulty or distress (7). 


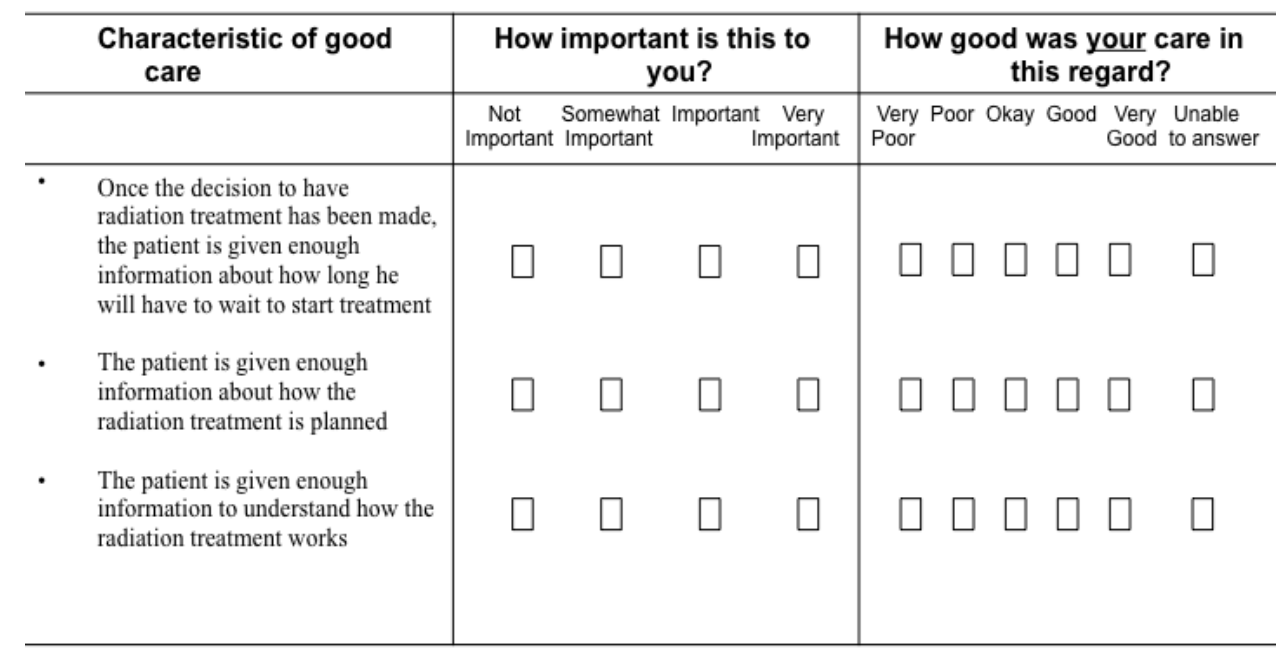

Figure 2-2: Sample page of the self-administered questionnaire

Our questionnaire was developed in 2009 and there have been other questionnaires published since then. Some have been previously described in another section, but ones pertinent to prostate cancer radiotherapy are described here.

Researchers in England have developed a specific prostate cancer questionnaire to assess the patient experience (PCQ-P) (117). It addresses aspects of information and explanation, involvement in decision making, provision of advice and support, delays in care, choice, coordination of care, and practical issues (e.g. hospital facilities and travel). Using a similar approach to the questionnaire we developed, it separates the questionnaire into sections. However, the PCQ-P includes sections related to GP visits and referral, tests at the hospital, diagnosis and treatment decision, treatment and discharge, and monitoring. The authors allowed for different modes of administration of their questionnaire, and several sections were provided to patients at a time. Patient feedback recommended that the sections should be administered as separate questionnaires, or in smaller combinations containing just a few sections. Both patients and healthcare providers suggested administering it prospectively, as soon as possible after each stage of care was competed (117), which is the approach we have used with our questionnaire. The PCQ-P has not yet been used as part of quality improvement, but it has been suggested that 
the PCQ-P could be used for benchmarking and comparisons between centres and that individual questions should be examined to identify areas of improvement. The PCQ-P asks patients to rate their experiences with elements of care covering all prostate cancer treatments. The treatmentspecific segment of the PCQ-P is fairly brief and since it is generic, it does not include questions specifically about radiation therapists or about the weekly review appointments during treatment (118). Therefore specific elements that may be important to patients undergoing radiotherapy for prostate cancer may not be captured by this questionnaire.

Questionnaires for assessing aspects of the quality of personal care during radiotherapy are now available. A patient satisfaction survey was used in British Columbia, Canada to assess satisfaction with radiotherapy delivery (119). The results from this survey were shared among staff members in order to identify areas in need of improvement. Despite the general nature of some of the satisfaction questions, they were able to identify areas in need of improvement and make changes that led to increased satisfaction scores (119). A modified version of this tool was used in Ontario, Canada, and although the researchers obtained similar results, they did not identify any specific areas to target for improvement. The researchers noted that it may be beneficial to time the delivery of the questions more closely to when the patient experienced that element of their care. They also acknowledged that it might be helpful to pair each question with a question about importance to identify priorities to patients (120), which is what we have done.

A questionnaire specific to radiotherapy has recently been developed in Sweden that includes 23 items focusing on the specific radiotherapy experience. Questions focus on domains related to psychological stress, physical discomfort and coping during treatment (121). These are very important issues, but this questionnaire does not address the full patient care continuum and does not cover all aspects of personal care.

Researchers in the Netherlands conducted focus groups and a concept-mapping exercise as a first step towards developing an instrument for use in assessing the quality of radiotherapy (122). This work is related to the generic Consumer Quality Index Cancer Care described earlier. 
Although the elements identified were specific to quality of care in radiotherapy, they included patients receiving treatment for all cancers. The elements of care identified as important may not then pertain to prostate cancer radiotherapy, as specific aspects of care important to patients may be unique to their situation (57). This work is still under development and the instrument is not yet available as this study focused on identifying elements of care, and their next steps involve designing a questionnaire to assess the quality of care from the patient's perspective (122).

Similarly, another survey was conducted in Australia by Mackenzie et al to gather patients' views about their care during radiotherapy. They used a unique approach of asking patients whether their well-being would have been improved if better care was provided across different domains of patient-centredness. They included eight questions, each related to a different domain. They identified domains that require improvement, but it is not yet clear how to develop targeted interventions to improve care for patients (54), which may be related to the general nature of the questions they asked.

The elements of care pertinent to patients undergoing radiotherapy for prostate cancer may be specific to their particular experience. We wanted to comprehensively assess the quality of personal care of patients undergoing radiotherapy for prostate cancer to complement previous work (4). We did a comprehensive search for a suitable instrument in 2009 and did not find one available (7). Although work has been done since, there is still no instrument available that is specifically designed to assess the quality of personal care in prostate cancer radiotherapy.

\subsection{Validity and Reliability}

Measurements of the quality of personal care need to be valid. Validity in this context relates to two different components: the validity of the indicators selected for quality assessment and the validity of the measurement tool (questionnaire) used to assess quality of care. As described in detail in chapter 3 of this thesis, when we identified the indicators of personal care 
applicable to prostate cancer radiotherapy, we focused on ensuring both face and content validity (7).

As for the validity of the information gleaned from a patient questionnaire, the quality of care delivered by a single institution cannot be accurately measured by an individual patient, but instead must be assessed across all patients receiving care. As mentioned previously, measurements of quality from the individual patient's perspective are affected by their expectations and perceptions of care (62), which are influenced by their own norms and values. Furthermore, the indicators within our questionnaire are definitive or causal indicators, which means each can influence the patient's well-being independent of the relationship to other elements of care $(123,124)$. Standard psychometric techniques often used for assessing construct validity and/or internal consistency of questionnaire items are not appropriate to use in this context $(123,125-128)$. We can, however, assess the stability of individual patient responses over time (129).

\subsection{Using Patient Feedback in Quality Assessment}

It is essential that patient views are incorporated when evaluating the quality of personal care (130). In 2016, the Canadian Partnership for Quality Radiotherapy produced a document with a specific guideline addressing patient involvement: "the radiation treatment program has a process to define, monitor and evaluate patient and family perspectives on service quality and to respond to feedback within a specified time frame..." $(131,132)$ We previously identified indicators of the quality of personal care and incorporated those into a patient questionnaire. This is an important part of the first step(s) of the health services research process to assess health system performance. This framework is shown in Figure 2-3, and indicates this process starts with "choosing and defining indicators" of health system performance, which are measurable aspects of care received (133). Once the measurement instrument is developed, the next step in the framework is "describe performance", but in describing the quality of care from the 
perspective of patients we must first make sure we are assessing elements of care important to patients $(8,9)$.

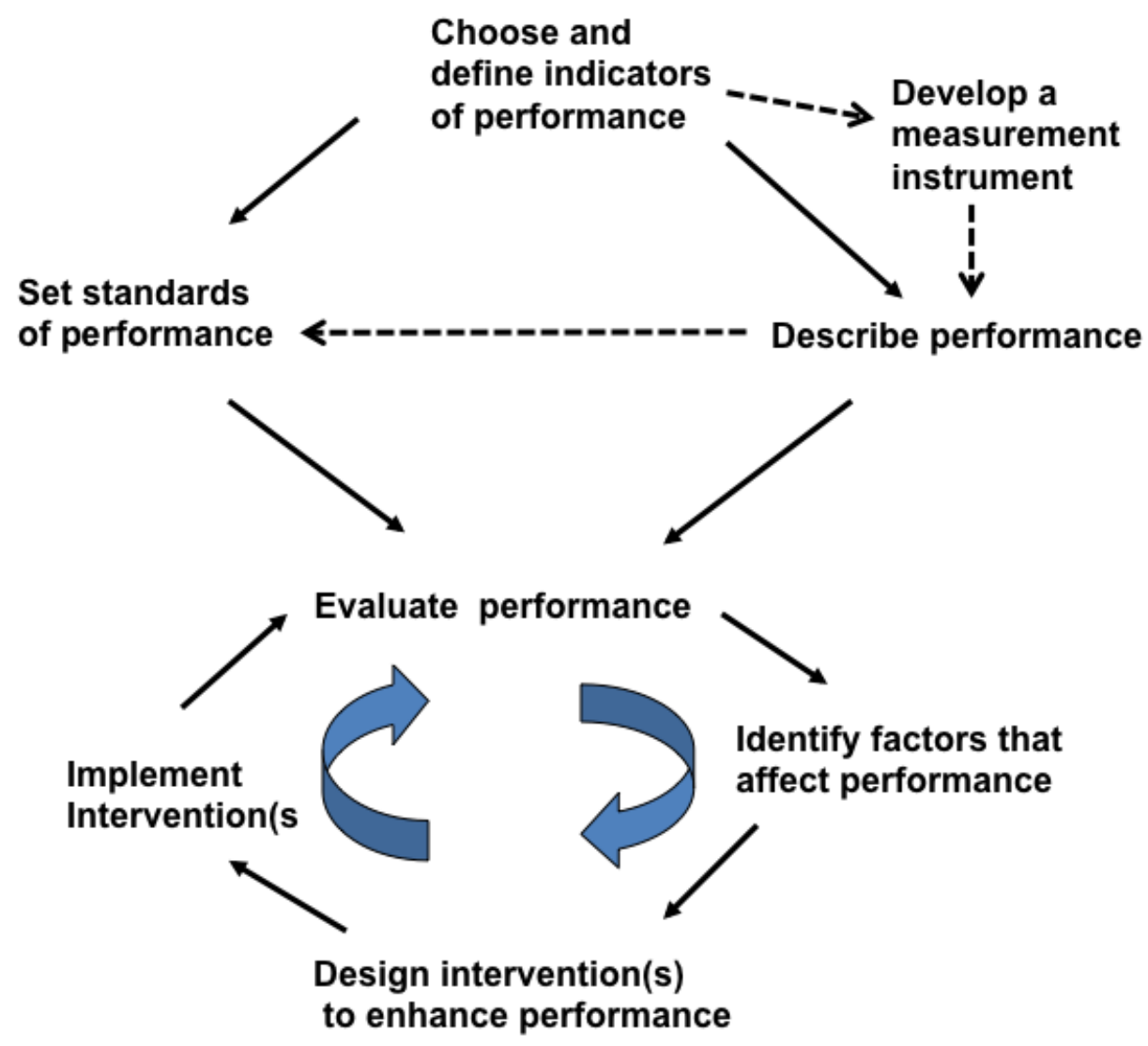

Figure 2-3 Framework for Health Services Research (adapted from 22)

Ultimately, to move this work forward and ensure data gathered is useful in a quality improvement setting, it needs to be summarized and presented in a way that allows health care managers and health care professionals to identify actionable targets for quality improvement $(10,11)$. Much of the published literature focuses on the development of questionnaires designed to assess the quality of care from the patient's perspective, but there is little research on how to effectively use patient data for quality improvement $(8,134-142)$. A recent systematic review highlights the lack of research in this area and proposes a framework for using patient data in 
quality improvement that involves "making sense of data" (benchmarking and comparing results), "communicating and explaining data" (interpret and disseminate results) and "planning for improvement" (discuss results with stakeholders to identify and select priorities for improvement). However, they point out that in order to effectively use patient experience data it is essential that an organization's leaders can understand the data collected (140). Barriers to using patient-reported data have been identified and tend to fall into three categories: characteristics of the organization, characteristics of the data, or characteristics of the individuals using the data $(8,10,136)$. Although many organizations have started collecting data in order to describe quality of care from the patient's perspective, few have adequate systems to use the data effectively and efficiently (70,143). It has previously been recognized that a structured, organized system for collecting and processing patient data in a timely manner, combined with an organizational environment that is open to using patient feedback, may enhance the use of data in quality improvement $(10,136,139-141,144)$. Additionally, data that are specific to the local context may increase uptake and use since it may make it easier to identify specific targets for quality improvement $(8,143,145)$.

\subsection{Summary and Rationale}

Measuring quality of care from the perspective of patients is essential as they are the best judges of the quality of non-technical (personal) aspects of care (5). In order to integrate quality assessments into a quality assurance program, we must begin by choosing and defining specific indicators of performance. Once we have appropriate indicators, we can then assess quality of care and seek to describe the current performance of the health care system (Figure 2-3) (22). In describing the current quality of care delivered to patients, we must focus on the aspects of care that are important $(8,9)$. In using quality data to evaluate and potentially improve care, we need to ensure we have appropriate methods for identifying the elements of care in need of improvement to patients. 
We have already asserted that measuring quality of care is complex and that quality indicators must be specific in order to effectively identify targets for quality improvement. Building upon this, we have also highlighted the challenges in summarizing and reporting on patient experiences and the lack of information about how to use these data effectively as part of a quality improvement program. It may be useful to conduct an assessment within a focused population as a model for conducting this type of work, and then, if successful, the applicability to more general contexts can be considered.

Previously, we developed a questionnaire for assessing the quality of personal care in prostate cancer radiotherapy (7). The objectives of this $\mathrm{PhD}$ thesis were: 1 ) to determine which elements of personal care were most important to patients undergoing radiotherapy for prostate cancer; 2) to develop a method of integrating ratings of importance and ratings of quality to identify elements of care that should become targets for quality improvement, and; 3) to describe the quality of personal care delivered to patients undergoing radiotherapy for prostate cancer in routine practice and to identify the elements of personal care that should be targeted for quality improvement. 


\section{Chapter 3}

What Aspects of Personal Care Are Most Important to Patients Undergoing Radiation Therapy for Prostate Cancer? 


\subsection{Abstract}

Purpose/Objective(s): The overall quality of patient care is a function of the quality of both its technical and non-technical components. The purpose of this study was to identify the elements of non-technical ("personal") care that are most important to patients undergoing radiotherapy for prostate cancer.

Materials and Methods: We reviewed the literature and interviewed patients and health professionals to identify elements of personal care pertinent to patients undergoing radiotherapy for prostate cancer. We identified 143 individual elements relating to 10 aspects of personal care. Patients undergoing radical radiation therapy for prostate cancer completed a self-administered questionnaire in which they rated the importance of each element. The overall importance of each element was measured by the percentage of respondents who rated it as "very important". The importance of each aspect of personal care was measured by the mean importance of its elements.

Results: One hundred eight patients completed the questionnaire. The percentage of patients who rated each element "very important" ranged from 7\% to 95\% (mean 61\%). The mean importance rating of the elements of each aspect of care varied significantly: "perceived competence of caregivers", 80\%; "empathy and respectfulness of caregivers", 67\%; "adequacy of information sharing", 67\%; "patient centeredness", 59\%; "accessibility of caregivers", 57\%; "continuity of care", 51\%; "privacy", 51\%; "convenience", 45\%; "comprehensiveness of services", 44\%; and "treatment environment", $30 \%(\mathrm{p}<0.0001)$. Neither age nor education was associated with importance ratings, but the patient's health status was associated with the rating of some elements of care. 
Conclusions: Many different elements of personal care are important to patients undergoing radiotherapy for prostate cancer, but the 3 aspects of care that most believe are most important are: the perceived competence of their caregivers, the empathy and respectfulness of their caregivers, and the adequacy of information sharing.

\subsection{Introduction}

Quality of care has been defined as "the degree to which health services for individuals and populations increase the likelihood of desired health outcomes and are consistent with current professional knowledge" (1). Health care has technical and non-technical components, and the quality of each influences the likelihood of achieving optimal outcomes (2). In the context of radiation therapy, the technical quality of treatment influences the probability of cure and complications, and the quality of nontechnical aspects of care may influence quality of life both during and after treatment.

Optimizing cancer outcomes therefore requires the optimization of quality of care (146). The importance of technical quality assurance in radiation therapy is already universally accepted. Standards for the technical quality of many components of radiation therapy practice are available, and quality indicators for the overall operations of radiotherapy programs have been published (147). In addition, technical quality indicators for specific types of radiotherapy have been developed and used to audit the quality of care of specific groups of patients. The American College of Radiology's Patterns of Care Study, today known as Quality Research in Radiation Oncology, was the pioneer in this field (39). Following their example, we recently developed a suite of Canadian indicators of the technical quality of radiotherapy for prostate cancer, based on evidence in the literature supplemented by expert opinion (3). These indicators were used in a nationwide, criterion-based audit of the technical quality of radiation therapy that identified 
opportunities for technical quality improvement at every center surveyed $(3,4)$. This study, however, did not evaluate the quality of nontechnical aspects of patient care. We therefore plan now to develop a suite of indicators of the quality of nontechnical aspects of care of patients undergoing radiotherapy for prostate cancer, to complement the technical quality indicators reported previously (3).

Donabedian referred to nontechnical aspects of care as interpersonal care (24), and for convenience we refer to it here as personal care. We searched the literature for a method of evaluating the quality of nontechnical aspects of the care of patients who undergo radiation therapy for prostate cancer, but did not succeed in identifying an appropriate instrument. Satisfaction questionnaires have been used in the past to assess quality of care from the patient's perspective $(56-58,148)$, but satisfaction is not a direct measure of quality because it is highly dependent on the patient's expectations (5). Furthermore, such studies often report uniformly high levels of satisfaction (59), making it difficult to identify targets for improvement.

The first step toward developing indicators of the quality of personal care was to define the scope of personal care and create a comprehensive list of the elements of personal care that are pertinent to patients who undergo radiation therapy for prostate cancer. We approached this by reviewing the literature and interviewing not only health professionals but also patients, who are recognized as the best judges of the quality of personal care (5) and therefore should be involved in the selection of appropriate indicators of care $(130,149,150)$. The second step was to survey patients undergoing radiation therapy for prostate cancer to determine which elements of personal care were most important to them. 


\subsection{Methods}

This study was approved by the Health Sciences Research Ethics Board at Queen's University (\#6003838).

\subsubsection{Defining the Scope of Personal Care}

We used a bottom-up inductive approach (149). We reviewed the literature and analyzed the content of existing instruments for measuring patients' satisfaction and patients' needs to identify a pool of items relating to individual elements of personal care pertinent to patients undergoing radiation therapy for prostate cancer. See appendix B2 for a complete list of sources that provided the 500 elements of care initially included in the study (see Figure 3-1). We classified these individual elements into 10 categories, each relating to a particular aspect of the quality of personal care. A preliminary classification, based on concepts and terms used in the literature pertaining to quality of care, patient satisfaction, and patients' rights, was expanded to accommodate all the elements of personal care (95) (Table 3-1). Each element of care was mapped to the corresponding step in the continuum of care, as shown in Figure 3-1 and described in detail in Appendix B1. 


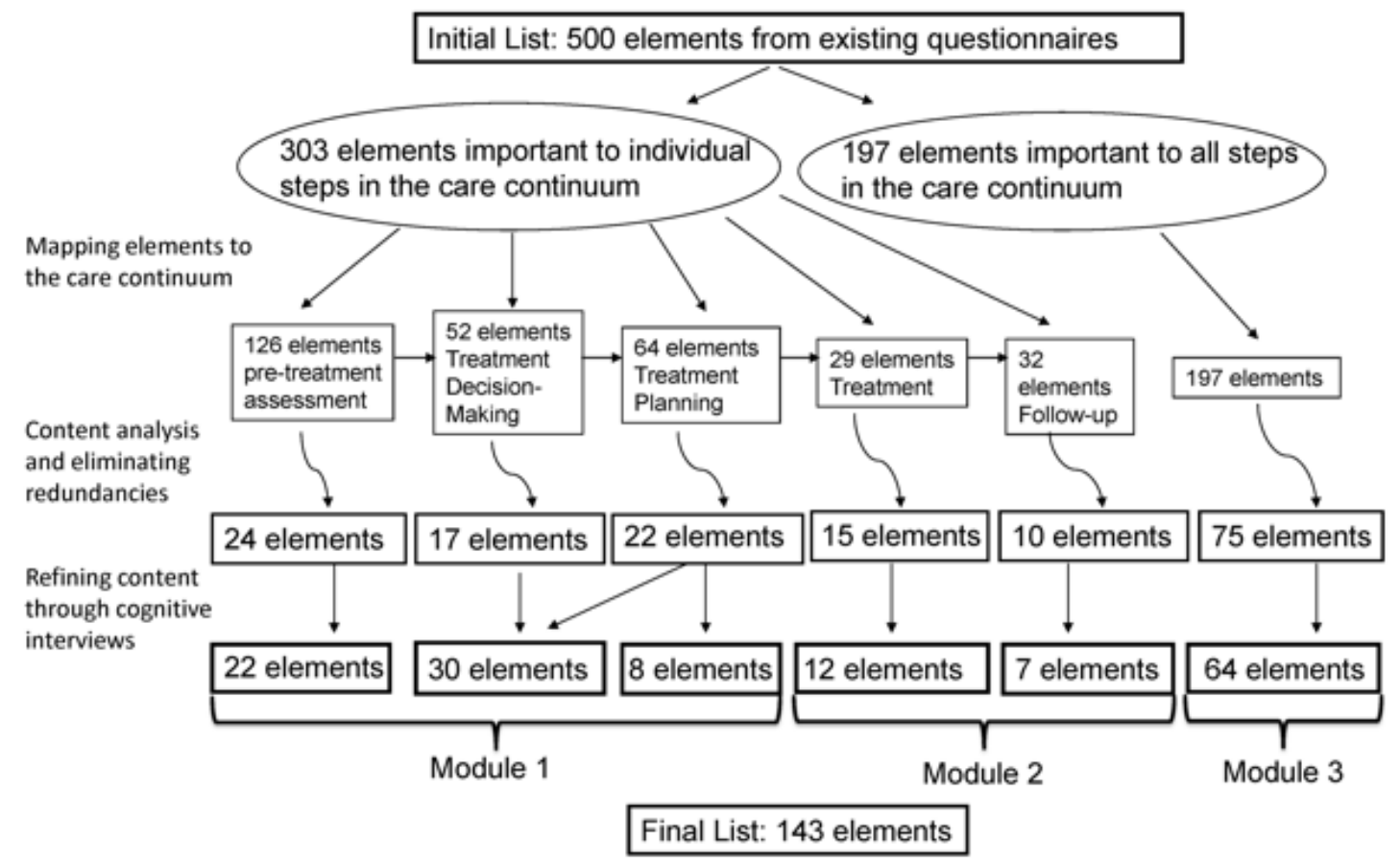

Figure 3-1: Identifying elements of the quality of personal care relevant to radiotherapy for prostate cancer (for details, see methods). 
Table 3-1: Aspects and sample elements of the quality of personal care

\begin{tabular}{|c|c|}
\hline Aspect of care & Sample elements \\
\hline \multirow[t]{3}{*}{ Patient centeredness } & The patient is involved as much as he wants in making the final decision about which treatment to have \\
\hline & $\begin{array}{l}\text { The patient is encouraged by the cancer center to bring a relative or friend along to the first appointment with the } \\
\text { radiation oncologist }\end{array}$ \\
\hline & $\begin{array}{l}\text { If the patient wants, the radiation oncologist is willing to answer all the questions the patient's family and friends } \\
\text { have }\end{array}$ \\
\hline \multirow{4}{*}{$\begin{array}{l}\text { Empathy and } \\
\text { Respectfulness of } \\
\text { Caregivers }\end{array}$} & The nurses shows sensitivity to the patient's feelings and emotional needs \\
\hline & The radiation therapists treat the patient with respect \\
\hline & The radiation oncologist makes the patient feel like he can ask any questions he wants to \\
\hline & The nurses are polite to the patient \\
\hline \multirow{5}{*}{$\begin{array}{l}\text { Perceived competence of } \\
\text { caregivers }\end{array}$} & The radiation oncologist reads the patient's previous medical records before seeing the patient for the first time \\
\hline & The patient has confidence in his treatment team that he is treated correctly every day \\
\hline & The radiation therapists are knowledgeable and experienced in dealing with prostate cancer \\
\hline & $\begin{array}{l}\text { The radiation oncologist is aware of the test results and has the results available when seeing the patient for the first } \\
\text { time }\end{array}$ \\
\hline & The radiation oncologist carefully assesses the patient's suitability for radiation treatment \\
\hline \multirow{4}{*}{$\begin{array}{l}\text { Adequacy of Information } \\
\text { Sharing }\end{array}$} & The radiation oncologist explains the different forms of treatment that are available for prostate cancer \\
\hline & $\begin{array}{l}\text { Someone on the health care team offers written information about prostate cancer to the patient that he can take home } \\
\text { with him }\end{array}$ \\
\hline & $\begin{array}{l}\text { The radiation oncologist makes sure the patient understands the treatment options before making up his mind about } \\
\text { which treatment to have }\end{array}$ \\
\hline & The radiation oncologist listens carefully to all the patient's concerns \\
\hline \multirow{4}{*}{$\begin{array}{l}\text { Accessibility of } \\
\text { caregivers }\end{array}$} & Someone at the cancer centre is available to answer the patient's questions in between appointments \\
\hline & The radiation oncologist takes the time to answer all of the patient's questions \\
\hline & The patient has a short wait to get an appointment to see the radiation oncologist for the first time \\
\hline & $\begin{array}{l}\text { The patient has a short wait in the waiting room when he comes to the cancer centre to see the radiation oncologist for } \\
\text { the first time }\end{array}$ \\
\hline
\end{tabular}




\begin{tabular}{|c|c|}
\hline \multirow{3}{*}{ Continuity of care } & The patient sees the same radiation therapists each time he goes for radiation treatment \\
\hline & $\begin{array}{l}\text { The radiation oncologist, nurses and radiation therapists work well together when treating the patient for prostate } \\
\text { cancer }\end{array}$ \\
\hline & The patient is aware of who to contact with questions about his prostate cancer and treatment \\
\hline \multirow{4}{*}{$\begin{array}{l}\text { Comprehensiveness of } \\
\text { Services }\end{array}$} & Someone on the healthcare team is available if needed to help explain the diagnosis to family members \\
\hline & $\begin{array}{l}\text { Someone at the cancer centre gives the patient information about support groups in his area for patients and/or family } \\
\text { members }\end{array}$ \\
\hline & $\begin{array}{l}\text { Someone at the cancer centre arranges for the patient to receive any help he needs in dealing with his anxiety about } \\
\text { the diagnosis }\end{array}$ \\
\hline & A social worker is available to provide advice on financial and social issues arising from the diagnosis \\
\hline \multirow{3}{*}{ Treatment Environment } & The furniture in the waiting room is comfortable \\
\hline & The cancer centre appears to be clean and well looked after \\
\hline & The waiting area and treatment rooms are quiet \\
\hline \multirow[t]{2}{*}{ Privacy } & There is enough space in the waiting room that the patient can have a private conversation with his companion \\
\hline & $\begin{array}{l}\text { The patient is aware that no one else other than him and the healthcare professionals looking after him are able to see } \\
\text { his medical records without his permission }\end{array}$ \\
\hline \multirow[t]{4}{*}{ Convenience } & Appointments are scheduled for a time that is convenient \\
\hline & Transportation to/from the cancer centre is available for the patient if needed \\
\hline & Directions and signs inside and outside the cancer centre are easy to understand \\
\hline & There is somewhere convenient to park \\
\hline
\end{tabular}




\subsubsection{Questionnaire Development}

We then constructed a self-administered questionnaire in which each element of quality was presented as a positive statement (Figure 3-2). Patients were asked to rate the importance of each element, on an ordinal scale, as shown in Figure 3-2.

\begin{tabular}{|c|c|c|c|c|c|c|c|}
\hline & \multirow[t]{2}{*}{$\begin{array}{l}\text { Characteristic of good } \\
\text { care }\end{array}$} & \multicolumn{3}{|c|}{$\begin{array}{c}\text { How important is this to } \\
\text { you? }\end{array}$} & \multicolumn{3}{|c|}{$\begin{array}{c}\text { How good was your care in } \\
\text { this regard? }\end{array}$} \\
\hline & & $\begin{array}{c}\text { Not } \\
\text { Importan }\end{array}$ & $\begin{array}{l}\text { Somewhat } \\
\text { Important }\end{array}$ & $\begin{array}{l}\text { Important Very } \\
\text { Important }\end{array}$ & $\begin{array}{l}\text { Very Poor Okay Good } \\
\text { Poor }\end{array}$ & $\begin{array}{l}\text { Very } \\
\text { Good }\end{array}$ & $\begin{array}{l}\text { Unable } \\
\text { to answer }\end{array}$ \\
\hline$\cdot$ & $\begin{array}{l}\text { The patient has a short wait to get } \\
\text { an appointment to see the } \\
\text { radiation oncologist for the } \\
\text { first time }\end{array}$ & $\square$ & $\square$ & $\square$ & $\square \square \square \square$ & $\square$ & $\square$ \\
\hline$\cdot$ & $\begin{array}{l}\text { The patient has a short wait in the } \\
\text { waiting room when he comes } \\
\text { to the cancer centre to see the } \\
\text { radiation oncologist for the } \\
\text { first time }\end{array}$ & $\square$ & $\square$ & $\square$ & $\square \square \square \square$ & $\square$ & $\square$ \\
\hline$\cdot$ & $\begin{array}{l}\text { The patient is encouraged by the } \\
\text { cancer centre to bring a } \\
\text { relative or friend along to the } \\
\text { first appointment with the } \\
\text { radiation oncologist }\end{array}$ & $\square$ & $\square$ & $\square$ & $\square \square \square \square$ & $\square$ & $\square$ \\
\hline
\end{tabular}

Figure 3-2: Sample page of the self-administered questionnaire

The questionnaire was revised on the basis of feedback about its clarity and comprehensiveness, obtained through cognitive interviews conducted by K.A.F. with a convenience sample of 8 patients who had undergone radiation therapy for prostate cancer and 4 health professionals from the Cancer Centre of Southeastern Ontario (CCSEO) involved in the care of patients with prostate cancer. The final questionnaire was divided into 3 modules, designed to be administered sequentially. Module 1, including elements pertinent to pre-treatment assessment and the treatment decision, was administered in the first week of treatment; module 2, including elements pertinent to treatment delivery and plans for follow-up, was administered at the end of treatment; 
and module 3, including elements relating to general aspects of care, was administered at first follow-up visit (7) (Figure 3-1). Each module also asked the patient to identify any other elements of care that he thought should be included. Preliminary testing on 28 patients showed that it was feasible for them to complete the questionnaire without difficulty or distress. Patients did not suggest any new elements of care to add to the questionnaire (7). Additional details of how the questionnaire was developed are available in the expanded methods section in appendix B1.

\subsubsection{Survey Population}

Patients starting radical external beam radiation therapy for localized prostate cancer at CCSEO between May 2011 and August 2014 were eligible to participate. Patients with clinically positive nodes were excluded. Patients who were incarcerated were excluded. Patients were excluded if the attending oncologist did not approve their recruitment (see Figure B1, Appendix B). Patients who had undergone prostatectomy or would receive brachytherapy were excluded. Patients who received adjuvant hormone treatment were included. Radiation therapy treatment protocols used at CCSEO for low-risk, intermediate-risk, and high-risk cases are described in appendix B1.

\subsubsection{Administration of the Questionnaire}

Patients were invited to participate in the study during their first week of radiation therapy. Participants were assured that their responses were confidential and that they would remain anonymous. Consenting patients were given each module of the questionnaire by hand at the appropriate point in time (Figure 3-1) along with a stamped addressed envelope in which to return it. Patients were asked to complete the questionnaire at home to give them as much time as they wished to complete this task and the opportunity to do so in the privacy and security of their own home. 
To assess test-retest reliability, patients recruited after May 2012 were mailed a second copy of module 3 within 10 days of the return of the first copy and were asked to complete it on receipt. The rationale for this approach is described in the expanded methods section in appendix B1.

\subsubsection{Data Management}

Questionnaires were stored in a locked cabinet in a secure facility. Patients were identified by study number only. Data were entered into a password-protected Microsoft Access database with the use of double entry. Analyses were conducted with SAS 9.3 (151).

\subsubsection{Analyses}

\subsubsection{Ranking by Importance}

Two different methods were used to rank the importance of the elements of care. We first dichotomized the ratings of importance provided on the 4-point scale shown in Figure 3-2 as "very important" versus "less important". The elements of care were then ranked based on the proportion of patients rating each as "very important", with ties being resolved based on the proportion rating each as "important" and, if necessary, by the proportion rating each as "somewhat important" (Method A). We also calculated the rank assigned to each element, by each individual patient, using fractional ranking to deal with ties. We then calculated the mean rank assigned to each element by the group of patients. Finally, each element was ranked based on the mean rank assigned to it by the group (Method B). For the overall group of patients, the 2 methods yielded almost identical results (Spearman $r=0.99$ ). We therefore used the simpler method A in our primary analysis. The importance of the 10 aspects of personal care was 
calculated by the mean importance of its constituent elements. The importance of different aspects of care was compared using generalized estimating equations.

\subsubsection{Sample size}

A target sample size of 96 patients was set to ensure maximum confidence intervals of $+/-10 \%$ on proportions of patients (152) (see also appendix B1 and appendix C1).

\subsubsection{Agreement}

We calculated the percentage of patients agreeing with the majority opinion on whether each element of care was or was not "very important" using the following formula: $50+\mid 50$ - \% "very important”| (153). This is scaled from 50 to 100, where 50 is complete disagreement and 100 is complete agreement. A threshold of agreement was set at $60 \%$ because at $60 \%$ agreement, with 108 respondents, the $95 \%$ confidence interval just excludes 50 and therefore represents the majority opinion.

\subsubsection{Test-retest Reliability}

Test-retest reliability was described by concordance on ratings of "very important", referred to as percentage of positive agreement (154). The kappa statistic was not used to describe test-retest reliability because the distribution of responses was skewed toward "very important" (155).

\subsubsection{Patient characteristics and importance rankings}

Spearman correlation was used to compare the importance rankings of different subgroups of patients defined by age, education and health status. Method B was used here to rank the elements of care because it is not influenced by the way in which different groups of individuals use the scale. (For additional explanation, see the expanded methods section in appendix B1). The Wilcoxon rank sum test was used to compare differences in the importance of individual elements of care from the perspective of different subgroups of patients. This exploratory analysis involved 
multiple comparisons, and we therefore applied the procedure suggested by Benjamini and Hochburg in assessing statistical significance (156), with the acceptable false discovery rate set at 0.25 .

\subsection{Results}

\subsubsection{Study Population}

Overall, 188 potentially eligible patients were seen at CCSEO between May 2011 and August 2014, of whom 147 consented to participate in the study, 139 received all 3 modules of the questionnaire, and 108 completed all 3 modules. Reasons for nonparticipation or noncompletion are shown in Figure B1 (Appendix B). Response rates for individual modules are provided in appendix B3.

Table B3-1 (Appendix B) shows the characteristics of the 108 patients who completed the entire questionnaire. Fifty-six percent were over the age of 70. Forty-five percent had received some postsecondary education. Eighty-one percent rated their health as "good" or "excellent". The age distribution of patients who did not complete the questionnaire was similar to that of patients who did complete it (Appendix C2).

The median time for completion of the complete questionnaire (all 3 modules) was 46 minutes (range, 17-105 minutes). Completion times for individual modules are provided in appendix B3.

\subsubsection{Ratings of Importance}

There were few missing responses. Ratings of importance were provided by $>90 \%$ of patients for every element. For additional details, see appendix B3. 
The respondents did not identify any additional elements of care that were important to them.

The percentage of patients rating each element of care as "very important" ranged from $7 \%$ for "the patient is treated in the same treatment room each day" to $95 \%$ for "the radiation oncologist is knowledgeable and experienced in dealing with prostate cancer". Table 3-2 shows the 10 highest ranked and 10 lowest ranked elements of care. Table B3-2 (Appendix B) shows the ranking of importance of all elements of care. The elements are ordered based on the percentage of patients rating each element of care as "very important" (method A), but rankings based on the mean rank assigned by the group are also shown for comparison (method B).

Table 3-2: Highest and lowest ranked elements of care by percentage of patients rating each one "very important"

\begin{tabular}{|l|c|c|}
\hline \multicolumn{1}{|c|}{ Elements of Care } & \multicolumn{1}{|c|}{ Importance } \\
\hline \multicolumn{1}{|c|}{ Top Elements } & $\begin{array}{c}\text { \% Very } \\
\text { Important } \\
(95 \% \text { CI })\end{array}$ & Rank \\
\hline $\begin{array}{l}\text { The radiation oncologist is knowledgeable and experienced in } \\
\text { dealing with prostate cancer }\end{array}$ & $\begin{array}{c}95.3 \\
(89.4,98.5)\end{array}$ & $\begin{array}{c}93.5 \\
(87.0,97.3)\end{array}$ \\
\hline $\begin{array}{l}\text { The radiation oncologist makes sure the patient knows that the } \\
\text { cancer is confined to the prostate, and there is no sign that it has } \\
\text { spread to any other part of the body }\end{array}$ & $\begin{array}{c}91.6 \\
(84.6,96.1)\end{array}$ & 3 \\
\hline $\begin{array}{l}\text { The patient trusts the radiation oncologist to look after him } \\
\text { properly }\end{array}$ & $\begin{array}{c}88.0 \\
(80.3,93.4)\end{array}$ & 4 \\
\hline $\begin{array}{l}\text { The cancer centre seems to have all the equipment and facilities } \\
\text { needed to completely care for the patient's prostate cancer }\end{array}$ & $\begin{array}{c}87.8 \\
(80.1,93.3)\end{array}$ & 5 \\
\hline $\begin{array}{l}\text { The radiation therapists are knowledgeable and experienced in } \\
\text { dealing with prostate cancer }\end{array}$ & $\begin{array}{c}87.0 \\
(79.2,92.7)\end{array}$ & 6 \\
\hline $\begin{array}{l}\text { The radiation oncologist, nurses and radiation therapists work } \\
\text { well together when treating the patient for prostate cancer }\end{array}$ & $\begin{array}{c}86.9 \\
(79.0,92.7)\end{array}$ & 7 \\
\hline $\begin{array}{l}\text { The radiation oncologist takes the time to answer all of the } \\
\text { patient's questions }\end{array}$ & $\begin{array}{c}86.0 \\
(77.9,91.9)\end{array}$ & 8 \\
\hline The radiation oncologist is honest with the patient & $\begin{array}{c}85.0 \\
(76.9,91.2)\end{array}$ & 9 \\
\hline $\begin{array}{l}\text { The radiation oncologist makes sure the patient knows the grade } \\
\text { of his cancer and understands what that means }\end{array}$ & $\begin{array}{c}84.8 \\
(76.4,91.0)\end{array}$ & 10 \\
\hline $\begin{array}{l}\text { The radiation oncologist gives the patient enough information } \\
\text { about the side effects of each treatment option }\end{array}$ & \\
\hline
\end{tabular}




\begin{tabular}{|c|c|c|}
\hline Bottom 10 Elements & $\begin{array}{l}\% \text { Very } \\
\text { Important } \\
(95 \% \mathrm{CI})\end{array}$ & Rank \\
\hline The waiting area and treatment rooms are quiet & $\begin{array}{c}30.6 \\
(22.0,40.2)\end{array}$ & 134 \\
\hline $\begin{array}{l}\text { The patient has a short wait in the waiting room when he comes } \\
\text { to the cancer centre to see the radiation oncologist for the first } \\
\text { time }\end{array}$ & $\begin{array}{c}26.4 \\
(18.3,35.9)\end{array}$ & 135 \\
\hline $\begin{array}{l}\text { A social worker is available to provide advice on financial and } \\
\text { social issues arising from the diagnosis }\end{array}$ & $\begin{array}{c}24.7 \\
(16.5,34.4)\end{array}$ & 136 \\
\hline $\begin{array}{l}\text { Someone at the cancer centre gives the patient information abut } \\
\text { support groups in his area for patients and/or family members }\end{array}$ & $\begin{array}{c}23.8 \\
(15.9,33.3)\end{array}$ & 137 \\
\hline The furniture in the waiting room is comfortable & $\begin{array}{c}23.2 \\
(15.6,32.2)\end{array}$ & 138 \\
\hline $\begin{array}{l}\text { The patient sees the same radiation therapists each time he goes } \\
\text { for radiation treatment }\end{array}$ & $\begin{array}{c}22.2 \\
(14.8,31.2) \\
\end{array}$ & 139 \\
\hline $\begin{array}{l}\text { There is enough space in the waiting room that the patient can } \\
\text { have a private conversation with his companion }\end{array}$ & $\begin{array}{c}19.6 \\
(12.6,28.4)\end{array}$ & 140 \\
\hline Food and drink facilities are available in or near the waiting room & $\begin{array}{c}11.3 \\
(6.0,18.9) \\
\end{array}$ & 141 \\
\hline Waiting areas are decorated nicely & $\begin{array}{c}10.4 \\
(5.3,17.8)\end{array}$ & 142 \\
\hline The patient is treated in the same treatment room each day & $\begin{array}{c}6.6 \\
(2.7,13.1)\end{array}$ & 143 \\
\hline
\end{tabular}

Figure 3-3 shows the ratings of importance of each aspect of care. The mean percentage of patients rating elements of care as "very important" within each category varied as follows $(\mathrm{p}<$ 0.0001): "perceived competence of caregivers", $80 \%$; "empathy and respectfulness of caregivers", 67\%; "adequacy of information sharing", 67\%; "patient centeredness", 59\%; “accessibility of caregivers", 57\%; "continuity of care", 51\%; "privacy", 51\%; "convenience", 45\%; "comprehensiveness", 44\%; and "the treatment environment", 30\% (for additional details please see appendix C3). Importance ratings also varied among the elements of individual aspects. For example, the percentage of patients rating elements of care within "adequacy of information sharing" as "very important" ranged from $38 \%$ for "The patient is made aware that he has the right to get a second opinion from another radiation oncologist" to $93 \%$ for "The radiation oncologist makes sure the patient knows that the cancer is confined to the prostate, and 
there is no sign that it has spread to any other part of the body".

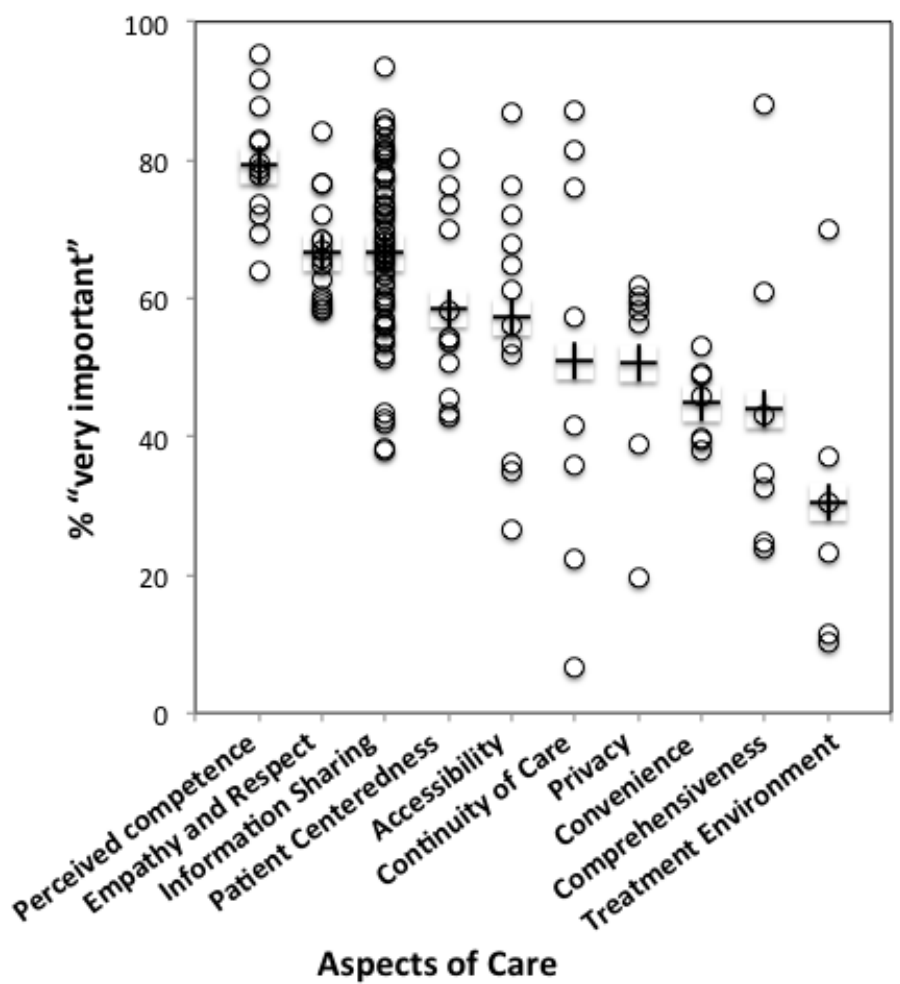

Figure 3-3: Comparison of the importance of aspects of personal care. Elements of care (o), mean importance of elements within each aspect $(+)$.

\subsubsection{Agreement on Ratings of Importance}

The majority of patients agreed that 80 elements of care were "very important" and that 22 elements of care were not "very important". Patients were divided in their opinion about the importance of the 41 other elements of care.

\subsubsection{Test-Retest Reliability}

Ninety-five patients were enrolled in the test-retest component of the study, and 63 completed and returned both copies of module 3. The median time between return of the first and second 
copies was 20 days (range, 8-74 days; interquartile range, 16-26 days). Variations in the interval between completion dates for the 2 copies of module 3 were primarily due to variations in the times the patients took to return the second copy of the questionnaire. Median positive agreement for the 64 elements included in module 3 was $82 \%$ (range, 58\%-97\%). Positive agreement was < $70 \%$ for 5 elements. (These 5 elements, which all ranked low in importance, are shown in table B3-3, Appendix B). Median agreement on ratings of not "very important" (negative agreement) was $73 \%$ (range, $40 \%-95 \%$ ).

\subsubsection{Relationship between patient characteristics and ratings of importance}

Figure 3-4 compares the ranks of importance assigned by different subgroups of patients. The high rank correlation coefficients indicate that patients ranked most elements of care similarly, regardless of age (Figure 3-4a), educational level (Figure 3-4b), and health status (Figure 3-4c). After the Benjamini-Hochburg procedure was applied, there were no significant differences among subgroups of patients defined by age and education level, but there were 3 elements where the importance differed on the basis of health status (Figure 3-4c). 

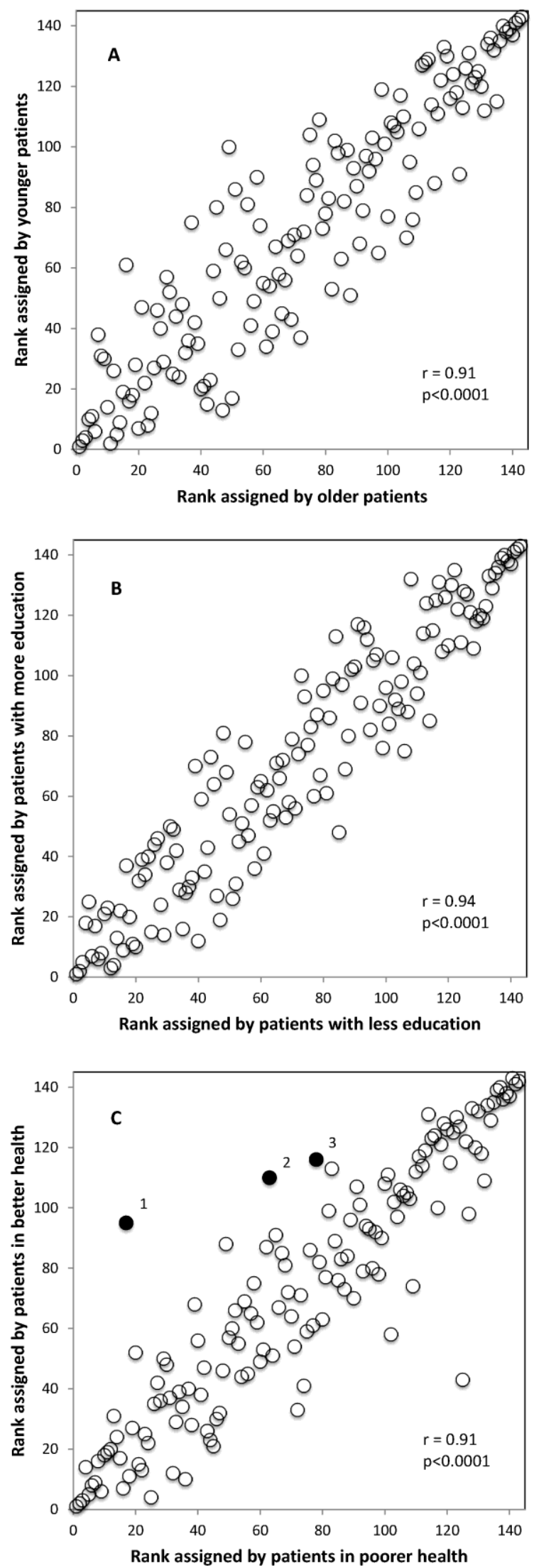
Figure 3-4: Relationship between patient characteristics and ratings of importance. Comparison of the ranks of each element of care between patients of different age (A), education level (B) and health status (C). Elements of care (o), elements of care rated significantly differently by subgroups of patients $(\bullet)$. Three elements were more important to patients in poorer health: 1 ) The cancer centre appears to be clean and well looked after; 2) The patient feels that his rights for

privacy are fully protected at the cancer centre; 3 ) The patient's family physician is kept informed about the cancer care.

\subsection{Discussion}

We found that many different elements of personal care are pertinent to patients who undergo radiation therapy for prostate cancer, but the aspects of care that are most important to most patients relate to the perceived competence of their caregivers, the empathy and respectfulness of caregivers, and the adequacy of information sharing. Individual patients expressed different priorities, but these were not predictable on the basis of their age, education or health status.

We used an inductive approach to identify the elements of personal care and determine the scope of personal care. We began by searching the literature for elements pertinent to patients undergoing radiation therapy for prostate cancer, and supplemented that list through cognitive interviews with prostate cancer patients and health care professionals and through successive rounds of pilot testing. The present survey failed to identify any additional elements, attesting to the content validity of the final questionnaire. These elements of care are what others have referred to as definitive, or causal, indicators $(123,124)$; that is, each element could influence a patient's well-being regardless of its relationship to other elements $(123,124)$. In this context, the results of validity or reliability investigations using correlation methods are difficult to interpret (125) and may encourage the elimination of important items, with a negative impact on content 
validity $(123,126-128)$. We therefore did not use factor analysis to assess construct validity, or Cronbach's alpha to assess internal consistency.

Our questionnaire was long, but surprisingly we achieved a response rate at least comparable with that observed in similar studies $(68,111,153)$. The setting in which the patients completed the questionnaire might have affected their responses. Our patients completed the questionnaire in their own homes because we believed they would be most likely to communicate their true feelings in this secure environment. However, they were not specifically instructed to do this independently, and some may had help from others. We acknowledge also that patients' rating of the importance might well change over time. Our questionnaire was delivered as 3 modules at specific points in time, with the goal of asking about the importance of each element at the point in time when it would be most relevant to that patient. However, the timing of delivery of the questions was not perfectly matched to the individual patient's trajectory, and differences between patients' scores may reflect differences in the timing of the questions in relation to key events in their trajectory. For example, the timing of delivery of module 1 in relation to the date of diagnosis varied depending on whether the patient started adjuvant hormone therapy before receiving radiation therapy (see Appendix C4). Finally, this study elicited the opinions of patients treated at just one center, and the generalizability of our findings is unknown.

Most previous studies that have sought to identify the aspects of care that are important to cancer patients have evaluated heterogeneous groups undergoing diverse treatments $(68,90,122,157)$. However, the specific aspects of care that are important to patients may be unique to their situation (57). The present study is unusual in focusing on the elements of care that are most important to a specific group of patients undergoing a specific type of treatment. Nonetheless our findings are largely consistent with those of other broader studies $(68,90,122,157)$. 
Efforts to improve the quality of personal care should focus on the elements of care that matter to patients (9). Previous work on the quality of nontechnical aspects of care has largely focused on assessing patient satisfaction $(158,159)$, evaluating the quality of specific aspects of care $(91,100,111)$, and identifying patients' needs (113). The questionnaire we used here was designed only to meet the limited objectives of the present study, but the inventory of elements of the quality of personal care that we assembled and prioritized based on the views of our respondents may be useful in developing better instruments for assessing the quality of personal care in future. 


\section{Chapter 4}

Development and Comparison of Methods to Identify Priorities for Improvement of the Quality of Personal Care in Patients Undergoing Radiotherapy for Prostate Cancer 


\subsection{Abstract}

Background: We previously developed a questionnaire to assess the quality of personal care in prostate cancer radiotherapy. Patients are asked to rate the importance of 143 elements of their care and to rate the quality of their care for each element. In order to improve the quality of care delivered to patients, the elements of care most in need of improvement must be identified.

Objective: To develop a method of integrating ratings of importance and ratings of quality to identify elements of care that should become targets for quality improvement.

Methods: We surveyed 108 patients undergoing radiotherapy for prostate cancer. We developed three methods to identify elements of care to target for quality improvement that were both important to the patient(s), and sub-optimal in quality. Spearman correlation was used to compare ranking of priorities across all three methods. Generalized estimating equations was used to assess the statistical ability of each method to discriminate between priorities for quality improvement.

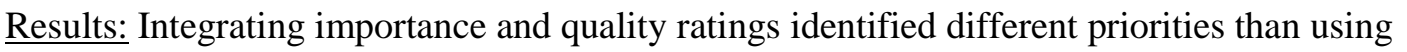
quality ratings alone. Two of the integrated methods identified priorities for quality improvement and their ranks similarly $(\mathrm{r}=0.91, \mathrm{p}<0.0001)$. Two methods were able to discriminate at the top 3 priorities, whereas the other method was only able to discriminate at the top 5. All methods identified elements related to communication of information about the disease and its treatment as priorities. 
Conclusions: Two methods produced similar results although one is easier to understand and theoretically superior since the ratings for importance and quality are linked for each individual and therefore not vulnerable to ecological fallacy. Further consultation with stakeholders is needed to determine how to best use these results as part of a quality improvement program.

Keywords: prostate cancer, quality, radiotherapy, quality improvement

\subsection{Introduction}

Quality of care is defined by the Institute of Medicine as "the degree to which health services for individuals and populations increase the likelihood of desired outcomes and are consistent with current professional knowledge" (1). Medical care consists of two components, technical care and non-technical care, the latter referred to as interpersonal care (24) or "personal care" (160). The quality of care delivered to patients affects outcomes (2).

Quality of care must be assessed in order to identify areas in need of improvement. Since a high quality of personal care is care that is consistent with patients' values and wishes, it is the patients who must assess its quality $(5,6)$.

We recently developed a suite of indicators for the assessment of personal care in the context of prostate cancer radiotherapy and surveyed patients about the quality of their care (160) [please note: reference 160 is included in this thesis as Chapter 3]. However, for data gathered to be useful in a quality improvement setting, it needs to be synthesized so that health care managers and health care professionals can identify actionable targets for quality improvement (10). 
Methods for identifying targets for quality improvement need to be valid, accurate, complete, actionable in terms of their ability of influence change, and easy to understand and interpret for relevant stakeholders $(23,133,161-163)$. Furthermore, when summarizing and describing patient data for quality improvement it is essential to target things that matter to patients $(8,9)$.

The objective of this study was to develop a method of integrating ratings of importance and ratings of quality to identify elements of care that should become targets for quality improvement.

\subsection{Methods}

\subsubsection{Data Collection}

We developed a questionnaire as previously described (160). Briefly, we identified elements of personal care relevant to patients undergoing radiotherapy for prostate cancer after a comprehensive literature review and interviews with patients and health care providers. We then grouped the elements of care into 10 categories corresponding to 10 aspects of personal care: 'empathy and respectfulness', 'perceived competence of caregivers', 'accessibility of caregivers', 'patient centeredness', 'privacy', 'continuity of care', 'communication', 'convenience', 'treatment environment', and 'comprehensiveness of services'. We constructed a selfadministered questionnaire that asked patients to rate the importance and quality of the care they received with respect to each element. Patients were asked: How important is this to you? and How good was your care in this regard?, and provided responses on an ordinal scale, as shown in Figure 4-1. Patients were also asked to provide information about their age, education level, 
marital status and general health. Details of the patient's cancer and treatment were obtained by medical chart review.

\begin{tabular}{l|c|c|c|}
\hline $\begin{array}{c}\text { Characteristic of good } \\
\text { care }\end{array}$ & $\begin{array}{c}\text { How important is this to } \\
\text { you? }\end{array}$ & $\begin{array}{c}\text { How good was your care in } \\
\text { this regard? }\end{array}$ \\
\hline $\begin{array}{l}\text { Once the decision to have } \\
\text { radiation treatment has been made, } \\
\text { the patient is given enough } \\
\text { information about how long he } \\
\text { will have to wait to start treatment }\end{array}$ & $\begin{array}{c}\text { Not Somewhat Important Very } \\
\text { Important Important }\end{array}$ & $\begin{array}{l}\text { Very Poor Okay Good Very Unable } \\
\text { Important to answer }\end{array}$ \\
Poor
\end{tabular}

Figure 4-1: Sample Page of the self-administered questionnaire

\subsubsection{Patient Selection and Recruitment}

Patients were eligible for this study if they started curative radiotherapy for prostate cancer at the Cancer Centre of Southeastern Ontario between May 2011 and August 2014. Patients were excluded if they had received brachytherapy. Patients were given the questionnaire by hand and asked to complete it at home and return by mail.

\subsubsection{Data Management}

Completed questionnaires were stored in a locked filing cabinet in a secure facility. Patients were identified by a study number only. Data were entered into a password protected Microsoft Access database using double entry. 


\subsubsection{Identifying Priorities for Quality Improvement}

Our goal was to synthesize the patient group's perception of quality of care to target elements of care for quality improvement that were both important to the patient(s), and sub-optimal in quality. We developed and compared three methods for identifying these targets, as described below.

The "individual priority-based method" begins by identifying the elements of care that each individual scored as both "very important" and less than "very good". These elements were deemed to be the individual's personal priorities for improvement. The priorities of the group were established by ranking the elements, based on the percentage of patients that identified them as a personal priority.

In the "group priority-based method" priorities for quality improvement were identified by ranking each element based on the product of the percentage of the group that rated it less than "very good", and the percentage of the group that rated it "very important": (100\% - \% "very good")*(\% "very important").

The "group ranking-based method" is based on the principles of importance performance analysis by Martilla and James (164). The elements of personal care were first ranked independently, by quality and by importance. Importance was ranked based on the percentage of patients rating each element "very important". Quality was ranked from best to worst, based on the percentage of patients rating each element "very good". Each element was characterized by 
two values: importance rank, and the inverse quality rank (quality ranked from worst to best). The elements were then ranked using the lower of the two ranks.

We used the Spearman correlation to compare the complete ranking of priorities across all three methods. We also used the Spearman correlation to compare the ranking of priorities from each method to the overall rank order generated using quality ratings or importance ratings alone. The statistical ability of each method to discriminate between priorities for quality improvement was assessed using generalized estimating equations (GEE). We did GEE with repeated measures to account for potential correlation of responses within patients, and we used the results of the type 3 analysis. Analyses were conducted with SAS 9.3 (151).

\subsubsection{Ethics}

This study was approved by the Health Sciences Research Ethics Board at Queen's University (\#6003838).

\subsection{Results}

\subsubsection{Recruitment and Compliance}

There were 188 patients who started radiotherapy for localized prostate cancer at CCSEO between May 2011 and August 2014. Of these, 108 patients completed the full questionnaire. For a more detailed description, please refer to our previous publication (160). 


\subsubsection{Study Population}

Fifty-six percent $(56 \%)$ of patients were aged 70 or older, and $45 \%$ had postsecondary education. Fifty-one percent (51\%) reported their health as "good" and 30\% reported their health as “excellent”. Eighty-four percent (84\%) were married/living common law. Ten percent (10\%) had low-risk disease, $50 \%$ had intermediate-risk disease, and $40 \%$ had high-risk disease.

\subsubsection{Missing Responses}

There were few missing responses. For each patient, the median number of elements missing an importance rating was 0 (range 0 to 32 , IQR 0 to 2 ), and the median number of elements missing a quality rating was 9 (range 0 to 49, IQR 5 to 16). However, for the individual priority-based method, ratings of importance and quality are linked, therefore patients must provide both ratings. The median number of elements missing either a quality, or importance rating was 9 (range 0 to 49, IQR 5 to 16) (for additional details please see Appendix D1).

\subsubsection{Identifying Priorities for Quality Improvement}

The correlation between each of the three methods and the overall rank order based on quality alone was: individual priority-based method versus quality, $r=0.64(\mathrm{p}<0.001)$; group prioritybased method versus quality, $\mathrm{r}=0.80(\mathrm{p}<0.0001)$; and group ranking-based method versus quality, $\mathrm{r}=0.26(\mathrm{p}=0.001)$. Therefore, the ranking of priorities for quality improvement generated by each method differs from the order of priorities generated using quality ratings alone.

Figure 4-2 compares the overall ranking of priorities for quality improvement between methods. There was a strong correlation between the overall ranking of elements of care provided by the group priority-based method and the individual priority-based method $(r=0.91)$. The correlation 
between the group ranking-based method and the other two methods was weaker: group rankingbased method versus the individual priority-based method $\mathrm{r}=0.68$, and the group ranking-based method versus the group priority-based method $\mathrm{r}=0.69$. 

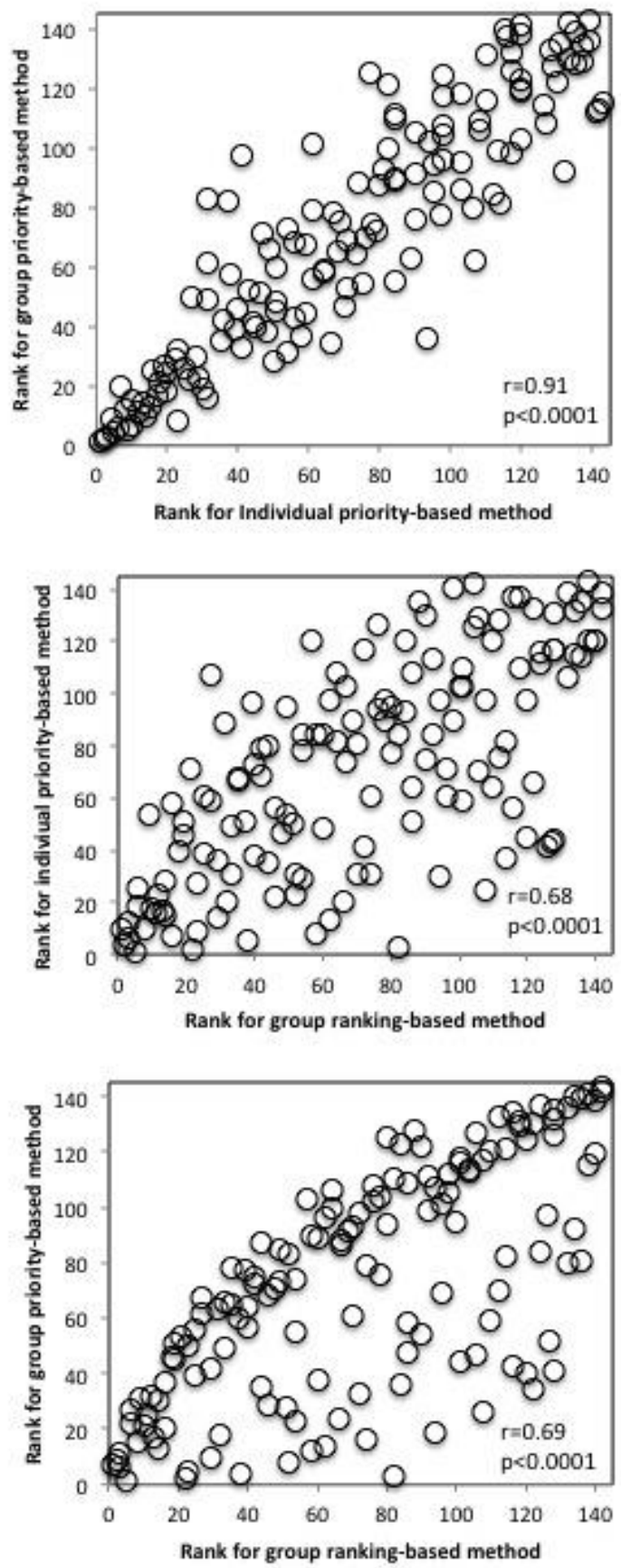

Figure 4-2: Rank correlation between results of the three methods 
For each method, the GEE analyses showed that the top 10 elements of care were identified as significantly different from the bottom 10 elements of care (in all cases, $\mathrm{p}<0.0001$ ). We then compared the top 10 elements to the next set of 10 elements, and again, found that the top elements of care were significantly different than the next set of 10 (individual priority-based method, $\mathrm{p}=0.0001$; group priority-based method, $\mathrm{p}=0.0003$; group ranking-based method, $\mathrm{p}=0.0003)$. We then modified the cut-off point to assess whether one method was better at discriminating between priorities for improvement (Table 4-1). The individual priority-based method and the group priority-based method were both able to discriminate at the top 3 priorities, whereas the group ranking-based method was only able to discriminate at the top 5 (for additional details, please see Appendix D2).

Table 4-1: Comparison of the three methods based on their ability to discriminate between top priorities for quality improvement*

\begin{tabular}{|l|l|l|l|l|}
\hline \multirow{1}{*}{ Method } & \multicolumn{3}{|c|}{ Comparison by GEE (generalized score statistic, $\mathrm{p}$-value) } \\
\cline { 2 - 5 } & $\begin{array}{c}\text { Top } 3 \text { to next } \\
3 \text { elements }\end{array}$ & $\begin{array}{c}\text { Top 5 to next } \\
5 \text { elements }\end{array}$ & $\begin{array}{c}\text { Top } 10 \text { to next 10 } \\
\text { elements }\end{array}$ & $\begin{array}{c}\text { Top 15 to } \\
\text { next } 15 \\
\text { elements }\end{array}$ \\
\hline $\begin{array}{l}\text { Individual } \\
\text { priority-based } \\
\text { method }\end{array}$ & $9.1, \mathrm{p}=0.0026$ & $15.9, \mathrm{p}<0.0001$ & $14.5, \mathrm{p}=0.0001$ & $\begin{array}{l}28.2, \\
\mathrm{p}<0.0001\end{array}$ \\
\hline $\begin{array}{l}\text { Group priority- } \\
\text { based method }\end{array}$ & $\begin{array}{l}14.6, \\
\mathrm{p}=0.0001\end{array}$ & $9.1, \mathrm{p}=0.0025$ & $12.9, \mathrm{p}=0.0003$ & $\begin{array}{l}28.9, \\
\mathrm{p}<0.0001\end{array}$ \\
\hline $\begin{array}{l}\text { Group ranking- } \\
\text { based method }\end{array}$ & $0.85, \mathrm{p}=0.36$ & $16.8, \mathrm{p}<0.0001$ & $13.0, \mathrm{p}=0.0003$ & $\begin{array}{l}19.2, \\
\mathrm{p}<0.0001\end{array}$ \\
\hline
\end{tabular}

*The priorities for quality improvement identified by each method are shown in Table 4-2 and Table D3-1 (Appendix D3).

Figure 4-3 shows the relationship between the quality and the importance of each element, using the format introduced by Martilla and James (164). The quality of each element is ranked from 
worst to best, based on the percentage of patients rating each element less than "very good". The top ranked elements of care identified using each of the three methods of integrating importance and quality ratings are highlighted in this figure and listed in Table 4-2. The full ranking of priorities for quality improvement is presented in Appendix D3. The individual priority-based method and the group priority-based method identified very similar elements in their top 10, with 8 elements of care in common. The top priorities identified by these two methods include elements with intermediate importance but very poor quality, and others that have intermediate quality but very high importance. The group ranking-based method has four elements in common with the group priority-based method and these same elements in common with the individual priority-based method with the addition of one other. These common elements are all related to communication of information about the disease or treatment and are elements that are of high importance and poor quality. The group ranking-based method prioritized elements of care with higher ratings of importance, but did not prioritize any elements of care with very low quality ratings that were still very important to a minority of patients. 


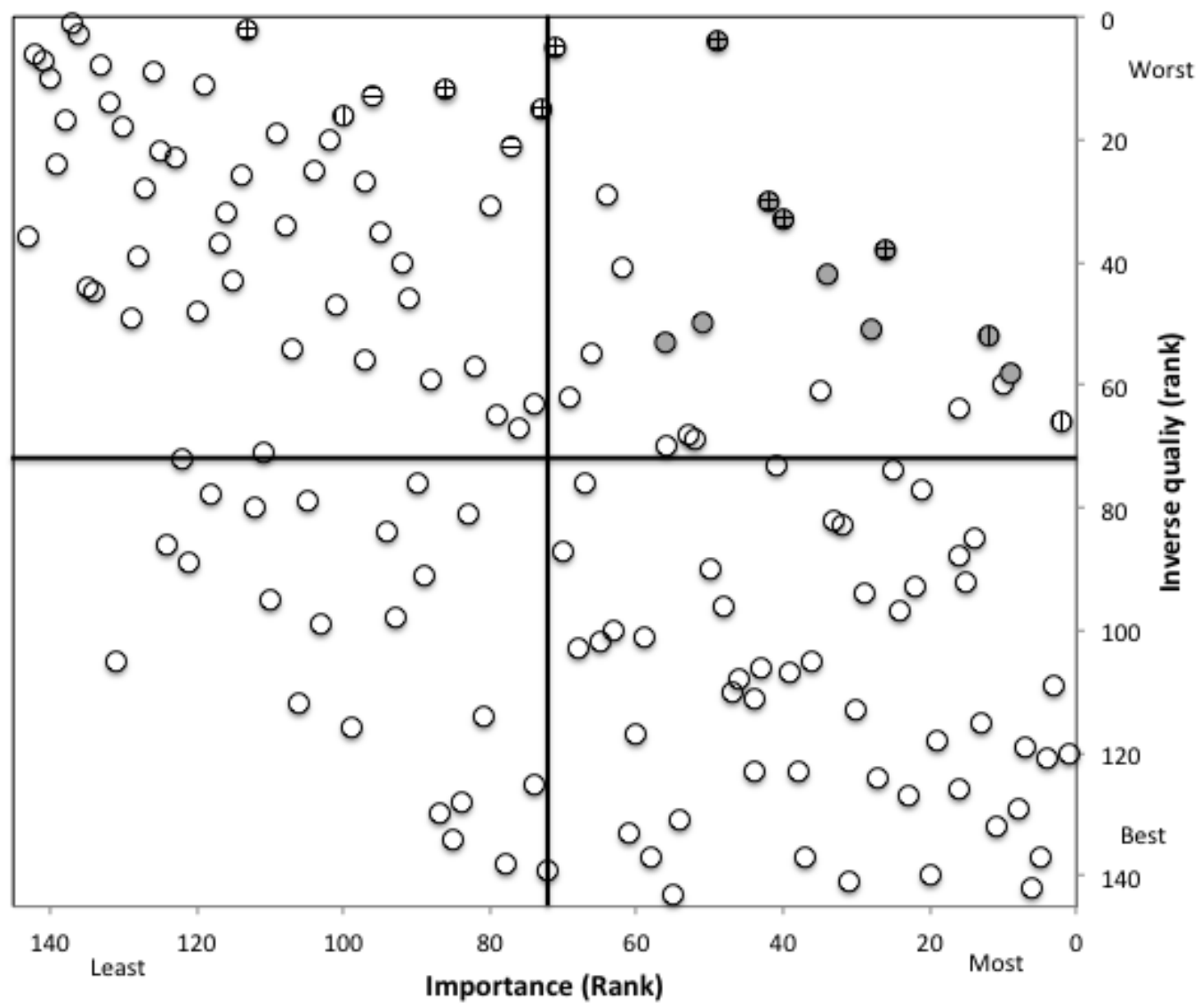

Figure 4-3: The Relationship between quality and importance: Each circle represents an element of care, ranked by importance on the x-axis, and by quality on the $y$-axis. Importance is ranked from most to least important. Quality is ranked from worst to best. The top priorities for quality improvement identified by each method are as follows: the individual priority-based method $(\mathbb{D})$, the group priority-based method $(\ominus)$, the group ranking-based method $\left({ }^{O}\right)$. Elements of care identified by more than one method are shown by combining the appropriate symbols. The vertical and horizontal lines show the median ranking of importance and quality, for reference. 
Table 4-2: The top elements of care identified by each method for identifying targets for quality improvement

\begin{tabular}{|c|c|c|c|c|c|c|c|c|c|c|}
\hline \multirow[b]{3}{*}{ Element of Care } & \multicolumn{4}{|c|}{ Summary Ratings } & \multicolumn{6}{|c|}{ Methods* } \\
\hline & \multicolumn{2}{|c|}{ Quality } & \multicolumn{2}{|c|}{ Importance } & \multicolumn{2}{|c|}{$\begin{array}{c}\text { Individual priority- } \\
\text { based }\end{array}$} & \multicolumn{2}{|c|}{ Group priority-based } & \multicolumn{2}{|c|}{ Group ranking-based } \\
\hline & $\begin{array}{c}\text { Inverse } \\
\text { rank }\end{array}$ & $\begin{array}{l}\text { \% "Very } \\
\text { Good" (95\% } \\
\text { CI) }\end{array}$ & Rank & $\begin{array}{l}\text { \% "Very } \\
\text { Important" } \\
(95 \% \mathrm{CI})\end{array}$ & Rank & $\begin{array}{l}\text { \% "very } \\
\text { good" AND } \\
\text { "very } \\
\text { important" }\end{array}$ & Rank & $\begin{array}{c}(100 \%-\% \\
\text { "very } \\
\text { good")*(\% } \\
\text { "very } \\
\text { important") }\end{array}$ & Rank & $\begin{array}{l}\text { Lower rank } \\
\text { of inverse } \\
\text { quality or } \\
\text { importance }\end{array}$ \\
\hline $\begin{array}{l}\text { Someone on the healthcare } \\
\text { team explains that radiation } \\
\text { treatment cannot usually be } \\
\text { given to the prostate again if it } \\
\text { is not successful the first time }\end{array}$ & 4 & $\begin{array}{c}39.8 \\
(29.8,50.5)\end{array}$ & 49 & $\begin{array}{c}69.9 \\
(60.1,78.6)\end{array}$ & 1 & $\begin{array}{c}40.9 \\
(30.8,51.6)\end{array}$ & 1 & 4209.4 & 5 & 49 \\
\hline $\begin{array}{l}\text { Someone on the healthcare } \\
\text { team explains the other } \\
\text { treatments that are available if } \\
\text { radiation treatment is not } \\
\text { successful }\end{array}$ & 5 & $\begin{array}{c}41.9 \\
(31.8,52.6)\end{array}$ & 71 & $\begin{array}{c}63.4 \\
(53.2,72.7)\end{array}$ & 2 & $\begin{array}{c}34.8 \\
(25.2,45.4)\end{array}$ & 2 & 3679.3 & 22 & 71 \\
\hline $\begin{array}{l}\text { There is somewhere } \\
\text { convenient to park }\end{array}$ & 2 & $\begin{array}{c}35.2 \\
(26.2,45.2)\end{array}$ & 113 & $\begin{array}{c}45.8 \\
(36.1,55.7)\end{array}$ & 3 & $\begin{array}{c}29.5 \\
(21.0,39.2)\end{array}$ & 3 & 2965.4 & 82 & 113 \\
\hline $\begin{array}{l}\text { Someone on the healthcare } \\
\text { team explains that radiation } \\
\text { treatment may permanently } \\
\text { affect bowel function }\end{array}$ & 33 & $\begin{array}{c}65.0 \\
(55.0,74.2)\end{array}$ & 40 & $\begin{array}{c}73.3 \\
(63.8,81.5)\end{array}$ & 4 & $\begin{array}{c}23.5 \\
(15.7,33.0)\end{array}$ & 9 & 2562.9 & 2 & 40 \\
\hline $\begin{array}{l}\text { Someone on the healthcare } \\
\text { team explains what prostate } \\
\text { cancer is and how it can affect } \\
\text { the patient's health }\end{array}$ & 12 & $\begin{array}{c}50.0 \\
(39.6,60.4)\end{array}$ & 86 & $\begin{array}{c}58.6 \\
(48.6,68.2)\end{array}$ & 5 & $\begin{array}{c}22.9 \\
(15.0,32.6)\end{array}$ & 4 & 2932.5 & 38 & 86 \\
\hline Someone on the healthcare & 30 & 63.1 & 42 & 72.4 & 6 & 22.6 & 6 & 2670.1 & 3 & 42 \\
\hline
\end{tabular}




\begin{tabular}{|c|c|c|c|c|c|c|c|c|c|c|}
\hline $\begin{array}{l}\text { team explains that radiation } \\
\text { treatment may permanently } \\
\text { affect bladder function }\end{array}$ & & $(53.0,72.4)$ & & $(62.8,80.7)$ & & $(14.9,31.9)$ & & & & \\
\hline $\begin{array}{l}\text { The radiation oncologist } \\
\text { makes sure the patient knows } \\
\text { that the cancer is confined to } \\
\text { the prostate, and there is no } \\
\text { sign that it has spread to any } \\
\text { other part of the body }\end{array}$ & 66 & $\begin{array}{c}77.7 \\
(68.4,85.3)\end{array}$ & 2 & $\begin{array}{c}93.5 \\
(87.0,97.3)\end{array}$ & 7 & $\begin{array}{c}20.4 \\
(13.1,29.5)\end{array}$ & 20 & 2087.0 & 16 & 66 \\
\hline $\begin{array}{l}\text { Someone on the healthcare } \\
\text { team explains when the } \\
\text { patient can resume all of his } \\
\text { previous activities after } \\
\text { radiation treatment }\end{array}$ & 16 & $\begin{array}{c}55.1 \\
(44.1,65.6)\end{array}$ & 100 & $\begin{array}{c}54.2 \\
(44.3,63.9)\end{array}$ & 8 & $\begin{array}{c}20.2 \\
(12.4,30.1)\end{array}$ & 12 & 2436.2 & 58 & 100 \\
\hline $\begin{array}{l}\text { The patient is given enough } \\
\text { information to understand } \\
\text { how the radiation treatment } \\
\text { works }\end{array}$ & 15 & $\begin{array}{c}54.7 \\
(44.8,64.4)\end{array}$ & 73 & $\begin{array}{c}62.3 \\
(52.3,71.5)\end{array}$ & 9 & $\begin{array}{c}20.0 \\
(12.8,28.9)\end{array}$ & 5 & 2819.1 & 23 & 73 \\
\hline $\begin{array}{l}\text { The radiation oncologist gives } \\
\text { the patient enough } \\
\text { information about the chance } \\
\text { of curing his cancer with each } \\
\text { treatment option }\end{array}$ & 38 & $\begin{array}{c}66.3 \\
(56.2,75.4)\end{array}$ & 26 & $\begin{array}{c}78.1 \\
(69.0,85.6)\end{array}$ & 10 & $\begin{array}{c}19.8 \\
(12.5,28.9)\end{array}$ & 7 & 2628.8 & 1 & 38 \\
\hline $\begin{array}{l}\text { The radiation oncologist } \\
\text { makes sure the patient knows } \\
\text { the stage of his cancer and } \\
\text { understands what that means }\end{array}$ & 52 & $\begin{array}{c}73.3 \\
(64.5,81.6)\end{array}$ & 12 & $\begin{array}{c}83.2 \\
(74.7,89.7)\end{array}$ & 10 & $\begin{array}{c}19.8 \\
(12.5,28.9)\end{array}$ & 15 & 2223.4 & 8 & 52 \\
\hline $\begin{array}{l}\text { The patient is made aware of } \\
\text { who to contact if he is } \\
\text { concerned about the cancer } \\
\text { coming back }\end{array}$ & 42 & $\begin{array}{c}67.4 \\
(56.5,77.2)\end{array}$ & 34 & $\begin{array}{c}75.9 \\
(66.8,83.6)\end{array}$ & 12 & $\begin{array}{c}19.8 \\
(12.0,29.8)\end{array}$ & 11 & 2472.3 & 3 & 42 \\
\hline $\begin{array}{l}\text { Someone at the cancer centre } \\
\text { arranges for the patient to } \\
\text { receive any help he needs in } \\
\text { dealing with his anxiety about }\end{array}$ & 21 & $\begin{array}{c}59.1 \\
(36.4,79.3)\end{array}$ & 77 & $\begin{array}{c}60.9 \\
(38.5,80.3)\end{array}$ & 14 & $\begin{array}{c}18.2 \\
(5.2,40.3)\end{array}$ & 10 & 2490.2 & 29 & 77 \\
\hline
\end{tabular}




\begin{tabular}{|c|c|c|c|c|c|c|c|c|c|c|}
\hline the diagnosis & & & & & & & & & & \\
\hline $\begin{array}{l}\text { The radiation oncologist } \\
\text { makes sure the patient knows } \\
\text { the grade of his cancer and } \\
\text { understands what that means }\end{array}$ & 58 & $\begin{array}{c}75.5 \\
(66.0,83.5)\end{array}$ & 9 & $\begin{array}{c}85.0 \\
(76.9,91.2)\end{array}$ & 18 & $\begin{array}{c}16.7 \\
(10.0,25.3)\end{array}$ & 21 & 2084.6 & 10 & 58 \\
\hline $\begin{array}{l}\text { Someone on the healthcare } \\
\text { team explains that the PSA } \\
\text { level is all that is needed to } \\
\text { tell if the cancer is under } \\
\text { control or not }\end{array}$ & 50 & $\begin{array}{c}72.4 \\
(61.8,81.5)\end{array}$ & 51 & $\begin{array}{c}69.5 \\
(59.8,78.1)\end{array}$ & 19 & $\begin{array}{c}16.1 \\
(9.1,25.5)\end{array}$ & 27 & 1918.1 & 6 & 51 \\
\hline $\begin{array}{l}\text { Someone on the healthcare } \\
\text { team answers any questions } \\
\text { the patient has about the } \\
\text { possible causes of prostate } \\
\text { cancer }\end{array}$ & 13 & $\begin{array}{c}53.8 \\
(37.2,69.9)\end{array}$ & 96 & $\begin{array}{c}56.1 \\
(39.8,71.5)\end{array}$ & 23 & $\begin{array}{c}15.4 \\
(5.9,30.5)\end{array}$ & 8 & 2589.0 & 52 & 96 \\
\hline $\begin{array}{l}\text { The patient is given enough } \\
\text { information about the chance } \\
\text { of curing his cancer with } \\
\text { radiation treatment }\end{array}$ & 51 & $\begin{array}{c}73.1 \\
(63.5,81.3)\end{array}$ & 28 & $\begin{array}{c}77.4 \\
(68.2,84.9)\end{array}$ & 26 & $\begin{array}{c}14.6 \\
(8.4,22.9)\end{array}$ & 22 & 2082.5 & 6 & 51 \\
\hline $\begin{array}{l}\text { The radiation oncologist } \\
\text { explains what each treatment } \\
\text { option involves }\end{array}$ & 53 & $\begin{array}{c}73.3 \\
(64.5,81.6)\end{array}$ & 56 & $\begin{array}{c}68.3 \\
(58.4,77.0)\end{array}$ & 54 & $\begin{array}{c}8.9 \\
(4.2,16.2)\end{array}$ & 31 & 1824.9 & 9 & 56 \\
\hline
\end{tabular}

*Grey shaded boxes highlight the top elements of care identified for each method 
Figure 4-3 illustrates that the integration of importance and quality ratings identifies different quality improvement targets than quality ratings alone since there is a cluster of elements in the top left of Figure 4-3 that are not identified for quality improvement.

As a sensitivity analysis, we explored the impact of flagging elements of care as needing improvement if they were rated less than "good", rather than less than "very good" as in our main results. We used the Spearman correlation coefficient to compare the rank order using this modified approach and the original approach for each of the three methods. The Spearman correlation coefficients were: individual priority-based method $r=0.88(\mathrm{p}<0.0001)$, group priority-based method $\mathrm{r}=0.91(\mathrm{p}<0.0001)$, group ranking-based method $\mathrm{r}=0.90(\mathrm{p}<0.0001)$. Very few elements identified as top priorities for quality improvement differed between the two approaches.

The number of elements of care we identified as a priority for each patient varied (median 7 , range 0 to 126 , IQR 1 to 15$)$. Despite this variability, the percentage of elements of care identified as priorities for quality improvement for each patient was similar among subgroups of patients defined by age, educational level, and health status, and there were no statistically significant differences (Appendix D4).

\subsection{Discussion}

We developed three methods for identifying priorities for quality improvement by integrating patients' importance and quality ratings. All three methods identified different priorities 
compared to quality rankings alone. The individual priority-based method and group prioritybased method generated a similar overall rank order $(r=0.91)$. These methods were also both able to discriminate between top quality improvement priorities and the rest. The specific elements they prioritized were similar: elements of intermediate importance but very poor quality, and others of intermediate quality but very high importance. The group ranking-based method chose elements of care with higher importance and gave less priority to very low quality ratings.

Identifying priorities for quality improvement using patient survey data has often focused on identifying the elements of care with the lowest quality ratings (141), but as shown here, this approach differs from what is found when ratings of importance are incorporated into ranking methods. In our study, all three methods identified elements of communication as ones in greatest need of improvement, which is consistent with the results of a recent systematic review that identified communication as the aspect of care most frequently reported as important by patients for the delivery of high quality of care (165). However, aspects of communication are not commonly targeted for quality improvement based on the results of surveys of patients experience (141).

For each method, we dichotomized both of our rating scales to consider only the highest cutpoint. Other researchers who have collected data on importance as well as on quality have converted rating scales to numeric scales and calculated means and/or medians for each question $(68,166)$, but we felt this was not an appropriate approach to take with our dataset especially since there were no numbers associated with the words in the original questionnaire to which patients could refer (167). We conducted a sensitivity analysis by modifying our cut-point for ranking 
elements of care based on quality ratings and found the ranking of priorities for quality improvement were similar across all three methods, regardless of how we defined our cut-point for quality.

The two group-based methods use aggregate data. The elements of care that are rated less than "very good" may not be the same elements of care rated "very important" to individual patients and therefore these methods are subject to an ecological fallacy. Since the individual prioritybased method links the ratings of importance and quality for each patient, it is not subject to the concerns of using aggregate data.

For each method, the denominator used for all calculations includes the percentage of patients providing a rating of importance and/or quality, not the total number of patients. Therefore, for all three methods, theoretically, elements of care applicable to only a minority of the population could be identified as priorities for quality improvement (assuming that missing responses indicate the element of care is not applicable to that patient). In using any of these methods in future, the number of individuals rating each element of care could be considered alongside the ranking and further discussions with health care managers and health care providers may be warranted to determine appropriate thresholds regarding the applicability of that element of care to the patient population (48).

We considered how easy it was to understand the quantities that underlay the final list of ranked elements of care. The quantities generated using the group priority-based method have limited meaning and are difficult to interpret (168), which is a disadvantage of this method in comparison 
to the other two (see Table 4-2). It is also worth noting that it is possible to generate confidence intervals for the individual priority-based method but we were unable to generate confidence intervals for the group priority-based and group ranking-based methods. We sought expert statistical advice and were informed that methods for calculating confidence intervals for these two methods are not straightforward, and that even if we did calculate them, they may not be useful.

The individual priority-based method offers an advantage over the other two methods since the quality and importance ratings are linked for individual patients. However, this advantage can also be a disadvantage as it doubles the amount of data required to collect. We previously found that ratings of importance were not associated with patient characteristics (160), and although we would certainly expect to observe differences in quality of care delivered between centres, it may be that importance ratings from patients do not differ from centre to centre. If this is true, then it adds an unnecessary burden on patients by asking them to rate the importance of each element, doubling the length of the questionnaire. If the group priority-based or group ranking-based methods were used to identify priorities for quality improvement, the aggregate importance ratings could be used and in future only quality ratings would be collected from patients.

In this paper, we presented the top elements of care identified as priorities for quality improvement using three integrated methods. For the individual priority-based method, these top priorities are ones where $19.8 \%$ or more of patients rated the element as "very important" and less than "very good". This threshold could be varied. For example, if a minimum threshold of $25 \%$ was used, this would have identified only 3 elements of care. Alternatively, a threshold of $15 \%$ 
would identify 25 elements of care as priorities for improvement. Consultation with healthcare providers and managers could identify appropriate thresholds to use for quality improvement, as others have done using similar approaches (166).

Although many organizations are collecting feedback from patients in order to improve quality of care, it is not yet known how to best use these data to improve care $(139,141,169)$. Three methods for integrating information about importance and quality of personal care have been presented here, but one is easier to understand and theoretically superior since the ratings for importance and quality are linked for each individual. Further involvement of stakeholders is needed to make sure these integrated methods address their needs $(70,170,171)$. Our future work will involve gathering feedback from clinicians and managers about the methods used here $(116,172)$. We believe that monitoring and reporting on the quality of personal care should be part of regular cancer centre quality assurance programs, and that the integrated methods presented here may be useful in identifying quality improvement targets. 


\section{Chapter 5}

Measuring the Quality of Personal Care in Patients Undergoing Radiotherapy for Prostate Cancer 


\subsection{Abstract}

Purpose: To describe the quality of the non-technical component of the care (personal care) of patients receiving radical radiotherapy for prostate cancer and identify elements of personal care that should be priorities for quality improvement.

Methods: One hundred and eight patients undergoing radiotherapy for localised prostate cancer completed a self-administered questionnaire that asked them to rate the importance of 143 nontechnical elements of care and to rate the quality of their own care with respect to each element. The elements that a patient rated as both "very important" and less than "very good" were deemed to be his priorities for improvement. The priorities of the population were established by ranking the elements based on the percentage of patients who identified them as a priority (importance/quality analysis).

Results: The response rate was $65 \%$. The percentage of elements rated "very good" varied from patient to patient: median $79 \%$ (interquartile range $69 \%-92 \%$ ). The percentage of elements rated either "very good" or "good", was higher: median 96\% (interquartile range 86\%-98\%). Nonetheless, almost every patient rated at least some elements of his care as less than optimal, regardless of the cut-off point used to define optimal quality. Patients assigned their lowest quality ratings to elements relating to the quality of the treatment environment and comprehensiveness of additional services available to them. However, patients rated most of these elements as relatively unimportant, and importance/quality analysis identified elements of care relating to communication of information about the disease and its treatment as the highest priorities for quality improvement. 
Conclusions: Most patients rated most elements of their personal care as very good, but almost all were able to identify some elements that were less than optimal. When ratings of quality were integrated with ratings of importance, elements relating to communication emerged as the patients' highest priorities for quality improvement.

Keywords: prostate cancer; quality; quality improvement; radiotherapy

\subsection{Introduction}

The quality of medical care is defined as "the degree to which health services for individuals and populations increase the likelihood of desired health outcomes and are consistent with current professional knowledge" (1). Medical care has technical and non-technical components (24), the latter sometimes referred to as "interpersonal care" or "personal care" $(24,160)$. The quality of care affects outcomes (2). In oncology, the quality of technical care may affect survival, whereas the quality of personal care may affect a patient's quality of life and their satisfaction with their care. Both technical and personal care must be optimised to achieve the best possible overall outcomes (146).

Quality improvement requires the definition of quality indicators and the development of methods for measuring quality in practice (22). Technical quality assurance has long been an integral part of the practice of radiotherapy, and indicators for the technical quality of the overall operations of radiation therapy programmes are already widely available (173). Indicators of the technical 
quality of radiation therapy for certain types of cancer have also been developed (39). Our group recently developed a suite of indicators of the technical quality of radiotherapy for prostate cancer (3). These indicators were used in a nationwide audit of the quality of radiotherapy for prostate cancer across Canada and opportunities for technical quality improvement were identified at every participating center (4). The quality of personal care was not evaluated in that audit.

We have since developed a self-administered questionnaire to elicit patients' views about the quality of the personal care that they receive while undergoing radiotherapy for prostate cancer (160) [please note: reference 160 is included in this thesis as Chapter 3]. The objectives of the present study were to describe the quality of personal care delivered to patients undergoing radiotherapy for prostate cancer in routine practice and to identify the elements of personal care that should be targeted for quality improvement.

\subsection{Materials and Methods}

\subsubsection{Questionnaire Development}

Elements of personal care relevant to patients undergoing radiotherapy for prostate cancer were identified based on a literature review and interviews with patients and health care providers and then organized into 10 categories relating to different aspects of personal care (160). We constructed a self-administered questionnaire to allow patients to rate the importance and quality of each of these elements based on their own experience. Each element of quality was presented as a positive statement and the patient was then asked: How important is this to you? and How good was your care in this regard? Patients provided their responses on ordinal scales as shown 
in Figure 5-1. The questionnaire was divided into three modules (160). Module 1, containing 60 questions pertinent to the treatment decision, was delivered in the first week of radiotherapy.

Module 2, containing 19 questions pertinent to the treatment period, was delivered in the last week of radiotherapy. Module 3, containing 64 questions pertinent to the overall treatment experience, was delivered at the first post-treatment visit, approximately 3 months after treatment was completed.

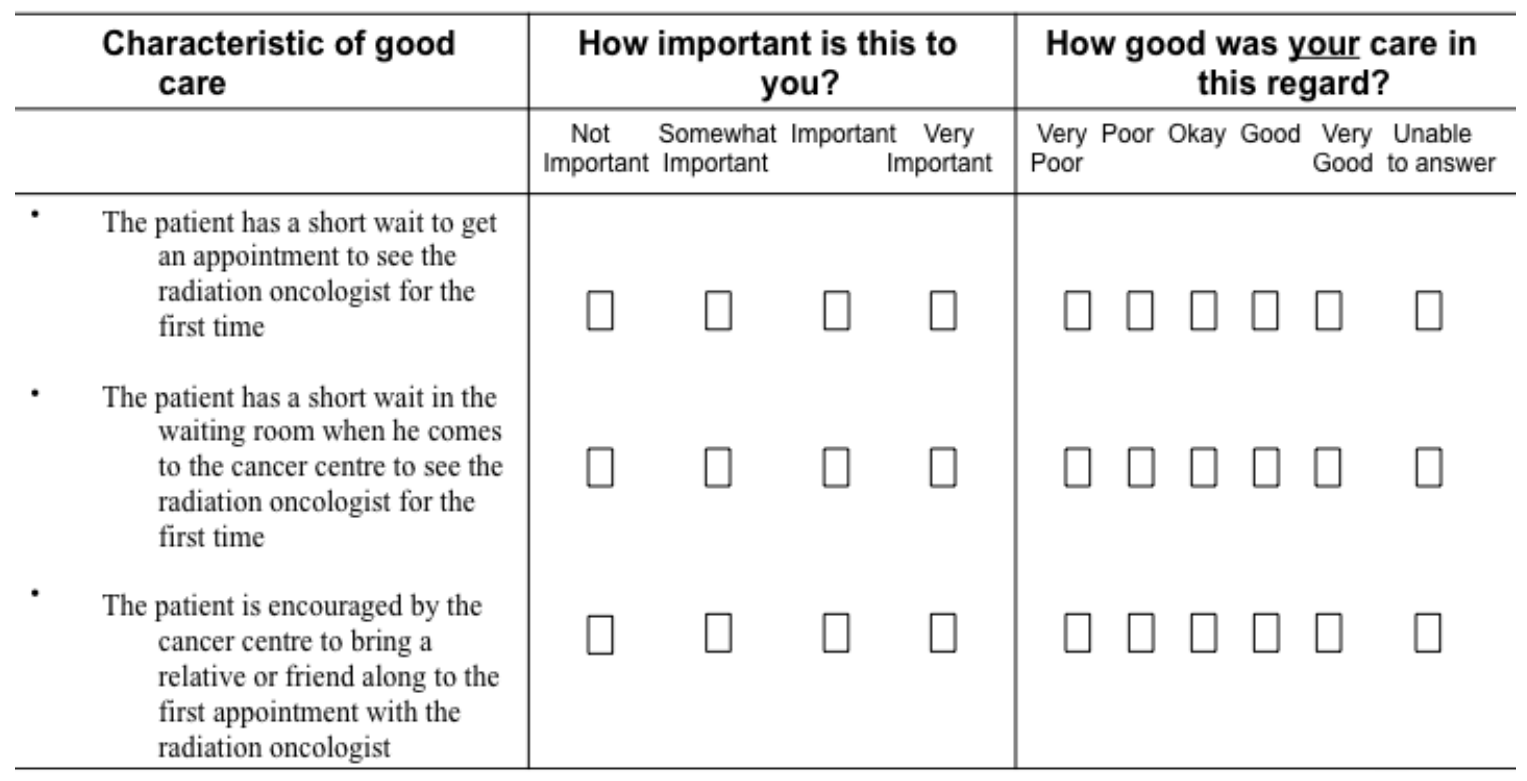

Figure 5-1: Sample page of the self-administered questionnaire

\subsubsection{Patient Selection and Recruitment}

The Cancer Centre of Southeastern Ontario (CCSEO) is a regional cancer centre integrated within a large general hospital. During the study period, the centre had 8.4 full-time equivalent radiation oncologists and treated a total of about 1100 new cases each year with radiotherapy. Patients starting external beam radiotherapy for localised prostate cancer at CCSEO between May 2011 
and August 2014 were eligible. Patients who had brachytherapy were excluded. We wanted to study a group of patients whose treatment experience was as uniform as possible and therefore we also excluded patients who had previously had a prostatectomy. If the radiation oncologist agreed, the patient was invited to participate during his first week of radiotherapy. Patients were assured that their responses were confidential.

\subsubsection{Administration of the Questionnaire}

Radiation therapists personally delivered each module of the questionnaire to the patient at the appropriate time points previously described, with instructions to complete it at home and return it by mail. To assess test-retest reliability, patients recruited after May 2012 were mailed a second copy of module 3 within 10 days of the return of the first copy and asked to complete it upon receipt.

\subsubsection{Patient Characteristics}

The questionnaire given at the start of treatment asked about the patient's age, education, marital status and general health. Details of the cancer and its treatment were obtained by chart review.

\subsubsection{Data Management}

Questionnaires were stored in a locked cabinet in a secure facility. Patients were identified by study number only. Data were entered into a password-protected Microsoft Access database using double entry. 


\subsubsection{Analytic Approach and Statistics}

\subsubsection{Test-retest Reliability}

Test-retest reliability was described by the percent positive agreement of ratings of "very good" for each element (155). Kappa was not used because the distribution of responses was skewed towards "very good" (154).

\subsubsection{Describing the Overall Quality of Personal Care}

The overall quality of the personal care of each patient was described by the percentage of the elements of care that he rated as "very good". The overall quality of personal care of groups of patients was described by the median percentage of elements rated as "very good" by the group. The Wilcoxon rank sum test was used to compare the ratings of overall quality provided by different groups of patients.

The quality of each element of personal care was described by the percentage of patients who rated it as "very good".

\subsubsection{Identifying Priorities for Quality Improvement}

The elements were ranked by quality based on the percentage of patients rating each element as "very good" and ties were resolved based on the percentage of patients rating each element as "good". Similarly, the elements were ranked by their importance based on the percentage of patients rating each as "very important". The elements of care that a patient rated as both "very important" and less than "very good" were deemed to be his personal priorities for improvement. The priorities of the population were established by ranking the elements based on the percentage 
of patients who identified them as a personal priority. This process is referred to below as importance/quality analysis. All analyses were conducted using SAS 9.3 (151).

\subsubsection{Ethics}

This study was approved by the Health Sciences Research Ethics Board at Queen's University (\#6003838).

\subsection{Results}

\subsubsection{Recruitment, Consent and Completion Rates}

Between May 2011 and August 2014, 188 patients started radiotherapy for localised prostate cancer at CCSEO. Of these, 108 completed the full questionnaire (57\%). Seventeen were excluded by the attending radiation oncologist, 147 agreed to participate, 20 declined and four were missed by the research team (Figure e1, Appendix E). Thirty-eight of the 147 participants dropped out before completing all three modules and one was excluded when his RT was discontinued (response rate, 65\%). Ninety-five per cent of the 108 patients who completed the entire questionnaire answered at least $99 \%$ of the questions. There was no deadline for the return of each module of the questionnaire, but $90 \%$ of questionnaires were returned within 6 weeks.

\subsubsection{Test-retest reliability}

Fifty-eight of the 78 patients included in the test-retest substudy repeated module 3 . The median positive agreement for quality ratings of the 64 elements in module 3 was $92 \%$ (range $68 \%$ 100\%) (for details, see Appendix F1). 


\subsubsection{The Study Population}

Table e1 (Appendix E) describes the characteristics of the study population. Fifty-six per cent were over the age of 70 years, and $49 \%$ had no postsecondary education. Eighty-one per cent described their general health as good or excellent. Ten per cent had low-risk disease, $50 \%$ had intermediate-risk disease, and 40\% had high-risk disease. Table e2 (Appendix E) describes their treatment. Most low- and intermediate-risk patients received $76 \mathrm{~Gy} / 38$ to the prostate by intensity-modulated radiotherapy. Most high-risk patients received with 46 Gy/23 to the pelvis followed by $30 \mathrm{~Gy} / 15$ to the prostate, plus hormonal therapy.

\subsubsection{Assessment of the Quality of Personal Care}

Panel A of Figure 5-2 shows that the percentage of the elements of care that each individual patient rated as "very good" varied with a median of 79\% and interquartile range (IQR) of 69\%92\%. The median percentage of elements that each patient rated as less than "very good" was 21\% (IQR 8\%-31\%). Panel A of Figure 5-2 also shows that the percentage of elements that each patient rated as either "very good" or "good" was higher, with a median of 96\% (IQR 86\%-98\%) and the percentage rated less than "good" was lower, with a median of 4\% (IQR 2\%-14\%). Some elements of care are more important than others to the individual patient (160). Panel B of Figure 5-2 shows the results of a separate analysis that included only elements of care identified as "very important" by the individual patient. Patients rated a higher percentage of these elements as "very good" (median 92\%, IQR 81\%-99\%), or at least "good" (median 98\%, IQR 93\%-100\%) and a lower percentage as less than "very good" (median 8\%, IQR 1\%-18\%) or less than "good" (median 2\%, IQR 0\%-7\%). 

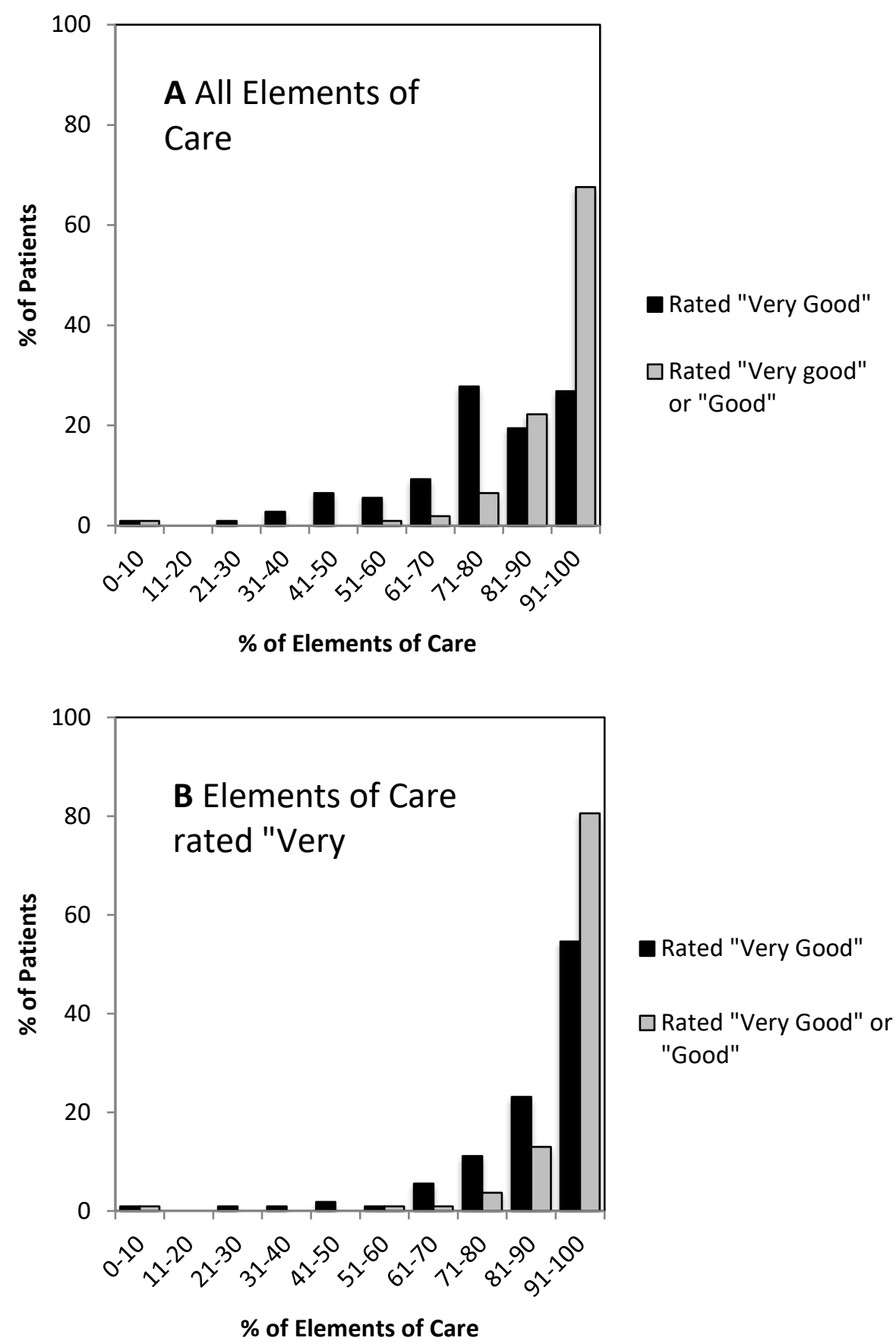

Figure 5-2: Patients' assessment of the quality of their care. Panel A shows frequency distributions of the percentage of all elements rated "very good" (black bars) and the percentage 
of elements rated either "very good" or "good" (grey bars). Panel B shows similar frequency distributions, but for the subset of elements that each patient rated as "very important".

Subgroups of patients defined by age, educational level, health status and details of their treatment all rated a very similar percentage of the elements of care as "very good" and there were no statistically significant differences between the quality ratings of any of these subgroups (for details see Table e3, Appendix E. Appendix F2 includes the results of an additional analysis comparing the percentage of elements of care rated "very good" over the course of the study period).

In Module 3, patients were asked to comment on the overall quality of their personal care during treatment; 93\% rated this as "very good" and 5\% rated this as "good". However, patients who rated their overall care as "very good" rated many of the individual elements of their care as less than "very good" (median 19\%; IQR 8-26\%) and some as less than "good"(median 4\%; IQR 1$12 \%)$.

\subsubsection{Identifying Opportunities for Quality Improvement}

We reasoned that the potential for quality improvement is greatest where quality is worst. We therefore ranked the elements of personal care based on the patients' collective ratings of their quality. The elements of care were ranked based on the percentage of patients who rated each element as "very good", which ranged from 33 to 96\%. Table 5-1 shows the top-ranked 10 and bottom-ranked 10 elements. The top 10, with least scope for improvement, included elements relating to the empathy and respectfulness of the healthcare providers, their communication skills, and the patient's perception of their competence. The bottom 10, with the greatest scope for 
improvement, included elements relating to the treatment environment, the comprehensiveness of services provided, the adequacy of the information provided about options available if radiotherapy fails and the right to a second opinion. A complete ranking of the quality of all the elements of care is provided in Table e4, Appendix E. A secondary analysis in which the elements were ranked based on the percentage rating each element as either "good" or "very good" gave very similar results (Appendix F3).

Table 5-1: Quality ranking of the elements of care based on the percentage of patients rating each element as "very good". The 10 highest ranked and 10 lowest ranked elements are given*.

\begin{tabular}{|l|c|c|}
\hline \multicolumn{1}{|c|}{ 10 Highest Ranked Elements of Care } & \multicolumn{2}{|c|}{ Quality } \\
\hline The radiation oncologist is polite to the patient & $\begin{array}{c}\text { \% Very Good } \\
(95 \% \text { CI })\end{array}$ & Rank \\
\hline $\begin{array}{l}\text { The radiation oncologist, nurses and radiation therapists work } \\
\text { well together when treating the patient for prostate cancer } \\
(90.7,99.0)\end{array}$ & $\begin{array}{c}96.2 \\
(90.6,99.0)\end{array}$ & 2 \\
\hline The radiation oncologist treats the patient with respect & $\begin{array}{c}96.2 \\
(90.6,99.0)\end{array}$ & 3 \\
\hline The radiation therapists are honest with the patient & $\begin{array}{c}96.1 \\
(90.3,98.9)\end{array}$ & 4 \\
\hline The radiation therapists care about the patient's well-being & $\begin{array}{c}95.2 \\
(89.0,98.4)\end{array}$ & 5 \\
\hline The radiation therapists treat the patient with respect & $\begin{array}{c}94.3 \\
(88.0,97.9)\end{array}$ & 6 \\
\hline $\begin{array}{l}\text { The radiation therapists are knowledgeable and experienced in } \\
\text { dealing with prostate cancer }\end{array}$ & $\begin{array}{c}94.3 \\
(88.0,97.9)\end{array}$ & 7 \\
\hline $\begin{array}{l}\text { The radiation therapists take the time to answer all of the patient's } \\
\text { questions }\end{array}$ & $\begin{array}{c}94.3 \\
(88.0,97.9)\end{array}$ & 7 \\
\hline $\begin{array}{l}\text { The radiation therapists explain things to the patient in a way that } \\
\text { he can understand }\end{array}$ & $\begin{array}{c}94.3 \\
(88.0,97.9)\end{array}$ & 7 \\
\hline The radiation therapists are polite to the patient & $\begin{array}{c}94.2 \\
(87.9,97.8)\end{array}$ & 10 \\
\hline
\end{tabular}




\begin{tabular}{|l|c|c|}
\hline \multicolumn{1}{|c|}{ 10 Lowest Ranked Elements of Care } & \multicolumn{2}{|c|}{ Quality } \\
\hline & $\begin{array}{c}\text { \% Very Good } \\
(95 \% \text { CI })\end{array}$ & Rank \\
\hline $\begin{array}{l}\text { There is enough space in the waiting room that the patient can } \\
\text { have a private conversation with his companion }\end{array}$ & $\begin{array}{c}48.5 \\
(38.6,58.6)\end{array}$ & 134 \\
\hline $\begin{array}{l}\text { The patient is made aware that he has the right to get a second } \\
\text { opinion from another radiation oncologist }\end{array}$ & $\begin{array}{c}47.3 \\
(36.9,57.9)\end{array}$ & 135 \\
\hline $\begin{array}{l}\text { The cancer centre provides resources to assist the patient in } \\
\text { understanding and dealing with prostate cancer (e.g. staffed } \\
\text { information services, library of books and DVDs about cancer) }\end{array}$ & $\begin{array}{c}44.8 \\
(34.2,55.9)\end{array}$ & 136 \\
\hline Food and drink facilities are available in or near the waiting room & $\begin{array}{c}43.8 \\
(33.6,54.2)\end{array}$ & 137 \\
\hline $\begin{array}{l}\text { Waiting areas are decorated nicely } \\
(32.9,52.4)\end{array}$ & 138 \\
\hline $\begin{array}{l}\text { Someone on the healthcare team explains the other treatments that } \\
\text { are available if radiation treatment is not successful }\end{array}$ & $\begin{array}{c}41.9 \\
(31.8,52.6)\end{array}$ & 139 \\
\hline $\begin{array}{l}\text { Someone on the healthcare team explains that radiation treatment } \\
\text { cannot usually be given to the prostate again if it is not successful } \\
\text { the first time }\end{array}$ & $\begin{array}{c}39.8 \\
(29.8,50.5)\end{array}$ & 140 \\
\hline $\begin{array}{l}\text { A social worker is available to provide advice on financial and } \\
\text { social issues arising from the diagnosis }\end{array}$ & $\begin{array}{c}39.7 \\
(27.0,53.4)\end{array}$ & 141 \\
\hline There is somewhere convenient to park & $\begin{array}{c}35.2 \\
(26.2,45.2)\end{array}$ & 142 \\
\hline $\begin{array}{l}\text { Someone at the cancer centre gives the patient information about } \\
\text { support groups in his area for patients and/or family members }\end{array}$ & $\begin{array}{c}33.3 \\
(23.1,44.9)\end{array}$ & 143 \\
\hline
\end{tabular}

* The quality ranking of all elements is provided in Table e4, Appendix E

Figure e2, Appendix E shows that patients ranked the quality of the elements of care very similarly, regardless of their age, educational level, health status or treatment regimen.

Figure e3, Appendix E displays the patients' ratings of the quality of groups of elements relating to different aspects of personal care. The quality of a group of related elements of care was described by the mean percentage of patients who rated those elements as "very good". We used generalised estimating equations to determine the significance of differences in the quality ratings 
of different groups of elements (174). (For additional details of this analysis please see Appendix F4). The mean percentage of patients rating elements of care "very good" within each group varied as follows: 'empathy and respectfulness', 92\%; 'perceived competence of caregivers', $88 \%$; 'accessibility of caregivers', $81 \%$; 'patient centeredness', $80 \%$; 'privacy', $79 \%$; 'continuity of care', 73\%; 'communication', 72\%; 'convenience', 70\%; 'treatment environment', $60 \%$; 'comprehensiveness of services', 56\% ( $\mathrm{p}<0.0001)$. Figure e3, Appendix E also shows that there were large differences between the quality ratings of individual elements within groups.

\subsubsection{Identifying Priorities for Quality Improvement}

Figure 5-3 displays the relationship between the quality and the importance of each element of care in a format introduced by Martilla and James (164). Quality is ranked from worst to best, based the percentage of patients rating each element less than "very good". Based on these aggregate results, the elements in quadrant $\mathrm{B}$, which rank above the median by importance and below the median by quality, would clearly be a higher priority for improvement than those in quadrant $\mathrm{C}$, which rank below the median by importance and above the median by quality. 


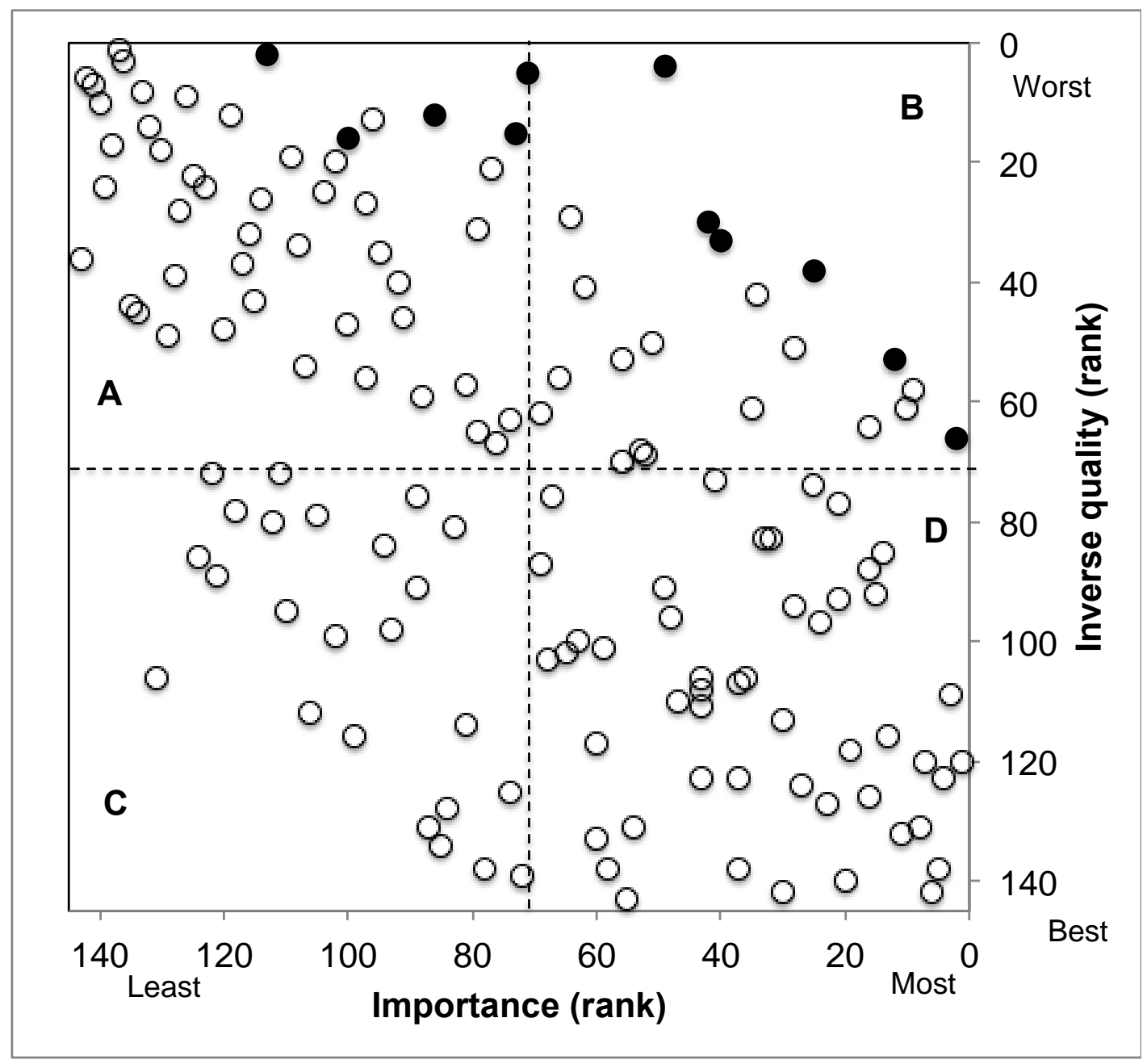

Figure 5-3: The relationship between quality and importance: Each circle represents an element of care, ranked by importance on the x-axis, and quality on the y-axis. Importance is ranked from the most to least important. Quality is ranked from worst to best. The division of each axis at the median creates four quadrants: (A) lower importance/lower quality, (B) higher importance/lower quality, (C) lower importance/higher quality and (D) higher importance/higher quality. The black circles represent the top priorities for quality improvement identified by the importance/quality analysis. 
We prioritised individual elements for quality improvement based on the percentage of patients who rated the element as both "very important" and less than "very good", using the process of importance/quality analysis described above. The top priorities are listed in Table 5-2 and flagged in Figure 5-3. Table 5-2 shows that the top priorities for quality improvement identified by importance/quality analysis differ from those identified by analysis of quality or importance alone. This is explained by the fact that many of the elements that ranked lowest in quality also ranked low in importance, and many of those that ranked highest in importance also ranked high in quality (see Figure 5-3). The top 10 priorities identified by importance/quality analysis therefore include some elements that have intermediate importance but very poor quality, and others that have intermediate quality but very high importance. Table 5-2 shows that most of the elements identified as highest priorities for improvement by importance/quality analysis relate to the communication of information about the disease itself and about the risks and benefits of treatment. A complete ranking of all elements is provided in Table e5, Appendix E.

Table 5-2: Top priorities for quality improvement. The priority ranking of all elements of care is provided in Table e5, Appendix E.

\begin{tabular}{|l|c|c|c|}
\hline Element of Care* & $\begin{array}{c}\text { Rank by } \\
\text { Importancel } \\
\text { quality }\end{array}$ & $\begin{array}{c}\text { Rank by } \\
\text { Quality } \\
\text { (inverse) }\end{array}$ & $\begin{array}{c}\text { Rank by } \\
\text { Importance }\end{array}$ \\
\hline $\begin{array}{l}\text { Someone on the healthcare team explains that } \\
\text { radiation treatment cannot usually be given to the } \\
\text { prostate again if it is not successful the first time (2) }\end{array}$ & 1 & 4 & 49 \\
\hline $\begin{array}{l}\text { Someone on the healthcare team explains the other } \\
\text { treatments that are available if radiation treatment is } \\
\text { not successful (2) }\end{array}$ & 2 & 5 & 71 \\
\hline $\begin{array}{l}\text { There is somewhere convenient to park (5) } \\
\begin{array}{l}\text { Someone on the healthcare team explains that } \\
\text { radiation treatment may permanently affect bowel } \\
\text { function (2) }\end{array}\end{array}$ & 3 & 33 & 40 \\
\hline
\end{tabular}




\begin{tabular}{|l|c|c|c|}
\hline $\begin{array}{l}\text { Someone on the healthcare team explains what } \\
\text { prostate cancer is and how it can affect the patient's } \\
\text { health (1) }\end{array}$ & 5 & 12 & 86 \\
\hline $\begin{array}{l}\text { Someone on the healthcare team explains that } \\
\text { radiation treatment may permanently affect bladder } \\
\text { function (2) }\end{array}$ & 6 & 30 & 2 \\
\hline $\begin{array}{l}\text { The radiation oncologist makes sure the patient knows } \\
\text { that the cancer is confined to the prostate, and there is } \\
\text { no sign that it has spread to any other part of the body } \\
(1)\end{array}$ & 7 & 86 & 16 \\
\hline $\begin{array}{l}\text { Someone on the healthcare team explains when the } \\
\text { patient can resume all of his previous activities after } \\
\text { radiation treatment (4) }\end{array}$ & 9 & 38 & 26 \\
\hline $\begin{array}{l}\text { The patient is given enough information to understand } \\
\text { how the radiation treatment works (3) }\end{array}$ & 10 & 52 & 12 \\
\hline $\begin{array}{l}\text { The radiation oncologist gives the patient enough } \\
\text { information about the chance of curing his cancer with } \\
\text { each treatment option (2) }\end{array}$ & 10 & & \\
\hline $\begin{array}{l}\text { The radiation oncologist makes sure the patient knows } \\
\text { the stage of his cancer and understands what that } \\
\text { means (1) }\end{array}$ & & 5 & \\
\hline
\end{tabular}

*The number in parentheses indicates the step in the treatment pathway the element refers to: (1) Pretreatment assessment, (2) Treatment decision-making, (3) Treatment planning, (4) Treatment and follow-up, (5) General aspects of care

\subsection{Discussion}

This survey showed that most patients undergoing radiotherapy for prostate cancer at this centre rated most of the elements of their personal care as "very good", the highest response category provided in the questionnaire. Patients assigned very high quality ratings to many of the elements of care that they rated as most important. This suggests that caregivers and managers share the patients' values and endeavor to optimise the quality of the elements of care that matter most to everyone. More importantly, however, most patients were able to identify many elements of their care that were suboptimal. This was true regardless of the cut-off point used to define suboptimal quality and regardless of whether the analysis was restricted to elements that the patient rated as 
important. Moreover, even patients who rated the overall quality of their personal care as "very good" rated many individual elements of their care as less than optimal. Thus, there seems to be substantial scope for improving the quality of the personal care of this group of patients. Most of the top priorities for quality improvement that emerge from the importance/quality analysis relate to problems in sharing information about the disease itself, and about the risks and benefits of treatment.

The survey was completed by only $57 \%$ of the potentially eligible patients treated during the study period (Figure e1, Appendix E). Patients who were excluded from participation at the request of their doctor and those who declined to participate might have rated the quality of their care differently from those who participated. However, those who completed the questionnaire rated the quality of their care very similarly, regardless of their age, educational level or general health status. This makes it unlikely that our findings were greatly influenced by the mix of patients included. However, it is possible that patients' reports of quality of care may have been influenced by how they felt during treatment (175). Our results are based on observations at a single centre and there is no basis for assuming that the quality of personal care is similar elsewhere. Furthermore, we do not know what level of quality is, in fact, achievable in this context. It would be unrealistic to expect that every patient would assign the highest possible rating to every element of his care, even under optimal conditions. It is not possible to set a priori performance targets for this type of quality indicator. Similar evaluations at multiple centers could, however, be used to determine the best achievable ratings, an approach we have used to set benchmarks for some indicators of the technical quality of radiotherapy for prostate cancer (4). It 
might then be possible to create specific guidelines for the delivery of the quality of personal care that could then be used for ongoing monitoring and quality assessment.

Previous studies of the non-technical component of health care have mainly been based on measurements of "patient satisfaction" $(56-58,148)$. This approach differs from ours in that the patients' satisfaction depends on their expectations, as well on as the quality of care delivered (59). Moreover, patient satisfaction surveys may not be the best way of identifying opportunities for quality improvement, because the broad questions that they usually ask often elicit uniformly high levels of satisfaction $(61,176)$. Likewise, in the present study, we found that most patients rated their overall care as "very good", while rating many individual elements of their personal care as less than optimal. Thus, allowing patients to report on individual elements of their care seems to be a more useful way of identifying specific and potentially actionable opportunities for quality improvement (59).

Our finding that elements of personal care related to patients' information needs were high priorities for quality improvement is consistent with the results of previous related work $(54,177)$. Optimising communication between healthcare providers and patients is challenging $(178,179)$, but interventions to meet the information needs of patients with early prostate cancer have been designed and evaluated $(180,181)$. One of these is an information booklet that has been shown to enhance patient knowledge and comprehension of facts about their disease, and that directly targets most of the communication-related elements of care that were identified as priorities for improvement in the present study (180). 
In collaboration with the genitourinary radiotherapy team at our centre, we plan to use the results of this survey to design an intervention to enhance the quality of personal care in this group of patients and to repeat this survey once this has been implemented. Although some elements of this questionnaire are necessarily specific to patients undergoing radiotherapy for localised prostate cancer, it could readily be adapted for use in other patient groups and we hope to extend its use to other sites. In the long term, we believe that monitoring the quality of personal care should become an integral part of ongoing programmes of quality assurance and quality improvement in the routine practice of radiotherapy. 


\section{Chapter 6}

\section{General Discussion}

\subsection{Summary of Main Findings}

In the first manuscript, "What Aspects of Personal Care Are Important to Patients Undergoing Radiation Therapy for Prostate Cancer?" we surveyed patients undergoing radiotherapy for prostate cancer to determine which elements of personal care were most important to them. Aspects of care most important to most patients were the perceived competence of their caregivers, the empathy and respectfulness of caregivers, and the adequacy of information sharing. The aspects of care of lesser importance to patients included convenience, comprehensiveness of services and the treatment environment. Importance ratings were not associated with the patient's age, education, or health status.

In the second manuscript, "Development and Comparison of Methods to Identify Priorities for Improvement of the Quality of Personal Care in Patients Undergoing Radiotherapy for Prostate Cancer" we developed and compared three methods for identifying priorities for quality improvement by integrating importance and quality ratings from patients. All three methods identified different priorities from what would be identified using quality rankings alone. Two methods produced similar results and prioritized elements of intermediate importance but very poor quality, and others of intermediate quality but very high importance. One method was easier to understand and theoretically superior since the ratings for importance and quality are linked for each individual and therefore not vulnerable to ecological fallacy. 
In our third manuscript, "Measuring the Quality of Personal Care in Patients Undergoing Radiotherapy for Prostate Cancer" we described the quality of personal care of patients undergoing radiotherapy for prostate cancer and identified the elements of personal care that should be targeted for quality improvement, incorporating some of what we learned from the first two manuscripts. We found that although most patients rated most elements of their care as "very good", they were also able to identify elements of care that were suboptimal. This was true regardless of the cut-off point we used to define quality, and whether or not the analysis was restricted to just the elements of care that were most important to individual patients. The top priorities for quality improvement related to communication of information about the disease, and the risks and benefits of treatment.

This thesis identified aspects of personal care important to men undergoing radiotherapy for prostate cancer and determined the relative importance of each element of care, developed and compared methods for integrating importance and quality ratings, and then used one of those methods to identify priorities for quality improvement. Throughout this work we explored some aspects related to implementation of this questionnaire; assessing the feasibility and acceptability of this questionnaire to patients, and the usability of the data gathered in terms of identifying priorities for quality improvement.

\subsection{Strengths and Limitations}

The individual manuscripts include a description of strengths and limitations relevant to each objective. In this section, the focus will be on the strengths and limitations of the overall thesis. 
We provided a detailed and comprehensive description of the quality of personal care patients receive while undergoing radiotherapy for prostate cancer. We had a very clearly defined study population undergoing a specific treatment and we determined it was feasible to conduct a survey to comprehensively assess the quality of their care during radiotherapy. The response rates for each module (conditional on completing earlier modules) was $>85 \%$ (Appendix B3) and missing data for our questionnaire was low. These observations support our earlier assertion in my MSc thesis that, based on pilot testing, the questionnaire does not appear to pose an undue burden on patients and that incomplete or missing data are likely related to the relevance of the content of the element of care to that individual patient (7).

We developed a method that integrated importance and quality ratings from patients and this allowed us to identify elements to target for quality improvement. The method that we developed is easy to understand and identifies a ranked list of priorities. The elements of care are very specific, and therefore actionable (67). The specificity and relevance of our results to a particular group of patients undergoing a particular treatment may make it easier to use these results for quality improvement (182).

Furthermore, by collecting ratings of importance in addition to quality we were able to determine the impact of the importance ratings on various methods for identifying priorities for quality improvement. It has been shown that the importance of each element of care, in addition to the quality of care received, will affect the patient experience (183). However, it is possible that importance ratings may already be partially incorporated into the patients' quality ratings, a topic that has been discussed in the quality of life literature with respect to importance and satisfaction ratings (168). Our results suggest that it is still beneficial to collect importance ratings in addition to quality, since in all cases, we found that by using importance ratings in addition to 
quality ratings we identified different priorities than if we had used quality ratings alone. Our method uses the importance ratings as a filter for selecting the elements of care applicable to each patient instead of multiplying ratings, which may address some of the concerns raised in the literature about weighting quality by importance using multiplicative methods (168).

There are several factors to consider when developing quality indicators and applying them to the assessment of quality of care (133), not all of which were evaluated in this study. We were able to assess the content validity and test-retest reliability of our questionnaire. Patients did not suggest any unique elements of care to add to our questionnaire, and our results suggest our questionnaire has acceptable test-retest reliability as the median percent positive agreement was $82 \%$ for the importance ratings and $92 \%$ for the quality ratings. Although we identified specific elements of care that can be targeted for quality improvement, further consultation with healthcare managers and healthcare providers is needed to determine how to best apply these indicators to the evaluation of quality of care. Additionally, our questionnaire is intended to be evaluative; therefore it should possess a high level of agreement to measure important changes in the quality of care. It should also be responsive to changes over time (184), but these are not properties we were able to assess in this study and further research is needed.

One consequence of our decision to study a well-defined population undergoing a specific treatment is that data collection took place over a 4-year time period. Therefore it is possible that the quality of care delivered to patients during the study period may have changed over time. One might be concerned that the elements of care identified as priorities for improvement and the description of quality of care may not be an accurate representation of the care experienced by patients over the full study period. The cancer centre did undergo several changes during the time period of the study: physical construction, change in managers of the 
radiotherapy department, changes in the radiation therapist team, and an overall increased interest in improving the patient experience (185). However, it is important to note that treatment protocols did not change during the study period and as shown in Appendix F2 the percentage of elements rated "very good" by each patient enrolled in the first half of the study compared to the second half were not statistically significantly different. Although there were no changes in treatment during the study period, there has since been a change in prostate cancer treatment guidelines with brachytherapy recommended for many of the patients who took part in our study (83). Future uses of this questionnaire will require review of the elements of care with this changing patient population in mind.

There may be barriers to the implementation of this questionnaire. In order to ensure the elements identified for quality improvement were actionable, we needed to have a comprehensive, specific set of elements. Therefore, our questionnaire is long and patients are asked to complete it over three time points. This appears to be quite a daunting task. However, we have shown that it is possible to conduct this type of assessment in this specific patient population, and by asking radiation therapists to hand out our questionnaires, we conducted our study alongside routine clinical practice. We believe it would not be difficult to do this type of quality assessment again in other centres.

Finally, the generalizability of our findings is unknown. In addition to the change in clinical practice guidelines, we don't know if our results are applicable to other institutional contexts. It would not be reasonable to assume the specific quality ratings would be generalizable as they should be reflective of the quality at our particular centre. However, the importance ratings may be generalizable, and the methods proposed to identify priorities for quality improvement may be generalizable as well. In our study, we found that quality and importance 
ratings were not associated with measured patient characteristics, but it is important to note that we were unable to measure all characteristics that may be associated with ratings (e.g. race/ethnicity). Since we focused on a specific population, although this work may provide a model for quality assessment, at the moment the questionnaire and our results are only applicable to this specific group of patients receiving external beam radiotherapy.

\subsection{Contributions of this research}

Previous research has identified indicators for the cancer patient experience (47) and indicators for patient-centered care $(48,53)$, but our work is unique in that we identified a comprehensive set of actionable indicators specific to a particular disease and treatment context, thus allowing for targeted quality improvement. This work also complements the work done by Brundage et al to assess the quality of technical care in prostate cancer radiotherapy $(3,4)$. As such, these two sets of indicators can be used to comprehensively assess the quality of care delivered to this patient population.

We identified a method for identifying priorities for quality improvement that involves combining importance and quality ratings. This particular approach of combining ratings is not unique, but the specific method we chose is novel as our method uses the importance ratings as a way to filter the elements of care used to describe quality, ignoring any elements of care that were less than "very important" to the patient.

This PhD thesis (together with work initiated in my MSc) developed indicators of the quality of personal care in prostate cancer radiotherapy, and explored some of issues around applying these quality indicators to the assessment of the quality of personal care in prostate cancer radiotherapy. This provides a foundation for conducting a national survey similar to the 
national patterns of care study done for assessing the quality of technical care in prostate cancer radiotherapy (4).

\subsection{Conclusions and Future Directions}

Returning to the Health Services Research Framework presented in Figure 2-3, this $\mathrm{PhD}$ project has built upon work completed during my Master's degree in which I identified indicators relevant to the quality of personal care of patients undergoing radiotherapy for prostate cancer and developed a measurement instrument. This $\mathrm{PhD}$ thesis has focused on the next step in the framework, "describing performance" by identifying the aspects of care important to patients, describing the quality of care received by patients and identifying potential areas to target for quality improvement. However, measurement alone is not sufficient for quality improvement and the process of using survey data to improve care is complex $(133,136-138,186)$. Further research will work on determining how to use these results as part of a quality assurance program to improve care. Similar assessments of the quality of personal care could be conducted at other centres following a process that our group has used previously for assessing the quality of technical care (4). Cross-centre assessments could help identify the highest achievable ratings of quality of personal care, which could be used to assign benchmarks and in setting standards.

It may be important to consider issues related to case-mix when making comparisons between centres. Although our data suggest case-mix adjustment may not be necessary, some previous research has indicated there is a need for case mix-adjustment with patient experience data (187189). Such adjustment could also increase the acceptability of the findings by health care providers (142). However, case-mix adjustment should be done cautiously as observed differences may reflect true differences in the quality of care and therefore may result in overadjustment $(163,190)$. 
There is a need for further research to assess how changes in processes of care may lead to quality improvement and improve patient outcomes (47). The validity of measures can also be assessed by examining their relationship with outcomes we believe are likely affected by the quality of personal care, such as patient satisfaction, decision regret, and quality of life.

Alternate approaches to data collection could be considered in future when using this questionnaire. We defined "responders" for this study as individuals who completed all three modules of the questionnaire, but this obviously meant it took longer to recruit patients to achieve our desired sample size. A faster approach would be to conduct cross-sectional surveys. Such surveys would target individuals all along the radiotherapy care continuum at one point in calendar time. For this study, we decided not to use this approach as we wanted patients to respond to all 143 elements of care on our questionnaire. However, faster, more timely results could enhance their use in quality improvement activities $(9,182)$.

Incorporating assessments of the quality of personal care into clinical practice requires engagement of healthcare providers and managers $(8,135)$. Future considerations and consultation with stakeholders should involve further assessment of the feasibility and acceptability of data collection, and refining appropriate methods for reporting on quality of care. As previously mentioned, we have recommended a method for identifying priorities for improvement but it simply produces a ranked list of priorities. Input from healthcare providers and managers is needed to determine the appropriate thresholds to use for quality improvement activities in order to "set standards" and "evaluate performance" (Figure 2-3) (191). We have already highlighted a few areas that should be considered when choosing appropriate thresholds for identifying priorities for improvement such as determining the applicability of that indicator to the specific patient population (48), but practical issues such as feasibility and cost of undertaking quality 
improvement activities are additional considerations that healthcare managers may need to make. For example, "there is somewhere convenient to park" emerged as the $3^{\text {rd }}$ priority for quality improvement in our results. Although this was deemed to be a priority for improvement by $29 \%$ of patients (and applicable to almost all patients; quality and importance ratings were provided by $97 \%$ of patients), it may not be practical to focus quality improvement efforts on this area. Ultimately, to see changes in the quality of care provided to patients, quality improvement activities need to be comprehensive and aim to engage all levels (healthcare providers, department, hospital) (192).

Comprehensive assessments of quality of care must include assessments of the quality of personal care. Although we designed our questionnaire with a focus on the quality of personal care in prostate cancer radiotherapy, many of its elements could be easily made generic to radiotherapy for all cancers. A more generic questionnaire could be more useful than one targeted at a specific patient group, allowing department-wide assessment of quality of care that would still ensure actionable results $(9,182)$. This would of course make our instrument more comparable to other published work $(54,91,119,121,122)$, but our suite of indicators is a complete list covering the full patient care continuum, and our modular approach gathers data at relevant time points. In future, we hope to see regular monitoring of the quality of personal care as part of quality assurance and quality improvement programs in radiotherapy. 


\section{References}

1. Lohr KN. Medicare: A strategy for quality assurance. Washington, D.C.: National Academy Press; 1990.

2. Donabedian A. The quality of care. How can it be assessed? 1988. Arch Pathol Lab Med. 1997;121(11):1145-50.

3. Danielson B, Brundage M, Pearcey R, Bass B, Pickles T, Bahary JP, et al. Development of indicators of the quality of radiotherapy for localized prostate cancer. Radiother Oncol. 2011;99(1):29-36.

4. Brundage M, Danielson B, Pearcey R, Bass B, Pickles T, Bahary J-P, et al. A criterionbased audit of the technical quality of external beam radiotherapy for prostate cancer. Radiother Oncol. 2013;107(3):339-45.

5. Darby C. Measuring the patient's perspective on the interpersonal aspects of cancer care. In: Lipscomb J, Gotay C, Snyder C, editors. Outcomes assessment in cancer: measures, methods, and applications. Cambridge, England: Cambridge University Press; 2004. p. 290-304.

6. Haggerty JL. Are measures of patient satisfaction hopelessly flawed. BMJ. 2010;341(c4783).

7. Foley K. Development of a questionnaire for measuring the quality of personal care in patients undergoing radiotherapy for prostate cancer [Internet]. Queen's University; 2010. Available from:

http://qspace.library.queensu.ca/bitstream/1974/6243/1/Foley_Kimberley_A_201012_MSc. pdf

8. Russell S. Patients' experiences: Top heavy with Research [Internet]. Research Matters: Melbourne; 2013 [cited 2015 Apr 8]. Available from: http://www.researchmatters.com.au/publications/PatientsExperiencesReview.pdf

9. Robert G. Rethinking policy approaches to measuring and improving patient experience. J Health Serv Res Policy. 2013;18(2):67-9.

10. Tasa K, Baker GR, Murray M. Using patient feedback for quality improvement. Qual Manag Healthc. 1996;4(2):55-67.

11. Patient-Centred Measurement and Reporting in Canada: Launching the Discussion Toward a Future State | CIHI [Internet]. 2017 [cited 2017 Sep 28]. Available from: https://www.cihi.ca/en/document/patient-centred-measurement-and-reporting-in-canadalaunching-the-discussion-toward-a 
12. Fitzmaurice C, Allen C, Barber RM, Barregard L, Bhutta ZA, Brenner H, et al. Global, Regional, and National Cancer Incidence, Mortality, Years of Life Lost, Years Lived With Disability, and Disability-Adjusted Life-years for 32 Cancer Groups, 1990 to 2015: A Systematic Analysis for the Global Burden of Disease Study. JAMA Oncol. 2017 Apr 1;3(4):524-48.

13. Canadian Cancer Statistics publication - Canadian Cancer Society [Internet]. [cited 2017 Sep 2]. Available from: http://www.cancer.ca/en/cancer-information/cancer-101/canadiancancer-statistics-publication/?region=on

14. WHO | National Cancer Control Programmes (NCCP) [Internet]. WHO. [cited 2017 Sep 2]. Available from: http://www.who.int/cancer/nccp/en/

15. Resources \& publications | Canadian Partnership Against Cancer [Internet]. [cited 2017 Sep 8]. Available from: http://www.partnershipagainstcancer.ca/resourcespublications/strategic-documents

16. WHO | Cancer control: Diagnosis and treatment [Internet]. [cited 2017 Sep 26]. Available from: http://www.who.int/cancer/publications/cancer_control_diagnosis/en/

17. Mackillop WJ, Kong W, Brundage M, Hanna TP, Zhang-Salomons J, McLaughlin P-Y, et al. A comparison of evidence-based estimates and empirical benchmarks of the appropriate rate of use of radiation therapy in Ontario. Int J Radiat Oncol Biol Phys. 2015;91(5):1099_ 107.

18. Radiation Therapy for Cancer [Internet]. National Cancer Institute. [cited 2017 Oct 8]. Available from: https://www.cancer.gov/about-cancer/treatment/types/radiationtherapy/radiation-fact-sheet

19. About radiotherapy | Cancer in general | Cancer Research UK [Internet]. [cited 2017 Oct 8]. Available from: http://www.cancerresearchuk.org/about-cancer/cancer-ingeneral/treatment/radiotherapy/about

20. External beam radiotherapy | Prostate Cancer UK [Internet]. [cited 2017 Sep 28]. Available from: https://prostatecanceruk.org/prostate-information/ourpublications/publications/external-beam-radiotherapy

21. External Beam Radiation - Prostate Cancer Canada [Internet]. [cited 2017 Sep 27]. Available from: http://prostatecancer.ca/Prostate-Cancer/Treatment/Radiation-Therapy

22. Mackillop WJ, Hanna, Timothy Paul, Brundage MD. Health Services Research in Radiation Oncology: Toward Achieving the Achievable for Patients with Cancer. In: Gunderson L, Tepper J, editors. Clinical Radiation Oncology. 4th ed. Philadelphia: Elsevier; 2016. p. 217-38. 
23. Brien S, Dixon E, Ghali W. Measuring and Reporting on Quality in Health Care: A Framework and Road Map for Improving Care. J Surg Oncol. 2009;99(Journal Article):462-6.

24. Donabedian A. Evaluating the quality of medical care. 1966. Milbank Q. 2005;83(4):691729.

25. Brook RH, McGlynn EA, Cleary PD. Quality of health care. Part 2: measuring quality of care. N Engl J Med. 1996;335(13):966-70.

26. Carinci F, Van Gool K, Mainz J, Veillard J, Pichora EC, Januel JM, et al. Towards actionable international comparisons of health system performance: expert revision of the OECD framework and quality indicators. Int J Qual Health Care. 2015 Apr 1;27(2):137-46.

27. Arah OA, Westert GP, Hurst J, Klazinga NS. A conceptual framework for the OECD Health Care Quality Indicators Project. Int J Qual Health Care. 2006 Sep 1;18(suppl_1):513.

28. CIHI Health Indicators | CIHI [Internet]. [cited 2017 Sep 8]. Available from: https://www.cihi.ca/en/cihi-health-indicators

29. Government of Canada SC. Data tables, maps and fact sheets [Internet]. 2013 [cited 2017 Sep 4]. Available from: http://www.statcan.gc.ca/pub/82-221-x/2013001/tbl-eng.htm\#ac

30. CSQI 2017 [Internet]. [cited 2017 Sep 8]. Available from: http://www.csqi.on.ca/

31. Technical Information - CSQI 2017 [Internet]. [cited 2017 Sep 28]. Available from: http://www.csqi.on.ca/by_patient_journey/treatment/person_centred_care/technical_info/

32. Smith P. Developing composite indicators for assessing health system efficiency. In: Measuring Up: Improving Health System Performance in OECD Countries. OECD Publications Service; 2002. p. 295-309.

33. Arah OA, Klazinga NS, Delnoij DMJ, Asbroek A ten, Custers T. Conceptual frameworks for health systems performance: a quest for effectiveness, quality, and improvement. Int J Qual Health Care. 2003;15(5):377-98.

34. Braithwaite J, Hibbert P, Blakely B, Plumb J, Hannaford N, Long JC, et al. Health system frameworks and performance indicators in eight countries: A comparative international analysis. SAGE Open Med. 2017 Jan;5:205031211668651.

35. Brook RH, McGlynn EA, Shekelle PG. Defining and measuring quality of care: a perspective from US researchers. Int J Qual Health Care. 2000;12(4):281-95.

36. Litwin MS, Steinberg M, Malin J, Naitoh J, McGuigan KA. Prostate Cancer Patient Outcomes and Choice of Providers: Development of an Infrastructure for Quality Assessment [Internet]. RAND CORP SANTA MONICA CA, RAND CORP SANTA 
MONICA CA; 2000 [cited 2017 Oct 24]. Report No.: MR-1227-BF. Available from: http://www.dtic.mil/docs/citations/ADA381288

37. Farquhar M. AHRQ Quality Indicators. In: Hughes RG, editor. Patient Safety and Quality: An Evidence-Based Handbook for Nurses [Internet]. Rockville (MD): Agency for Healthcare Research and Quality (US); 2008 [cited 2017 Sep 4]. (Advances in Patient Safety). Available from: http://www.ncbi.nlm.nih.gov/books/NBK2664/

38. Government of Canada SC. Health Indicators framework [Internet]. 2013 [cited 2017 Sep 4]. Available from: http://www.statcan.gc.ca/pub/82-221-x/2013001/hifw-eng.htm

39. Owen JB, Sedransk J, Pajak TF. National averages for process and outcome in radiation oncology: Methodology of the Patterns of Care Study. Semin Radiat Oncol. 7(2):101-7.

40. Caring for Quality in Health - Lessons Learnt from 15 Reviews of Health Care Quality - en - OECD [Internet]. [cited 2017 Sep 4]. Available from: http://www.oecd.org/health/caringfor-quality-in-health-9789264267787-en.htm

41. Tzelepis F, Rose SK, Sanson-Fisher RW, Clinton-McHarg T, Carey ML, Paul CL. Are we missing the Institute of Medicine's mark? A systematic review of patient-reported outcome measures assessing quality of patient-centred cancer care. BMC Cancer. 2014;14(1):41.

42. Arora NK. Can You Hear Me Now? Importance of Assessing Patients' Cancer Care Experiences. J Oncol Pract. 2017 Aug;13(8):515-8.

43. Ganz PA. Institute of Medicine Report on Delivery of High-Quality Cancer Care. J Oncol Pract. 2014 May 1;10(3):193-5.

44. Lehrman PhD W, Silvera MHA, Jason A, others. The patient experience movement moment. Patient Exp J. 2014;1(2):9-11.

45. Saunders C, Carter DJ, Jordan A, Duffield C, Bichel-Findlay J. Cancer patient experience measures: An evidence review. J Psychosoc Oncol. 2016;34(3):200-22.

46. Mollica MA, Lines LM, Halpern MT, Ramirez E, Schussler N, Urato M, et al. Patient experiences of cancer care: scoping review, future directions, and introduction of a new data resource: Surveillance Epidemiology and End Results-Consumer Assessment of Healthcare Providers and Systems (SEER-CAHPS). Patient Exp J. 2017;4(1):103-21.

47. Williams KE, Sansoni J, Morris D, Thompson C. A Delphi study to develop indicators of cancer patient experience for quality improvement. Support Care Cancer. 2017 Jul 15;1-10.

48. Ouwens M, Hermens R, Hulscher M, Vonk-Okhuijsen S, Tjan-Heijnen V, Termeer R, et al. Development of indicators for patient-centred cancer care. Support Care Cancer. 2010;18(1):121. 
49. Institute for Healthcare Improvement: Across the Chasm Aim \#3: Health Care Must Be Patient-Centered [Internet]. [cited 2017 Sep 15]. Available from:

http://www.ihi.org/resources/Pages/ImprovementStories/AcrosstheChasmAim3HealthCare MustBePatientCentered.aspx

50. Hudon C, Fortin M, Haggerty JL, Lambert M, Poitras M-E. Measuring patients' perceptions of patient-centered care: a systematic review of tools for family medicine. Ann Fam Med. 2011;9(2):155-64.

51. McCormack LA, Treiman K, Rupert D, Williams-Piehota P, Nadler E, Arora NK, et al. Measuring patient-centered communication in cancer care: A literature review and the development of a systematic approach. Soc Sci Med. 2011 Apr 1;72(7):1085-95.

52. Person-Centred Care Guideline - CCO [Internet]. [cited 2017 Sep 8]. Available from: https://www.cancercare.on.ca/pcs/person_centred_care/person_centred_care_guideline/

53. Uphoff EP, Wennekes L, Punt CJ, Grol RP, Wollersheim HC, Hermens RP, et al. Development of generic quality indicators for patient-centered cancer care by using a RAND modified Delphi method. Cancer Nurs. 2012;35(1):29-37.

54. Mackenzie LJ, Sanson-Fisher RW, Carey ML, D'Este CA. Radiation oncology outpatient perceptions of patient-centred care: a cross-sectional survey. BMJ Open. 2013 Jan 1;3(2):e001265.

55. Brédart A, Kop J-L, Efficace F, Beaudeau A, Brito T, Dolbeault S, et al. Quality of care in the oncology outpatient setting from patients' perspective: a systematic review of questionnaires' content and psychometric performance. Psychooncology. 2015;24(4):382 94.

56. Campbell SM, Roland MO, Buetow SA. Defining quality of care. Soc Sci Med. 2000;51(11):1611-25.

57. Sixma HJ, Kerssens J, van Campen C, Peters L. Quality of care from the patients' perspective: from theoretical concept to a new measurement instrument. Health Expect. 1998;1(2):82-95.

58. Cleary P, McNeil B. Patient satisfaction as an indicator of quality care. Inquiry. 1988;25(1):25-36.

59. Sofaer S, Firminger K. Patient Perceptions of the Quality of Health Services. Annu Rev Public Health. 2005;26(1):513-59.

60. Saila T, Mattila E, Kaila M, Aalto P, Kaunonen M. Measuring patient assessments of the quality of outpatient care: a systematic review. J Eval Clin Pract. 2008;14(1):148-54.

61. Sitzia J, Wood N. Patient satisfaction: A review of issues and concepts. Soc Sci Med. 1997;45(12):1829-43. 
62. Newsome PRH, Wright GH. Patient Management: A review of patient satisfaction: 1. Concepts of satisfaction. Br Dent J. 1999;186(Journal Article):161-5.

63. Nguyen TVF, Anota A, Brédart A, Monnier A, Bosset J-F, Mercier M. A longitudinal analysis of patient satisfaction with care and quality of life in ambulatory oncology based on the OUT-PATSAT35 questionnaire. BMC Cancer. 2014 Jan 25;14(1):42.

64. Garratt A. National and cross-national surveys of patient experiences. Struc Tured Rev Oslo Nas Kunnskapssenter Helsetjenesten Rapp [Internet]. 2008 [cited 2017 Sep 4];7. Available from: http://www.oecd.org/els/health-systems/39493930.pdf

65. Hassett MJ, McNiff KK, Dicker AP, Gilligan T, Hendricks CB, Lennes I, et al. HighPriority Topics for Cancer Quality Measure Development: Results of the 2012 American Society of Clinical Oncology Collaborative Cancer Measure Summit. J Oncol Pract. 2014 May 1;10(3):e160-6.

66. Jenkinson C, Coulter A, Bruster S. The Picker Patient Experience Questionnaire: development and validation using data from in-patient surveys in five countries. Int $\mathrm{J}$ Qual Health Care. 2002 Oct 1;14(5):353-8.

67. Jenkinson C, Coulter A, Bruster S, Richards N, Chandola T. Patients' experiences and satisfaction with health care: results of a questionnaire study of specific aspects of care. Qual Saf Health Care. 2002;11(4):335-9.

68. Booij JC, Zegers M, Evers PMPJ, Hendriks M, Delnoij DMJ, Rademakers JJDJM. Improving cancer patient care: development of a generic cancer consumer quality index questionnaire for cancer patients. BMJ Cancer. 2013;13(Journal Article):203.

69. Mack JW, Jacobson J, Frank D, Cronin AM, Horvath K, Allen V, et al. Evaluation of Patient and Family Outpatient Complaints as a Strategy to Prioritize Efforts to Improve Cancer Care Delivery. Jt Comm J Qual Patient Saf. 2017 Oct;43(10):498-507.

70. Coulter A, Locock L, Ziebland S, Calabrese J. Collecting data on patient experience is not enough: they must be used to improve care. BMJ. 2014 Mar 27;348:g2225.

71. GLOBOCAN Cancer Fact Sheets: prostate cancer [Internet]. [cited 2017 Sep 7]. Available from: http://globocan.iarc.fr/old/FactSheets/cancers/prostate-new.asp

72. Hsing AW, Chokkalingam AP. Prostate cancer epidemiology. Front Biosci. 2006;11:1388413.

73. Patel AR, Klein EA. Risk factors for prostate cancer. Nat Rev Urol. 2009;6(2):87.

74. Grönberg H. Prostate cancer epidemiology. The Lancet. 2003;361(9360):859-64.

75. Fradet Y, Klotz L, Trachtenberg J, Zlotta A. The burden of prostate cancer in Canada. Can Urol Assoc J. 2009 Jun;3(3 Suppl 2):S92-100. 
76. Bell N, Gorber SC, Shane A, Joffres M, Singh H, Dickinson J, et al. Recommendations on screening for prostate cancer with the prostate-specific antigen test. Can Med Assoc J. 2014 Nov 4;186(16):1225-34.

77. Romero-Otero J, García-Gómez B, Duarte-Ojeda JM, Rodríguez-Antolín A, Vilaseca A, Carlsson SV, et al. Active Surveillance for Prostate Cancer. Int J Urol Off J Jpn Urol Assoc. 2016 Mar;23(3):211-8.

78. Thompson I, Thrasher JB, Aus G, Burnett AL, Canby-Hagino ED, Cookson MS, et al. Guideline for the management of clinically localized prostate cancer: 2007 update. J Urol. 2007;177(6):2106-31.

79. Chen RC, Rumble RB, Loblaw DA, Finelli A, Ehdaie B, Cooperberg MR, et al. Active Surveillance for the Management of Localized Prostate Cancer (Cancer Care Ontario Guideline): American Society of Clinical Oncology Clinical Practice Guideline Endorsement. J Clin Oncol. 2016 Jun 20;34(18):2182-90.

80. Heidenreich A, Bastian PJ, Bellmunt J, Bolla M, Joniau S, Kwast T van der, et al. EAU Guidelines on Prostate Cancer. Part 1: Screening, Diagnosis, and Local Treatment with Curative Intent-Update 2013. Eur Urol. 2014 Jan 1;65(1):124-37.

81. Genitourinary Cancer [Internet]. ASCO. [cited 2017 Sep 27]. Available from: http://www.asco.org/practice-guidelines/quality-guidelines/guidelines/genitourinary-cancer

82. Mottet N, Bellmunt J, Bolla M, Briers E, Cumberbatch MG, Santis MD, et al. EAUESTRO-SIOG Guidelines on Prostate Cancer. Part 1: Screening, Diagnosis, and Local Treatment with Curative Intent. Eur Urol. 2017 Apr 1;71(4):618-29.

83. Chin J, Rumble RB, Kollmeier M, Heath E, Efstathiou J, Dorff T, et al. Brachytherapy for Patients With Prostate Cancer: American Society of Clinical Oncology/Cancer Care Ontario Joint Guideline Update. J Clin Oncol. 2017 Mar 27;35(15):1737-43.

84. Peschel RE, Colberg JW. Surgery, brachytherapy, and external-beam radiotherapy for early prostate cancer. Lancet Oncol. 2003;4(4):233-41.

85. Hamdy FC, Donovan JL, Lane JA, Mason M, Metcalfe C, Holding P, et al. 10-Year Outcomes after Monitoring, Surgery, or Radiotherapy for Localized Prostate Cancer. N Engl J Med. 2016 Oct 13;375(15):1415-24.

86. Spencer BA, Steinberg M, Malin J, Adams J, Litwin MS. Quality-of-care indicators for early-stage prostate cancer. J Clin Oncol. 2003;21(10):1928-36.

87. Miller DC, Litwin MS, Sanda MG, Montie JE, Dunn RL, Resh J, et al. Use of quality indicators to evaluate the care of patients with localized prostate carcinoma. Cancer. 2003;97(6):1428-35. 
88. Spencer BA, Miller DC, Litwin MS, Ritchey JD, Stewart AK, Dunn RL, et al. Variations in quality of care for men with early-stage prostate cancer. J Clin Oncol. 2008;26(22):373542.

89. Miller DC, Spencer BA, Ritchey J, Stewart AK, Dunn RL, Sandler HM, et al. Treatment choice and quality of care for men with localized prostate cancer. Med Care.

2007;45(5):401-9.

90. Wiggers JH, Donovan KO, Redman S, Sanson-Fisher RW. Cancer patient satisfaction with care. Cancer. 1990;66(3):610-6.

91. Siekkinen M, Laiho R, Ruotsalainen E, Katajisto J, Pyrhonen S, Leino-Kilpi H. Quality of care experienced by Finnish cancer patients during radiotherapy. Eur J Cancer Care (Engl). 2008;17(4):387-93.

92. Institute of Medicine, Shaping the Future (Newsletter of the IOM) [Internet]. [cited 2015 Jul 13]. Available from: http://health.usf.edu/medicine/educationalaffairs/pace_files/IOM\%20Quality\%20Initiative.p df

93. Ware JE, Snyder MK, Wright WR, Davies AR. Defining and measuring patient satisfaction with medical care. Eval Program Plann. 1983;6(3):247-63.

94. Hudak PL, Wright JG. The characteristics of patient satisfaction measures. Spine. 2000;25(24):3167-77.

95. American Hospital Association. Management Advisory: A Patient's Bill of Rights [Internet]. [cited 2015 May 31]. Available from:

http://www.qcc.cuny.edu/SocialSciences/ppecorino/MEDICAL_ETHICS_TEXT/Chapter_6 _Patient_Rights/Readings_The\%20Patient_Bill_of_Rights.htm

96. de Kok M, Scholte RW, Sixma HJ, van der Weijden T, Spijkers KF, van de Velde CJ, et al. The patient's perspective of the quality of breast cancer care. The development of an instrument to measure quality of care through focus groups and concept mapping with breast cancer patients. Eur J Cancer. 2007;43(8):1257-64.

97. Haddad S, Potvin L, Roberge D, Pineault R, Remondin M. Patient perception of quality following a visit to a doctor in a primary care unit. Fam Pract. 2000;17(1):21-9.

98. Schneider EC, Epstein AM, Malin JL, Kahn KL, Emanuel EJ. Developing a system to assess the quality of cancer care: ASCO's national initiative on cancer care quality. J Clin Oncol. 2004;22(15):2985-91.

99. Loblaw DA, Bezjak A, Bunston T. Development and testing of a visit-specific patient satisfaction questionnaire: the Princess Margaret Hospital Satisfaction With Doctor Questionnaire. J Clin Oncol. 1999;17(6):1931-1931. 
100. Sandoval GA, Levinton C, Blackstien-Hirsch P, Brown AD. Selecting predictors of cancer patients' overall perceptions of the quality of care received. Ann Oncol. 2006;17(1):151-6.

101. McKinley RK, Manku-Scott T, Hastings AM, French DP, Baker R. Reliability and validity of a new measure of patient satisfaction with out of hours primary medical care in the United Kingdom: development of a patient questionnaire. Bmj. 1997;314(7075):193.

102. Newmann J, Pfettscher S. End-Stage Renal Disease: Patient Satisfaction (Adapted from KDQOL) [Internet]. [cited $2015 \mathrm{Jul}$ 13]. Available from: http://www.promotingexcellence.org/tools/pe4785.html

103. NHS Survey of Cancer Patients [Internet]. [cited 2009 Jan 6]. Available from: http://www.dh.gov.uk/en/Publicationsandstatistics/PublishedSurvey/NationalsurveyofNHSp atients/Nationalsurveycancer/index.htm

104. NHS Survey of Family Members [Internet]. [cited 2009 Jan 6]. Available from: http://www.dh.gov.uk/en/Publicationsandstatistics/PublishedSurvey/NationalsurveyofNHSp atients/Nationalsurveycancer/index.htm

105. NSW Health: Patient Survey 2008 - Cancer Care Survey. NRC Picker;

106. INPATSAT-32 - an in-patient questionnaire to assess satisfaction with care [Internet]. EORTC: European Organization for Research and Treatment of Cancer. [cited 2015 Jul 13]. Available from: http://groups.eortc.be/qol/sites/default/files/img/specimen_inpatsat32_english.pdf

107. Boberg EW, Gustafson DH, Hawkins RP, Offord KP, Koch C, Wen K-Y, et al. Assessing the unmet information, support and care delivery needs of men with prostate cancer. Patient Educ Couns. 2003;49(3):233-42.

108. Lintz K, Moynihan C, Steginga S, Norman A, Eeles R, Huddart R, et al. Prostate cancer patients' support and psychological care needs: Survey from a non-surgical oncology clinic. Psychooncology. 2003;12(8):769-83.

109. Templeton HR, others. Adaptation of an instrument to measure the informational needs of men with prostate cancer. J Adv Nurs. 2001;35(3):357-64.

110. Steginga SK, Occhipinti S, Dunn J, Gardiner RA, Heathcote P, Yaxley J. The supportive care needs of men with prostate cancer (2000). Psychooncology. 2001;10(1):66-75.

111. Feldman-Stewart D, Brundage M, Hayter C, Groome P, Nickel C, Downes H, et al. What questions do patients with curable prostate cancer want answered? Med Decis Making. 2000;20(Journal Article):7-19.

112. Cossich T, Schofield P, McLachlan SA. Validation of the cancer needs questionnaire (CNQ) short-form version in an ambulatory cancer setting. Qual Life Res. 2004;13(7):1225-33. 
113. Sanson-Fisher R, Girgis A, Boyes A, Bonevski B, Burton L, Cook P. The unmet supportive care needs of patients with cancer. Cancer. 2000;88(1):226-37.

114. Literature Review and Environmental Scan for Cancer Performance Indicators - Update 2007. Canadian Council on Health Services Accreditation; 2008.

115. Appendix C, Inventory of Cancer Performance Indicators Identified in Literature Review and Environmental Scan - Update 2007. Canadian Council on Health Services Accreditation; 2008.

116. Gagliardi A, Lemieux-Charles L, Brown A, Sullivan T, Goel V. Stakeholder preferences for cancer care performance indicators. Int J Health Care Qual Assur. 2008;21(2):175-89.

117. Tarrant C, Baker R, Colman AM, Sinfield P, Agarwal S, Mellon JK, et al. The Prostate Care Questionnaire for Patients (PCQ-P): Reliability, validity and acceptability. BMC Health Serv Res. 2009 Nov 4;9(1):199.

118. Baker R, Sinfield P, Agarwal S, Tarrant C, Mellon JK, Stewart W, et al. The Development of the Prostate Care Questionnaires for Patients (PCQ-P) and Carers (PCQ-C) [Internet]. National Co-ordinating Centre for NHS Service Delivery and Organisation R\&D (NCCSDO); 2008 [cited 2017 Oct 11]. Available from: http://www.netscc.ac.uk/hsdr/files/project/SDO_FR_08-1418-077_V01.pdf

119. French J, McGahan C. Measuring patient satisfaction with radiation therapy service delivery. In: Healthcare management forum [Internet]. SAGE Publications Sage CA: Los Angeles, CA; 2009 [cited 2017 Oct 6]. p. 40-50. Available from: http://journals.sagepub.com.proxy.queensu.ca/doi/abs/10.1016/S0840-4704(10)60141-X

120. Muraj Z. Assessing Patient Satisfaction in a Radiation Therapy Department Using a Survey Tool. 46(2):182-8.

121. Olausson K, Hansson AH, Zackrisson B, Edvardsson D, Östlund U, Nyholm T. Development and psychometric testing of an instrument to measure the patient's experience of external radiotherapy: The Radiotherapy Experience Questionnaire (RTEQ). Tech Innov Patient Support Radiat Oncol. 2017;3:7-12.

122. Nijman JL, Sixma H, van Triest B, Keus RB, Hendriks M. The quality of radiation care: the results of focus group interviews and concept mapping to explore the patient's perspective. Radiother Oncol. 2012;102(1):154-60.

123. Streiner DL. Being inconsistent about consistency: When coefficient alpha does and doesn't matter. J Pers Assess. 2003;80(3):217-22.

124. Fayers PM, Hand DJ. Causal variables, indicator variables and measurement scales: an example from quality of life. J R Stat Soc Ser A. 2002;165(2):233-53. 
125. Wright JG, Feinsten AR. A comparative contrast of clinimetric and psychometric methods for constructing indexes and rating scales. J Clin Epidemiol. 1992;45(11):1201-18.

126. Guyatt GH, Kirshner B, Jaeschke R. Measuring health status: What are the necessary measurement properties? J Clin Epidemiol. 1992;45(12):1341-5.

127. Juniper EF, Guyatt GH, Streiner DL, King DR. Clinical impact versus factor analysis for quality of life questionnaire construction. J Clin Epidemiol. 1997;50(3):233-8.

128. Marx RG, Bombardier C, Hogg-Johnson S, Wright JG. Clinimetric and Psychometric Strategies for Development of a Health Measurement Scale. J Clin Epidemiol. 1999;52(2):105-11.

129. de Vet HCW, Terwee CB, Bouter LM. Current challenges in clinimetrics. J Clin Epidemiol. 2003;56(12):1137-41.

130. Kötter T, Schaefer FA, Scherer M, Blozik E. Involving patients in quality indicator development - a systematic review. Patient Prefer Adherence. 2013;7:259-68.

131. Patient Perspective | Canadian Partnership for Quality Radiotherapy [Internet]. [cited 2017 Sep 11]. Available from: http://www.cpqr.ca/programs/patients-perspective/

132. Purificacion S, Brown E, Anne-Davis C, French J. Patient engagement in radiation therapy. Healthc Manage Forum. 2016 Sep 1;29(5):187-95.

133. Campbell SM, Braspenning J, Hutchinson A, Marshall MN. Research methods used in developing and applying quality indicators in primary care. BMJ. 2003;326(7393):816-9.

134. Wensing M, Elwyn G. Research on patients' views in the evaluation and improvement of quality of care. Qual Saf Health Care. 2002;11(2):153-7.

135. Wensing M, Vingerhoets E, Grol R. Feedback based on patient evaluations: a tool for quality improvement? Patient Educ Couns. 2003;51(2):149-53.

136. Davies E, Cleary P. Hearing the patient's voice? Factors affecting the use of patient survey data in quality improvement. Qual Saf Health Care. 2005;14(6):428-32.

137. Davies E, Shaller D, Edgman-Levitan S, Safran DG, Oftedahl G, Sakowski J, et al. Evaluating the use of a modified CAHPS survey to support improvements in patient-centred care: lessons from a quality improvement collaborative. Health Expect. 2008;11(2):160-76.

138. Davies EA, Meterko MM, Charns MP, Seibert MEN, Cleary PD. Factors affecting the use of patient survey data for quality improvement in the Veterans Health Administration. BMC Health Serv Res. 2011;11(1):334. 
139. Flott KM, Graham C, Darzi A, Mayer E. Can we use patient-reported feedback to drive change? The challenges of using patient-reported feedback and how they might be addressed. BMJ Qual Saf. 2016;bmjqs - 2016.

140. Kumah E, Osei-Kesse F, Anaba C. Understanding and Using Patient Experience Feedback to Improve Health Care Quality: Systematic Review and Framework Development. J Patient-Centered Res Rev. 2017;4(1):24-31.

141. Gleeson H, Calderon A, Swami V, Deighton J, Wolpert M, Edbrooke-Childs J. Systematic review of approaches to using patient experience data for quality improvement in healthcare settings. BMJ Open. 2016;6(8):e011907.

142. Ahmed F, Burt J, Roland M. Measuring patient experience: concepts and methods. PatientPatient-Centered Outcomes Res. 2014;7(3):235-41.

143. Tsianakas V, Maben J, Wiseman T, Robert G, Richardson A, Madden P, et al. Using patients' experiences to identify priorities for quality improvement in breast cancer care: patient narratives, surveys or both? BMC Health Serv Res. 2012;12(1):271.

144. Barr JK, Giannotti TE, Sofaer S, Duquette CE, Waters WJ, Petrillo MK. Using Public Reports of Patient Satisfaction for Hospital Quality Improvement. Health Serv Res. 2006 Jun;41(3 Pt 1):663.

145. Fitzpatrick R. Capturing what matters to patients when they evaluate their hospital care. Qual Saf Health Care. 2002;11(4):306-306.

146. Mackillop W. Health services research in radiation oncology. In: Gunderson L, Tepper J, editors. Clinical radiation oncology. Philadelphia: Churchill Livingstone; 2007. p. 215-37.

147. Canadian Partnership for Quality Radiotherapy: Quality Assurance Guidelines for Canadian Radiation Treatment Programs [Internet]. [cited 2015 Jun 2]. Available from:

http://www.cpqr.ca/wp-content/uploads/2013/09/QRT2013-09-02.pdf

148. Nguyen TVF, Bosset J-F, Monnier A, Fournier J, Perrin V, Baumann C, et al. Determinants of patient satisfaction in ambulatory oncology: a cross sectional study based on the OUTPATSAT35 questionnaire. BMC Cancer. 2011 Dec 28;11(1):526.

149. Stelfox HT, Straus SE. Measuring quality of care: considering conceptual approaches to quality indicator development and evaluation. J Clin Epidemiol. 2013 Dec;66(12):1328-37.

150. Boivin A, Lehoux P, Lacombe R, Burgers J, Grol R. Involving patients in setting priorities for healthcare improvement: a cluster randomized trial. Implement Sci. $2014 \mathrm{Feb}$ 20;9(1):24.

151. SAS. Cary, NC, USA: SAS Institute; 2011. 
152. Sample size for a single proportion [Internet]. [cited 2015 Sep 22]. Available from: https://www.stat.auckland.ac.nz/ wild/ChanceEnc/Ch08.psampsize.pdf

153. Feldman-Stewart D, Brundage MD, Hayter C, Groome P, Nickel JC, Downes H, et al. What prostate cancer patients should know: variation in professionals' opinions. Radiother Oncol. 1998;49(2):111-23.

154. Cicchetti DV, Feinstein AR. High agreement but low kappa: II. Resolving the paradoxes. J Clin Epidemiol. 1990;43(6):551-8.

155. Feinstein AR, Cicchetti DV. High agreement but low kappa: I. The problems of two paradoxes. J Clin Epidemiol. 1990;43(6):543-9.

156. Benjamini Y, Hochberg Y. Controlling the false discovery rate: a practical and powerful approach to multiple testing. J R Stat Soc Ser B Methodol. 1995;289-300.

157. Richard ML, Parmar MP, Calestagne PP, McVey L. Seeking patient feedback: an important dimension of quality in cancer care. J Nurs Care Qual. 2010;25(4):344-51.

158. Jayadevappa R, Schwartz JS, Chhatre S, Wein AJ, Malkowicz SB. Satisfaction with Care: A Measure of Quality of Care in Prostate Cancer Patients. Med Decis Making. 2010;30(2):234-45.

159. Brédart A, Razavi D, Delvaux N, Goodman V, Farvacques C, Van Heer C. A comprehensive assessment of satisfaction with care for cancer patients. Support Care Cancer. 1998;6(6):518-23.

160. Foley KA, Feldman-Stewart D, Groome PA, Brundage MD, McArdle S, Wallace D, et al. What Aspects of Personal Care Are Most Important to Patients Undergoing Radiation Therapy for Prostate Cancer? Int J Radiat Oncol • Biol • Phys. 2016 Feb 1;94(2):280-8.

161. Brien SE, Lorenzetti DL, Lewis S, Kennedy J, Ghali WA. Overview of a formal scoping review on health system report cards. Implement Sci. 2010;5(1):2.

162. Mannion R, Davies HT. Reporting health care performance: learning from the past, prospects for the future. J Eval Clin Pract. 2002;8(2):215-28.

163. Freeman T. Using performance indicators to improve health care quality in the public sector: a review of the literature. Health Serv Manage Res. 2002;15(2):126-37.

164. Martilla JA, James JC. Importance-performance analysis. J Mark. 1977;(Journal Article):77-9.

165. Mohammed K, Nolan MB, Rajjo T, Shah ND, Prokop LJ, Varkey P, et al. Creating a patient-centered health care delivery system: a systematic review of health care quality from the patient perspective. Am J Med Qual. 2016;31(1):12-21. 
166. Fröjd C, Swenne CL, Rubertsson C, Gunningberg L, Wadensten B. Patient information and participation still in need of improvement: evaluation of patients' perceptions of quality of care. J Nurs Manag. 2011;19(2):226-36.

167. Sullivan GM, Artino AR. Analyzing and Interpreting Data From Likert-Type Scales. J Grad Med Educ. 2013 Dec 1;5(4):541-2.

168. Trauer T, Mackinnon A. Why are we weighting? The role of importance ratings in quality of life measurement. Qual Life Res. 2001;10(7):579-85.

169. Al-Abri R, Al-Balushi A. Patient satisfaction survey as a tool towards quality improvement. Oman Med J. 2014;29(1):3.

170. Foundation CHSR, others. Performance reporting to help organizations promote quality improvement. Healthc Policy. 2008;4(2):70.

171. Wallace J, Teare GF, Verrall T, Chan BT. Public reporting on the quality of healthcare: emerging evidence on promising practices for effective reporting. Ott Can Can Health Serv Res Found [Internet]. 2007 [cited 2017 Jul 22]; Available from: http://www.cfhifcass.ca/SearchResultsNews/07-09-07/df3cb521-037d-4d94-a658-bec0d9fe0013.aspx

172. van den Berg MJ, Kringos DS, Marks LK, Klazinga NS. The Dutch health care performance report: seven years of health care performance assessment in the Netherlands. Health Res Policy Syst. 2014;12(1):1.

173. Canadian Partnership for Quality Radiotherapy: Quality Assurance Guidelines for Canadian Radiation Treatment Programs [Internet]. [cited 2015 Jun 3]. Available from: http://www.cpqr.ca/wp-content/uploads/2013/09/QRT2015-12-03.pdf

174. Hanley JA, Negassa A, Edwardes MD deB, Forrester JE. Statistical Analysis of Correlated Data Using Generalized Estimating Equations: An Orientation. Am J Epidemiol. 2003 Feb 15;157(4):364-75.

175. Feyer P, Kleeberg UR, Steingräber M, Günther W, Behrens M. Frequency of side effects in outpatient cancer care and their influence on patient satisfaction - a prospective survey using the PASQOC® questionnaire. Support Care Cancer. 2008;16(6):567-75.

176. Aharony L, Strasser S. Patient satisfaction: what we know about and what we still need to explore. Med Care Rev. 1993;50(1):49-79.

177. Puts MTE, Papoutsis A, Springall E, Tourangeau AE. A systematic review of unmet needs of newly diagnosed older cancer patients undergoing active cancer treatment. Support Care Cancer. 2012;20(7):1377-94.

178. Feldman-Stewart D, Brundage MD, Tishelman C. A conceptual framework for patientprofessional communication: an application to the cancer context. Psychooncology. 2005;14(10):801-9. 
179. Brundage MD, Feldman-Stewart D, Tishelman C. How do interventions designed to improve provider-patient communication work? Illustrative applications of a framework for communication. Acta Oncol. 2010;49(2):136-43.

180. Feldman-Stewart D, Brundage MD, Van Manen L, Skarsgard D, Siemens R. Evaluation of a question-and-answer booklet on early-stage prostate-cancer. Patient Educ Couns. 2003;49(2):115-24.

181. Feldman-Stewart D, Brundage MD, Manen LV, Svenson O. Patient-focussed decisionmaking in early-stage prostate cancer: insights from a cognitively based decision aid. Health Expect. 2004;7(2):126-41.

182. Reeves R, Seccombe I. Do patient surveys work? The influence of a national survey programme on local quality-improvement initiatives. BMJ Qual Saf. 2008 Dec $1 ; 17(6): 437-41$.

183. Sandager M, Freil M, Knudsen JL. Please tick the appropriate box: Perspectives on patient reported experience. Patient Exp J. 2016;3(1):63-79.

184. Terwee CB, Bot SDM, de Boer MR, van der Windt DAWM, Knol DL, Dekker J, et al. Quality criteria were proposed for measurement properties of health status questionnaires. J Clin Epidemiol. 2007;60(1):34-42.

185. McTavish A, Phillips C. Transforming the patient experience: Bringing to life a patient- and family-centred interprofessional collaborative practice model of care at Kingston General Hospital. Patient Exp J. 2014 Apr 30;1(1):50-5.

186. Berwick DM, James B, Coye MJ. Connections between quality measurement and improvement. Med Care. 2003;41(1):I - 30.

187. Paddison C, Elliott M, Parker R, Staetsky L, Lyratzopoulos G, Campbell JL, et al. Should measures of patient experience in primary care be adjusted for case mix? Evidence from the English General Practice Patient Survey. BMJ Qual Saf. 2012;bmjqs - 2011.

188. Holzer BM, Minder CE. A simple approach to fairer hospital benchmarking using patient experience data. Int J Qual Health Care J Int Soc Qual Health Care. 2011 Oct;23(5):524-30.

189. Manary MP, Boulding W, Staelin R, Glickman SW. The patient experience and health outcomes. N Engl J Med. 2013;368(3):201-3.

190. Perneger TV. Adjustment for patient characteristics in satisfaction surveys. Int J Qual Health Care J Int Soc Qual Health Care. 2004 Dec;16(6):433-5.

191. Reeves D, Campbell SM, Adams J, Shekelle PG, Kontopantelis E, Roland MO. Combining multiple indicators of clinical quality: an evaluation of different analytic approaches. Med Care. 2007;45(6):489-96. 
192. Grol R, Grimshaw J. From best evidence to best practice: effective implementation of change in patients' care. The lancet. 2003;362(9391):1225-30.

193. Twisk J, de Vente W. Attrition in longitudinal studies. How to deal with missing data. J Clin Epidemiol. 2002 Apr;55(4):329-37.

194. Ballinger GA. Using generalized estimating equations for longitudinal data analysis. Organ Res Methods. 2004;7(2):127-50.

195. PROC GENMOD: Generalized Estimating Equations :: SAS/STAT(R) 9.22 User's Guide [Internet]. [cited 2017 Sep 29]. Available from:

https://support.sas.com/documentation/cdl/en/statug/63347/HTML/default/viewer.htm\#statu g_genmod_sect049.htm 
Appendix A

Ethics Approval 
QUEEN'S UNIVERSITY HEALTH SCIENCES \& AFFILIATED TEACHING HOSPITALS RESEARCH ETHICS BOARD

Dr. William Mackillop

Full Board Review

Meeting Date:

Department of Community Health and Epidemiology

$\bigotimes \quad$ Expedited Review

Queen's University

Dear Dr. Mackillop,

Study Title: $\quad$ Defining and evaluating quality indicators of personal care in prostate cancer external beam radiotherapy

Co-Investigators: $\quad$ Dr. D. Feldman-Stewart, Dr. M. Brundage, Ms. K. Foley and Mr. D. Wallace

I am writing to acknowledge receipt of your recent ethics submission. We have examined the protocol and consent form for your project (as stated above) and consider it to be ethically acceptable. This approval is valid for one year from the date of the Chair's signature below. This approval will be reported to the Research Ethics Board. Please attend carefully to the following list of ethics requirements you must fulfill over the course of your study:

- Reporting of Amendments: If there are any changes to your study (e.g. consent, protocol, study procedures, etc.), you must submit an amendment to the Research Ethics Board for approval. (see http://www.queensu.ca/vpr/reb.htm).

- Reporting of Serious Adverse Events: Any unexpected serious adverse event occurring locally must be reported within 2 working days or earlier if required by the study sponsor. All other serious adverse events must be reported within 15 days after becoming aware of the information.

- Reporting of Complaints: Any complaints made by participants or persons acting on behalf of participants must be reported to the Research Ethics Board within 7 days of becoming aware of the complaint. Note: All documents supplied to participants must have the contact information for the Research Ethics Board.

Innual Renewal: Prior to the expiration of your approval (which is one year from the date of the Chair's signature below), you will be reminded to submit your renewal form along with any new changes or amendments you wish to make to your study. If there have been no major changes to your protocol, your approval may be renewed for another year.

Yours sincerely,

Culuet Clank

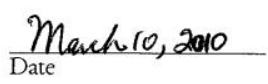

ORIGINAL TO INVESTIGATOR - COPY TO DEPARTMENT HEAD. COPY TO HOSPITAL(S) /P\&T (II appropriate) - FILE COPY

Study Code: EPID-304-10

Investigators please note that if your trial is registered by the sponsor, you must take responsibility to ensure that the registration information is accurate and complete 
QUEEN'S UNIVERSITY HEALTH SCIENCES \& AFFILIATED TEACHING HOSPITALS RESEARCH ETHICS BOARD

The membership of this Research Ethics Board complies with the membership requirements for Research Ethics Boards as defined by the Tri-Council Policy Statement; Part C Division 5 of the Food and Drug Regulations, OHRP, and U.S DHHS Code of Federal Regulations Title 45, Part 46 and carries out its functions in a manner consistent with Good Clinical Practices.

Federalwide Assurance Number : \#FWA00004184 \#IRB00001173

Current 2009 membership of the Queen's University Health Sciences \& Affiliated Teaching Hospitals Research Ethics Board

Dr. A.F. Clark

Dr. H. Abdollah

Rev. T. Deline

Dr. M. Evans

Dr. S. Irving

Prof. L. Keeping-Burke

Mrs. J. Kotecha

Dr. J. Low

Dr. W. Racz

Dr. B. Simchison

Dr. A.N. Singh

Dr. E. Tsai

Rev. J. Warren

Ms. K. Weisbaum

Dr. S. Wood
Emeritus Professor, Department of Biochemistry, Faculty of Health Sciences, Queen's University (Chair)

Professor, Department of Medicine, Queen's University

Community Member

Community Member

Psychologist, Providence Care, St. Mary's of the Lake Hospital Site

Assistant Professor, School of Nursing, Queen's University

Research \& Programs Manager, Centre for Studies in Primary Care, Department of Family Medicine, Queen's University

Emeritus Professor, Department of Obstetrics and Gynaecology,

Queen's University and Kingston General Hospital

Emeritus Professor, Department of Pharmacology \& Toxicology, Queen's

Assistant Professor, Department of Anesthesiology, Queen's University

WHO Professor in Psychosomatic Medicine and Psychopharmacology Professor of Psychiatry and Pharmacology

Chair and Head, Division of Psychopharmacology, Queen's University Director \& Chief of Psychiatry, Academic Unit, Quinte Health Care, Belleville General Hospital

Associate Professor, Department of Paediatrics and Office of Bioethics, Queen's University

Community Member

LL.B. and Adjunct Instructor, Department of Family Medicine (Bioethics)

Director, Office of Research Services (Ex-Officio) 


\section{Appendix B}

\section{E-Supplement for the manuscript titled, "What Aspects of Personal Care Are Most Important to Patients Undergoing Radiation Therapy for Prostate Cancer?"}

\section{Appendix B1: Expanded Methods}

\section{Defining the Scope of Personal Care}

Personal care was defined here as including all the nontechnical elements of care provided to patients within a health care institution. We used a "bottom-up" inductive approach to identify elements of personal care pertinent to patients undergoing radiation therapy for prostate cancer. We reviewed the literature and analyzed the content of existing instruments for measuring patients' satisfaction and patients' needs to identify a pool of questions relating to individual elements of personal care pertinent to patients undergoing radiation therapy for prostate cancer. Literature searches were conducted in MEDLINE. A comprehensive search strategy was used to target previous work on the assessment of personal care. Specific search terms included: "patient satisfaction”, “questionnaire", “process assessment”, "patient care”, “quality of health care”, "quality indicators, health care", "health care surveys", "needs assessment", "patient centered care", and "health care quality, access and evaluation". This search was conducted in December 2009 and since we wanted to identify recent work on this topic, only papers published between 1996 and 2009 were considered. The references from relevant papers were also searched and papers outside of the targeted year range were included. The 'grey' literature was also searched 
using Google with the above key words. See appendix B2 for a complete list of sources that provided the 500 elements of care initially included in the study (see Figure 3-1).

\section{Classifying the Elements of Care}

We then classified these individual elements into 10 categories, each relating to a particular aspect of the quality of personal care. A preliminary classification, based on concepts and terms used in the literature pertaining to quality of care, patient satisfaction, and patients' rights, was expanded to accommodate all the elements of personal care (95) (Table 3-1). Two reviewers (KAF an epidemiologist, and WJM a radiation oncologist) classified each element independently and consensus was reached on elements where reviewers disagreed.

\section{Mapping the Elements of Care to the Continuum of Care}

Each element of care was mapped to the corresponding step in the continuum of care as shown in Figure 3-1. KAF and DW organized the elements into sub groups within each step of the care continuum and within each aspect of care based on similarity. Areas of disagreement were discussed with WJM and consensus was reached. Redundant and closely overlapping elements were identified and replaced by a single element which was constructed by KAF and WJM to capture the focus of the similar items.

\section{Questionnaire Development}

We then constructed a self-administered questionnaire in which each element of care was presented as a positive statement (Figure 3-2). All the elements of quality of personal care were presented as positive statements to minimize the risk of patients becoming confused as they worked their way through this long questionnaire. Elements of care were organized by topic and 
we also ensured that their order followed the temporal sequence of events during care delivery. Patients were asked to rate the importance of each element, on an ordinal scale, as shown in Figure 3-2. Patients were also asked to rate the quality of each element of their personal care. Only the ratings of importance were analyzed here. Patients' assessment of quality will be described in a future manuscript.

\section{$\underline{\text { Cognitive Interviews }}$}

The questionnaire was revised based on the basis of feedback about its clarity and comprehensiveness, obtained through cognitive interviews conducted by KAF with a convenience sample of 8 patients who had undergone radiation therapy for prostate cancer and 4 health professionals from the Cancer Centre of Southeastern Ontario (CCSEO) involved in the care of patients with prostate cancer.

Because the questionnaire was long, the interview was split into a series of interviews, arranged so that each one took approximately one hour. Five of the eight patients completed the full questionnaire in a series of interviews; three patients only completed part of the questionnaire. Pre-scripted verbal probes were primarily used to gather information about the cognitive processes used to rate each indicator (7). Spontaneous verbal probes were also used during the interviews, as the need arose. We made many changes to the questionnaire in response to feedback provided by the interviewees, including: changes to the response categories; changes to the order in which the elements were presented; addition of new elements; elimination of redundant elements; and clarification of the wording of confusing elements (Figure 3-1). 


\section{Configuring the Questionnaire}

The final questionnaire was divided into 3 modules, designed to be administered sequentially. Module 1, including elements pertinent to pretreatment assessment and the treatment decision, was administered in the first week of treatment; module 2, including elements pertinent to treatment delivery and plans for follow-up was administered at the end of treatment; and module 3, elements relating to general aspects of care, was administered at first follow-up visit (7) (Figure 3-1).

Each module also asked the patient to identify any other elements of care that he thought should be included. Preliminary testing on 28 patients showed that it was feasible for them to complete the questionnaire without difficulty or distress. Patients did not suggest any new elements of care to add to the questionnaire (7).

\section{$\underline{\text { Survey Population }}$}

Patients starting radical external beam radiation therapy for localized prostate cancer at CCSEO between May 2011 and August 2014 were eligible to participate. Patients with clinically positive nodes were excluded. Patients who were incarcerated were excluded. Patients were excluded if the attending oncologist did not approve their recruitment (see Figure B1). Patients who had undergone prostatectomy or would receive brachytherapy were excluded. Patients who received adjuvant hormonal treatment were included. Patients with low-risk localized disease received single-phase IMRT photon therapy, $70 \mathrm{~Gy} / 35$ fractions to the prostate and proximal seminal vesicles with a $0.8 \mathrm{~cm}$ margin for planning treatment volume. Patients with intermediate-risk disease received $76 \mathrm{~Gy} / 38$ fractions to the same volume with the same technique. Patients with high-risk localized disease (PSA >20ng/ml or Gleason Score 8 or higher, clinically node 
negative) received two phase treatment, with $46 \mathrm{~Gy} / 23$ fractions to prostate and pelvic nodes, followed by IMRT boost of $30 \mathrm{~Gy} / 15$ fractions to the prostate and proximal seminal vesicles, and 2 years of adjuvant hormonal therapy. Radiation therapy was usually started within 30 days of start of hormonal therapy; long courses of neoadjuvant therapy were not utilized during the study period.

\section{Administration of the Questionnaire}

Patients were invited to participate in the study during their first week of radiation therapy. Participants were assured that their responses were confidential and that they would remain anonymous. Consenting patients were given each module of the questionnaire by hand at the appropriate point in time (Figure 3-1) along with a stamped addressed envelope in which to return it. Patients were asked to complete the questionnaire at home to give them as much time as they wished to complete this task and the opportunity to do so in the privacy and security of their own home.

To assess test-retest reliability, patients recruited after May 2012 were mailed a second copy of module 3 within 10 days of the return of the first copy, and were asked to complete it upon receipt. Test-retest reliability was assessed on module 3 only, because it was not deemed feasible to assess reliability at the points in time when modules 1 and 2 were administered because the patient's health and treatment status was rapidly evolving. Our intention was to have patients complete the second copy of module 3, 10-14 days after they had completed the first. We selected this period for assessing the reliability of importance ratings, on the assumption that it would probably be long enough to prevent them from recalling their previous scores, but probably not long enough for a change in their true beliefs about the importance the elements of care included 
in module 3. Although we planned for a test-retest interval of 10-14 days, this was not strictly controlled and patients who returned their second copy of module 3 later than we had intended were not excluded from the analysis.

\section{Data Management}

Questionnaires were stored in a locked cabinet in a secure facility. Patients were identified by

study number only. Data were entered into a password-protected Microsoft Access database with the use of double entry. Analyses were conducted with SAS 9.3 (151).

\section{$\underline{\text { Analyses }}$}

\section{Ranking by Importance}

Two different methods were used to rank the importance of the elements of care. We first dichotomized the ratings of importance provided on the 4-point scale shown in Figure 3-2, as "very important" versus less important. The elements of care were then ranked based on the proportion of patients rating each as "very important", with ties being resolved based on the proportion rating each as "important", and, if necessary, by the proportion rating each as "somewhat important" (Method A). We also calculated the rank assigned to each element, by each individual patient, using fractional ranking to deal with ties. We then calculated the mean rank assigned to each element by the group of patients. Finally, each element was ranked based on the mean rank assigned to it by the group (Method B). For the overall group of patients, the two methods yielded almost identical results (Spearman $r=.99$ ). We therefore used the simpler method A in our primary analysis. The importance of the 10 aspects of personal care was 
calculated by the mean importance of its constituent elements. The importance of different aspects of care was compared using generalized estimating equations.

\section{Sample size}

Since we planned to describe importance by the proportion of patients rating each element "very important", a target sample size of 96 patients was set to ensure maximum confidence intervals of +/- $10 \%$ on proportions of patients (152).

\section{Agreement}

We calculated the percentage of patients agreeing with the majority opinion on whether each element of care was or was not "very important" using the following formula: $50+\mid 50-\%$ "very important"| (153). This is scaled from 50 to 100 , where 50 is complete disagreement and 100 is complete agreement. A threshold of agreement was set at $60 \%$ because at $60 \%$ agreement with 108 respondents, the $95 \%$ confidence interval just excludes 50 and therefore represents the majority opinion.

\section{Test-retest Reliability}

Test-retest reliability was described by concordance on ratings of "very important", referred to as percentage of positive agreement (154). The K statistic was not used to describe test-retest reliability because the distribution of responses was skewed toward "very important" (155). 


\section{Patient characteristics and importance rankings}

Spearman correlation was used to compare the importance rankings of different subgroups of patients defined by age, education and health status. Initially we used Method A to compare the percentage of patients rating each element of care "very important" between subgroups, but we realized this method was influenced by the way in which different groups of individuals use the scale. For example, younger patients tended to rate more things "very important" than older patients, and as a result, many elements of care were identified as significantly different between these two groups simply because older and younger patients used the scale differently. Therefore, Method B was used here to rank the elements of care because it is not influenced by the way in which different groups of individuals use the scale. The Wilcoxon rank sum test was used to compare differences in the importance of individual elements of care from the perspective of different subgroups of patients. This exploratory analysis involved multiple comparisons, and we therefore applied the procedure suggested by Benjamini and Hochburg (156) in assessing statistical significance, with the acceptable false discovery rate set at 0.25 . 


\section{Appendix B2: Source references used to identify elements and aspects of the quality of personal care relevant to patients undergoing radiation therapy for prostate}

\section{cancer}

1. American Hospital Association. Management Advisory: A Patient's Bill of Rights. http://www.qcc.cuny.edu/SocialSciences/ppecorino/MEDICAL_ETHICS_TEXT/Chapter_6_ Patient_Rights/Readings_The\%20Patient_Bill_of_Rights.htm. Accessed May 31, 2015.

2. Boberg EW, Gustafson DH, Hawkins RP, et al. Assessing the unmet information, support and care delivery needs of men with prostate cancer. Patient education and counseling. 2003;49(3):233-242.

3. Canadian Council for Health Services Accreditation: Appendix C, Inventory of Cancer Performance Indicators Identified in Literature Review and Environmental Scan - Update 2007. 2008.

4. Canadian Council for Health Services Accreditation: Literature Review and Environmental Scan for Cancer Performance Indicators - Update 2007. 2008.

5. Cossich T, Schofield P, McLachlan SA. Validation of the cancer needs questionnaire (CNQ) short-form version in an ambulatory cancer setting. Quality of Life Research.

2004;13(7):1225-1233.

6. De Kok M, Scholte RW, Sixma HJ, et al. The patient's perspective of the quality of breast cancer care. The development of an instrument to measure quality of care through focus groups and concept mapping with breast cancer patients. EurJCancer. 2007;43(8):1257-1264.

7. Feldman-Stewart D, Brundage M, Hayter C, et al. What questions do patients with curable prostate cancer want answered? Medical Decision Making. 2000;20(Journal Article):7-19.

8. Gagliardi A, Lemieux-Charles L, Brown A, Sullivan T, Goel V. Stakeholder preferences for cancer care performance indicators. International Journal of Health Care Quality Assurance. 2008;21(2):175-189.

9. Haddad S, Potvin L, Roberge D, Pineault R, Remondin M. Patient perception of quality following a visit to a doctor in a primary care unit. Family practice. 2000;17(1):21-29.

10. Hudak PL, Wright JG. The characteristics of patient satisfaction measures. Spine. 2000;25(24):3167-3177. 
11. INPATSAT-32 - an in-patient questionnaire to assess satisfaction with care. EORTC:

European Organization for Research and Treatment of Cancer.

http://groups.eortc.be/qol/sites/default/files/img/specimen_in-patsat32_english.pdf. Accessed July 13, 2015.

12. Institute of Medicine, Shaping the Future (Newsletter of the IOM). http://health.usf.edu/medicine/educationalaffairs/pace_files/IOM\%20Quality\%20Initiative.pd f. Accessed July 13, 2015.

13. Lintz K, Moynihan C, Steginga S, et al. Prostate cancer patients' support and psychological care needs: Survey from a non-surgical oncology clinic. Psycho-Oncology. 2003;12(8):769783.

14. Loblaw DA, Bezjak A, Bunston T. Development and testing of a visit-specific patient satisfaction questionnaire: the Princess Margaret Hospital Satisfaction With Doctor Questionnaire. Journal of Clinical Oncology. 1999;17(6):1931-1931.

15. McKinley RK, Manku-Scott T, Hastings AM, French DP, Baker R. Reliability and validity of a new measure of patient satisfaction with out of hours primary medical care in the United Kingdom: development of a patient questionnaire. Bmj. 1997;314(7075):193.

16. Miller DC, Litwin MS, Sanda MG, et al. Use of quality indicators to evaluate the care of patients with localized prostate carcinoma. Cancer. 2003;97(6):1428-1435.

17. Newmann J, Pfettscher S. End-Stage Renal Disease: Patient Satisfaction (Adapted from KDQOL). http://www.promotingexcellence.org/tools/pe4785.html. Accessed July 13, 2015.

18. NHS Survey of Cancer Patients (2000). National Centre for Social Research, Picker Institute - Europe.

19. NHS Survey of Family Members (2000). National Centre for Social Research, Picker Institute - Europe.

20. NSW Health: Patient Survey 2008 - Cancer Care Survey.

21. Sandoval GA, Levinton C, Blackstien-Hirsch P, Brown AD. Selecting predictors of cancer patients' overall perceptions of the quality of care received. Annals of Oncology. 2006;17(1):151-156. 
22. Sanson-Fisher R, Girgis A, Boyes A, Bonevski B, Burton L, Cook P. The unmet supportive care needs of patients with cancer. Cancer. 2000;88(1):226-237. doi:10.1002/(SICI)10970142(20000101)88:1<226::AID-CNCR30>3.0.CO;2-P.

23. Schneider EC, Epstein AM, Malin JL, Kahn KL, Emanuel EJ. Developing a system to assess the quality of cancer care: ASCO's national initiative on cancer care quality. Journal of Clinical Oncology. 2004;22(15):2985-2991.

24. Sitzia J, Wood N. Patient satisfaction: A review of issues and concepts. SocSciMed. 1997;45(12):1829-1843. doi:10.1016/S0277-9536(97)00128-7.

25. Spencer BA, Steinberg M, Malin J, Adams J, Litwin MS. Quality-of-care indicators for earlystage prostate cancer. Journal of clinical oncology. 2003;21(10):1928-1936.

26. Steginga SK, Occhipinti S, Dunn J, Gardiner RA, Heathcote P, Yaxley J. The supportive care needs of men with prostate cancer (2000). Psycho-Oncology. 2001;10(1):66-75.

27. Templeton HR, others. Adaptation of an instrument to measure the informational needs of men with prostate cancer. Journal of advanced nursing. 2001;35(3):357-364.

28. Ware JE, Snyder MK, Wright WR, Davies AR. Defining and measuring patient satisfaction with medical care. Evaluation and program planning. 1983;6(3):247-263.

29. Wiggers JH, Donovan KO, Redman S, Sanson-Fisher RW. Cancer patient satisfaction with care. Cancer. 1990;66(3):610-616. 
May 2011 - August 2014:

188 patients started radical radiotherapy

$\downarrow \longrightarrow 17$ excluded by the RO

171 patients

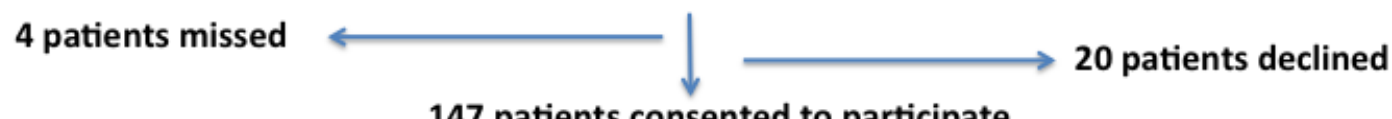

147 patients consented to participate

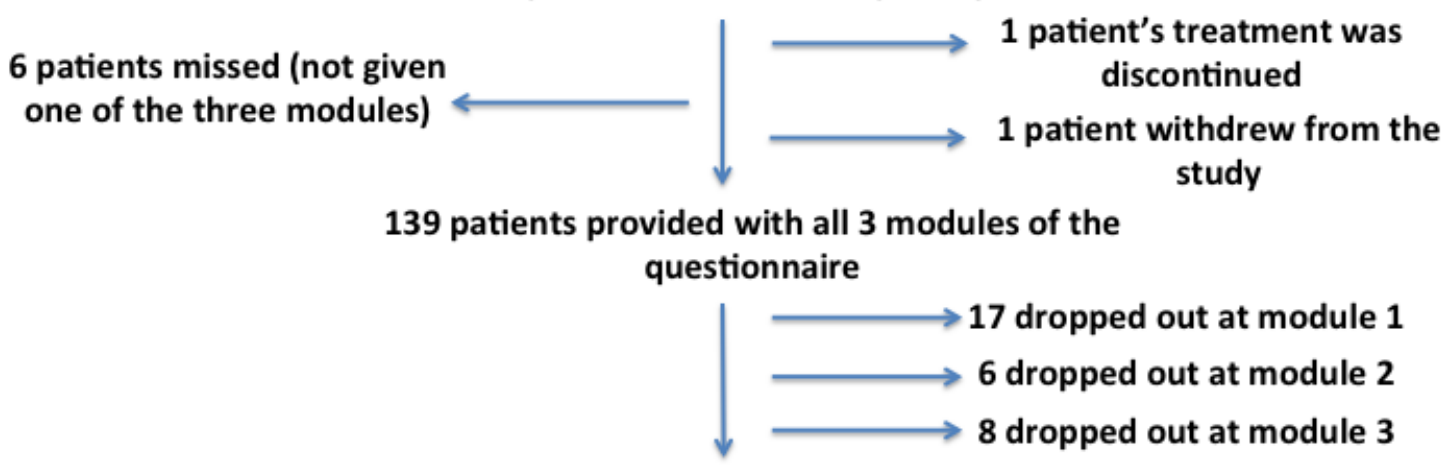

108 returned all 3 modules

Figure B1: Recruitment and retention of patient study subjects. The attending radiation oncologist excluded 17 patients for the following reasons: anxiety (5), depression (2), schizophrenia (2), cognitive difficulties (2), language barrier (1), other co-morbidities (3). Reasons for exclusion for 2 patients are unknown. 


\section{Appendix B3: Time to completion, Response Rate by Module and Completeness of Responses}

The median time of completion was: module 1, 23 minutes (range 7-70); module 2, 10 minutes (range 2-35); and module 3, 13 minutes (range 5-40). The median time for completion of the complete questionnaire (all three modules) was 46 minutes (range 17 to 105).

The response rate for module 1 (for the 139 patients provided with all 3 modules of the questionnaire) was $86 \%$. The response rate for module 2 (conditional on completing module 1) was $95 \%$ and the response rate for module 3 (conditional on completing modules 1 and 2) was $93 \%$.

There were few missing responses. Ratings of importance were provided by $>90 \%$ of patients for every element; the mean completeness of responses for all elements was $98.4 \%$. Mean completeness of responses rates was: higher for younger patients $c f$ older patients $(98.8 \%$ vs $98.1 \%)$; higher in those with more education $c f$ less education (99.2\% vs $97.6 \%)$; and higher in those in excellent health $c f$ those in poorer health (98.7\% vs $98.2 \%)$. These differences were statistically significant $(\mathrm{p}<.05)$, but too small to have any meaningful impact on our results.

We conducted a sensitivity analysis to assess the impact of missing data on our rank order. Missing responses were coded as "very important" and the elements of care were re-ranked based on the percentage of patients rating each one as "very important". The Spearman correlation 
coefficient comparing the new rank order to the original order was 1.0 and there were no changes in the 10 highest and 10 lowest ranked elements of care. 
Table B3-1: Patient characteristics

\begin{tabular}{|l|l|}
\hline Characteristic & \# of Patients $(\%)$ \\
\hline Age & \\
\hline 50 & $0(0)$ \\
$50-59$ & $7(7)$ \\
$60-69$ & $40(37)$ \\
$\geq 70$ & $61(56)$ \\
\hline Education Level & $17(16)$ \\
Less than high school & $36(33)$ \\
High school & $24(22)$ \\
College diploma & $16(15)$ \\
University degree & $9(8)$ \\
Post-graduate degree & $6(6)$ \\
Unknown & \\
Single & $0(0)$ \\
Separated/Widowed/Divorced & $12(11)$ \\
Married/Living common-law & $91(84)$ \\
Unknown & $5(5)$ \\
\hline Poor & \\
Fair & $1(1)$ \\
Good & $14(13)$ \\
Excellent & $55(51)$ \\
Unknown & $32(30)$ \\
\hline
\end{tabular}

*Percentages may not add up to 100 due to rounding. 
Table B3-2: Importance ratings for all elements of the quality of personal care

\begin{tabular}{|c|c|c|c|}
\hline \multirow[t]{2}{*}{ Element of Care } & \multicolumn{2}{|c|}{$\begin{array}{c}\text { Importance } \\
\text { (Method A: \% } \\
\text { "Very Important") }\end{array}$} & \multirow{2}{*}{$\begin{array}{c}\text { Importance } \\
\text { (Method B: } \\
\text { mean ranks) } \\
\text { Rank }\end{array}$} \\
\hline & $\begin{array}{c}\% \\
(95 \% C I)\end{array}$ & Rank & \\
\hline $\begin{array}{l}\text { The radiation oncologist is knowledgeable and } \\
\text { experienced in dealing with prostate cancer }\end{array}$ & $\begin{array}{c}95.3 \\
(89.4,98.5)\end{array}$ & 1 & 1 \\
\hline $\begin{array}{l}\text { The radiation oncologist makes sure the patient } \\
\text { knows that the cancer is confined to the prostate, } \\
\text { and there is no sign that it has spread to any other } \\
\text { part of the body }\end{array}$ & $\begin{array}{c}93.5 \\
(87.0,97.3)\end{array}$ & 2 & 2 \\
\hline $\begin{array}{l}\text { The patient trusts the radiation oncologist to look } \\
\text { after him properly }\end{array}$ & $\begin{array}{c}91.6 \\
(84.6,96.1)\end{array}$ & 3 & 3 \\
\hline $\begin{array}{l}\text { The cancer centre seems to have all the } \\
\text { equipment and facilities needed to completely } \\
\text { care for the patient's prostate cancer }\end{array}$ & $\begin{array}{c}88.0 \\
(80.3,93.4)\end{array}$ & 4 & 4 \\
\hline $\begin{array}{l}\text { The radiation therapists are knowledgeable and } \\
\text { experienced in dealing with prostate cancer }\end{array}$ & $\begin{array}{c}87.8 \\
(80.1,93.3)\end{array}$ & 5 & 6 \\
\hline $\begin{array}{l}\text { The radiation oncologist, nurses and radiation } \\
\text { therapists work well together when treating the } \\
\text { patient for prostate cancer }\end{array}$ & $\begin{array}{c}87.0 \\
(79.2,92.7)\end{array}$ & 6 & 5 \\
\hline $\begin{array}{l}\text { The radiation oncologist takes the time to answer } \\
\text { all of the patient's questions }\end{array}$ & $\begin{array}{c}86.9 \\
(79.0,92.7)\end{array}$ & 7 & 7 \\
\hline The radiation oncologist is honest with the patient & $\begin{array}{c}86.0 \\
(77.9,91.9)\end{array}$ & 8 & 8 \\
\hline $\begin{array}{l}\text { The radiation oncologist makes sure the patient } \\
\text { knows the grade of his cancer and understands } \\
\text { what that means }\end{array}$ & $\begin{array}{c}85.0 \\
(76.9,91.2)\end{array}$ & 9 & 9 \\
\hline $\begin{array}{l}\text { The radiation oncologist gives the patient enough } \\
\text { information about the side effects of each } \\
\text { treatment option }\end{array}$ & $\begin{array}{c}84.8 \\
(76.4,91.0)\end{array}$ & 10 & 11 \\
\hline $\begin{array}{l}\text { The radiation oncologist makes the patient feel } \\
\text { like he can ask any questions he wants to }\end{array}$ & $\begin{array}{c}84.1 \\
(75.8,90.5)\end{array}$ & 11 & 10 \\
\hline $\begin{array}{l}\text { The radiation oncologist makes sure the patient } \\
\text { knows the stage of his cancer and understands } \\
\text { what that means }\end{array}$ & $\begin{array}{c}83.2 \\
(74.7,89.7)\end{array}$ & 12 & 12 \\
\hline $\begin{array}{l}\text { The nurses are knowledgeable and experienced in } \\
\text { dealing with prostate cancer }\end{array}$ & $\begin{array}{c}83.0 \\
(74.5,89.6)\end{array}$ & 13 & 13 \\
\hline $\begin{array}{l}\text { The radiation oncologist is aware of the test } \\
\text { results and has the results available when seeing } \\
\text { the patient for the first time }\end{array}$ & $\begin{array}{c}82.7 \\
(74.0,89.4)\end{array}$ & 14 & 15 \\
\hline $\begin{array}{l}\text { The radiation oncologist explains the different } \\
\text { forms of treatment that are available for prostate } \\
\text { cancer }\end{array}$ & $\begin{array}{c}82.1 \\
(73.4,88.8)\end{array}$ & 15 & 17 \\
\hline
\end{tabular}




\begin{tabular}{|c|c|c|c|}
\hline $\begin{array}{l}\text { The radiation oncologist makes sure the patient } \\
\text { understands the benefits of radiation treatment } \\
\text { and its side effects before asking for consent to } \\
\text { have radiation treatment }\end{array}$ & $\begin{array}{c}81.3 \\
(72.6,88.2)\end{array}$ & 16 & 16 \\
\hline $\begin{array}{l}\text { The patient is aware of who to contact with } \\
\text { questions about his prostate cancer and treatment }\end{array}$ & $\begin{array}{c}81.3 \\
(72.6,88.2) \\
\end{array}$ & 16 & 19 \\
\hline $\begin{array}{l}\text { The radiation oncologist listens carefully to all } \\
\text { the patient's concerns }\end{array}$ & $\begin{array}{c}81.3 \\
(72.6,88.2) \\
\end{array}$ & 16 & 18 \\
\hline $\begin{array}{l}\text { The radiation oncologist explains things to the } \\
\text { patient in a way that he can understand }\end{array}$ & $\begin{array}{c}81.1 \\
(72.4,88.1) \\
\end{array}$ & 19 & 20 \\
\hline $\begin{array}{l}\text { The radiation therapists are honest with the } \\
\text { patient }\end{array}$ & $\begin{array}{c}81.0 \\
(72.1,88.0) \\
\end{array}$ & 20 & 14 \\
\hline $\begin{array}{l}\text { The patient is given enough information about the } \\
\text { possible side effects of radiation treatment }\end{array}$ & $\begin{array}{c}80.2 \\
(71.3,87.3)\end{array}$ & 21 & 22 \\
\hline $\begin{array}{l}\text { The patient gets all the help he needs from the } \\
\text { radiation oncologist to make up his mind about } \\
\text { which treatment to have }\end{array}$ & $\begin{array}{c}80.2 \\
(71.3,87.3)\end{array}$ & 22 & 25 \\
\hline $\begin{array}{l}\text { The patient has confidence in his treatment team } \\
\text { that he is treated correctly every day }\end{array}$ & $\begin{array}{c}79.2 \\
(70.3,86.5) \\
\end{array}$ & 23 & 21 \\
\hline $\begin{array}{l}\text { The radiation oncologist carefully assesses the } \\
\text { patient's suitability for radiation treatment }\end{array}$ & $\begin{array}{c}78.8 \\
(69.7,86.2)\end{array}$ & 24 & 24 \\
\hline $\begin{array}{l}\text { The information about treatment options is } \\
\text { provided to the patient before any decision is } \\
\text { made about the way he will be treated }\end{array}$ & $\begin{array}{c}78.1 \\
(69.0,85.6)\end{array}$ & 25 & 28 \\
\hline $\begin{array}{l}\text { The radiation oncologist gives the patient enough } \\
\text { information about the chance of curing his cancer } \\
\text { with each treatment option }\end{array}$ & $\begin{array}{c}78.1 \\
(69.0,85.6)\end{array}$ & 26 & 27 \\
\hline $\begin{array}{l}\text { The patient trusts the radiation therapists to look } \\
\text { after him properly }\end{array}$ & $\begin{array}{c}77.8 \\
(68.8,85.2)\end{array}$ & 27 & 23 \\
\hline $\begin{array}{l}\text { The patient is given enough information about the } \\
\text { chance of curing his cancer with radiation } \\
\text { treatment }\end{array}$ & $\begin{array}{c}77.4 \\
(68.2,84.9)\end{array}$ & 28 & 29 \\
\hline $\begin{array}{l}\text { The radiation oncologist makes sure the patient } \\
\text { understands the treatment options before making } \\
\text { up his mind about which treatment to have }\end{array}$ & $\begin{array}{c}77.4 \\
(68.2,84.9)\end{array}$ & 29 & 34 \\
\hline $\begin{array}{l}\text { The radiation oncologist cares about the patient's } \\
\text { well-being }\end{array}$ & $\begin{array}{c}76.6 \\
(67.5,84.3) \\
\end{array}$ & 30 & 26 \\
\hline $\begin{array}{l}\text { The radiation oncologist treats the patient with } \\
\text { respect }\end{array}$ & $\begin{array}{c}76.6 \\
(67.5,84.3) \\
\end{array}$ & 31 & 30 \\
\hline $\begin{array}{l}\text { The patient has enough time with the radiation } \\
\text { oncologist to get all of the information he needs } \\
\text { about treatment options }\end{array}$ & $\begin{array}{c}76.4 \\
(67.2,84.1)\end{array}$ & 32 & 35 \\
\hline $\begin{array}{l}\text { The patient gets enough information from the } \\
\text { radiation oncologist to be able to participate in the } \\
\text { decision about treatment }\end{array}$ & $\begin{array}{c}76.2 \\
(66.9,84.0)\end{array}$ & 33 & 36 \\
\hline
\end{tabular}




\begin{tabular}{|c|c|c|c|}
\hline $\begin{array}{l}\text { The patient is made aware of who to contact if he } \\
\text { is concerned about the cancer coming back }\end{array}$ & $\begin{array}{c}75.9 \\
(66.8,83.6)\end{array}$ & 34 & 33 \\
\hline $\begin{array}{l}\text { The radiation oncologist makes sure the patient } \\
\text { understands the results of the biopsy of the } \\
\text { prostate, the blood tests, and any x-rays and scans } \\
\text { he may have had }\end{array}$ & $\begin{array}{c}75.7 \\
(66.5,83.5)\end{array}$ & 35 & 31 \\
\hline $\begin{array}{l}\text { The nurses explain things to the patient in a way } \\
\text { that he can understand }\end{array}$ & $\begin{array}{c}74.8 \\
(65.4,82.7)\end{array}$ & 36 & 31 \\
\hline $\begin{array}{l}\text { The radiation therapists explain things to the } \\
\text { patient in a way that he can understand }\end{array}$ & $\begin{array}{c}73.6 \\
(64.2,81.7) \\
\end{array}$ & 37 & 37 \\
\hline $\begin{array}{l}\text { During treatment, the radiation oncologist, nurses } \\
\text { and radiation therapists do everything they can to } \\
\text { help the patient get through treatment with as few } \\
\text { problems as possible }\end{array}$ & $\begin{array}{c}73.6 \\
(64.2,81.7)\end{array}$ & 38 & 38 \\
\hline $\begin{array}{l}\text { The patient is involved as much as he wants in } \\
\text { making the final decision about which treatment } \\
\text { to have }\end{array}$ & $\begin{array}{c}73.6 \\
(64.2,81.7)\end{array}$ & 39 & 46 \\
\hline $\begin{array}{l}\text { Someone on the healthcare team explains that } \\
\text { radiation treatment may permanently affect bowel } \\
\text { function }\end{array}$ & $\begin{array}{c}73.3 \\
(63.8,81.5)\end{array}$ & 40 & 39 \\
\hline $\begin{array}{l}\text { Someone on the healthcare team explains that } \\
\text { doctors will be monitoring PSA levels at regular } \\
\text { intervals during follow-up from radiation } \\
\text { treatment }\end{array}$ & $\begin{array}{c}73.2 \\
(63.8,81.2)\end{array}$ & 41 & 40 \\
\hline $\begin{array}{l}\text { Someone on the healthcare team explains that } \\
\text { radiation treatment may permanently affect } \\
\text { bladder function }\end{array}$ & $\begin{array}{c}72.4 \\
(62.8,80.7)\end{array}$ & 42 & 42 \\
\hline $\begin{array}{l}\text { The nurses take the time to answer all of the } \\
\text { patient's questions }\end{array}$ & $\begin{array}{c}72.0 \\
(62.4,80.2) \\
\end{array}$ & 43 & 41 \\
\hline $\begin{array}{l}\text { The nurses listen carefully to all the patient's } \\
\text { concerns }\end{array}$ & $\begin{array}{c}72.0 \\
(62.4,80.2)\end{array}$ & 44 & 45 \\
\hline $\begin{array}{l}\text { The nurses make the patient feel like he can ask } \\
\text { any questions he wants to }\end{array}$ & $\begin{array}{c}72.0 \\
(62.4,80.2)\end{array}$ & 44 & 43 \\
\hline $\begin{array}{l}\text { The patient trusts the nurses to look after him } \\
\text { properly }\end{array}$ & $\begin{array}{c}72.0 \\
(62.4,80.2)\end{array}$ & 46 & 44 \\
\hline The nurses are honest with the patient & $\begin{array}{c}71.4 \\
(61.8,79.8)\end{array}$ & 47 & 47 \\
\hline $\begin{array}{l}\text { The cancer centre appears to be clean and well } \\
\text { looked after }\end{array}$ & $\begin{array}{c}70.0 \\
(60.5,78.6)\end{array}$ & 48 & 48 \\
\hline $\begin{array}{l}\text { Someone on the healthcare team explains that } \\
\text { radiation treatment cannot usually be given to the } \\
\text { prostate again if it is not successful the first time }\end{array}$ & $\begin{array}{c}69.9 \\
(60.1,78.6)\end{array}$ & 49 & 51 \\
\hline $\begin{array}{l}\text { The patient has enough time to consider the } \\
\text { treatment options before it is decided how he will } \\
\text { be treated }\end{array}$ & $\begin{array}{c}70.0 \\
(60.1,78.6)\end{array}$ & 50 & 59 \\
\hline
\end{tabular}




\begin{tabular}{|c|c|c|c|}
\hline $\begin{array}{l}\text { Someone on the healthcare team explains that the } \\
\text { PSA level is all that is needed to tell if the cancer } \\
\text { is under control or not }\end{array}$ & $\begin{array}{c}69.5 \\
(59.8,78.1)\end{array}$ & 51 & 53 \\
\hline $\begin{array}{l}\text { The radiation oncologist reads the patient's } \\
\text { previous medical records before seeing the patient } \\
\text { for the first time }\end{array}$ & $\begin{array}{c}69.2 \\
(59.4,77.9)\end{array}$ & 52 & 56 \\
\hline $\begin{array}{l}\text { Someone on the healthcare team explains the } \\
\text { arrangements for follow-up care after the } \\
\text { radiation treatment is over }\end{array}$ & $\begin{array}{c}68.9 \\
(59.1,77.5)\end{array}$ & 53 & 50 \\
\hline $\begin{array}{l}\text { The radiation therapists make the patient feel like } \\
\text { he can ask any questions he wants to }\end{array}$ & $\begin{array}{c}68.6 \\
(58.8,77.3) \\
\end{array}$ & 54 & 49 \\
\hline The radiation oncologist is polite to the patient & $\begin{array}{c}68.5 \\
(58.9,77.1)\end{array}$ & 55 & 55 \\
\hline $\begin{array}{l}\text { The radiation oncologist describes and explains } \\
\text { all of the treatment options that are available to } \\
\text { the patient other than radiation treatment }\end{array}$ & $\begin{array}{c}68.3 \\
(58.4,77.0)\end{array}$ & 56 & 60 \\
\hline $\begin{array}{l}\text { The radiation oncologist explains what each } \\
\text { treatment option involves }\end{array}$ & $\begin{array}{c}68.3 \\
(58.4,77.0) \\
\end{array}$ & 56 & 57 \\
\hline $\begin{array}{l}\text { The radiation therapists take the time to answer } \\
\text { all of the patient's questions }\end{array}$ & $\begin{array}{c}67.9 \\
(58.2,76.7)\end{array}$ & 58 & 52 \\
\hline $\begin{array}{l}\text { Someone on the healthcare team explains that } \\
\text { radiation treatment often causes urinary } \\
\text { symptoms during treatment }\end{array}$ & $\begin{array}{c}67.3 \\
(57.6,76.0)\end{array}$ & 59 & 61 \\
\hline $\begin{array}{l}\text { The radiation therapists listen carefully to all the } \\
\text { patient's concerns }\end{array}$ & $\begin{array}{c}66.7 \\
(56.8,75.6) \\
\end{array}$ & 60 & 54 \\
\hline The nurses treat the patient with respect & $\begin{array}{c}66.7 \\
(56.8,75.6) \\
\end{array}$ & 61 & 58 \\
\hline $\begin{array}{l}\text { The radiation oncologist tells the patient about his } \\
\text { PSA level and explains what that means }\end{array}$ & $\begin{array}{c}66.4 \\
(56.6,75.2)\end{array}$ & 62 & 63 \\
\hline $\begin{array}{l}\text { The radiation oncologist shows sensitivity to the } \\
\text { patient's feelings and emotional needs }\end{array}$ & $\begin{array}{c}65.7 \\
(56.0,74.6)\end{array}$ & 63 & 64 \\
\hline $\begin{array}{l}\text { Someone on the healthcare team explains who to } \\
\text { contact if additional care is needed in recovery } \\
\text { after radiation treatment }\end{array}$ & $\begin{array}{c}65.7 \\
(55.8,74.7)\end{array}$ & 64 & 62 \\
\hline $\begin{array}{l}\text { Someone on the healthcare team explains that } \\
\text { radiation treatment often causes bowel symptoms } \\
\text { during treatment }\end{array}$ & $\begin{array}{c}65.4 \\
(55.6,74.4)\end{array}$ & 65 & 65 \\
\hline $\begin{array}{l}\text { Someone on the healthcare team gives the patient } \\
\text { written information about the side effects of each } \\
\text { treatment option }\end{array}$ & $\begin{array}{c}65.1 \\
(55.2,74.1)\end{array}$ & 66 & 66 \\
\hline $\begin{array}{l}\text { Someone on the healthcare team is always } \\
\text { available to answer the patient's questions and } \\
\text { advise on the management of side effects during } \\
\text { the course of radiation treatment }\end{array}$ & $\begin{array}{c}64.8 \\
(55.0,73.8)\end{array}$ & 67 & 67 \\
\hline The nurses care about the patient's well-being & 64.8 & 68 & 68 \\
\hline
\end{tabular}




\begin{tabular}{|c|c|c|c|}
\hline & $(54.8,73.8)$ & & \\
\hline $\begin{array}{l}\text { The radiation oncologist asks the patient about } \\
\text { any other medical problems he may have }\end{array}$ & $\begin{array}{c}63.8 \\
(53.8,73.0) \\
\end{array}$ & 69 & 70 \\
\hline $\begin{array}{l}\text { Someone on the health care team offers written } \\
\text { information about prostate cancer to the patient } \\
\text { that he can take home with him }\end{array}$ & $\begin{array}{c}63.8 \\
(53.8,73.0)\end{array}$ & 70 & 71 \\
\hline $\begin{array}{l}\text { Someone on the healthcare team explains the } \\
\text { other treatments that are available if radiation } \\
\text { treatment is not successful }\end{array}$ & $\begin{array}{c}63.4 \\
(53.2,72.7)\end{array}$ & 71 & 74 \\
\hline $\begin{array}{l}\text { The radiation therapists care about the patient's } \\
\text { well-being }\end{array}$ & $\begin{array}{c}62.9 \\
(52.9,72.1)\end{array}$ & 72 & 69 \\
\hline $\begin{array}{l}\text { The patient is given enough information to } \\
\text { understand how the radiation treatment works }\end{array}$ & $\begin{array}{c}62.3 \\
(52.3,71.5) \\
\end{array}$ & 73 & 76 \\
\hline $\begin{array}{l}\text { Someone on the healthcare team explains that } \\
\text { radiation treatment involves the use of high } \\
\text { energy rays directed at the prostate from outside } \\
\text { the body }\end{array}$ & $\begin{array}{c}61.7 \\
(51.8,70.9)\end{array}$ & 74 & 72 \\
\hline $\begin{array}{l}\text { The patient feels that he can trust the radiation } \\
\text { oncologist with confidential information }\end{array}$ & $\begin{array}{c}61.7 \\
(51.8,70.9) \\
\end{array}$ & 75 & 73 \\
\hline $\begin{array}{l}\text { Someone at the cancer centre is available to } \\
\text { answer the patient's questions in between } \\
\text { appointments }\end{array}$ & $\begin{array}{c}61.3 \\
(51.4,70.6)\end{array}$ & 76 & 75 \\
\hline $\begin{array}{l}\text { Someone at the cancer centre arranges for the } \\
\text { patient to receive any help he needs in dealing } \\
\text { with his anxiety about the diagnosis }\end{array}$ & $\begin{array}{c}60.9 \\
(38.5,80.3)\end{array}$ & 77 & 109 \\
\hline $\begin{array}{l}\text { The radiation therapists treat the patient with } \\
\text { respect }\end{array}$ & $\begin{array}{c}60.4 \\
(50.4,69.8) \\
\end{array}$ & 78 & 78 \\
\hline $\begin{array}{l}\text { The patient feels that his rights for privacy are } \\
\text { fully protected at the cancer centre }\end{array}$ & $\begin{array}{c}60.2 \\
(50.3,69.5)\end{array}$ & 79 & 82 \\
\hline $\begin{array}{l}\text { Once the decision to have radiation treatment has } \\
\text { been made, the patient is given enough } \\
\text { information about how long he will have to wait } \\
\text { to start treatment }\end{array}$ & $\begin{array}{c}60.2 \\
(50.3,69.5)\end{array}$ & 80 & 84 \\
\hline The nurses are polite to the patient & $\begin{array}{c}59.8 \\
(49.9,69.2)\end{array}$ & 81 & 77 \\
\hline $\begin{array}{l}\text { Someone on the healthcare team explains that } \\
\text { radiation treatment may permanently affect } \\
\text { sexual functioning }\end{array}$ & $\begin{array}{c}59.8 \\
(49.9,69.2)\end{array}$ & 82 & 92 \\
\hline $\begin{array}{l}\text { The patient understands that there is no } \\
\text { immediate rush to make a decision about } \\
\text { treatment although it's best to make a decision } \\
\text { within a week or two }\end{array}$ & $\begin{array}{c}59.4 \\
(49.5,68.9)\end{array}$ & 83 & 85 \\
\hline $\begin{array}{l}\text { The patient feels that he can trust the radiation } \\
\text { therapists with confidential information }\end{array}$ & $\begin{array}{c}59.3 \\
(49.4,68.6) \\
\end{array}$ & 84 & 79 \\
\hline The radiation therapists are polite to the patient & 59.0 & 85 & 80 \\
\hline
\end{tabular}




\begin{tabular}{|c|c|c|c|}
\hline & $(49.0,68.6)$ & & \\
\hline $\begin{array}{l}\text { Someone on the healthcare team explains what } \\
\text { prostate cancer is and how it can affect the } \\
\text { patient's health }\end{array}$ & $\begin{array}{c}58.6 \\
(48.6,68.2)\end{array}$ & 86 & 81 \\
\hline $\begin{array}{l}\text { The radiation therapists show sensitivity to the } \\
\text { patient's feelings and emotional needs }\end{array}$ & $\begin{array}{c}58.5 \\
(48.5,68.0)\end{array}$ & 87 & 83 \\
\hline $\begin{array}{l}\text { The patient is aware that no one else other than } \\
\text { him and the healthcare professionals looking after } \\
\text { him are able to see his medical records without } \\
\text { his permission }\end{array}$ & $\begin{array}{c}58.3 \\
(48.4,67.8)\end{array}$ & 88 & 99 \\
\hline $\begin{array}{l}\text { The nurses show sensitivity to the patient's } \\
\text { feelings and emotional needs }\end{array}$ & $\begin{array}{c}58.1 \\
(48.1,67.7)\end{array}$ & 89 & 89 \\
\hline $\begin{array}{l}\text { The radiation oncologist shows interest in the } \\
\text { patient as a person, not just as a patient }\end{array}$ & $\begin{array}{c}58.1 \\
(48.1,67.7) \\
\end{array}$ & 90 & 93 \\
\hline $\begin{array}{l}\text { The patient's family physician is kept informed } \\
\text { about the cancer care }\end{array}$ & $\begin{array}{c}57.4 \\
(47.5,66.9)\end{array}$ & 91 & 95 \\
\hline $\begin{array}{l}\text { Someone on the healthcare team explains that the } \\
\text { course of treatment needs to be completed } \\
\text { without taking a break (of longer than a few days) }\end{array}$ & $\begin{array}{c}57.0 \\
(47.1,66.5)\end{array}$ & 92 & 87 \\
\hline $\begin{array}{l}\text { Someone on the healthcare team explains that } \\
\text { radiation treatment often causes temporary } \\
\text { fatigue }\end{array}$ & $\begin{array}{c}56.6 \\
(46.6,66.2)\end{array}$ & 93 & 94 \\
\hline $\begin{array}{l}\text { The patient feels that he can trust the nurses with } \\
\text { confidential information }\end{array}$ & $\begin{array}{c}56.5 \\
(46.6,66.0)\end{array}$ & 94 & 86 \\
\hline $\begin{array}{l}\text { The radiation oncologist explains to the patient } \\
\text { that he can change his mind about which } \\
\text { treatment to have as long as he does so before the } \\
\text { treatment starts }\end{array}$ & $\begin{array}{c}56.2 \\
(46.2,65.9)\end{array}$ & 95 & 97 \\
\hline $\begin{array}{l}\text { Someone on the healthcare team answers any } \\
\text { questions the patient has about the possible } \\
\text { causes of prostate cancer }\end{array}$ & $\begin{array}{c}56.1 \\
(39.8,71.5)\end{array}$ & 96 & 110 \\
\hline $\begin{array}{l}\text { The patient is given enough information about } \\
\text { how the radiation treatment is planned }\end{array}$ & $\begin{array}{c}56.1 \\
(46.2,65.7) \\
\end{array}$ & 97 & 88 \\
\hline $\begin{array}{l}\text { The patient has enough time with a member of } \\
\text { the healthcare team to discuss the treatment plan }\end{array}$ & $\begin{array}{c}56.1 \\
(46.2,65.7)\end{array}$ & 97 & 90 \\
\hline $\begin{array}{l}\text { The radiation therapists show interest in the } \\
\text { patient as a person, not just as a patient }\end{array}$ & $\begin{array}{c}54.3 \\
(44.3,64.0) \\
\end{array}$ & 99 & 103 \\
\hline $\begin{array}{l}\text { Someone on the healthcare team explains when } \\
\text { the patient can resume all of his previous } \\
\text { activities after radiation treatment }\end{array}$ & $\begin{array}{c}54.2 \\
(44.3,63.9)\end{array}$ & 100 & 98 \\
\hline $\begin{array}{l}\text { The patient is aware that he has a right to see all } \\
\text { the information in his medical record }\end{array}$ & $\begin{array}{c}54.2 \\
(44.3,63.9) \\
\end{array}$ & 101 & 96 \\
\hline $\begin{array}{l}\text { Someone on the healthcare team gives enough } \\
\text { information and direction to the patient about } \\
\text { how to care for himself after radiation treatment }\end{array}$ & $\begin{array}{c}53.8 \\
(43.8,63.5)\end{array}$ & 102 & 91 \\
\hline
\end{tabular}




\begin{tabular}{|c|c|c|c|}
\hline $\begin{array}{l}\text { The nurses show interest in the patient as a } \\
\text { person, not just as a patient }\end{array}$ & $\begin{array}{c}53.8 \\
(43.8,63.5)\end{array}$ & 103 & 104 \\
\hline $\begin{array}{l}\text { Someone on the healthcare team explains how the } \\
\text { patient should modify his diet to avoid bowel } \\
\text { upset during the course of radiation treatment }\end{array}$ & $\begin{array}{c}53.7 \\
(43.8,63.4)\end{array}$ & 104 & 100 \\
\hline $\begin{array}{l}\text { The patient has a short wait to start treatment } \\
\text { after the decision was made to have radiation } \\
\text { treatment }\end{array}$ & $\begin{array}{c}53.3 \\
(43.4,63.0)\end{array}$ & 105 & 102 \\
\hline $\begin{array}{l}\text { The cancer centre has a place to stay overnight if } \\
\text { the patient lives far away }\end{array}$ & $\begin{array}{c}53.0 \\
(42.8,63.1) \\
\end{array}$ & 106 & 111 \\
\hline $\begin{array}{l}\text { The patient has a short wait to get an appointment } \\
\text { to see the radiation oncologist for the first time }\end{array}$ & $\begin{array}{c}51.9 \\
(42.0,61.7)\end{array}$ & 107 & 106 \\
\hline $\begin{array}{l}\text { Before radiation treatment starts, the patient is } \\
\text { given enough information about what will happen } \\
\text { each day when he comes for treatment }\end{array}$ & $\begin{array}{c}51.8 \\
(42.0,61.6)\end{array}$ & 108 & 101 \\
\hline $\begin{array}{l}\text { The patient is given enough information about } \\
\text { how the treatment is scheduled and flexibility in } \\
\text { the daily appointment times }\end{array}$ & $\begin{array}{c}51.4 \\
(41.5,61.2)\end{array}$ & 109 & 108 \\
\hline $\begin{array}{l}\text { If the patient wants, the radiation oncologist is } \\
\text { willing to answer all the questions the patient's } \\
\text { family and friends have }\end{array}$ & $\begin{array}{c}50.6 \\
(39.3,61.9)\end{array}$ & 110 & 105 \\
\hline $\begin{array}{l}\text { Once an appointment is made for the patient it is } \\
\text { not cancelled or postponed }\end{array}$ & $\begin{array}{c}49.1 \\
(39.3,58.9) \\
\end{array}$ & 111 & 107 \\
\hline $\begin{array}{l}\text { Transportation to/from the cancer centre is } \\
\text { available for the patient if needed }\end{array}$ & $\begin{array}{c}49.0 \\
(38.7,59.3) \\
\end{array}$ & 112 & 119 \\
\hline There is somewhere convenient to park & $\begin{array}{c}45.8 \\
(36.1,55.7) \\
\end{array}$ & 113 & 112 \\
\hline $\begin{array}{l}\text { If the patient wants, someone on the healthcare } \\
\text { team is willing to answer questions about } \\
\text { treatment from family or friends }\end{array}$ & $\begin{array}{c}45.6 \\
(30.9,61.0)\end{array}$ & 114 & 121 \\
\hline $\begin{array}{l}\text { Once the treatment starts, someone on the } \\
\text { healthcare team reminds the patient of the } \\
\text { potential side effects to expect during the course } \\
\text { of radiation treatment }\end{array}$ & $\begin{array}{c}43.5 \\
(34.0,53.4)\end{array}$ & 115 & 113 \\
\hline $\begin{array}{l}\text { The patient is encouraged by the cancer centre to } \\
\text { bring a relative or friend along to the first } \\
\text { appointment with the radiation oncologist }\end{array}$ & $\begin{array}{c}43.4 \\
(33.8,53.4)\end{array}$ & 116 & 118 \\
\hline $\begin{array}{l}\text { Someone on the healthcare team is available if } \\
\text { needed to help explain the diagnosis to family } \\
\text { members }\end{array}$ & $\begin{array}{c}43.0 \\
(33.1,53.3)\end{array}$ & 117 & 127 \\
\hline $\begin{array}{l}\text { The patient is welcome to bring a friend or } \\
\text { relative with him to his appointments }\end{array}$ & $\begin{array}{c}42.9 \\
(33.2,52.9)\end{array}$ & 118 & 115 \\
\hline $\begin{array}{l}\text { Someone on the healthcare team explains that } \\
\text { prostate cancer is not infectious and that it cannot } \\
\text { be transmitted to anyone else }\end{array}$ & $\begin{array}{c}42.6 \\
(32.8,52.8)\end{array}$ & 119 & 123 \\
\hline
\end{tabular}




\begin{tabular}{|c|c|c|c|}
\hline $\begin{array}{l}\text { Someone on the healthcare team explains that } \\
\text { radiation treatment is delivered by the radiation } \\
\text { therapists, not a radiation oncologist }\end{array}$ & $\begin{array}{c}42.1 \\
(32.6,52.0)\end{array}$ & 120 & 125 \\
\hline $\begin{array}{l}\text { The radiation oncologist or the nurse see the } \\
\text { patient at least once a week during the course of } \\
\text { radiation treatment }\end{array}$ & $\begin{array}{c}41.5 \\
(32.0,51.5)\end{array}$ & 121 & 114 \\
\hline $\begin{array}{l}\text { Appointments are scheduled for a time that is } \\
\text { convenient }\end{array}$ & $\begin{array}{c}39.8 \\
(30.5,49.7)\end{array}$ & 122 & 116 \\
\hline $\begin{array}{l}\text { Directions and signs inside and outside the cancer } \\
\text { centre are easy to understand }\end{array}$ & $\begin{array}{c}39.6 \\
(30.2,49.6)\end{array}$ & 123 & 120 \\
\hline The patient has enough privacy during his care & $\begin{array}{c}38.9 \\
(29.7,48.8)\end{array}$ & 124 & 117 \\
\hline $\begin{array}{l}\text { Someone on the healthcare team explains that } \\
\text { radiation treatment can only be delivered at a few } \\
\text { specialized treatment centres }\end{array}$ & $\begin{array}{c}38.2 \\
(28.8,48.4)\end{array}$ & 125 & 131 \\
\hline $\begin{array}{l}\text { The patient is made aware that he has the right to } \\
\text { get a second opinion from another radiation } \\
\text { oncologist }\end{array}$ & $\begin{array}{c}38.1 \\
(28.8,48.1)\end{array}$ & 126 & 130 \\
\hline $\begin{array}{l}\text { The patient can find his way around the cancer } \\
\text { centre easily }\end{array}$ & $\begin{array}{c}38.0 \\
(28.8,47.8) \\
\end{array}$ & 127 & 122 \\
\hline The atmosphere in the waiting room is relaxing & $\begin{array}{c}37.0 \\
(27.9,46.9)\end{array}$ & 128 & 124 \\
\hline $\begin{array}{l}\text { The patient has a short wait in the waiting room } \\
\text { for daily radiation treatment }\end{array}$ & $\begin{array}{c}36.1 \\
(27.1,45.9)\end{array}$ & 129 & 128 \\
\hline $\begin{array}{l}\text { The radiation oncologist sees the patient at least } \\
\text { once a week during the course of radiation } \\
\text { treatment }\end{array}$ & $\begin{array}{c}35.9 \\
(26.7,46.0)\end{array}$ & 130 & 129 \\
\hline $\begin{array}{l}\text { During treatment, the radiation therapists make } \\
\text { enough time for the patient }\end{array}$ & $\begin{array}{c}34.9 \\
(25.9,44.8)\end{array}$ & 131 & 126 \\
\hline $\begin{array}{l}\text { Someone on the healthcare team other than the } \\
\text { radiation oncologist is available to provide } \\
\text { support to the patient in making the decision } \\
\text { about treatment }\end{array}$ & $\begin{array}{c}34.6 \\
(25.6,44.6)\end{array}$ & 132 & 132 \\
\hline $\begin{array}{l}\text { The cancer centre provides resources to assist the } \\
\text { patient in understanding and dealing with prostate } \\
\text { cancer (e.g. staffed information services, library } \\
\text { of books and DVDs about cancer) }\end{array}$ & $\begin{array}{c}32.7 \\
(23.7,42.7)\end{array}$ & 133 & 133 \\
\hline The waiting area and treatment rooms are quiet & $\begin{array}{c}30.6 \\
(22.0,40.2) \\
\end{array}$ & 134 & 134 \\
\hline $\begin{array}{l}\text { The patient has a short wait in the waiting room } \\
\text { when he comes to the cancer centre to see the } \\
\text { radiation oncologist for the first time }\end{array}$ & $\begin{array}{c}26.4 \\
(18.3,35.9)\end{array}$ & 135 & 135 \\
\hline $\begin{array}{l}\text { A social worker is available to provide advice on } \\
\text { financial and social issues arising from the } \\
\text { diagnosis }\end{array}$ & $\begin{array}{c}24.7 \\
(16.5,34.4)\end{array}$ & 136 & 140 \\
\hline
\end{tabular}




\begin{tabular}{|c|c|c|c|}
\hline $\begin{array}{l}\text { Someone at the cancer centre gives the patient } \\
\text { information about support groups in his area for } \\
\text { patients and/or family members }\end{array}$ & $\begin{array}{c}23.8 \\
(15.9,33.3)\end{array}$ & 137 & 137 \\
\hline The furniture in the waiting room is comfortable & $\begin{array}{c}23.2 \\
(15.6,32.2)\end{array}$ & 138 & 136 \\
\hline $\begin{array}{l}\text { The patient sees the same radiation therapists } \\
\text { each time he goes for radiation treatment }\end{array}$ & $\begin{array}{c}22.2 \\
(14.8,31.2)\end{array}$ & 139 & 139 \\
\hline $\begin{array}{l}\text { There is enough space in the waiting room that } \\
\text { the patient can have a private conversation with } \\
\text { his companion }\end{array}$ & $\begin{array}{c}19.6 \\
(12.6,28.4)\end{array}$ & 140 & 138 \\
\hline $\begin{array}{l}\text { Food and drink facilities are available in or near } \\
\text { the waiting room }\end{array}$ & $\begin{array}{c}11.3 \\
(6.0,18.9) \\
\end{array}$ & 141 & 142 \\
\hline Waiting areas are decorated nicely & $\begin{array}{c}10.4 \\
(5.3,17.8)\end{array}$ & 142 & 141 \\
\hline $\begin{array}{l}\text { The patient is treated in the same treatment room } \\
\text { each day }\end{array}$ & $\begin{array}{c}6.6 \\
(2.7,13.1) \\
\end{array}$ & 143 & 143 \\
\hline
\end{tabular}

Table B3-3: Elements of care with $<70 \%$ positive agreement

\begin{tabular}{|l|c|c|}
\hline \multicolumn{1}{|c|}{ Element of Care } & $\begin{array}{c}\text { Positive } \\
\text { Agreement (\%) }\end{array}$ & $\begin{array}{c}\text { Rank } \\
\text { (\% "Very } \\
\text { Important") }\end{array}$ \\
\hline Waiting areas are decorated nicely & 67 & 142 \\
\hline $\begin{array}{l}\text { If the patient wants, the radiation oncologist is willing to } \\
\text { answer all the questions the patient's family and friends } \\
\text { have }\end{array}$ & 65 & 110 \\
\hline The furniture in the waiting room is comfortable & 62 & 138 \\
\hline $\begin{array}{l}\text { Food and drink facilities are available in or near the waiting } \\
\text { room }\end{array}$ & 60 & 140 \\
\hline $\begin{array}{l}\text { There is enough space in the waiting room that the patient } \\
\text { can have a private conversation with his companion }\end{array}$ & 58 & \\
\hline
\end{tabular}




\section{Appendix C}

\section{Additional results for the manuscript titled, "What Aspects of Personal Care Are Most Important to Patients Undergoing Radiation Therapy for Prostate Cancer?"}

\section{Appendix C1: Additional rationale for our sample size calculation}

Since we planned to describe importance by the proportion of patients rating each element "very important", a target sample size of 96 patients was set to ensure maximum confidence intervals of +/- $10 \%$ on proportions of patients. In discussion amongst our study team we agreed that a maximum of $+/-10 \%$ would provide a reasonable degree of precision on our proportions. We agreed that it was not practical or feasible to significantly extend the study period to recruit additional study participants in order to obtain narrower confidence limits.

Appendix C2: Comparing ages between responders and non-responders

Table C2-1 shows the age distribution of responders and non-responders, $\mathrm{p}=0.90$.

\begin{tabular}{|l|l|l|l|}
\hline & $\begin{array}{l}\text { Age }<70 \\
\mathrm{~N}(\%)\end{array}$ & $\begin{array}{l}\text { Age } \geq 70 \\
\mathrm{~N}(\%)\end{array}$ & Total \\
\hline Non responder & $17(45)$ & $21(55)$ & 38 \\
\hline Responder & $47(44)$ & $61(56)$ & 108 \\
\hline Total & 64 & 82 & $146^{*}$ \\
\hline
\end{tabular}

*Although there were 147 patients who consented to participate in this study, one patient's treatment was discontinued and therefore became ineligible (Figure B1, Appendix B). 


\section{Appendix C3: Assumptions of Generalized Estimating Equations}

Generalized Estimating Equations (GEE) assumes that data is missing completely at random (MCAR). This assumption is not likely met in our dataset, but we decided not to use imputation to address this. Previous research has shown imputation is not necessarily needed when using GEE as results on incomplete datasets are comparable to results when imputation is used (193). Additionally, the amount of missing data in our study was low. For each patient, the median percentage of elements missing an importance rating was $0 \%$ (range $0 \%$ to $22 \%$, IQR $0 \%$ to $1 \%$ ).

The working correlation structure must be specified when using GEE to ensure parameters are estimated appropriately. We compared various correlation structures using the QIC for comparison, and although the "independent" structure resulted in the smallest QIC, we decided to use the "exchangeable" correlation structure instead. The exchangeable correlation structure assumes that correlations within a subject are equally correlated, which we felt was more appropriate than an independent correlation structure. When QIC values are similar, selecting a correlation matrix that makes more sense theoretically has been identified as an appropriate approach (194). However, fortunately GEE is robust to the choice of correlation structure even if we have misspecified the correlation matrix (195).

Table C3-1: QIC values for different GEE correlation structures

\begin{tabular}{|l|l|}
\hline Correlation structure & QIC value \\
\hline Exchangeable & 19279.6 \\
\hline Autoregressive & 22755.0 \\
\hline
\end{tabular}




\begin{tabular}{|l|l|}
\hline Independent & 19278.9 \\
\hline Unstructured & 19685.2 \\
\hline
\end{tabular}

\section{Appendix C4: Timing of module 1 in relation to the diagnosis}

After this study was published we completed a chart review. The median length of time from

diagnosis to the beginning of treatment in this study population was about 12 weeks (median 12.1 weeks, IQR 9.3-19.6). 


\section{Appendix D}

\section{E-Supplement for the Manuscript titled, "Development and Comparison of Methods to Identify Priorities for Improvement of the Quality of Personal Care in Patients Undergoing Radiotherapy for Prostate Cancer"}

\section{Appendix D1: Missing Responses and Sensitivity Analyses}

We conducted a sensitivity analysis to assess the impact of missing data on our ranking of priorities for quality improvement by the individual priority-based method. For each patient, missing responses were coded for importance and quality as "very important" and less than "very good", respectively. The elements of care were re-ranked based on the percentage of patients rating each one as a priority for quality improvement. The Spearman correlation coefficient comparing the new rank order to the original order was 1.0 and there were no changes in either the specific elements of care or in the rank order of the elements identified as the 10 highest priorities for quality improvement.

\section{Appendix D2: Assumptions of Generalized Estimating Equations}

Assumptions of GEE were outlined in Appendix C3 with respect to the analysis of the results of the importance ratings. However the same approach was used here; we did not use imputation to deal with missing data as it is not necessarily needed with GEE (193) and again, the amount of missing data was relatively low as described in the results. As a reminder, for each patient, the 
median number of elements missing an importance rating was 0 (range 0 to 32 , IQR 0 to 2), and the median number of elements missing a quality rating was 9 (range 0 to 49 , IQR 5 to 16). Again, we compared various correlation structures using the QIC. For simplicity, I have only shown the QIC for the models using the individual priority-based method. However again, we chose the "exchangeable" structure as we felt it was most appropriate for these data (194).

Table D2-1: QIC values for different correlation structures (comparing the top 10 to the bottom 10 using the individual priority-based method)

\begin{tabular}{|l|l|}
\hline Correlation structure & QIC value \\
\hline Exchangeable & 1368.4 \\
\hline Autoregressive & 1368.5 \\
\hline Independent & 1369.3 \\
\hline Unstructured & Not calculated (error) \\
\hline
\end{tabular}

Table D2-2: QIC values for different correlation structures (comparing the top 3 to the next 3 using the individual priority-based method)

\begin{tabular}{|l|l|}
\hline Correlation structure & QIC value \\
\hline Exchangeable & 705.3 \\
\hline Autoregressive & 705.7 \\
\hline Independent & 705.2 \\
\hline Unstructured & 705.6 \\
\hline
\end{tabular}

Table D2-3: QIC values for different correlation structures (comparing the top 5 to the next 5 using the individual priority-based method) 


\begin{tabular}{|l|l|}
\hline Correlation structure & QIC value \\
\hline Exchangeable & 1215.0 \\
\hline Autoregressive & 1215.2 \\
\hline Independent & 1215.2 \\
\hline Unstructured & $\begin{array}{l}\text { QIC calculated, but procedure terminated } \\
\text { due to errors }\end{array}$ \\
\hline
\end{tabular}

Table D2-4: QIC values for different correlation structures (comparing the top 10 to the next 10 using the individual priority-based method)

\begin{tabular}{|l|l|}
\hline Correlation structure & QIC value \\
\hline Exchangeable & 2061.7 \\
\hline Autoregressive & 2062.5 \\
\hline Independent & 2062.9 \\
\hline Unstructured & Not calculated (error) \\
\hline
\end{tabular}

Table D2-5: QIC values for different correlation structures (comparing the top 15 to the next 15 using the individual priority-based method)

\begin{tabular}{|l|l|}
\hline Correlation structure & QIC value \\
\hline Exchangeable & 2760.1 \\
\hline Autoregressive & 2061.0 \\
\hline Independent & 2761.3 \\
\hline Unstructured & Not calculated (error) \\
\hline
\end{tabular}




\section{Appendix D3: The full ranking of priorities for quality improvement identified by each method}

Table D3-1: The elements of care identified by each method for identifying targets for quality improvement

\begin{tabular}{|c|c|c|c|c|c|c|c|c|c|c|}
\hline \multirow[b]{3}{*}{ Element of Care } & \multicolumn{4}{|c|}{ Summary Ratings } & \multicolumn{6}{|c|}{ Methods* } \\
\hline & \multicolumn{2}{|c|}{ Quality } & \multicolumn{2}{|c|}{ Importance } & \multicolumn{2}{|c|}{$\begin{array}{c}\text { Individual priority- } \\
\text { based }\end{array}$} & \multicolumn{2}{|c|}{ Group priority-based } & \multicolumn{2}{|c|}{$\begin{array}{c}\text { Group ranking- } \\
\text { based }\end{array}$} \\
\hline & $\begin{array}{l}\text { Inverse } \\
\text { rank }\end{array}$ & $\begin{array}{l}\text { \% "Very } \\
\text { Good" (95\% } \\
\text { CI) }\end{array}$ & Rank & $\begin{array}{l}\text { \% "Very } \\
\text { Important" } \\
(95 \% \mathrm{CI})\end{array}$ & Rank & $\begin{array}{c}\text { \% "very } \\
\text { good" AND } \\
\text { "very } \\
\text { important" }\end{array}$ & Rank & $\begin{array}{l}(100 \%-\% \\
\text { "very } \\
\text { good")*(\% } \\
\text { "very } \\
\text { important") }\end{array}$ & Rank & $\begin{array}{l}\text { Lower rank } \\
\text { of inverse } \\
\text { quality or } \\
\text { importance }\end{array}$ \\
\hline $\begin{array}{l}\text { Someone on the healthcare team } \\
\text { explains that radiation treatment } \\
\text { cannot usually be given to the } \\
\text { prostate again if it is not successful } \\
\text { the first time }\end{array}$ & 4 & $\begin{array}{c}39.8 \\
(29.8,50.5)\end{array}$ & 49 & $\begin{array}{c}69.9 \\
(60.1,78.6)\end{array}$ & 1 & $\begin{array}{c}40.9 \\
(30.8,51.6)\end{array}$ & 1 & 4209.4 & 5 & 49 \\
\hline $\begin{array}{l}\text { Someone on the healthcare team } \\
\text { explains the other treatments that are } \\
\text { available if radiation treatment is not } \\
\text { successful }\end{array}$ & 5 & $\begin{array}{c}41.9 \\
(31.8,52.6)\end{array}$ & 71 & $\begin{array}{c}63.4 \\
(53.2,72.7)\end{array}$ & 2 & $\begin{array}{c}34.8 \\
(25.2,45.4)\end{array}$ & 2 & 3679.3 & 22 & 71 \\
\hline $\begin{array}{l}\text { There is somewhere convenient to } \\
\text { park }\end{array}$ & 2 & $\begin{array}{c}35.2 \\
(26.2,45.2)\end{array}$ & 113 & $\begin{array}{c}45.8 \\
(36.1,55.7)\end{array}$ & 3 & $\begin{array}{c}29.5 \\
(21.0,39.2)\end{array}$ & 3 & 2965.4 & 82 & 113 \\
\hline $\begin{array}{l}\text { Someone on the healthcare team } \\
\text { explains that radiation treatment may } \\
\text { permanently affect bowel function }\end{array}$ & 33 & $\begin{array}{c}65.0 \\
(55.0,74.2)\end{array}$ & 40 & $\begin{array}{c}73.3 \\
(63.8,81.5)\end{array}$ & 4 & $\begin{array}{c}23.5 \\
(15.7,33.0)\end{array}$ & 9 & 2562.9 & 2 & 40 \\
\hline $\begin{array}{l}\text { Someone on the healthcare team } \\
\text { explains what prostate cancer is and } \\
\text { how it can affect the patient's health }\end{array}$ & 12 & $\begin{array}{c}50.0 \\
(39.6,60.4)\end{array}$ & 86 & $\begin{array}{c}58.6 \\
(48.6,68.2)\end{array}$ & 5 & $\begin{array}{c}22.9 \\
(15.0,32.6)\end{array}$ & 4 & 2932.5 & 38 & 86 \\
\hline Someone on the healthcare team & 30 & 63.1 & 42 & 72.4 & 6 & 22.6 & 6 & 2670.1 & 3 & 42 \\
\hline
\end{tabular}




\begin{tabular}{|c|c|c|c|c|c|c|c|c|c|c|}
\hline $\begin{array}{l}\text { explains that radiation treatment may } \\
\text { permanently affect bladder function }\end{array}$ & & $(53.0,72.4)$ & & $(62.8,80.7)$ & & $(14.9,31.9)$ & & & & \\
\hline $\begin{array}{l}\text { The radiation oncologist makes sure } \\
\text { the patient knows that the cancer is } \\
\text { confined to the prostate, and there is } \\
\text { no sign that it has spread to any other } \\
\text { part of the body }\end{array}$ & 66 & $\begin{array}{c}77.7 \\
(68.4,85.3)\end{array}$ & 2 & $\begin{array}{c}93.5 \\
(87.0,97.3)\end{array}$ & 7 & $\begin{array}{c}20.4 \\
(13.1,29.5)\end{array}$ & 20 & 2087.0 & 16 & 66 \\
\hline $\begin{array}{l}\text { Someone on the healthcare team } \\
\text { explains when the patient can resume } \\
\text { all of his previous activities after } \\
\text { radiation treatment }\end{array}$ & 16 & $\begin{array}{c}55.1 \\
(44.1,65.6)\end{array}$ & 100 & $\begin{array}{c}54.2 \\
(44.3,63.9)\end{array}$ & 8 & $\begin{array}{c}20.2 \\
(12.4,30.1)\end{array}$ & 12 & 2436.2 & 58 & 100 \\
\hline $\begin{array}{l}\text { The patient is given enough } \\
\text { information to understand how the } \\
\text { radiation treatment works }\end{array}$ & 15 & $\begin{array}{c}54.7 \\
(44.8,64.4)\end{array}$ & 73 & $\begin{array}{c}62.3 \\
(52.3,71.5)\end{array}$ & 9 & $\begin{array}{c}20.0 \\
(12.8,28.9)\end{array}$ & 5 & 2819.1 & 23 & 73 \\
\hline $\begin{array}{l}\text { The radiation oncologist gives the } \\
\text { patient enough information about the } \\
\text { chance of curing his cancer with each } \\
\text { treatment option }\end{array}$ & 38 & $\begin{array}{c}66.3 \\
(56.2,75.4)\end{array}$ & 26 & $\begin{array}{c}78.1 \\
(69.0,85.6)\end{array}$ & 10 & $\begin{array}{c}19.8 \\
(12.5,28.9)\end{array}$ & 7 & 2628.8 & 1 & 38 \\
\hline $\begin{array}{l}\text { The radiation oncologist makes sure } \\
\text { the patient knows the stage of his } \\
\text { cancer and understands what that } \\
\text { means }\end{array}$ & 52 & $\begin{array}{c}73.3 \\
(64.5,81.6)\end{array}$ & 12 & $\begin{array}{c}83.2 \\
(74.7,89.7)\end{array}$ & 10 & $\begin{array}{c}19.8 \\
(12.5,28.9)\end{array}$ & 15 & 2223.4 & 8 & 52 \\
\hline $\begin{array}{l}\text { The patient is made aware of who to } \\
\text { contact if he is concerned about the } \\
\text { cancer coming back }\end{array}$ & 42 & $\begin{array}{c}67.4 \\
(56.5,77.2)\end{array}$ & 34 & $\begin{array}{c}75.9 \\
(66.8,83.6)\end{array}$ & 12 & $\begin{array}{c}19.8 \\
(12.0,29.8)\end{array}$ & 11 & 2472.3 & 3 & 42 \\
\hline $\begin{array}{l}\text { Someone on the healthcare team } \\
\text { gives enough information and } \\
\text { direction to the patient about how to } \\
\text { care for himself after radiation } \\
\text { treatment }\end{array}$ & 20 & $\begin{array}{c}57.6 \\
(46.9,67.8)\end{array}$ & 102 & $\begin{array}{c}53.8 \\
(43.8,63.5)\end{array}$ & 13 & $\begin{array}{c}19.6 \\
(12.0,29.2)\end{array}$ & 14 & 2279.3 & 62 & 102 \\
\hline $\begin{array}{l}\text { Someone at the cancer centre } \\
\text { arranges for the patient to receive } \\
\text { any help he needs in dealing with his } \\
\text { anxiety about the diagnosis }\end{array}$ & 21 & $\begin{array}{c}59.1 \\
(36.4,79.3)\end{array}$ & 77 & $\begin{array}{c}60.9 \\
(38.5,80.3)\end{array}$ & 14 & $\begin{array}{c}18.2 \\
(5.2,40.3)\end{array}$ & 10 & 2490.2 & 29 & 77 \\
\hline Someone on the healthcare team & 29 & 63.0 & 64 & 65.7 & 15 & 17.4 & 13 & 2428.6 & 14 & 64 \\
\hline
\end{tabular}




\begin{tabular}{|c|c|c|c|c|c|c|c|c|c|c|}
\hline $\begin{array}{l}\text { explains who to contact if additional } \\
\text { care is needed in recovery after } \\
\text { radiation treatment }\end{array}$ & & $(52.3,72.9)$ & & $(55.8,74.7)$ & & $(10.3,26.7)$ & & & & \\
\hline $\begin{array}{l}\text { The radiation oncologist gives the } \\
\text { patient enough information about the } \\
\text { side effects of each treatment option }\end{array}$ & 60 & $\begin{array}{c}76.0 \\
(66.6,83.8)\end{array}$ & 10 & $\begin{array}{c}84.8 \\
(76.4,91.0)\end{array}$ & 16 & $\begin{array}{c}17.3 \\
(10.6,26.0)\end{array}$ & 25 & 2037.6 & 11 & 60 \\
\hline $\begin{array}{l}\text { The radiation oncologist tells the } \\
\text { patient about his PSA level and } \\
\text { explains what that means }\end{array}$ & 41 & $\begin{array}{c}67.3 \\
(57.3,76.3)\end{array}$ & 62 & $\begin{array}{c}66.4 \\
(56.6,75.2)\end{array}$ & 17 & $\begin{array}{c}16.8 \\
(10.1,25.6)\end{array}$ & 17 & 2168.0 & 13 & 62 \\
\hline $\begin{array}{l}\text { The radiation oncologist makes sure } \\
\text { the patient knows the grade of his } \\
\text { cancer and understands what that } \\
\text { means }\end{array}$ & 58 & $\begin{array}{c}75.5 \\
(66.0,83.5)\end{array}$ & 9 & $\begin{array}{c}85.0 \\
(76.9,91.2)\end{array}$ & 18 & $\begin{array}{c}16.7 \\
(10.0,25.3)\end{array}$ & 21 & 2084.6 & 10 & 58 \\
\hline $\begin{array}{l}\text { Someone on the healthcare team } \\
\text { explains that the PSA level is all that } \\
\text { is needed to tell if the cancer is under } \\
\text { control or not }\end{array}$ & 50 & $\begin{array}{c}72.4 \\
(61.8,81.5)\end{array}$ & 51 & $\begin{array}{c}69.5 \\
(59.8,78.1)\end{array}$ & 19 & $\begin{array}{c}16.1 \\
(9.1,25.5)\end{array}$ & 27 & 1918.1 & 6 & 51 \\
\hline $\begin{array}{l}\text { Once the decision to have radiation } \\
\text { treatment has been made, the patient } \\
\text { is given enough information about } \\
\text { how long he will have to wait to start } \\
\text { treatment }\end{array}$ & 31 & $\begin{array}{c}64.5 \\
(54.6,73.5)\end{array}$ & 80 & $\begin{array}{c}60.2 \\
(50.3,69.5)\end{array}$ & 20 & $\begin{array}{c}15.9 \\
(9.5,24.2)\end{array}$ & 18 & 2137.3 & 32 & 80 \\
\hline $\begin{array}{l}\text { Someone on the healthcare team } \\
\text { explains how the patient should } \\
\text { modify his diet to avoid bowel upset } \\
\text { during the course of radiation } \\
\text { treatment }\end{array}$ & 25 & $\begin{array}{c}61.7 \\
(51.8,70.9)\end{array}$ & 104 & $\begin{array}{c}53.7 \\
(43.8,63.4)\end{array}$ & 20 & $\begin{array}{c}15.9 \\
(9.5,24.2)\end{array}$ & 24 & 2057.8 & 66 & 104 \\
\hline $\begin{array}{l}\text { Someone on the healthcare team } \\
\text { explains that the course of treatment } \\
\text { needs to be completed without taking } \\
\text { a break (of longer than a few days) }\end{array}$ & 40 & $\begin{array}{c}67.0 \\
(57.0,75.9)\end{array}$ & 92 & $\begin{array}{c}57.0 \\
(47.1,66.5)\end{array}$ & 22 & $\begin{array}{c}15.5 \\
(9.2,24.0)\end{array}$ & 29 & 1881.9 & 46 & 92 \\
\hline $\begin{array}{l}\text { The radiation oncologist makes sure } \\
\text { the patient understands the results of } \\
\text { the biopsy of the prostate, the blood } \\
\text { tests, and any x-rays and scans he }\end{array}$ & 61 & $\begin{array}{c}76.0 \\
(66.6,83.8)\end{array}$ & 35 & $\begin{array}{c}75.7 \\
(66.5,83.5)\end{array}$ & 23 & $\begin{array}{c}15.4 \\
(9.1,23.8)\end{array}$ & 32 & 1819.8 & 12 & 61 \\
\hline
\end{tabular}




\begin{tabular}{|c|c|c|c|c|c|c|c|c|c|c|}
\hline may have had & & & & & & & & & & \\
\hline $\begin{array}{l}\text { Someone on the healthcare team } \\
\text { answers any questions the patient has } \\
\text { about the possible causes of prostate } \\
\text { cancer }\end{array}$ & 13 & $\begin{array}{c}53.8 \\
(37.2,69.9)\end{array}$ & 96 & $\begin{array}{c}56.1 \\
(39.8,71.5)\end{array}$ & 23 & $\begin{array}{c}15.4 \\
(5.9,30.5)\end{array}$ & 8 & 2589.0 & 52 & 96 \\
\hline $\begin{array}{l}\text { The patient is made aware that he has } \\
\text { the right to get a second opinion } \\
\text { from another radiation oncologist }\end{array}$ & 9 & $\begin{array}{c}47.3 \\
(36.9,57.9)\end{array}$ & 126 & $\begin{array}{c}38.1 \\
(28.8,48.1)\end{array}$ & 25 & $\begin{array}{c}15.2 \\
(8.6,24.2)\end{array}$ & 26 & 2007.5 & 108 & 126 \\
\hline $\begin{array}{l}\text { The patient is given enough } \\
\text { information about the chance of } \\
\text { curing his cancer with radiation } \\
\text { treatment }\end{array}$ & 51 & $\begin{array}{c}73.1 \\
(63.5,81.3)\end{array}$ & 28 & $\begin{array}{c}77.4 \\
(68.2,84.9)\end{array}$ & 26 & $\begin{array}{c}14.6 \\
(8.4,22.9)\end{array}$ & 22 & 2082.5 & 6 & 51 \\
\hline $\begin{array}{l}\text { Someone on the healthcare team } \\
\text { explains that doctors will be } \\
\text { monitoring PSA levels at regular } \\
\text { intervals during follow-up from } \\
\text { radiation treatment }\end{array}$ & 73 & $\begin{array}{c}79.4 \\
(70.0,86.9)\end{array}$ & 41 & $\begin{array}{c}73.2 \\
(63.8,81.2)\end{array}$ & 27 & $\begin{array}{c}14.4 \\
(8.1,23.0)\end{array}$ & 50 & 1508.4 & 23 & 73 \\
\hline $\begin{array}{l}\text { The radiation oncologist makes sure } \\
\text { the patient understands the benefits } \\
\text { of radiation treatment and its side } \\
\text { effects before asking for consent to } \\
\text { have radiation treatment }\end{array}$ & 64 & $\begin{array}{c}77.4 \\
(68.2,84.9)\end{array}$ & 16 & $\begin{array}{c}81.3 \\
(72.6,88.2)\end{array}$ & 28 & $\begin{array}{c}14.3 \\
(8.2,22.5)\end{array}$ & 30 & 1840.9 & 14 & 64 \\
\hline $\begin{array}{l}\text { The patient is given enough } \\
\text { information about how the radiation } \\
\text { treatment is planned }\end{array}$ & 27 & $\begin{array}{c}62.9 \\
(52.9,72.1)\end{array}$ & 97 & $\begin{array}{c}56.1 \\
(46.2,65.7)\end{array}$ & 29 & $\begin{array}{c}13.6 \\
(7.6,21.8)\end{array}$ & 23 & 2082.4 & 54 & 97 \\
\hline $\begin{array}{l}\text { Someone on the healthcare team } \\
\text { explains that prostate cancer is not } \\
\text { infectious and that it cannot be } \\
\text { transmitted to anyone else }\end{array}$ & 11 & $\begin{array}{c}50.0 \\
(39.0,61.0)\end{array}$ & 119 & $\begin{array}{c}42.6 \\
(32.8,52.8)\end{array}$ & 30 & $\begin{array}{c}12.8 \\
(6.6,21.7)\end{array}$ & 19 & 2128.5 & 94 & 119 \\
\hline $\begin{array}{l}\text { Someone on the healthcare team } \\
\text { explains that radiation treatment may } \\
\text { permanently affect sexual } \\
\text { functioning }\end{array}$ & 57 & $\begin{array}{c}74.8 \\
(65.4,82.7)\end{array}$ & 82 & $\begin{array}{c}59.8 \\
(49.9,69.2)\end{array}$ & 31 & $\begin{array}{c}12.3 \\
(6.7,20.1)\end{array}$ & 49 & 1509.0 & 33 & 82 \\
\hline $\begin{array}{l}\text { The cancer centre appears to be clean } \\
\text { and well looked after }\end{array}$ & 96 & $\begin{array}{c}85.8 \\
(77.7,91.9)\end{array}$ & 48 & $\begin{array}{c}70.0 \\
(60.5,78.6)\end{array}$ & 31 & $\begin{array}{c}12.3 \\
(6.7,20.1)\end{array}$ & 83 & 991.8 & 52 & 96 \\
\hline
\end{tabular}




\begin{tabular}{|c|c|c|c|c|c|c|c|c|c|c|}
\hline $\begin{array}{l}\text { The patient has a short wait to get an } \\
\text { appointment to see the radiation } \\
\text { oncologist for the first time }\end{array}$ & 54 & $\begin{array}{c}73.6 \\
(64.1,81.7)\end{array}$ & 107 & $\begin{array}{c}51.9 \\
(42.0,61.7)\end{array}$ & 31 & $\begin{array}{c}12.3 \\
(6.7,20.1)\end{array}$ & 61 & 1370.9 & 70 & 107 \\
\hline $\begin{array}{l}\text { The patient is given enough } \\
\text { information about how the treatment } \\
\text { is scheduled and flexibility in the } \\
\text { daily appointment times }\end{array}$ & 19 & $\begin{array}{c}57.0 \\
(47.1,66.5)\end{array}$ & 109 & $\begin{array}{c}51.4 \\
(41.5,61.2)\end{array}$ & 31 & $\begin{array}{c}12.3 \\
(6.7,20.1)\end{array}$ & 16 & 2209.7 & 74 & 109 \\
\hline $\begin{array}{l}\text { The patient's family physician is } \\
\text { kept informed about the cancer care }\end{array}$ & 46 & $\begin{array}{c}69.2 \\
(57.8,79.2)\end{array}$ & 91 & $\begin{array}{c}57.4 \\
(47.5,66.9)\end{array}$ & 35 & $\begin{array}{c}11.5 \\
(5.4,20.8)\end{array}$ & 35 & 1766.5 & 44 & 91 \\
\hline $\begin{array}{l}\text { The patient is given enough } \\
\text { information about the possible side } \\
\text { effects of radiation treatment }\end{array}$ & 77 & $\begin{array}{c}80.4 \\
(71.6,87.4)\end{array}$ & 21 & $\begin{array}{c}80.2 \\
(71.3,87.3)\end{array}$ & 36 & $\begin{array}{c}11.3 \\
(6.0,18.9)\end{array}$ & 42 & 1574.1 & 29 & 77 \\
\hline $\begin{array}{l}\text { The patient has a short wait in the } \\
\text { waiting room for daily radiation } \\
\text { treatment }\end{array}$ & 49 & $\begin{array}{c}72.2 \\
(62.8,80.4)\end{array}$ & 129 & $\begin{array}{c}36.1 \\
(27.1,45.9)\end{array}$ & 37 & $\begin{array}{c}11.1 \\
(5.9,18.6)\end{array}$ & 82 & 1003.1 & 114 & 129 \\
\hline $\begin{array}{l}\text { The patient is aware that no one else } \\
\text { other than him and the healthcare } \\
\text { professionals looking after him are } \\
\text { able to see his medical records } \\
\text { without his permission }\end{array}$ & 59 & $\begin{array}{c}75.6 \\
(64.9,84.4)\end{array}$ & 88 & $\begin{array}{c}58.3 \\
(48.4,67.8)\end{array}$ & 38 & $\begin{array}{c}11.0 \\
(5.1,19.8)\end{array}$ & 57 & 1422.7 & 40 & 88 \\
\hline $\begin{array}{l}\text { The information about treatment } \\
\text { options is provided to the patient } \\
\text { before any decision is made about } \\
\text { the way he will be treated }\end{array}$ & 74 & $\begin{array}{c}79.4 \\
(70.3,86.8)\end{array}$ & 25 & $\begin{array}{c}78.1 \\
(69.0,85.6)\end{array}$ & 39 & $\begin{array}{c}10.8 \\
(5.5,18.5)\end{array}$ & 39 & 1608.1 & 25 & 74 \\
\hline $\begin{array}{l}\text { Someone on the healthcare team } \\
\text { explains the arrangements for follow } \\
\text { - up care after the radiation treatment } \\
\text { is over }\end{array}$ & 68 & $\begin{array}{c}77.9 \\
(68.2,85.8)\end{array}$ & 53 & $\begin{array}{c}68.9 \\
(59.1,77.5)\end{array}$ & 40 & $\begin{array}{c}10.6 \\
(5.2,18.7)\end{array}$ & 46 & 1522.7 & 18 & 68 \\
\hline $\begin{array}{l}\text { Before radiation treatment starts, the } \\
\text { patient is given enough information } \\
\text { about what will happen each day } \\
\text { when he comes for treatment }\end{array}$ & 34 & $\begin{array}{c}65.1 \\
(55.2,74.1)\end{array}$ & 108 & $\begin{array}{c}51.8 \\
(42.0,61.6)\end{array}$ & 41 & $\begin{array}{c}10.4 \\
(5.3,17.8)\end{array}$ & 33 & 1810.1 & 72 & 108 \\
\hline $\begin{array}{l}\text { The patient has a short wait in the } \\
\text { waiting room when he comes to the }\end{array}$ & 44 & $\begin{array}{c}67.9 \\
(58.2,76.7) \\
\end{array}$ & 135 & $\begin{array}{c}26.4 \\
(18.3,35.9) \\
\end{array}$ & 41 & $\begin{array}{c}10.4 \\
(5.3,17.8) \\
\end{array}$ & 97 & 847.6 & 126 & 135 \\
\hline
\end{tabular}




\begin{tabular}{|c|c|c|c|c|c|c|c|c|c|c|}
\hline \multicolumn{11}{|l|}{$\begin{array}{l}\text { cancer centre to see the radiation } \\
\text { oncologist for the first time }\end{array}$} \\
\hline $\begin{array}{l}\text { A social worker is available to } \\
\text { provide advice on financial and } \\
\text { social issues arising from the } \\
\text { diagnosis }\end{array}$ & 3 & $\begin{array}{c}39.7 \\
(27.0,53.4)\end{array}$ & 136 & $\begin{array}{c}24.7 \\
(16.5,34.4)\end{array}$ & 43 & $\begin{array}{c}10.3 \\
(3.9,21.2)\end{array}$ & 52 & 1492.8 & 127 & 136 \\
\hline $\begin{array}{l}\text { Someone at the cancer centre gives } \\
\text { the patient information about support } \\
\text { groups in his area for patients and/or } \\
\text { family members }\end{array}$ & 1 & $\begin{array}{c}33.3 \\
(23.1,44.9)\end{array}$ & 137 & $\begin{array}{c}23.8 \\
(15.9,33.3)\end{array}$ & 44 & $\begin{array}{c}10.3 \\
(4.5,19.2)\end{array}$ & 41 & 1584.1 & 128 & 137 \\
\hline $\begin{array}{l}\text { Someone on the healthcare team } \\
\text { other than the radiation oncologist is } \\
\text { available to provide support to the } \\
\text { patient in making the decision about } \\
\text { treatment }\end{array}$ & 14 & $\begin{array}{c}53.9 \\
(43.0,64.6)\end{array}$ & 132 & $\begin{array}{c}34.6 \\
(25.6,44.6)\end{array}$ & 45 & $\begin{array}{c}10.2 \\
(4.8,18.5)\end{array}$ & 40 & 1594.9 & 120 & 132 \\
\hline $\begin{array}{l}\text { The radiation oncologist reads the } \\
\text { patient's previous medical records } \\
\text { before seeing the patient for the first } \\
\text { time }\end{array}$ & 69 & $\begin{array}{c}78.3 \\
(68.4,86.2)\end{array}$ & 52 & $\begin{array}{c}69.2 \\
(59.4,77.9)\end{array}$ & 46 & $\begin{array}{c}9.8 \\
(4.6,17.8)\end{array}$ & 51 & 1505.1 & 19 & 69 \\
\hline $\begin{array}{l}\text { The patient gets all the help he needs } \\
\text { from the radiation oncologist to } \\
\text { make up his mind about which } \\
\text { treatment to have }\end{array}$ & 93 & $\begin{array}{c}84.6 \\
(76.2,90.9)\end{array}$ & 22 & $\begin{array}{c}80.2 \\
(71.3,87.3)\end{array}$ & 47 & $\begin{array}{c}9.7 \\
(4.8,17.1)\end{array}$ & 71 & 1233.3 & 48 & 93 \\
\hline $\begin{array}{l}\text { The patient is aware that he has a } \\
\text { right to see all the information in his } \\
\text { medical record }\end{array}$ & 47 & $\begin{array}{c}69.9 \\
(59.5,79.0)\end{array}$ & 101 & $\begin{array}{c}54.2 \\
(44.3,63.9)\end{array}$ & 48 & $\begin{array}{c}9.7 \\
(4.5,17.6)\end{array}$ & 38 & 1632.3 & 60 & 101 \\
\hline $\begin{array}{l}\text { The patient gets enough information } \\
\text { from the radiation oncologist to be } \\
\text { able to participate in the decision } \\
\text { about treatment }\end{array}$ & 82 & $\begin{array}{c}82.9 \\
(74.3,89.5)\end{array}$ & 33 & $\begin{array}{c}76.2 \\
(66.9,84.0)\end{array}$ & 49 & $\begin{array}{c}9.6 \\
(4.7,17.0)\end{array}$ & 66 & 1305.9 & 33 & 82 \\
\hline $\begin{array}{l}\text { The radiation oncologist explains to } \\
\text { the patient that he can change his } \\
\text { mind about which treatment to have } \\
\text { as long as he does so before the } \\
\text { treatment starts }\end{array}$ & 35 & $\begin{array}{c}66.0 \\
(55.7,75.3)\end{array}$ & 95 & $\begin{array}{c}56.2 \\
(46.2,65.9)\end{array}$ & 50 & $\begin{array}{c}9.4 \\
(4.4,17.0)\end{array}$ & 28 & 1911.6 & 51 & 95 \\
\hline
\end{tabular}




\begin{tabular}{|c|c|c|c|c|c|c|c|c|c|c|}
\hline $\begin{array}{l}\text { The radiation oncologist asks the } \\
\text { patient about any other medical } \\
\text { problems he may have }\end{array}$ & 62 & $\begin{array}{c}76.0 \\
(66.4,84.0)\end{array}$ & 69 & $\begin{array}{c}63.8 \\
(53.8,73.0)\end{array}$ & 51 & $\begin{array}{c}9.0 \\
(4.2,16.4)\end{array}$ & 45 & 1531.4 & 19 & 69 \\
\hline $\begin{array}{l}\text { The radiation oncologist is aware of } \\
\text { the test results and has the results } \\
\text { available when seeing the patient for } \\
\text { the first time }\end{array}$ & 85 & $\begin{array}{c}83.2 \\
(74.4,89.9)\end{array}$ & 14 & $\begin{array}{c}82.7 \\
(74.0,89.4)\end{array}$ & 51 & $\begin{array}{c}9.0 \\
(4.2,16.4)\end{array}$ & 60 & 1391.7 & 37 & 85 \\
\hline $\begin{array}{l}\text { The patient is encouraged by the } \\
\text { cancer center to bring a relative or } \\
\text { friend along to the first appointment } \\
\text { with the radiation oncologist }\end{array}$ & 32 & $\begin{array}{c}65.0 \\
(54.8,74.3)\end{array}$ & 116 & $\begin{array}{c}43.4 \\
(33.8,53.4)\end{array}$ & 51 & $\begin{array}{c}9.0 \\
(4.2,16.4)\end{array}$ & 48 & 1519.0 & 86 & 116 \\
\hline $\begin{array}{l}\text { The radiation oncologist explains } \\
\text { what each treatment option involves }\end{array}$ & 53 & $\begin{array}{c}73.3 \\
(64.5,81.6) \\
\end{array}$ & 56 & $\begin{array}{c}68.3 \\
(58.4,77.0) \\
\end{array}$ & 54 & $\begin{array}{c}8.9 \\
(4.2,16.2) \\
\end{array}$ & 31 & 1824.9 & 9 & 56 \\
\hline $\begin{array}{l}\text { The radiation oncologist makes sure } \\
\text { the patient understands the treatment } \\
\text { options before making up his mind } \\
\text { about which treatment to have }\end{array}$ & 94 & $\begin{array}{c}85.3 \\
(76.9,91.5)\end{array}$ & 29 & $\begin{array}{c}77.4 \\
(68.2,84.9)\end{array}$ & 54 & $\begin{array}{c}8.9 \\
(4.2,16.2)\end{array}$ & 73 & 1138.0 & 49 & 94 \\
\hline $\begin{array}{l}\text { The radiation oncologist explains the } \\
\text { different forms of treatment that are } \\
\text { available for prostate cancer }\end{array}$ & 92 & $\begin{array}{c}84.3 \\
(75.8,90.8)\end{array}$ & 15 & $\begin{array}{c}82.1 \\
(73.4,88.8)\end{array}$ & 56 & $\begin{array}{c}8.8 \\
(4.1,16.1)\end{array}$ & 68 & 1287.8 & 46 & 92 \\
\hline $\begin{array}{l}\text { The radiation oncologist sees the } \\
\text { patient at least once a week during } \\
\text { the course of radiation treatment }\end{array}$ & 18 & $\begin{array}{c}56.7 \\
(46.6,66.4)\end{array}$ & 130 & $\begin{array}{c}35.9 \\
(26.7,46.0)\end{array}$ & 56 & $\begin{array}{c}8.8 \\
(4.1,16.1)\end{array}$ & 43 & 1554.3 & 116 & 130 \\
\hline $\begin{array}{l}\text { Someone on the healthcare team } \\
\text { gives the patient written information } \\
\text { about the side effects of each } \\
\text { treatment option }\end{array}$ & 55 & $\begin{array}{c}74.3 \\
(64.8,82.3)\end{array}$ & 66 & $\begin{array}{c}65.1 \\
(55.2,74.1)\end{array}$ & 58 & $\begin{array}{c}8.6 \\
(4.0,15.8)\end{array}$ & 37 & 1673.5 & 16 & 66 \\
\hline $\begin{array}{l}\text { Someone on the healthcare team is } \\
\text { always available to answer the } \\
\text { patient's questions and advise on the } \\
\text { management of side effects during } \\
\text { the course of radiation treatment }\end{array}$ & 76 & $\begin{array}{c}80.0 \\
(71.1,87.2)\end{array}$ & 67 & $\begin{array}{c}64.8 \\
(55.0,73.8)\end{array}$ & 59 & $\begin{array}{c}8.6 \\
(4.0,15.6)\end{array}$ & 67 & 1296.2 & 27 & 76 \\
\hline $\begin{array}{l}\text { Directions and signs inside and } \\
\text { outside the cancer centre are easy to } \\
\text { understand }\end{array}$ & 23 & $\begin{array}{c}61.3 \\
(51.4,70.6)\end{array}$ & 123 & $\begin{array}{c}39.6 \\
(30.2,49.6)\end{array}$ & 59 & $\begin{array}{c}8.6 \\
(4.0,15.6)\end{array}$ & 44 & 1532.5 & 101 & 123 \\
\hline
\end{tabular}




\begin{tabular}{|c|c|c|c|c|c|c|c|c|c|c|}
\hline $\begin{array}{l}\text { Someone on the healthcare team } \\
\text { explains that radiation treatment } \\
\text { involves the use of high energy rays } \\
\text { directed at the prostate from outside } \\
\text { the body }\end{array}$ & 63 & $\begin{array}{c}76.6 \\
(67.5,84.3)\end{array}$ & 74 & $\begin{array}{c}61.7 \\
(51.8,70.9)\end{array}$ & 61 & $\begin{array}{c}8.5 \\
(4.0,15.5)\end{array}$ & 56 & 1440.8 & 25 & 74 \\
\hline $\begin{array}{l}\text { The patient trusts the radiation } \\
\text { oncologist to look after him properly }\end{array}$ & 109 & $\begin{array}{c}88.7 \\
(81.1,94.0)\end{array}$ & 3 & $\begin{array}{c}91.6 \\
(84.6,96.1)\end{array}$ & 61 & $\begin{array}{c}8.5 \\
(4.0,15.5)\end{array}$ & 79 & 1036.8 & 74 & 109 \\
\hline $\begin{array}{l}\text { The radiation oncologist is } \\
\text { knowledgeable and experienced in } \\
\text { dealing with prostate cancer }\end{array}$ & 120 & $\begin{array}{c}91.5 \\
(84.5,96.0)\end{array}$ & 1 & $\begin{array}{c}95.3 \\
(89.4,98.5)\end{array}$ & 61 & $\begin{array}{c}8.5 \\
(4.0,15.5)\end{array}$ & 101 & 809.4 & 96 & 120 \\
\hline $\begin{array}{l}\text { Once the treatment starts, someone } \\
\text { on the healthcare team reminds the } \\
\text { patient of the potential side effects to } \\
\text { expect during the course of radiation } \\
\text { treatment }\end{array}$ & 43 & $\begin{array}{c}67.6 \\
(57.9,76.3)\end{array}$ & 115 & $\begin{array}{c}43.5 \\
(34.0,53.4)\end{array}$ & 64 & $\begin{array}{c}8.3 \\
(3.9,15.2)\end{array}$ & 58 & 1410.5 & 86 & 115 \\
\hline $\begin{array}{l}\text { The patient can find his way around } \\
\text { the cancer centre easily }\end{array}$ & 28 & $\begin{array}{c}63.0 \\
(53.1,72.1) \\
\end{array}$ & 127 & $\begin{array}{c}38.0 \\
(28.8,47.8)\end{array}$ & 64 & $\begin{array}{c}8.3 \\
(3.9,15.2) \\
\end{array}$ & 59 & 1406.0 & 110 & 127 \\
\hline $\begin{array}{l}\text { The cancer centre provides resources } \\
\text { to assist the patient in understanding } \\
\text { and dealing with prostate cancer (e.g. } \\
\text { staffed information services, library } \\
\text { of books and DVDs about cancer) }\end{array}$ & 8 & $\begin{array}{c}44.8 \\
(34.2,55.9)\end{array}$ & 133 & $\begin{array}{c}32.7 \\
(23.7,42.7)\end{array}$ & 66 & $\begin{array}{c}8.0 \\
(3.3,15.9)\end{array}$ & 34 & 1802.4 & 122 & 133 \\
\hline $\begin{array}{l}\text { The patient understands that there is } \\
\text { no immediate rush to make a } \\
\text { decision about treatment although } \\
\text { it's best to make a decision within a } \\
\text { week or two }\end{array}$ & 81 & $\begin{array}{c}82.5 \\
(73.8,89.3)\end{array}$ & 83 & $\begin{array}{c}59.4 \\
(49.5,68.9)\end{array}$ & 67 & $\begin{array}{c}7.8 \\
(3.4,14.9)\end{array}$ & 78 & 1038.8 & 35 & 83 \\
\hline $\begin{array}{l}\text { The patient has enough time with the } \\
\text { radiation oncologist to get all of the } \\
\text { information he needs about treatment } \\
\text { options }\end{array}$ & 83 & $\begin{array}{c}82.9 \\
(74.3,89.5)\end{array}$ & 32 & $\begin{array}{c}76.4 \\
(67.2,84.1)\end{array}$ & 68 & $\begin{array}{c}7.6 \\
(3.4,14.5)\end{array}$ & 65 & 1309.8 & 35 & 83 \\
\hline $\begin{array}{l}\text { The patient has enough time to } \\
\text { consider the treatment options before } \\
\text { it is decided how he will be treated }\end{array}$ & 90 & $\begin{array}{c}84.2 \\
(75.6,90.7)\end{array}$ & 50 & $\begin{array}{c}70.0 \\
(60.1,78.6)\end{array}$ & 69 & $\begin{array}{c}6.9 \\
(2.8,13.8)\end{array}$ & 75 & 1107.2 & 42 & 90 \\
\hline Someone on the healthcare team & 22 & 60.2 & 125 & 38.2 & 70 & 6.9 & 47 & 1520.8 & 106 & 125 \\
\hline
\end{tabular}




\begin{tabular}{|c|c|c|c|c|c|c|c|c|c|c|}
\hline $\begin{array}{l}\text { explains that radiation treatment can } \\
\text { only be delivered at a few specialized } \\
\text { treatment centers }\end{array}$ & & $(49.2,70.5)$ & & $(28.8,48.4)$ & & $(2.6,14.4)$ & & & & \\
\hline $\begin{array}{l}\text { The radiation oncologist describes } \\
\text { and explains all of the treatment } \\
\text { options that are available to the } \\
\text { patient other than radiation treatment }\end{array}$ & 70 & $\begin{array}{c}78.4 \\
(69.2,86.0)\end{array}$ & 56 & $\begin{array}{c}68.3 \\
(58.4,77.0)\end{array}$ & 71 & $\begin{array}{c}6.9 \\
(2.8,13.6)\end{array}$ & 53 & 1472.6 & 21 & 70 \\
\hline $\begin{array}{l}\text { Someone on the healthcare team } \\
\text { explains that radiation treatment is } \\
\text { delivered by the radiation therapists, } \\
\text { not a radiation oncologist }\end{array}$ & 48 & $\begin{array}{c}70.6 \\
(60.8,79.2)\end{array}$ & 120 & $\begin{array}{c}42.1 \\
(32.6,52.0)\end{array}$ & 71 & $\begin{array}{c}6.9 \\
(2.8,13.6)\end{array}$ & 69 & 1237.0 & 96 & 120 \\
\hline $\begin{array}{l}\text { The patient is aware of who to } \\
\text { contact with questions about his } \\
\text { prostate cancer and treatment }\end{array}$ & 88 & $\begin{array}{c}83.8 \\
(75.4,90.3)\end{array}$ & 16 & $\begin{array}{c}81.3 \\
(72.6,88.2)\end{array}$ & 73 & $\begin{array}{c}6.7 \\
(2.7,13.2)\end{array}$ & 64 & 1316.4 & 40 & 88 \\
\hline $\begin{array}{l}\text { The nurses explain things to the } \\
\text { patient in a way that he can } \\
\text { understand }\end{array}$ & 105 & $\begin{array}{c}87.8 \\
(80.1,93.4)\end{array}$ & 36 & $\begin{array}{c}74.8 \\
(65.4,82.7)\end{array}$ & 74 & $\begin{array}{c}6.5 \\
(2.7,13.0)\end{array}$ & 88 & 908.4 & 67 & 105 \\
\hline $\begin{array}{l}\text { Someone on the healthcare team is } \\
\text { available if needed to help explain } \\
\text { the diagnosis to family members }\end{array}$ & 37 & $\begin{array}{c}66.2 \\
(54.6,76.6)\end{array}$ & 117 & $\begin{array}{c}43.0 \\
(33.1,53.3)\end{array}$ & 75 & $\begin{array}{c}6.5 \\
(2.1,14.5)\end{array}$ & 54 & 1452.1 & 90 & 117 \\
\hline $\begin{array}{l}\text { The atmosphere in the waiting room } \\
\text { is relaxing }\end{array}$ & 39 & $\begin{array}{c}66.7 \\
(57.0,75.4)\end{array}$ & 128 & $\begin{array}{c}37.0 \\
(27.9,46.9)\end{array}$ & 76 & $\begin{array}{c}6.5 \\
(2.6,12.9)\end{array}$ & 70 & 1234.5 & 112 & 128 \\
\hline $\begin{array}{l}\text { The cancer centre has a place to stay } \\
\text { overnight if the patient lives far away }\end{array}$ & 112 & $\begin{array}{c}89.8 \\
(77.8,96.6)\end{array}$ & 106 & $\begin{array}{c}53.0 \\
(42.8,63.1)\end{array}$ & 77 & $\begin{array}{c}6.1 \\
(1.3,16.9)\end{array}$ & 125 & 540.6 & 80 & 112 \\
\hline $\begin{array}{l}\text { The radiation oncologist carefully } \\
\text { assesses the patient's suitability for } \\
\text { radiation treatment }\end{array}$ & 97 & $\begin{array}{c}85.9 \\
(77.4,92.0)\end{array}$ & 24 & $\begin{array}{c}78.8 \\
(69.7,86.2)\end{array}$ & 78 & $\begin{array}{c}6.1 \\
(2.3,12.7)\end{array}$ & 74 & 1114.9 & 54 & 97 \\
\hline $\begin{array}{l}\text { The radiation oncologist shows } \\
\text { interest in the patient as a person, not } \\
\text { just as a patient }\end{array}$ & 76 & $\begin{array}{c}80.0 \\
(70.8,87.3)\end{array}$ & 90 & $\begin{array}{c}58.1 \\
(48.1,67.7)\end{array}$ & 79 & $\begin{array}{c}6.0 \\
(2.2,12.6)\end{array}$ & 72 & 1162.0 & 42 & 90 \\
\hline $\begin{array}{l}\text { The nurses show sensitivity to the } \\
\text { patient's feelings and emotional } \\
\text { needs }\end{array}$ & 91 & $\begin{array}{c}84.2 \\
(75.6,90.7)\end{array}$ & 89 & $\begin{array}{c}58.1 \\
(48.1,67.7)\end{array}$ & 80 & $\begin{array}{c}5.9 \\
(2.2,12.5)\end{array}$ & 87 & 920.3 & 44 & 91 \\
\hline The patient is involved as much as he & 107 & 88.4 & 39 & 73.6 & 81 & 5.9 & 93 & 857.2 & 70 & 107 \\
\hline
\end{tabular}




\begin{tabular}{|c|c|c|c|c|c|c|c|c|c|c|}
\hline $\begin{array}{l}\text { wants in making the final decision } \\
\text { about which treatment to have }\end{array}$ & & $(80.5,93.8)$ & & $(64.2,81.7)$ & & $(2.2,12.4)$ & & & & \\
\hline $\begin{array}{l}\text { The nurses care about the patient's } \\
\text { well-being }\end{array}$ & 103 & $\begin{array}{c}87.4 \\
(79.4,93.1)\end{array}$ & 68 & $\begin{array}{c}64.8 \\
(54.8,73.8)\end{array}$ & 82 & $\begin{array}{c}5.8 \\
(2.2,12.2)\end{array}$ & 100 & 817.3 & 64 & 103 \\
\hline $\begin{array}{l}\text { The radiation oncologist is honest } \\
\text { with the patient }\end{array}$ & 129 & $\begin{array}{c}93.2 \\
(86.5,97.2)\end{array}$ & 8 & $\begin{array}{c}86.0 \\
(77.9,91.9)\end{array}$ & 82 & $\begin{array}{c}5.8 \\
(2.2,12.2)\end{array}$ & 121 & 584.7 & 114 & 129 \\
\hline $\begin{array}{l}\text { The patient has enough time with a } \\
\text { member of the healthcare team to } \\
\text { discuss the treatment plan }\end{array}$ & 56 & $\begin{array}{c}74.3 \\
(64.8,82.3)\end{array}$ & 97 & $\begin{array}{c}56.1 \\
(46.2,65.7)\end{array}$ & 84 & $\begin{array}{c}5.7 \\
(2.1,12.0)\end{array}$ & 55 & 1441.6 & 54 & 97 \\
\hline $\begin{array}{l}\text { The radiation oncologist shows } \\
\text { sensitivity to the patient's feelings } \\
\text { and emotional needs }\end{array}$ & 100 & $\begin{array}{c}86.7 \\
(78.6,92.5)\end{array}$ & 63 & $\begin{array}{c}65.7 \\
(56.0,74.6)\end{array}$ & 84 & $\begin{array}{c}5.7 \\
(2.1,12.0)\end{array}$ & 90 & 876.3 & 58 & 100 \\
\hline $\begin{array}{l}\text { Someone on the healthcare team } \\
\text { explains that radiation treatment } \\
\text { often causes urinary symptoms } \\
\text { during treatment }\end{array}$ & 101 & $\begin{array}{c}86.8 \\
(78.9,92.6)\end{array}$ & 59 & $\begin{array}{c}67.3 \\
(57.6,76.0)\end{array}$ & 84 & $\begin{array}{c}5.7 \\
(2.1,12.0)\end{array}$ & 89 & 888.9 & 60 & 101 \\
\hline $\begin{array}{l}\text { The radiation oncologist cares about } \\
\text { the patient's well-being }\end{array}$ & 113 & $\begin{array}{c}90.5 \\
(83.2,95.3)\end{array}$ & 30 & $\begin{array}{c}76.6 \\
(67.5,84.3)\end{array}$ & 84 & $\begin{array}{c}5.7 \\
(2.1,12.0)\end{array}$ & 110 & 729.6 & 82 & 113 \\
\hline $\begin{array}{l}\text { The radiation oncologist explains } \\
\text { things to the patient in a way that he } \\
\text { can understand }\end{array}$ & 118 & $\begin{array}{c}91.4 \\
(84.4,96.0)\end{array}$ & 19 & $\begin{array}{c}81.1 \\
(72.4,88.1)\end{array}$ & 84 & $\begin{array}{c}5.7 \\
(2.1,12.0)\end{array}$ & 111 & 695.3 & 92 & 118 \\
\hline $\begin{array}{l}\text { The patient feels that his rights for } \\
\text { privacy are fully protected at the } \\
\text { cancer centre }\end{array}$ & 65 & $\begin{array}{c}77.5 \\
(67.4,85.7)\end{array}$ & 79 & $\begin{array}{c}60.2 \\
(50.3,69.5)\end{array}$ & 89 & $\begin{array}{c}5.6 \\
(1.8,12.6)\end{array}$ & 63 & 1352.5 & 31 & 79 \\
\hline $\begin{array}{l}\text { The nurses take the time to answer } \\
\text { all of the patient's questions }\end{array}$ & 106 & $\begin{array}{c}87.8 \\
(80.1,93.4) \\
\end{array}$ & 43 & $\begin{array}{c}72.0 \\
(62.4,80.2) \\
\end{array}$ & 90 & $\begin{array}{c}5.6 \\
(2.1,11.8) \\
\end{array}$ & 91 & 874.3 & 69 & 106 \\
\hline $\begin{array}{l}\text { Once an appointment is made for the } \\
\text { patient it is not cancelled or } \\
\text { postponed }\end{array}$ & 71 & $\begin{array}{c}78.5 \\
(69.5,85.9)\end{array}$ & 111 & $\begin{array}{c}49.1 \\
(39.3,58.9)\end{array}$ & 90 & $\begin{array}{c}5.6 \\
(2.1,11.8)\end{array}$ & 76 & 1055.0 & 78 & 111 \\
\hline $\begin{array}{l}\text { The cancer centre seems to have all } \\
\text { the equipment and facilities needed } \\
\text { to completely care for the patient's } \\
\text { prostate cancer }\end{array}$ & 121 & $\begin{array}{c}91.6 \\
(84.6,96.1)\end{array}$ & 4 & $\begin{array}{c}88.0 \\
(80.3,93.4)\end{array}$ & 90 & $\begin{array}{c}5.6 \\
(2.1,11.8)\end{array}$ & 105 & 739.7 & 98 & 121 \\
\hline
\end{tabular}




\begin{tabular}{|c|c|c|c|c|c|c|c|c|c|c|}
\hline $\begin{array}{l}\text { If the patient wants, someone on the } \\
\text { healthcare team is willing to answer } \\
\text { questions about treatment from } \\
\text { family or friends }\end{array}$ & 26 & $\begin{array}{c}62.5 \\
(45.8,77.3)\end{array}$ & 114 & $\begin{array}{c}45.6 \\
(30.9,61.0)\end{array}$ & 93 & $\begin{array}{c}5.1 \\
(0.6,17.3)\end{array}$ & 36 & 1711.9 & 84 & 114 \\
\hline $\begin{array}{l}\text { The nurses are honest with the } \\
\text { patient }\end{array}$ & 110 & $\begin{array}{c}88.9 \\
(81.0,94.3)\end{array}$ & 47 & $\begin{array}{c}71.4 \\
(61.8,79.8)\end{array}$ & 94 & $\begin{array}{c}5.0 \\
(1.7,11.4)\end{array}$ & 102 & 793.6 & 76 & 110 \\
\hline $\begin{array}{l}\text { The patient feels that he can trust the } \\
\text { nurses with confidential information }\end{array}$ & 84 & $\begin{array}{c}83.0 \\
(74.2,89.8)\end{array}$ & 94 & $\begin{array}{c}56.5 \\
(46.6,66.0)\end{array}$ & 95 & $\begin{array}{c}5.0 \\
(1.6,11.3) \\
\end{array}$ & 85 & 960.2 & 49 & 94 \\
\hline $\begin{array}{l}\text { Transportation to/from the cancer } \\
\text { centre is available for the patient if } \\
\text { needed }\end{array}$ & 80 & $\begin{array}{c}82.5 \\
(67.2,92.7)\end{array}$ & 112 & $\begin{array}{c}49.0 \\
(38.7,59.3)\end{array}$ & 95 & $\begin{array}{c}5.0 \\
(0.6,16.9)\end{array}$ & 94 & 857.2 & 80 & 112 \\
\hline $\begin{array}{l}\text { Someone on the health care team } \\
\text { offers written information about } \\
\text { prostate cancer to the patient that he } \\
\text { can take home with him }\end{array}$ & 87 & $\begin{array}{c}83.5 \\
(74.9,90.1)\end{array}$ & 70 & $\begin{array}{c}63.8 \\
(53.8,73.0)\end{array}$ & 97 & $\begin{array}{c}4.8 \\
(1.6,11.0)\end{array}$ & 77 & 1052.9 & 39 & 87 \\
\hline $\begin{array}{l}\text { Someone on the healthcare team } \\
\text { explains that radiation treatment } \\
\text { often causes bowel symptoms during } \\
\text { treatment }\end{array}$ & 102 & $\begin{array}{c}86.9 \\
(79.0,92.7)\end{array}$ & 65 & $\begin{array}{c}65.4 \\
(55.6,74.4)\end{array}$ & 98 & $\begin{array}{c}4.7 \\
(1.6,10.7)\end{array}$ & 96 & 855.7 & 62 & 102 \\
\hline $\begin{array}{l}\text { The nurses listen carefully to all the } \\
\text { patient's concerns }\end{array}$ & 111 & $\begin{array}{c}89.6 \\
(82.2,94.7) \\
\end{array}$ & 44 & $\begin{array}{c}72.0 \\
(62.4,80.2) \\
\end{array}$ & 98 & $\begin{array}{c}4.7 \\
(1.6,10.7)\end{array}$ & 104 & 746.9 & 78 & 111 \\
\hline $\begin{array}{l}\text { The radiation oncologist takes the } \\
\text { time to answer all of the patient's } \\
\text { questions }\end{array}$ & 119 & $\begin{array}{c}91.5 \\
(84.5,96.0)\end{array}$ & 7 & $\begin{array}{c}86.9 \\
(79.0,92.7)\end{array}$ & 98 & $\begin{array}{c}4.7 \\
(1.6,10.7)\end{array}$ & 107 & 738.0 & 94 & 119 \\
\hline $\begin{array}{l}\text { The radiation oncologist listens } \\
\text { carefully to all the patient's concerns }\end{array}$ & 126 & $\begin{array}{c}92.4 \\
(85.7,96.7) \\
\end{array}$ & 16 & $\begin{array}{c}81.3 \\
(71.6,88.2) \\
\end{array}$ & 98 & $\begin{array}{c}4.7 \\
(1.6,10.7)\end{array}$ & 117 & 613.9 & 108 & 126 \\
\hline $\begin{array}{l}\text { The radiation oncologist makes the } \\
\text { patient feel like he can ask any } \\
\text { questions he wants to }\end{array}$ & 132 & $\begin{array}{c}93.4 \\
(86.9,97.3)\end{array}$ & 11 & $\begin{array}{c}84.1 \\
(75.8,90.5)\end{array}$ & 98 & $\begin{array}{c}4.7 \\
(1.6,10.7)\end{array}$ & 124 & 555.1 & 120 & 132 \\
\hline $\begin{array}{l}\text { The patient has a short wait to start } \\
\text { treatment after the decision was } \\
\text { made to have radiation treatment }\end{array}$ & 79 & $\begin{array}{c}82.2 \\
(73.7,89.0)\end{array}$ & 105 & $\begin{array}{c}53.3 \\
(43.4,63.0)\end{array}$ & 103 & $\begin{array}{c}4.7 \\
(1.5,10.6)\end{array}$ & 86 & 946.1 & 67 & 105 \\
\hline $\begin{array}{l}\text { Appointments are scheduled for a } \\
\text { time that is convenient }\end{array}$ & 72 & $\begin{array}{c}78.5 \\
(69.5,85.9) \\
\end{array}$ & 122 & $\begin{array}{c}39.8 \\
(30.5,49.7) \\
\end{array}$ & 103 & $\begin{array}{c}4.7 \\
(1.5,10.6) \\
\end{array}$ & 95 & 855.9 & 100 & 122 \\
\hline
\end{tabular}




\begin{tabular}{|c|c|c|c|c|c|c|c|c|c|c|}
\hline $\begin{array}{l}\text { The nurses make the patient feel like } \\
\text { he can ask any questions he wants to }\end{array}$ & 123 & $\begin{array}{c}91.6 \\
(84.6,96.1) \\
\end{array}$ & 44 & $\begin{array}{c}72.0 \\
(62.4,80.2) \\
\end{array}$ & 103 & $\begin{array}{c}4.7 \\
(1.5,10.6) \\
\end{array}$ & 118 & 605.2 & 101 & 123 \\
\hline $\begin{array}{l}\text { The furniture in the waiting room is } \\
\text { comfortable }\end{array}$ & 17 & $\begin{array}{c}55.6 \\
(45.7,65.1)\end{array}$ & 138 & $\begin{array}{c}23.2 \\
(15.6,32.2)\end{array}$ & 106 & $\begin{array}{c}4.6 \\
(1.5,10.5)\end{array}$ & 80 & 1028.8 & 132 & 138 \\
\hline $\begin{array}{l}\text { Someone at the cancer centre is } \\
\text { available to answer the patient's } \\
\text { questions in between appointments }\end{array}$ & 67 & $\begin{array}{c}77.8 \\
(67.8,85.9)\end{array}$ & 76 & $\begin{array}{c}61.3 \\
(51.4,70.6)\end{array}$ & 107 & $\begin{array}{c}4.4 \\
(1.2,11.0)\end{array}$ & 62 & 1362.5 & 27 & 76 \\
\hline $\begin{array}{l}\text { The nurses show interest in the } \\
\text { patient as a person, not just as a } \\
\text { patient }\end{array}$ & 99 & $\begin{array}{c}86.3 \\
(78.0,92.3)\end{array}$ & 103 & $\begin{array}{c}53.8 \\
(43.8,63.5)\end{array}$ & 108 & $\begin{array}{c}3.9 \\
(1.1,9.7)\end{array}$ & 106 & 738.3 & 64 & 103 \\
\hline $\begin{array}{l}\text { The nurses are knowledgeable and } \\
\text { experienced in dealing with prostate } \\
\text { cancer }\end{array}$ & 115 & $\begin{array}{c}91.2 \\
(83.9,95.9)\end{array}$ & 13 & $\begin{array}{c}83.0 \\
(74.5,89.6)\end{array}$ & 108 & $\begin{array}{c}3.9 \\
(1.1,9.7)\end{array}$ & 109 & 732.2 & 86 & 115 \\
\hline $\begin{array}{l}\text { During treatment, the radiation } \\
\text { oncologist, nurses and radiation } \\
\text { therapists do everything they can to } \\
\text { help the patient get through treatment } \\
\text { with as few problems as possible }\end{array}$ & 123 & $\begin{array}{c}91.6 \\
(84.6,96.1)\end{array}$ & 38 & $\begin{array}{c}73.6 \\
(64.2,81.7)\end{array}$ & 110 & $\begin{array}{c}3.8 \\
(1.0,9.4)\end{array}$ & 116 & 618.8 & 101 & 123 \\
\hline $\begin{array}{l}\text { During treatment, the radiation } \\
\text { therapists make enough time for the } \\
\text { patient }\end{array}$ & 105 & $\begin{array}{c}87.8 \\
(80.1,93.4)\end{array}$ & 131 & $\begin{array}{c}34.9 \\
(25.9,44.8)\end{array}$ & 110 & $\begin{array}{c}3.8 \\
(1.0,9.4)\end{array}$ & 131 & 424.2 & 118 & 131 \\
\hline $\begin{array}{l}\text { The waiting area and treatment } \\
\text { rooms are quiet }\end{array}$ & 45 & $\begin{array}{c}68.5 \\
(58.9,77.1)\end{array}$ & 134 & $\begin{array}{c}30.6 \\
(22.0,40.2)\end{array}$ & 112 & $\begin{array}{c}3.7 \\
(1.0,9.2)\end{array}$ & 84 & 962.0 & 124 & 134 \\
\hline $\begin{array}{l}\text { The patient is welcome to bring a } \\
\text { friend or relative with him to his } \\
\text { appointments }\end{array}$ & 78 & $\begin{array}{c}80.8 \\
(71.7,88.0)\end{array}$ & 118 & $\begin{array}{c}42.9 \\
(33.2,52.9)\end{array}$ & 113 & $\begin{array}{c}3.0 \\
(0.6,8.6)\end{array}$ & 99 & 822.5 & 92 & 118 \\
\hline $\begin{array}{l}\text { There is enough space in the waiting } \\
\text { room that the patient can have a } \\
\text { private conversation with his } \\
\text { companion }\end{array}$ & 10 & $\begin{array}{c}48.5 \\
(38.6,58.6)\end{array}$ & 140 & $\begin{array}{c}19.6 \\
(12.6,28.4)\end{array}$ & 114 & $\begin{array}{c}2.9 \\
(0.6,8.4)\end{array}$ & 81 & 1010.2 & 136 & 140 \\
\hline $\begin{array}{l}\text { The radiation therapists care about } \\
\text { the patient's well-being }\end{array}$ & 139 & $\begin{array}{c}95.2 \\
(89.0,98.4)\end{array}$ & 72 & $\begin{array}{c}62.9 \\
(52.9,72.1) \\
\end{array}$ & 115 & $\begin{array}{c}2.9 \\
(0.6,8.3)\end{array}$ & 140 & 304.9 & 134 & 139 \\
\hline
\end{tabular}




\begin{tabular}{|c|c|c|c|c|c|c|c|c|c|c|}
\hline $\begin{array}{l}\text { The radiation therapists are polite to } \\
\text { the patient }\end{array}$ & 134 & $\begin{array}{c}94.2 \\
(87.9,97.8)\end{array}$ & 85 & $\begin{array}{c}59.0 \\
(49.0,68.6)\end{array}$ & 116 & $\begin{array}{c}2.9 \\
(0.6,8.2)\end{array}$ & 137 & 340.7 & 124 & 134 \\
\hline $\begin{array}{l}\text { The patient trusts the nurses to look } \\
\text { after him properly }\end{array}$ & 108 & $\begin{array}{c}88.6 \\
(80.9,94.0)\end{array}$ & 46 & $\begin{array}{c}72.0 \\
(62.4,80.2)\end{array}$ & 117 & $\begin{array}{c}2.9 \\
(0.6,8.1)\end{array}$ & 98 & 822.5 & 72 & 108 \\
\hline $\begin{array}{l}\text { The radiation therapists are } \\
\text { knowledgeable and experienced in } \\
\text { dealing with prostate cancer }\end{array}$ & 137 & $\begin{array}{c}94.3 \\
(88.0,97.9)\end{array}$ & 5 & $\begin{array}{c}87.8 \\
(80.1,93.3)\end{array}$ & 117 & $\begin{array}{c}2.9 \\
(0.6,8.1)\end{array}$ & 126 & 501.6 & 128 & 137 \\
\hline $\begin{array}{l}\text { The radiation therapists explain } \\
\text { things to the patient in a way that he } \\
\text { can understand }\end{array}$ & 137 & $\begin{array}{c}94.3 \\
(88.0,97.9)\end{array}$ & 37 & $\begin{array}{c}73.6 \\
(64.2,81.7)\end{array}$ & 117 & $\begin{array}{c}2.9 \\
(0.6,8.1)\end{array}$ & 132 & 420.1 & 128 & 137 \\
\hline $\begin{array}{l}\text { Someone on the healthcare team } \\
\text { explains that radiation treatment } \\
\text { often causes temporary fatigue }\end{array}$ & 98 & $\begin{array}{c}86.1 \\
(78.1,92.0)\end{array}$ & 93 & $\begin{array}{c}56.6 \\
(46.6,66.2)\end{array}$ & 120 & $\begin{array}{c}2.8 \\
(0.6,8.0)\end{array}$ & 103 & 786.2 & 57 & 98 \\
\hline The nurses are polite to the patient & 114 & $\begin{array}{c}90.6 \\
(83.3,95.4)\end{array}$ & 81 & $\begin{array}{c}59.8 \\
(49.9,69.2)\end{array}$ & 120 & $\begin{array}{c}2.8 \\
(0.6,8.0)\end{array}$ & 123 & 564.0 & 84 & 114 \\
\hline $\begin{array}{l}\text { The patient has confidence in his } \\
\text { treatment team that he is treated } \\
\text { correctly every day }\end{array}$ & 127 & $\begin{array}{c}92.5 \\
(85.8,96.7)\end{array}$ & 23 & $\begin{array}{c}79.2 \\
(70.3,86.5)\end{array}$ & 120 & $\begin{array}{c}2.8 \\
(0.6,8.0)\end{array}$ & 120 & 592.8 & 110 & 127 \\
\hline $\begin{array}{l}\text { The radiation oncologist treats the } \\
\text { patient with respect }\end{array}$ & 141 & $\begin{array}{c}96.2 \\
(90.6,99.0)\end{array}$ & 31 & $\begin{array}{c}76.6 \\
(67.5,84.3)\end{array}$ & 120 & $\begin{array}{c}2.8 \\
(0.6,8.0)\end{array}$ & 141 & 288.9 & 138 & 141 \\
\hline Waiting areas are decorated nicely & 6 & $\begin{array}{c}42.4 \\
(32.9,52.4)\end{array}$ & 142 & $\begin{array}{c}10.4 \\
(5.3,17.8)\end{array}$ & 120 & $\begin{array}{c}2.8 \\
(0.6,8.0)\end{array}$ & 119 & 597.4 & 140 & 142 \\
\hline $\begin{array}{l}\text { The radiation oncologist, nurses and } \\
\text { radiation therapists work well } \\
\text { together when treating the patient for } \\
\text { prostate cancer }\end{array}$ & 142 & $\begin{array}{c}96.2 \\
(90.6,99.0)\end{array}$ & 6 & $\begin{array}{c}87.0 \\
(79.2,92.7)\end{array}$ & 120 & $\begin{array}{c}2.8 \\
(0.6,8.0)\end{array}$ & 138 & 328.1 & 140 & 142 \\
\hline $\begin{array}{l}\text { The patient trusts the radiation } \\
\text { therapists to look after him properly }\end{array}$ & 124 & $\begin{array}{c}91.7 \\
(84.8,96.1)\end{array}$ & 27 & $\begin{array}{c}77.8 \\
(68.8,85.2)\end{array}$ & 126 & $\begin{array}{c}2.8 \\
(0.6,7.9)\end{array}$ & 114 & 647.9 & 104 & 124 \\
\hline If the patient wants, the radiation & 95 & 85.5 & 110 & 50.6 & 127 & 2.6 & 108 & 732.5 & 76 & 110 \\
\hline
\end{tabular}




\begin{tabular}{|c|c|c|c|c|c|c|c|c|c|c|}
\hline $\begin{array}{l}\text { oncologist is willing to answer all the } \\
\text { questions the patient's family and } \\
\text { friends have }\end{array}$ & & $(75.6,92.6)$ & & $(39.3,61.9)$ & & $(0.3,9.2)$ & & & & \\
\hline $\begin{array}{l}\text { The patient feels that he can trust the } \\
\text { radiation therapists with confidential } \\
\text { information }\end{array}$ & 128 & $\begin{array}{c}93.1 \\
(86.4,97.2)\end{array}$ & 84 & $\begin{array}{c}59.3 \\
(49.4,68.6)\end{array}$ & 128 & $\begin{array}{c}2.0 \\
(0.2,6.9)\end{array}$ & 133 & 406.5 & 112 & 128 \\
\hline $\begin{array}{l}\text { The patient feels that he can trust the } \\
\text { radiation oncologist with confidential } \\
\text { information }\end{array}$ & 125 & $\begin{array}{c}92.2 \\
(85.3,96.6)\end{array}$ & 75 & $\begin{array}{c}61.7 \\
(51.8,70.9)\end{array}$ & 129 & $\begin{array}{c}1.9 \\
(0.2,6.8)\end{array}$ & 127 & 479.2 & 106 & 125 \\
\hline $\begin{array}{l}\text { The radiation therapists listen } \\
\text { carefully to all the patient's concerns }\end{array}$ & 117 & $\begin{array}{c}91.4 \\
(84.2,96.0) \\
\end{array}$ & 60 & $\begin{array}{c}66.7 \\
(56.8,75.6) \\
\end{array}$ & 130 & $\begin{array}{c}1.9 \\
(0.2,6.8)\end{array}$ & 122 & 576.7 & 90 & 117 \\
\hline $\begin{array}{l}\text { The radiation therapists take the time } \\
\text { to answer all of the patient's } \\
\text { questions }\end{array}$ & 137 & $\begin{array}{c}94.3 \\
(88.0,97.9)\end{array}$ & 58 & $\begin{array}{c}67.9 \\
(58.2,76.7)\end{array}$ & 131 & $\begin{array}{c}1.9 \\
(0.2,6.7)\end{array}$ & 135 & 387.8 & 128 & 137 \\
\hline $\begin{array}{l}\text { The patient sees the same radiation } \\
\text { therapists each time he goes for } \\
\text { radiation treatment }\end{array}$ & 24 & $\begin{array}{c}61.3 \\
(51.4,70.6)\end{array}$ & 139 & $\begin{array}{c}22.2 \\
(14.8,31.2)\end{array}$ & 132 & $\begin{array}{c}1.9 \\
(0.2,6.6)\end{array}$ & 92 & 859.5 & 134 & 139 \\
\hline $\begin{array}{l}\text { The nurses treat the patient with } \\
\text { respect }\end{array}$ & 133 & $\begin{array}{c}93.5 \\
(87.0,97.3)\end{array}$ & 61 & $\begin{array}{c}66.7 \\
(56.8,75.6)\end{array}$ & 133 & $\begin{array}{c}1.9 \\
(0.2,6.6)\end{array}$ & 130 & 436.0 & 122 & 133 \\
\hline $\begin{array}{l}\text { The radiation oncologist is polite to } \\
\text { the patient }\end{array}$ & 143 & $\begin{array}{c}96.3 \\
(90.7,99.0)\end{array}$ & 55 & $\begin{array}{c}68.5 \\
(58.9,77.1)\end{array}$ & 133 & $\begin{array}{c}1.9 \\
(0.2,6.6)\end{array}$ & 142 & 256.3 & 142 & 143 \\
\hline $\begin{array}{l}\text { The radiation therapists show interest } \\
\text { in the patient as a person, not just as } \\
\text { a patient }\end{array}$ & 116 & $\begin{array}{c}91.2 \\
(83.9,95.9)\end{array}$ & 99 & $\begin{array}{c}54.3 \\
(44.3,64.0)\end{array}$ & 135 & $\begin{array}{c}1.0 \\
(0.0,5.3)\end{array}$ & 128 & 478.8 & 88 & 116 \\
\hline $\begin{array}{l}\text { The radiation therapists are honest } \\
\text { with the patient }\end{array}$ & 140 & $\begin{array}{c}96.1 \\
(90.3,98.9)\end{array}$ & 20 & $\begin{array}{c}81.0 \\
(72.1,88.0)\end{array}$ & 135 & $\begin{array}{c}1.0 \\
(0.0,5.3)\end{array}$ & 139 & 317.3 & 136 & 140 \\
\hline $\begin{array}{l}\text { The radiation therapists show } \\
\text { sensitivity to the patient's feelings } \\
\text { and emotional needs }\end{array}$ & 130 & $\begin{array}{c}93.2 \\
(86.5,97.2)\end{array}$ & 87 & $\begin{array}{c}58.5 \\
(48.5,68.0)\end{array}$ & 137 & $\begin{array}{c}1.0 \\
(0.0,5.3)\end{array}$ & 134 & 397.7 & 116 & 130 \\
\hline $\begin{array}{l}\text { The radiation therapists make the } \\
\text { patient feel like he can ask any } \\
\text { questions he wants to }\end{array}$ & 131 & $\begin{array}{c}93.2 \\
(86.5,97.2)\end{array}$ & 54 & $\begin{array}{c}68.6 \\
(58.8,77.3)\end{array}$ & 137 & $\begin{array}{c}1.0 \\
(0.0,5.3)\end{array}$ & 129 & 466.3 & 118 & 131 \\
\hline
\end{tabular}




\begin{tabular}{|c|c|c|c|c|c|c|c|c|c|c|}
\hline $\begin{array}{l}\text { The radiation therapists treat the } \\
\text { patient with respect }\end{array}$ & 138 & $\begin{array}{c}94.3 \\
(88.0,97.9)\end{array}$ & 78 & $\begin{array}{c}60.4 \\
(50.4,69.8)\end{array}$ & 139 & $\begin{array}{c}1.0 \\
(0.0,5.2)\end{array}$ & 136 & 344.8 & 132 & 138 \\
\hline $\begin{array}{l}\text { The patient is treated in the same } \\
\text { treatment room each day }\end{array}$ & 36 & $\begin{array}{c}66.0 \\
(56.2,75.0)\end{array}$ & 143 & $\begin{array}{c}6.6 \\
(2.7,13.1)\end{array}$ & 139 & $\begin{array}{c}1.0 \\
(0.0,5.2)\end{array}$ & 143 & 224.1 & 142 & 143 \\
\hline $\begin{array}{l}\text { The radiation oncologist or the nurse } \\
\text { see the patient at least once a week } \\
\text { during the course of radiation } \\
\text { treatment }\end{array}$ & 89 & $\begin{array}{c}84.1 \\
(75.8,90.5)\end{array}$ & 121 & $\begin{array}{c}41.5 \\
(32.0,51.5)\end{array}$ & 141 & $\begin{array}{c}0.9 \\
(0.0,5.1)\end{array}$ & 112 & 659.6 & 98 & 121 \\
\hline $\begin{array}{l}\text { The patient has enough privacy } \\
\text { during his care }\end{array}$ & 86 & $\begin{array}{c}83.3 \\
(74.9,89.8)\end{array}$ & 124 & $\begin{array}{c}38.9 \\
(29.7,48.8)\end{array}$ & 142 & $\begin{array}{c}0.9 \\
(0.0,5.0)\end{array}$ & 113 & 648.3 & 104 & 124 \\
\hline $\begin{array}{l}\text { Food and drink facilities are } \\
\text { available in or near the waiting room }\end{array}$ & 7 & $\begin{array}{c}43.8 \\
(33.6,54.2)\end{array}$ & 141 & $\begin{array}{c}11.3 \\
(6.0,18.9)\end{array}$ & 143 & $\begin{array}{c}0.0 \\
(0.0,3.8)\end{array}$ & 115 & 636.8 & 138 & 141 \\
\hline
\end{tabular}

*Grey shaded boxes highlight the top elements of care identified for each method 
Appendix D4: Comparing the percentage of elements of care identified as priorities for improvement among subgroups of patients

Table D4-1: Comparison of the percentage of elements of care identified as priorities for quality improvement (QI) by different subgroups of patients

\begin{tabular}{|l|c|c|}
\hline \multicolumn{1}{|c|}{ Characteristic } & $\begin{array}{c}\text { Median \% of elements } \\
\text { identified as priorities for } \\
\text { QI }\end{array}$ & p-value \\
\hline Age & 5.9 & 0.25 \\
& 3.9 & \\
$\geq 70$ & 5.1 & 0.51 \\
\hline $\begin{array}{l}\text { Educational status } \\
\text { No postsecondary education } \\
\text { Postsecondary education }\end{array}$ & 5.9 & 0.29 \\
\hline $\begin{array}{l}\text { Self-rated health status } \\
\text { Poor, fair or good } \\
\text { Excellent }\end{array}$ & 5.4 & \\
\hline
\end{tabular}




\section{Appendix E}

\section{E-supplement for the manuscript titled, "Measuring the Quality of Personal Care in Patients Undergoing Radiotherapy for Prostate Cancer"}

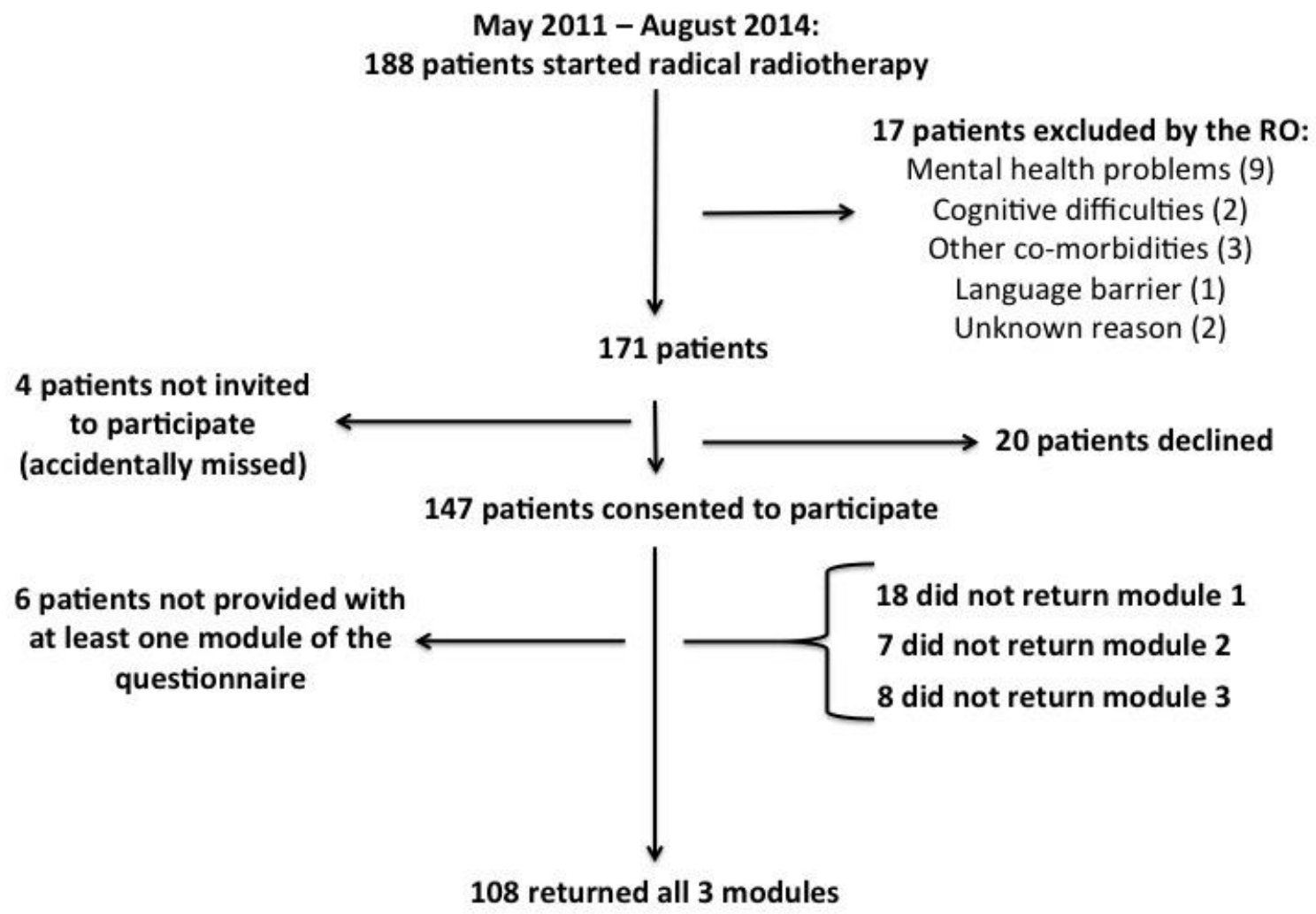

Figure e1: Recruitment and retention of patient study subjects. 
Table e1: Patient characteristics

\begin{tabular}{|c|c|c|}
\hline Characteristic & & $\begin{array}{l}\text { Number of Patients } \\
(\%)\end{array}$ \\
\hline Age & $\begin{array}{l}<50 \\
50-59 \\
60-69 \\
\geq 70 \\
\end{array}$ & $\begin{array}{l}0(0 \%) \\
7(6 \%) \\
40(37 \%) \\
61(56 \%)\end{array}$ \\
\hline Self-reported Health Status & $\begin{array}{l}\text { Poor } \\
\text { Fair } \\
\text { Good } \\
\text { Excellent } \\
\text { Unknown }\end{array}$ & $\begin{array}{l}1(1 \%) \\
14(13 \%) \\
55(51 \%) \\
32(30 \%) \\
6(6 \%) \\
\end{array}$ \\
\hline Education Level & $\begin{array}{l}\text { Less than high school } \\
\text { High School } \\
\text { College diploma } \\
\text { University degree } \\
\text { Post-graduate degree } \\
\text { Unknown }\end{array}$ & $\begin{array}{l}17(16 \%) \\
36(33 \%) \\
24(22 \%) \\
16(15 \%) \\
9(8 \%) \\
6(6 \%) \\
\end{array}$ \\
\hline Marital Status & $\begin{array}{l}\text { Single } \\
\text { Separated/Widowed/Divorced } \\
\text { Married/Living common-law } \\
\text { Unknown }\end{array}$ & $\begin{array}{l}0(0 \%) \\
12(11 \%) \\
91(84 \%) \\
5(5 \%) \\
\end{array}$ \\
\hline T-category & $\begin{array}{l}\text { T1c } \\
\text { T2 } \\
\text { T2a } \\
\text { T2b } \\
\text { T2c } \\
\text { T3 } \\
\end{array}$ & $\begin{array}{l}57(53 \%) \\
3(3 \%) \\
25(23 \%) \\
14(13 \%) \\
7(6 \%) \\
2(2 \%) \\
\end{array}$ \\
\hline Pre-Treatment PSA & $\begin{array}{l}<10 \\
10-19 \\
\geq 20 \\
\end{array}$ & $\begin{array}{l}68(63 \%) \\
26(24 \%) \\
14(13 \%) \\
\end{array}$ \\
\hline Gleason score & $\begin{array}{l}6 \\
7 \\
8 \\
9 \\
\end{array}$ & $\begin{array}{l}12(11 \%) \\
65(60 \%) \\
14(13 \%) \\
17(16 \%) \\
\end{array}$ \\
\hline Risk Group & $\begin{array}{l}\text { Low } \\
\text { Intermediate } \\
\text { High }\end{array}$ & $\begin{array}{l}11(10 \%) \\
54(50 \%) \\
43(40 \%)\end{array}$ \\
\hline
\end{tabular}

*Percentages may not add up to 100 due to rounding. 
Table e2: Treatment

\begin{tabular}{|c|c|c|c|c|}
\hline & $\begin{array}{l}\text { Total } \\
\text { number of } \\
\text { cases }\end{array}$ & Low risk & $\begin{array}{l}\text { Intermediate } \\
\text { risk }\end{array}$ & $\begin{array}{l}\text { High } \\
\text { risk }\end{array}$ \\
\hline $\begin{array}{c}\text { Hormone therapy } \\
\text { Yes } \\
\text { No }\end{array}$ & $\begin{array}{l}46 \\
62 \\
\end{array}$ & $\begin{array}{l}0 \\
11 \\
\end{array}$ & $\begin{array}{l}5 \\
49 \\
\end{array}$ & $\begin{array}{l}41 \\
2 \\
\end{array}$ \\
\hline $\begin{array}{l}\text { RT to Prostate only: } \\
\qquad 70 \mathrm{~Gy}, 35 \text { fractions } \\
76 \mathrm{~Gy}, 38 \text { fractions } \\
\text { RT to Pelvis* + prostate: } \\
* * 76 \mathrm{~Gy}, 38 \text { fractions } \\
* * 74 \mathrm{~Gy}, 37 \text { fractions } \\
* * 72 \mathrm{~Gy}, 36 \text { fractions } \\
\text { **70 Gy, } 35 \text { fractions } \\
* * 66 \mathrm{~Gy}, 33 \text { fractions }\end{array}$ & $\begin{array}{l}62 \\
46\end{array}$ & $\begin{array}{l}6 \\
5 \\
0 \\
0 \\
0 \\
0 \\
0\end{array}$ & $\begin{array}{l}0 \\
49 \\
5 \\
0 \\
0 \\
0 \\
0\end{array}$ & $\begin{array}{l}0 \\
2 \\
36 \\
2 \\
1 \\
1 \\
1 * * *\end{array}$ \\
\hline Total & 108 & 11 & 54 & 43 \\
\hline
\end{tabular}

*All pelvic radiation was given as 46 Gy in 23 fractions

**Total dose to prostate

***After the study had been completed, this patient was discovered to have had a previous radical prostatectomy. We elected not to exclude this case. No other patients included in the study had either radical surgery or brachytherapy. 
Table e3: Comparison of the overall quality of care provided by different subgroups of patients

\begin{tabular}{|l|c|c|}
\hline \multicolumn{1}{|c|}{ Characteristic } & $\begin{array}{c}\text { Median \% of elements rated } \\
\text { "very good" }\end{array}$ & p-value \\
\hline Age & 79 & 0.69 \\
$<70$ & 80 & 0.91 \\
\hline 70 & 78 & \\
Educational status & 80 & 0.80 \\
No postsecondary education & & \\
Postsecondary education & 80 & 0.44 \\
\hline Self-rated health status & 77 & \\
Poor, fair or good & 78 & 0.33 \\
Excellent & 80 & \\
\hline Hormone treatment & 80 & \\
Yes & 77 & \\
\hline Region irradiated & & \\
Prostate only & & \\
Whole pelvis & & \\
\hline
\end{tabular}


Table e4: Elements of care ranked by the percentage of patents rating each one "very good"

\begin{tabular}{|c|c|c|}
\hline \multirow[t]{2}{*}{ Elements of Care } & \multicolumn{2}{|c|}{ Quality } \\
\hline & $\begin{array}{l}\text { \% Very Good } \\
(95 \% \mathrm{CI})\end{array}$ & Rank \\
\hline The radiation oncologist is polite to the patient & $\begin{array}{c}96.3 \\
(90.7,99.0)\end{array}$ & 1 \\
\hline $\begin{array}{l}\text { The radiation oncologist, nurses and radiation therapists work } \\
\text { well together when treating the patient for prostate cancer }\end{array}$ & $\begin{array}{c}96.2 \\
(90.6,99.0)\end{array}$ & 2 \\
\hline The radiation oncologist treats the patient with respect & $\begin{array}{c}96.2 \\
(90.6,99.0)\end{array}$ & 3 \\
\hline The radiation therapists are honest with the patient & $\begin{array}{c}96.1 \\
(90.3,98.9)\end{array}$ & 4 \\
\hline The radiation therapists care about the patient's well-being & $\begin{array}{c}95.2 \\
(89.0,98.4)\end{array}$ & 5 \\
\hline The radiation therapists treat the patient with respect & $\begin{array}{c}94.3 \\
(88.0,97.9)\end{array}$ & 6 \\
\hline $\begin{array}{l}\text { The radiation therapists are knowledgeable and experienced in } \\
\text { dealing with prostate cancer }\end{array}$ & $\begin{array}{c}94.3 \\
(88.0,97.9)\end{array}$ & 7 \\
\hline $\begin{array}{l}\text { The radiation therapists take the time to answer all of the patient's } \\
\text { questions }\end{array}$ & $\begin{array}{c}94.3 \\
(88.0,97.9)\end{array}$ & 7 \\
\hline $\begin{array}{l}\text { The radiation therapists explain things to the patient in a way that } \\
\text { he can understand }\end{array}$ & $\begin{array}{c}94.3 \\
(88.0,97.9) \\
\end{array}$ & 7 \\
\hline The radiation therapists are polite to the patient & $\begin{array}{c}94.2 \\
(87.9,97.8)\end{array}$ & 10 \\
\hline The nurses treat the patient with respect & $\begin{array}{c}93.5 \\
(87.0,97.3) \\
\end{array}$ & 11 \\
\hline $\begin{array}{l}\text { The radiation oncologist makes the patient feel like he can ask } \\
\text { any questions he wants to }\end{array}$ & $\begin{array}{c}93.4 \\
(86.9,97.3) \\
\end{array}$ & 12 \\
\hline $\begin{array}{l}\text { The radiation therapists make the patient feel like he can ask any } \\
\text { questions he wants to }\end{array}$ & $\begin{array}{c}93.2 \\
(86.5,97.2)\end{array}$ & 13 \\
\hline $\begin{array}{l}\text { The radiation therapists show sensitivity to the patient's feelings } \\
\text { and emotional needs }\end{array}$ & $\begin{array}{c}93.2 \\
(86.5,97.2)\end{array}$ & 14 \\
\hline The radiation oncologist is honest with the patient & $\begin{array}{c}93.2 \\
(86.5,97.2)\end{array}$ & 15 \\
\hline $\begin{array}{l}\text { The patient feels that he can trust the radiation therapists with } \\
\text { confidential information }\end{array}$ & $\begin{array}{c}93.1 \\
(86.4,97.2) \\
\end{array}$ & 16 \\
\hline $\begin{array}{l}\text { The patient has confidence in his treatment team that he is treated } \\
\text { correctly every day }\end{array}$ & $\begin{array}{c}92.5 \\
(85.8,96.7)\end{array}$ & 17 \\
\hline $\begin{array}{l}\text { The radiation oncologist listens carefully to all the patient's } \\
\text { concerns }\end{array}$ & $\begin{array}{c}92.4 \\
(85.7,96.7) \\
\end{array}$ & 18 \\
\hline $\begin{array}{l}\text { The patient feels that he can trust the radiation oncologist with } \\
\text { confidential information }\end{array}$ & $\begin{array}{c}92.2 \\
(85.3,96.6) \\
\end{array}$ & 19 \\
\hline The patient trusts the radiation therapists to look after him & 91.7 & 20 \\
\hline
\end{tabular}




\begin{tabular}{|c|c|c|}
\hline properly & $(84.8,96.1)$ & \\
\hline $\begin{array}{l}\text { During treatment, the radiation oncologist, nurses and radiation } \\
\text { therapists do everything they can to help the patient get through } \\
\text { treatment with as few problems as possible }\end{array}$ & $\begin{array}{c}91.6 \\
(84.6,96.1)\end{array}$ & 21 \\
\hline $\begin{array}{l}\text { The nurses make the patient feel like he can ask any questions he } \\
\text { wants to }\end{array}$ & $\begin{array}{c}91.6 \\
(84.6,96.1)\end{array}$ & 21 \\
\hline $\begin{array}{l}\text { The cancer centre seems to have all the equipment and facilities } \\
\text { needed to completely care for the patient's prostate cancer }\end{array}$ & $\begin{array}{c}91.6 \\
(84.6,96.1)\end{array}$ & 23 \\
\hline $\begin{array}{l}\text { The radiation oncologist is knowledgeable and experienced in } \\
\text { dealing with prostate cancer }\end{array}$ & $\begin{array}{c}91.5 \\
(84.5,96.0)\end{array}$ & 24 \\
\hline $\begin{array}{l}\text { The radiation oncologist takes the time to answer all of the } \\
\text { patient's questions }\end{array}$ & $\begin{array}{c}91.5 \\
(84.5,96.0)\end{array}$ & 25 \\
\hline $\begin{array}{l}\text { The radiation oncologist explains things to the patient in a way } \\
\text { that he can understand }\end{array}$ & $\begin{array}{c}91.4 \\
(84.4,96.0) \\
\end{array}$ & 26 \\
\hline $\begin{array}{l}\text { The radiation therapists listen carefully to all the patient's } \\
\text { concerns }\end{array}$ & $\begin{array}{c}91.4 \\
(84.2,96.0)\end{array}$ & 27 \\
\hline $\begin{array}{l}\text { The radiation therapists show interest in the patient as a person, } \\
\text { not just as a patient }\end{array}$ & $\begin{array}{c}91.2 \\
(83.9,95.9) \\
\end{array}$ & 28 \\
\hline $\begin{array}{l}\text { The nurses are knowledgeable and experienced in dealing with } \\
\text { prostate cancer }\end{array}$ & $\begin{array}{c}91.2 \\
(83.9,95.9) \\
\end{array}$ & 29 \\
\hline The nurses are polite to the patient & $\begin{array}{c}90.6 \\
(83.3,95.4) \\
\end{array}$ & 30 \\
\hline The radiation oncologist cares about the patient's well-being & $\begin{array}{c}90.5 \\
(83.2,95.3) \\
\end{array}$ & 31 \\
\hline $\begin{array}{l}\text { The cancer centre has a place to stay overnight if the patient lives } \\
\text { far away }\end{array}$ & $\begin{array}{c}89.8 \\
(77.8,96.6)\end{array}$ & 32 \\
\hline The nurses listen carefully to all the patient's concerns & $\begin{array}{c}89.6 \\
(82.2,94.7) \\
\end{array}$ & 33 \\
\hline The nurses are honest with the patient & $\begin{array}{c}88.9 \\
(81.0,94.3) \\
\end{array}$ & 34 \\
\hline $\begin{array}{l}\text { The patient trusts the radiation oncologist to look after him } \\
\text { properly }\end{array}$ & $\begin{array}{c}88.7 \\
(81.1,94.0) \\
\end{array}$ & 35 \\
\hline The patient trusts the nurses to look after him properly & $\begin{array}{c}88.6 \\
(80.9,94.0) \\
\end{array}$ & 36 \\
\hline $\begin{array}{l}\text { The patient is involved as much as he wants in making the final } \\
\text { decision about which treatment to have }\end{array}$ & $\begin{array}{c}88.4 \\
(80.5,93.8)\end{array}$ & 37 \\
\hline The nurses take the time to answer all of the patient's questions & $\begin{array}{c}87.8 \\
(80.1,93.4) \\
\end{array}$ & 38 \\
\hline $\begin{array}{l}\text { During treatment, the radiation therapists make enough time for } \\
\text { the patient }\end{array}$ & $\begin{array}{c}87.8 \\
(80.1,93.4) \\
\end{array}$ & 39 \\
\hline $\begin{array}{l}\text { The nurses explain things to the patient in a way that he can } \\
\text { understand }\end{array}$ & $\begin{array}{c}87.8 \\
(80.1,93.4) \\
\end{array}$ & 39 \\
\hline The nurses care about the patient's well-being & $\begin{array}{c}87.4 \\
(79.4,93.1) \\
\end{array}$ & 41 \\
\hline Someone on the healthcare team explains that radiation tre & 86.9 & 42 \\
\hline
\end{tabular}




\begin{tabular}{|c|c|c|}
\hline often causes bowel symptoms during treatment & $(79.0,92.7)$ & \\
\hline $\begin{array}{l}\text { Someone on the healthcare team explains that radiation treatment } \\
\text { often causes urinary symptoms during treatment }\end{array}$ & $\begin{array}{c}86.8 \\
(78.8,92.6) \\
\end{array}$ & 43 \\
\hline $\begin{array}{l}\text { The radiation oncologist shows sensitivity to the patient's feelings } \\
\text { and emotional needs }\end{array}$ & $\begin{array}{c}86.7 \\
(78.6,92.5) \\
\end{array}$ & 44 \\
\hline $\begin{array}{l}\text { The nurses show interest in the patient as a person, not just as a } \\
\text { patient }\end{array}$ & $\begin{array}{c}86.3 \\
(78.0,92.3)\end{array}$ & 45 \\
\hline $\begin{array}{l}\text { Someone on the healthcare team explains that radiation treatment } \\
\text { often causes temporary fatigue }\end{array}$ & $\begin{array}{c}86.1 \\
(78.1,92.0)\end{array}$ & 46 \\
\hline $\begin{array}{l}\text { The radiation oncologist carefully assesses the patient's suitability } \\
\text { for radiation treatment }\end{array}$ & $\begin{array}{c}85.9 \\
(77.4,92.0)\end{array}$ & 47 \\
\hline The cancer centre appears to be clean and well looked after & $\begin{array}{c}85.8 \\
(77.7,91.9) \\
\end{array}$ & 48 \\
\hline $\begin{array}{l}\text { If the patient wants, the radiation oncologist is willing to answer } \\
\text { all the questions the patient's family and friends have }\end{array}$ & $\begin{array}{c}85.5 \\
(75.6,92.6)\end{array}$ & 49 \\
\hline $\begin{array}{l}\text { The radiation oncologist makes sure the patient understands the } \\
\text { treatment options before making up his mind about which } \\
\text { treatment to have }\end{array}$ & $\begin{array}{c}85.3 \\
(76.9,91.5)\end{array}$ & 50 \\
\hline $\begin{array}{l}\text { The patient gets all the help he needs from the radiation } \\
\text { oncologist to make up his mind about which treatment to have }\end{array}$ & $\begin{array}{c}84.6 \\
(76.2,90.9) \\
\end{array}$ & 51 \\
\hline $\begin{array}{l}\text { The radiation oncologist explains the different forms of treatment } \\
\text { that are available for prostate cancer }\end{array}$ & $\begin{array}{c}84.3 \\
(75.8,90.8) \\
\end{array}$ & 52 \\
\hline $\begin{array}{l}\text { The nurses show sensitivity to the patient's feelings and } \\
\text { emotional needs }\end{array}$ & $\begin{array}{c}84.2 \\
(75.6,90.7) \\
\end{array}$ & 53 \\
\hline $\begin{array}{l}\text { The patient has enough time to consider the treatment options } \\
\text { before it is decided how he will be treated }\end{array}$ & $\begin{array}{c}84.2 \\
(75.6,90.7) \\
\end{array}$ & 54 \\
\hline $\begin{array}{l}\text { The radiation oncologist or the nurse see the patient at least once } \\
\text { a week during the course of radiation treatment }\end{array}$ & $\begin{array}{c}84.1 \\
(75.8,90.5) \\
\end{array}$ & 55 \\
\hline $\begin{array}{l}\text { The patient is aware of who to contact with questions about his } \\
\text { prostate cancer and treatment }\end{array}$ & $\begin{array}{c}83.8 \\
(75.4,90.3)\end{array}$ & 56 \\
\hline $\begin{array}{l}\text { Someone on the health care team offers written information about } \\
\text { prostate cancer to the patient that he can take home with him }\end{array}$ & $\begin{array}{c}83.5 \\
(74.9,90.1) \\
\end{array}$ & 57 \\
\hline The patient has enough privacy during his care & $\begin{array}{c}83.3 \\
(74.9,89.8) \\
\end{array}$ & 58 \\
\hline $\begin{array}{l}\text { The radiation oncologist is aware of the test results and has the } \\
\text { results available when seeing the patient for the first time }\end{array}$ & $\begin{array}{c}83.2 \\
(74.4,89.9)\end{array}$ & 59 \\
\hline $\begin{array}{l}\text { The patient feels that he can trust the nurses with confidential } \\
\text { information }\end{array}$ & $\begin{array}{c}83.0 \\
(74.2,89.8) \\
\end{array}$ & 60 \\
\hline $\begin{array}{l}\text { The patient has enough time with the radiation oncologist to get } \\
\text { all of the information he needs about treatment options }\end{array}$ & $\begin{array}{c}82.9 \\
(74.3,89.5) \\
\end{array}$ & 61 \\
\hline $\begin{array}{l}\text { The patient gets enough information from the radiation oncologist } \\
\text { to be able to participate in the decision about treatment }\end{array}$ & $\begin{array}{c}82.9 \\
(74.3,89.5) \\
\end{array}$ & 62 \\
\hline $\begin{array}{l}\text { The patient understands that there is no immediate rush to make a } \\
\text { decision about treatment although it's best to make a decision } \\
\text { within a week or two }\end{array}$ & $\begin{array}{c}82.5 \\
(73.8,89.3)\end{array}$ & 63 \\
\hline
\end{tabular}




\begin{tabular}{|c|c|c|}
\hline $\begin{array}{l}\text { Transportation to/from the cancer centre is available for the } \\
\text { patient if needed }\end{array}$ & $\begin{array}{c}82.5 \\
(67.2,92.7) \\
\end{array}$ & 64 \\
\hline $\begin{array}{l}\text { The patient has a short wait to start treatment after the decision } \\
\text { was made to have radiation treatment }\end{array}$ & $\begin{array}{c}82.2 \\
(73.7,89.0) \\
\end{array}$ & 65 \\
\hline $\begin{array}{l}\text { The patient is welcome to bring a friend or relative with him to } \\
\text { his appointments }\end{array}$ & $\begin{array}{c}80.8 \\
(71.7,88.0)\end{array}$ & 66 \\
\hline $\begin{array}{l}\text { The patient is given enough information about the possible side } \\
\text { effects of radiation treatment }\end{array}$ & $\begin{array}{c}80.4 \\
(71.6,87.4) \\
\end{array}$ & 67 \\
\hline $\begin{array}{l}\text { The radiation oncologist shows interest in the patient as a person, } \\
\text { not just as a patient }\end{array}$ & $\begin{array}{c}80.0 \\
(70.8,87.3) \\
\end{array}$ & 68 \\
\hline $\begin{array}{l}\text { Someone on the healthcare team is always available to answer the } \\
\text { patient's questions and advise on the management of side effects } \\
\text { during the course of radiation treatment }\end{array}$ & $\begin{array}{c}80.0 \\
(71.1,87.2)\end{array}$ & 68 \\
\hline $\begin{array}{l}\text { The information about treatment options is provided to the patient } \\
\text { before any decision is made about the way he will be treated }\end{array}$ & $\begin{array}{c}79.4 \\
(70.3,86.8) \\
\end{array}$ & 70 \\
\hline $\begin{array}{l}\text { Someone on the healthcare team explains that doctors will be } \\
\text { monitoring PSA levels at regular intervals during follow-up from } \\
\text { radiation treatment }\end{array}$ & $\begin{array}{c}79.4 \\
(70.0,86.9)\end{array}$ & 71 \\
\hline Appointments are scheduled for a time that is convenient & $\begin{array}{c}78.5 \\
(69.5,85.9) \\
\end{array}$ & 72 \\
\hline $\begin{array}{l}\text { Once an appointment is made for the patient it is not cancelled or } \\
\text { postponed }\end{array}$ & $\begin{array}{c}78.5 \\
(69.5,85.9) \\
\end{array}$ & 73 \\
\hline $\begin{array}{l}\text { The radiation oncologist describes and explains all of the } \\
\text { treatment options that are available to the patient other than } \\
\text { radiation treatment }\end{array}$ & $\begin{array}{c}78.4 \\
(69.2,86.0)\end{array}$ & 74 \\
\hline $\begin{array}{l}\text { The radiation oncologist reads the patient's previous medical } \\
\text { records before seeing the patient for the first time }\end{array}$ & $\begin{array}{c}78.3 \\
(68.4,86.2)\end{array}$ & 75 \\
\hline $\begin{array}{l}\text { Someone on the healthcare team explains the arrangements for } \\
\text { follow -up care after the radiation treatment is over }\end{array}$ & $\begin{array}{c}77.9 \\
(68.2,85.8)\end{array}$ & 76 \\
\hline $\begin{array}{l}\text { Someone at the cancer centre is available to answer the patient's } \\
\text { questions in between appointments }\end{array}$ & $\begin{array}{c}77.8 \\
(67.8,85.9) \\
\end{array}$ & 77 \\
\hline $\begin{array}{l}\text { The radiation oncologist makes sure the patient knows that the } \\
\text { cancer is confined to the prostate, and there is no sign that it has } \\
\text { spread to any other part of the body }\end{array}$ & $\begin{array}{c}77.7 \\
(68.4,85.3)\end{array}$ & 78 \\
\hline $\begin{array}{l}\text { The patient feels that his rights for privacy are fully protected at } \\
\text { the cancer centre }\end{array}$ & $\begin{array}{c}77.5 \\
(67.4,85.7)\end{array}$ & 79 \\
\hline $\begin{array}{l}\text { The radiation oncologist makes sure the patient understands the } \\
\text { benefits of radiation treatment and its side effects before asking } \\
\text { for consent to have radiation treatment }\end{array}$ & $\begin{array}{c}77.4 \\
(68.2,84.9)\end{array}$ & 80 \\
\hline $\begin{array}{l}\text { Someone on the healthcare team explains that radiation treatment } \\
\text { involves the use of high energy rays directed at the prostate from } \\
\text { outside the body }\end{array}$ & $\begin{array}{c}76.6 \\
(67.5,84.3)\end{array}$ & 81 \\
\hline $\begin{array}{l}\text { The radiation oncologist asks the patient about any other medical } \\
\text { problems he may have }\end{array}$ & $\begin{array}{c}76.0 \\
(66.4,84.0)\end{array}$ & 82 \\
\hline The radiation oncologist makes sure the patient understands the & 76.0 & 83 \\
\hline
\end{tabular}




\begin{tabular}{|c|c|c|}
\hline $\begin{array}{l}\text { results of the biopsy of the prostate, the blood tests, and any x- } \\
\text { rays and scans he may have had }\end{array}$ & $(66.6,83.8)$ & \\
\hline $\begin{array}{l}\text { The radiation oncologist gives the patient enough information } \\
\text { about the side effects of each treatment option }\end{array}$ & $\begin{array}{c}76.0 \\
(66.6,83.8) \\
\end{array}$ & 84 \\
\hline $\begin{array}{l}\text { The patient is aware that no one else other than him and the } \\
\text { healthcare professionals looking after him are able to see his } \\
\text { medical records without his permission }\end{array}$ & $\begin{array}{c}75.6 \\
(64.9,84.4)\end{array}$ & 85 \\
\hline $\begin{array}{l}\text { The radiation oncologist makes sure the patient knows the grade } \\
\text { of his cancer and understands what that means }\end{array}$ & $\begin{array}{c}75.5 \\
(66.0,83.5)\end{array}$ & 86 \\
\hline $\begin{array}{l}\text { Someone on the healthcare team explains that radiation treatment } \\
\text { may permanently affect sexual functioning }\end{array}$ & $\begin{array}{c}74.8 \\
(65.4,82.7)\end{array}$ & 87 \\
\hline $\begin{array}{l}\text { The patient has enough time with a member of the healthcare } \\
\text { team to discuss the treatment plan }\end{array}$ & $\begin{array}{c}74.3 \\
(64.8,82.3) \\
\end{array}$ & 88 \\
\hline $\begin{array}{l}\text { Someone on the healthcare team gives the patient written } \\
\text { information about the side effects of each treatment option }\end{array}$ & $\begin{array}{c}74.3 \\
(64.8,82.3)\end{array}$ & 89 \\
\hline $\begin{array}{l}\text { The patient has a short wait to get an appointment to see the } \\
\text { radiation oncologist for the first time }\end{array}$ & $\begin{array}{c}73.6 \\
(64.1,81.7) \\
\end{array}$ & 90 \\
\hline $\begin{array}{l}\text { The radiation oncologist explains what each treatment option } \\
\text { involves }\end{array}$ & $\begin{array}{c}73.3 \\
(64.5,81.6) \\
\end{array}$ & 91 \\
\hline $\begin{array}{l}\text { The radiation oncologist makes sure the patient knows the stage } \\
\text { of his cancer and understands what that means }\end{array}$ & $\begin{array}{c}73.3 \\
(64.5,81.6)\end{array}$ & 92 \\
\hline $\begin{array}{l}\text { The patient is given enough information about the chance of } \\
\text { curing his cancer with radiation treatment }\end{array}$ & $\begin{array}{c}73.1 \\
(63.5,81.3) \\
\end{array}$ & 93 \\
\hline $\begin{array}{l}\text { Someone on the healthcare team explains that the PSA level is all } \\
\text { that is needed to tell if the cancer is under control or not }\end{array}$ & $\begin{array}{c}72.4 \\
(61.8,81.5)\end{array}$ & 94 \\
\hline $\begin{array}{l}\text { The patient has a short wait in the waiting room for daily } \\
\text { radiation treatment }\end{array}$ & $\begin{array}{c}72.2 \\
(62.8,80.4) \\
\end{array}$ & 95 \\
\hline $\begin{array}{l}\text { Someone on the healthcare team explains that radiation treatment } \\
\text { is delivered by the radiation therapists, not a radiation oncologist }\end{array}$ & $\begin{array}{c}70.6 \\
(60.8,79.2) \\
\end{array}$ & 96 \\
\hline $\begin{array}{l}\text { The patient is aware that he has a right to see all the information } \\
\text { in his medical record }\end{array}$ & $\begin{array}{c}69.9 \\
(59.5,79.0)\end{array}$ & 97 \\
\hline $\begin{array}{l}\text { The patient's family physician is kept informed about the cancer } \\
\text { care }\end{array}$ & $\begin{array}{c}69.2 \\
(57.8,79.2) \\
\end{array}$ & 98 \\
\hline The waiting area and treatment rooms are quiet & $\begin{array}{c}68.5 \\
(58.9,77.1)\end{array}$ & 99 \\
\hline $\begin{array}{l}\text { The patient has a short wait in the waiting room when he comes } \\
\text { to the cancer centre to see the radiation oncologist for the first } \\
\text { time }\end{array}$ & $\begin{array}{c}67.9 \\
(58.2,76.7)\end{array}$ & 100 \\
\hline $\begin{array}{l}\text { Once the treatment starts, someone on the healthcare team } \\
\text { reminds the patient of the potential side effects to expect during } \\
\text { the course of radiation treatment }\end{array}$ & $\begin{array}{c}67.6 \\
(57.9,76.3)\end{array}$ & 101 \\
\hline $\begin{array}{l}\text { The patient is made aware of who to contact if he is concerned } \\
\text { about the cancer coming back }\end{array}$ & $\begin{array}{c}67.4 \\
(56.5,77.2)\end{array}$ & 102 \\
\hline $\begin{array}{l}\text { The radiation oncologist tells the patient about his PSA level and } \\
\text { explains what that means }\end{array}$ & $\begin{array}{c}67.3 \\
(57.3,76.3)\end{array}$ & 103 \\
\hline
\end{tabular}




\begin{tabular}{|c|c|c|}
\hline $\begin{array}{l}\text { Someone on the healthcare team explains that the course of } \\
\text { treatment needs to be completed without taking a break (of longer } \\
\text { than a few days) }\end{array}$ & $\begin{array}{c}67.0 \\
(57.0,75.9)\end{array}$ & 104 \\
\hline The atmosphere in the waiting room is relaxing & $\begin{array}{c}66.7 \\
(57.0,75.4)\end{array}$ & 105 \\
\hline $\begin{array}{l}\text { The radiation oncologist gives the patient enough information } \\
\text { about the chance of curing his cancer with each treatment option }\end{array}$ & $\begin{array}{c}66.3 \\
(56.2,75.4) \\
\end{array}$ & 106 \\
\hline $\begin{array}{l}\text { Someone on the healthcare team is available if needed to help } \\
\text { explain the diagnosis to family members }\end{array}$ & $\begin{array}{c}66.2 \\
(54.6,76.6)\end{array}$ & 107 \\
\hline The patient is treated in the same treatment room each day & $\begin{array}{c}66.0 \\
(56.2,75.0)\end{array}$ & 108 \\
\hline $\begin{array}{l}\text { The radiation oncologist explains to the patient that he can change } \\
\text { his mind about which treatment to have as long as he does so } \\
\text { before the treatment starts }\end{array}$ & $\begin{array}{c}66.0 \\
(55.7,75.3)\end{array}$ & 109 \\
\hline $\begin{array}{l}\text { Before radiation treatment starts, the patient is given enough } \\
\text { information about what will happen each day when he comes for } \\
\text { treatment }\end{array}$ & $\begin{array}{c}65.1 \\
(55.2,74.1)\end{array}$ & 110 \\
\hline $\begin{array}{l}\text { Someone on the healthcare team explains that radiation treatment } \\
\text { may permanently affect bowel function }\end{array}$ & $\begin{array}{c}65.0 \\
(55.0,74.2)\end{array}$ & 111 \\
\hline $\begin{array}{l}\text { The patient is encouraged by the cancer center to bring a relative } \\
\text { or friend along to the first appointment with the radiation } \\
\text { oncologist }\end{array}$ & $\begin{array}{c}65.0 \\
(54.8,74.3)\end{array}$ & 112 \\
\hline $\begin{array}{l}\text { Once the decision to have radiation treatment has been made, the } \\
\text { patient is given enough information about how long he will have } \\
\text { to wait to start treatment }\end{array}$ & $\begin{array}{c}64.5 \\
(54.6,73.5)\end{array}$ & 113 \\
\hline $\begin{array}{l}\text { Someone on the healthcare team explains that radiation treatment } \\
\text { may permanently affect bladder function }\end{array}$ & $\begin{array}{c}63.1 \\
(53.0,72.4) \\
\end{array}$ & 114 \\
\hline $\begin{array}{l}\text { Someone on the healthcare team explains who to contact if } \\
\text { additional care is needed in recovery after radiation treatment }\end{array}$ & $\begin{array}{c}63.0 \\
(52.3,72.9)\end{array}$ & 115 \\
\hline The patient can find his way around the cancer centre easily & $\begin{array}{c}63.0 \\
(53.1,72.1)\end{array}$ & 116 \\
\hline $\begin{array}{l}\text { The patient is given enough information about how the radiation } \\
\text { treatment is planned }\end{array}$ & $\begin{array}{c}62.9 \\
(52.9,72.1)\end{array}$ & 117 \\
\hline $\begin{array}{l}\text { If the patient wants, someone on the healthcare team is willing to } \\
\text { answer questions about treatment from family or friends }\end{array}$ & $\begin{array}{c}62.5 \\
(45.8,77.3) \\
\end{array}$ & 118 \\
\hline $\begin{array}{l}\text { Someone on the healthcare team explains how the patient should } \\
\text { modify his diet to avoid bowel upset during the course of } \\
\text { radiation treatment }\end{array}$ & $\begin{array}{c}61.7 \\
(51.8,70.9)\end{array}$ & 119 \\
\hline $\begin{array}{l}\text { The patient sees the same radiation therapists each time he goes } \\
\text { for radiation treatment }\end{array}$ & $\begin{array}{c}61.3 \\
(51.4,70.6) \\
\end{array}$ & 120 \\
\hline $\begin{array}{l}\text { Directions and signs inside and outside the cancer centre are easy } \\
\text { to understand }\end{array}$ & $\begin{array}{c}61.3 \\
(51.4,70.6) \\
\end{array}$ & 121 \\
\hline $\begin{array}{l}\text { Someone on the healthcare team explains that radiation treatment } \\
\text { can only be delivered at a few specialized treatment centers }\end{array}$ & $\begin{array}{c}60.2 \\
(49.2,70.5)\end{array}$ & 122 \\
\hline Someone at the cancer centre arranges for the patient to receive & 59.1 & 123 \\
\hline
\end{tabular}




\begin{tabular}{|c|c|c|}
\hline any help he needs in dealing with his anxiety about the diagnosis & $(36.4,79.3)$ & \\
\hline $\begin{array}{l}\text { Someone on the healthcare team gives enough information and } \\
\text { direction to the patient about how to care for himself after } \\
\text { radiation treatment }\end{array}$ & $\begin{array}{c}57.6 \\
(46.9,67.8)\end{array}$ & 124 \\
\hline $\begin{array}{l}\text { The patient is given enough information about how the treatment } \\
\text { is scheduled and flexibility in the daily appointment times }\end{array}$ & $\begin{array}{c}57.0 \\
(47.1,66.5)\end{array}$ & 125 \\
\hline $\begin{array}{l}\text { The radiation oncologist sees the patient at least once a week } \\
\text { during the course of radiation treatment }\end{array}$ & $\begin{array}{c}56.7 \\
(46.6,66.4)\end{array}$ & 126 \\
\hline The furniture in the waiting room is comfortable & $\begin{array}{c}55.6 \\
(45.7,65.1)\end{array}$ & 127 \\
\hline $\begin{array}{l}\text { Someone on the healthcare team explains when the patient can } \\
\text { resume all of his previous activities after radiation treatment }\end{array}$ & $\begin{array}{c}55.1 \\
(44.1,65.6)\end{array}$ & 128 \\
\hline $\begin{array}{l}\text { The patient is given enough information to understand how the } \\
\text { radiation treatment works }\end{array}$ & $\begin{array}{c}54.7 \\
(44.8,64.4) \\
\end{array}$ & 129 \\
\hline $\begin{array}{l}\text { Someone on the healthcare team other than the radiation } \\
\text { oncologist is available to provide support to the patient in making } \\
\text { the decision about treatment }\end{array}$ & $\begin{array}{c}53.9 \\
(43.0,64.6)\end{array}$ & 130 \\
\hline $\begin{array}{l}\text { Someone on the healthcare team answers any questions the } \\
\text { patient has about the possible causes of prostate cancer }\end{array}$ & $\begin{array}{c}53.8 \\
(37.2,69.9) \\
\end{array}$ & 131 \\
\hline $\begin{array}{l}\text { Someone on the healthcare team explains what prostate cancer is } \\
\text { and how it can affect the patient's health }\end{array}$ & $\begin{array}{c}50.0 \\
(39.6,60.4)\end{array}$ & 132 \\
\hline $\begin{array}{l}\text { Someone on the healthcare team explains that prostate cancer is } \\
\text { not infectious and that it cannot be transmitted to anyone else }\end{array}$ & $\begin{array}{c}50.0 \\
(39.0,61.0)\end{array}$ & 133 \\
\hline $\begin{array}{l}\text { There is enough space in the waiting room that the patient can } \\
\text { have a private conversation with his companion }\end{array}$ & $\begin{array}{c}48.5 \\
(38.6,58.6)\end{array}$ & 134 \\
\hline $\begin{array}{l}\text { The patient is made aware that he has the right to get a second } \\
\text { opinion from another radiation oncologist }\end{array}$ & $\begin{array}{c}47.3 \\
(36.9,57.9) \\
\end{array}$ & 135 \\
\hline $\begin{array}{l}\text { The cancer centre provides resources to assist the patient in } \\
\text { understanding and dealing with prostate cancer (e.g. staffed } \\
\text { information services, library of books and DVDs about cancer) }\end{array}$ & $\begin{array}{c}44.8 \\
(34.2,55.9)\end{array}$ & 136 \\
\hline Food and drink facilities are available in or near the waiting room & $\begin{array}{c}43.8 \\
(33.6,54.2)\end{array}$ & 137 \\
\hline Waiting areas are decorated nicely & $\begin{array}{c}42.4 \\
(32.9,52.4) \\
\end{array}$ & 138 \\
\hline $\begin{array}{l}\text { Someone on the healthcare team explains the other treatments that } \\
\text { are available if radiation treatment is not successful }\end{array}$ & $\begin{array}{c}41.9 \\
(31.8,52.6)\end{array}$ & 139 \\
\hline $\begin{array}{l}\text { Someone on the healthcare team explains that radiation treatment } \\
\text { cannot usually be given to the prostate again if it is not successful } \\
\text { the first time }\end{array}$ & $\begin{array}{c}39.8 \\
(29.8,50.5)\end{array}$ & 140 \\
\hline $\begin{array}{l}\text { A social worker is available to provide advice on financial and } \\
\text { social issues arising from the diagnosis }\end{array}$ & $\begin{array}{c}39.7 \\
(27.0,53.4)\end{array}$ & 141 \\
\hline There is somewhere convenient to park & $\begin{array}{c}35.2 \\
(26.2,45.2) \\
\end{array}$ & 142 \\
\hline Someone at the cancer centre gives the patient information about & 33.3 & 143 \\
\hline
\end{tabular}



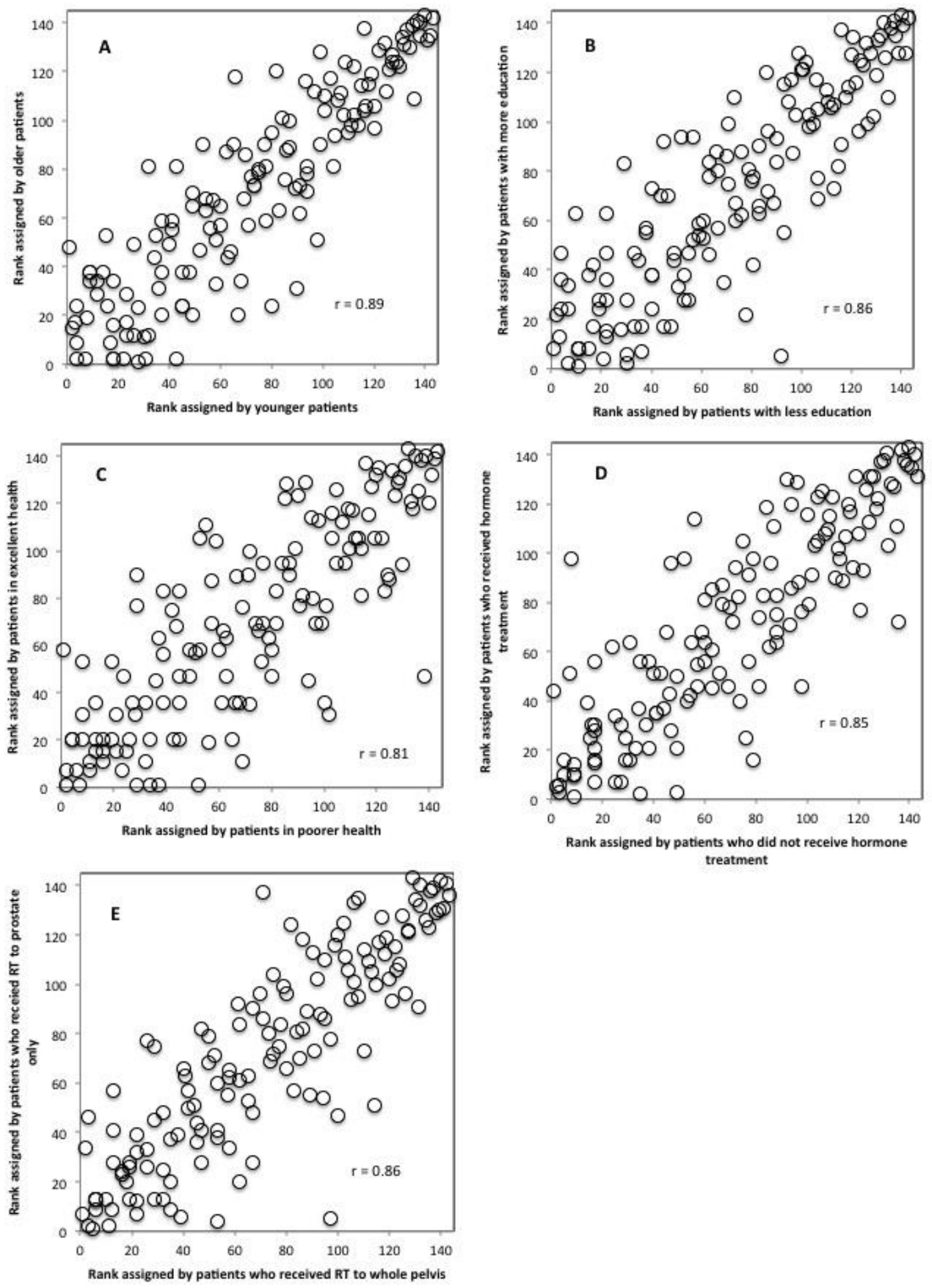
Figure e2: Relationship between patient characteristics and ratings of quality. Comparison of the ranks of each element of care between patients of different ages ( $<70 \mathrm{vs} \geq 70$ ) (A), education level (college diploma or higher vs high school or less) (B), health status (excellent health vs poor, fair or good) (C), receipt of hormone treatment (yes vs no) (D), and region irradiated (prostate only vs whole pelvis) (E). 


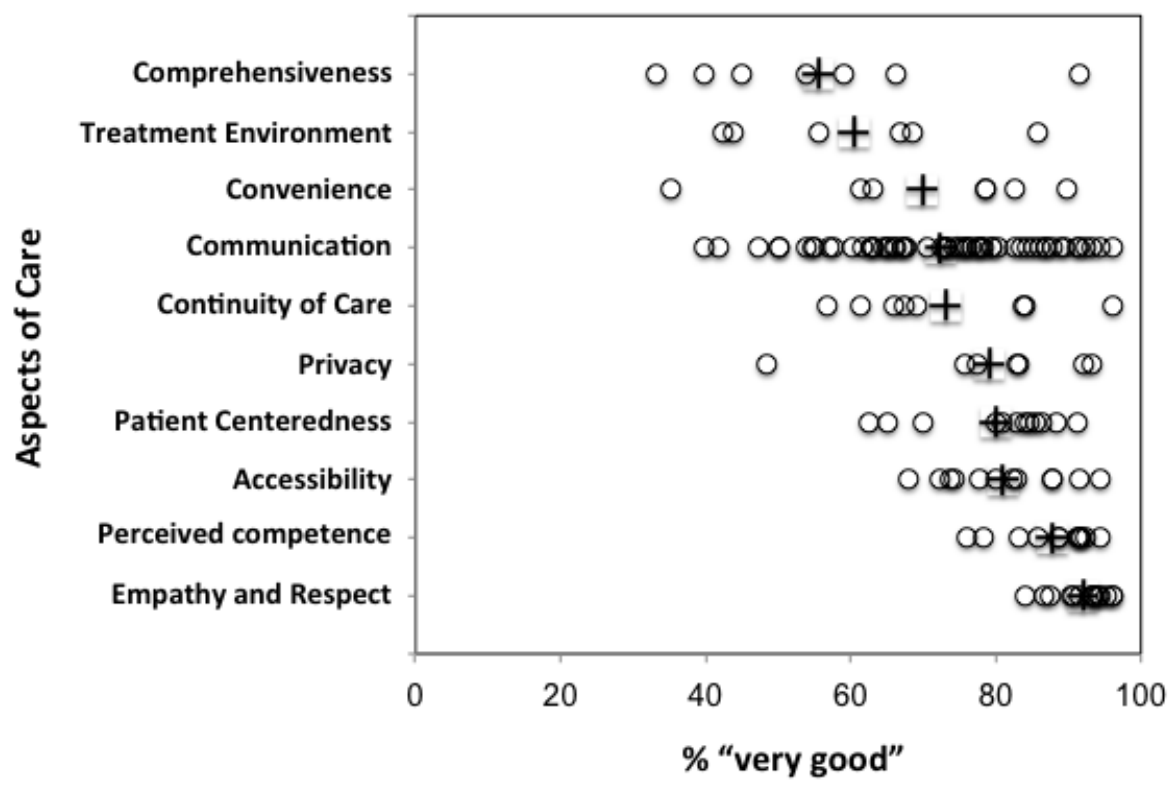

Figure e3: Patients' assessment of the quality of ten different aspects of their care. The individual elements of care (o) were assigned to ten categories corresponding to different aspects of care. The mean percentage of "very good" ratings in each category is shown by a cross $(+)$. 
Table e5: Ranking of the priorities for quality improvement identified by the importance/quality analysis and ranking by quality and importance alone

\begin{tabular}{|c|c|c|c|c|}
\hline Element of Care* & Aspect of Care & $\begin{array}{l}\text { Rank by } \\
\text { Importance } \\
\text { /quality }\end{array}$ & $\begin{array}{l}\text { Rank by } \\
\text { Quality } \\
\text { (inverse) }\end{array}$ & $\begin{array}{c}\text { Rank by } \\
\text { Importance }\end{array}$ \\
\hline $\begin{array}{l}\text { Someone on the healthcare team } \\
\text { explains that radiation treatment } \\
\text { cannot usually be given to the } \\
\text { prostate again if it is not successful } \\
\text { the first time (2) }\end{array}$ & $\begin{array}{l}\text { Adequacy of } \\
\text { Information } \\
\text { Sharing }\end{array}$ & 1 & 4 & 49 \\
\hline $\begin{array}{l}\text { Someone on the healthcare team } \\
\text { explains the other treatments that are } \\
\text { available if radiation treatment is not } \\
\text { successful (2) }\end{array}$ & $\begin{array}{l}\text { Adequacy of } \\
\text { Information } \\
\text { Sharing }\end{array}$ & 2 & 5 & 71 \\
\hline $\begin{array}{l}\text { There is somewhere convenient to } \\
\text { park (5) }\end{array}$ & Convenience & 3 & 2 & 113 \\
\hline $\begin{array}{l}\text { Someone on the healthcare team } \\
\text { explains that radiation treatment may } \\
\text { permanently affect bowel function } \\
\text { (2) }\end{array}$ & $\begin{array}{l}\text { Adequacy of } \\
\text { Information } \\
\text { Sharing }\end{array}$ & 4 & 33 & 40 \\
\hline $\begin{array}{l}\text { Someone on the healthcare team } \\
\text { explains what prostate cancer is and } \\
\text { how it can affect the patient's health } \\
\text { (1) }\end{array}$ & $\begin{array}{l}\text { Adequacy of } \\
\text { Information } \\
\text { Sharing }\end{array}$ & 5 & 12 & 86 \\
\hline $\begin{array}{l}\text { Someone on the healthcare team } \\
\text { explains that radiation treatment may } \\
\text { permanently affect bladder function } \\
\text { (2) }\end{array}$ & $\begin{array}{l}\text { Adequacy of } \\
\text { Information } \\
\text { Sharing }\end{array}$ & 6 & 30 & 42 \\
\hline $\begin{array}{l}\text { The radiation oncologist makes sure } \\
\text { the patient knows that the cancer is } \\
\text { confined to the prostate, and there is } \\
\text { no sign that it has spread to any other } \\
\text { part of the body (1) }\end{array}$ & $\begin{array}{l}\text { Adequacy of } \\
\text { Information } \\
\text { Sharing }\end{array}$ & 7 & 66 & 2 \\
\hline $\begin{array}{l}\text { Someone on the healthcare team } \\
\text { explains when the patient can resume } \\
\text { all of his previous activities after } \\
\text { radiation treatment (4) }\end{array}$ & $\begin{array}{l}\text { Adequacy of } \\
\text { Information } \\
\text { Sharing }\end{array}$ & 8 & 16 & 100 \\
\hline $\begin{array}{l}\text { The patient is given enough } \\
\text { information to understand how the } \\
\text { radiation treatment works (3) }\end{array}$ & $\begin{array}{l}\text { Adequacy of } \\
\text { Information } \\
\text { Sharing }\end{array}$ & 9 & 15 & 73 \\
\hline $\begin{array}{l}\text { The radiation oncologist gives the } \\
\text { patient enough information about the } \\
\text { chance of curing his cancer with } \\
\text { each treatment option (2) }\end{array}$ & $\begin{array}{l}\text { Adequacy of } \\
\text { Information } \\
\text { Sharing }\end{array}$ & 10 & 38 & 25 \\
\hline
\end{tabular}




\begin{tabular}{|c|c|c|c|c|}
\hline $\begin{array}{l}\text { The radiation oncologist makes sure } \\
\text { the patient knows the stage of his } \\
\text { cancer and understands what that } \\
\text { means (1) }\end{array}$ & $\begin{array}{l}\text { Adequacy of } \\
\text { Information } \\
\text { Sharing }\end{array}$ & 10 & 52 & 12 \\
\hline $\begin{array}{l}\text { The patient is made aware of who to } \\
\text { contact if he is concerned about the } \\
\text { cancer coming back (4) }\end{array}$ & $\begin{array}{l}\text { Continuity of } \\
\text { care }\end{array}$ & 12 & 42 & 34 \\
\hline $\begin{array}{l}\text { Someone on the healthcare team } \\
\text { gives enough information and } \\
\text { direction to the patient about how to } \\
\text { care for himself after radiation } \\
\text { treatment (4) }\end{array}$ & $\begin{array}{l}\text { Adequacy of } \\
\text { Information } \\
\text { Sharing }\end{array}$ & 13 & 20 & 102 \\
\hline $\begin{array}{l}\text { Someone at the cancer centre } \\
\text { arranges for the patient to receive } \\
\text { any help he needs in dealing with his } \\
\text { anxiety about the diagnosis (1) }\end{array}$ & $\begin{array}{l}\text { Comprehensive } \\
\text { ness }\end{array}$ & 14 & 21 & 77 \\
\hline $\begin{array}{l}\text { Someone on the healthcare team } \\
\text { explains who to contact if additional } \\
\text { care is needed in recovery after } \\
\text { radiation treatment (4) }\end{array}$ & $\begin{array}{l}\text { Adequacy of } \\
\text { Information } \\
\text { Sharing }\end{array}$ & 15 & 29 & 64 \\
\hline $\begin{array}{l}\text { The radiation oncologist gives the } \\
\text { patient enough information about the } \\
\text { side effects of each treatment option } \\
\text { (2) }\end{array}$ & $\begin{array}{l}\text { Adequacy of } \\
\text { Information } \\
\text { Sharing }\end{array}$ & 16 & 60 & 10 \\
\hline $\begin{array}{l}\text { The radiation oncologist tells the } \\
\text { patient about his PSA level and } \\
\text { explains what that means (1) }\end{array}$ & $\begin{array}{l}\text { Adequacy of } \\
\text { Information } \\
\text { Sharing }\end{array}$ & 17 & 41 & 62 \\
\hline $\begin{array}{l}\text { The radiation oncologist makes sure } \\
\text { the patient knows the grade of his } \\
\text { cancer and understands what that } \\
\text { means (1) }\end{array}$ & $\begin{array}{l}\text { Adequacy of } \\
\text { Information } \\
\text { Sharing }\end{array}$ & 18 & 58 & 9 \\
\hline $\begin{array}{l}\text { Someone on the healthcare team } \\
\text { explains that the PSA level is all that } \\
\text { is needed to tell if the cancer is under } \\
\text { control or not (4) }\end{array}$ & $\begin{array}{l}\text { Adequacy of } \\
\text { Information } \\
\text { Sharing }\end{array}$ & 19 & 50 & 51 \\
\hline $\begin{array}{l}\text { Once the decision to have radiation } \\
\text { treatment has been made, the patient } \\
\text { is given enough information about } \\
\text { how long he will have to wait to start } \\
\text { treatment (3) }\end{array}$ & $\begin{array}{l}\text { Adequacy of } \\
\text { Information } \\
\text { Sharing }\end{array}$ & 20 & 31 & 80 \\
\hline $\begin{array}{l}\text { Someone on the healthcare team } \\
\text { explains how the patient should } \\
\text { modify his diet to avoid bowel upset } \\
\text { during the course of radiation } \\
\text { treatment (4) }\end{array}$ & $\begin{array}{l}\text { Adequacy of } \\
\text { Information } \\
\text { Sharing }\end{array}$ & 20 & 25 & 104 \\
\hline Someone on the healthcare team & Adequacy of & 22 & 40 & 92 \\
\hline
\end{tabular}




\begin{tabular}{|c|c|c|c|c|}
\hline $\begin{array}{l}\text { explains that the course of treatment } \\
\text { needs to be completed without taking } \\
\text { a break (of longer than a few days) } \\
\text { (3) }\end{array}$ & $\begin{array}{l}\text { Information } \\
\text { Sharing }\end{array}$ & & & \\
\hline $\begin{array}{l}\text { The radiation oncologist makes sure } \\
\text { the patient understands the results of } \\
\text { the biopsy of the prostate, the blood } \\
\text { tests, and any x-rays and scans he } \\
\text { may have had (1) }\end{array}$ & $\begin{array}{l}\text { Adequacy of } \\
\text { Information } \\
\text { Sharing }\end{array}$ & 23 & 61 & 35 \\
\hline $\begin{array}{l}\text { Someone on the healthcare team } \\
\text { answers any questions the patient has } \\
\text { about the possible causes of prostate } \\
\text { cancer (1) }\end{array}$ & $\begin{array}{l}\text { Adequacy of } \\
\text { Information } \\
\text { Sharing }\end{array}$ & 23 & 13 & 96 \\
\hline $\begin{array}{l}\text { The patient is made aware that he } \\
\text { has the right to get a second opinion } \\
\text { from another radiation oncologist (2) }\end{array}$ & $\begin{array}{l}\text { Adequacy of } \\
\text { Information } \\
\text { Sharing }\end{array}$ & 25 & 9 & 126 \\
\hline $\begin{array}{l}\text { The patient is given enough } \\
\text { information about the chance of } \\
\text { curing his cancer with radiation } \\
\text { treatment }(2)\end{array}$ & $\begin{array}{l}\text { Adequacy of } \\
\text { Information } \\
\text { Sharing }\end{array}$ & 26 & 51 & 28 \\
\hline $\begin{array}{l}\text { Someone on the healthcare team } \\
\text { explains that doctors will be } \\
\text { monitoring PSA levels at regular } \\
\text { intervals during follow-up from } \\
\text { radiation treatment (4) }\end{array}$ & $\begin{array}{l}\text { Adequacy of } \\
\text { Information } \\
\text { Sharing }\end{array}$ & 27 & 73 & 41 \\
\hline $\begin{array}{l}\text { The radiation oncologist makes sure } \\
\text { the patient understands the benefits } \\
\text { of radiation treatment and its side } \\
\text { effects before asking for consent to } \\
\text { have radiation treatment ( } 2 \text { ) }\end{array}$ & $\begin{array}{l}\text { Adequacy of } \\
\text { Information } \\
\text { Sharing }\end{array}$ & 28 & 64 & 16 \\
\hline $\begin{array}{l}\text { The patient is given enough } \\
\text { information about how the radiation } \\
\text { treatment is planned (3) }\end{array}$ & $\begin{array}{l}\text { Adequacy of } \\
\text { Information } \\
\text { Sharing }\end{array}$ & 29 & 27 & 97 \\
\hline $\begin{array}{l}\text { Someone on the healthcare team } \\
\text { explains that prostate cancer is not } \\
\text { infectious and that it cannot be } \\
\text { transmitted to anyone else (1) }\end{array}$ & $\begin{array}{l}\text { Adequacy of } \\
\text { Information } \\
\text { Sharing }\end{array}$ & 30 & 11 & 119 \\
\hline $\begin{array}{l}\text { Someone on the healthcare team } \\
\text { explains that radiation treatment may } \\
\text { permanently affect sexual } \\
\text { functioning (2) }\end{array}$ & $\begin{array}{l}\text { Adequacy of } \\
\text { Information } \\
\text { Sharing }\end{array}$ & 31 & 57 & 82 \\
\hline $\begin{array}{l}\text { The cancer centre appears to be } \\
\text { clean and well looked after (5) }\end{array}$ & $\begin{array}{l}\text { Acceptability of } \\
\text { Treatment } \\
\text { Environment } \\
\end{array}$ & 31 & 96 & 48 \\
\hline $\begin{array}{l}\text { The patient has a short wait to get an } \\
\text { appointment to see the radiation }\end{array}$ & Accessibility & 31 & 54 & 107 \\
\hline
\end{tabular}




\begin{tabular}{|c|c|c|c|c|}
\hline oncologist for the first time (1) & & & & \\
\hline $\begin{array}{l}\text { The patient is given enough } \\
\text { information about how the treatment } \\
\text { is scheduled and flexibility in the } \\
\text { daily appointment times ( } 3 \text { ) }\end{array}$ & $\begin{array}{l}\text { Adequacy of } \\
\text { Information } \\
\text { Sharing }\end{array}$ & 31 & 19 & 109 \\
\hline $\begin{array}{l}\text { The patient's family physician is } \\
\text { kept informed about the cancer care } \\
\text { (5) }\end{array}$ & $\begin{array}{l}\text { Continuity of } \\
\text { Care }\end{array}$ & 35 & 46 & 91 \\
\hline $\begin{array}{l}\text { The patient is given enough } \\
\text { information about the possible side } \\
\text { effects of radiation treatment ( } 2 \text { ) }\end{array}$ & $\begin{array}{l}\text { Adequacy of } \\
\text { Information } \\
\text { Sharing }\end{array}$ & 36 & 77 & 21 \\
\hline $\begin{array}{l}\text { The patient has a short wait in the } \\
\text { waiting room for daily radiation } \\
\text { treatment (4) }\end{array}$ & Accessibility & 37 & 49 & 129 \\
\hline $\begin{array}{l}\text { The patient is aware that no one else } \\
\text { other than him and the healthcare } \\
\text { professionals looking after him are } \\
\text { able to see his medical records } \\
\text { without his permission (5) }\end{array}$ & Privacy & 38 & 59 & 88 \\
\hline $\begin{array}{l}\text { The information about treatment } \\
\text { options is provided to the patient } \\
\text { before any decision is made about } \\
\text { the way he will be treated (2) }\end{array}$ & $\begin{array}{l}\text { Adequacy of } \\
\text { Information } \\
\text { Sharing }\end{array}$ & 39 & 74 & 25 \\
\hline $\begin{array}{l}\text { Someone on the healthcare team } \\
\text { explains the arrangements for follow } \\
\text {-up care after the radiation treatment } \\
\text { is over (4) }\end{array}$ & $\begin{array}{l}\text { Adequacy of } \\
\text { Information } \\
\text { Sharing }\end{array}$ & 40 & 68 & 53 \\
\hline $\begin{array}{l}\text { Before radiation treatment starts, the } \\
\text { patient is given enough information } \\
\text { about what will happen each day } \\
\text { when he comes for treatment ( } 3 \text { ) }\end{array}$ & $\begin{array}{l}\text { Adequacy of } \\
\text { Information } \\
\text { Sharing }\end{array}$ & 41 & 34 & 108 \\
\hline $\begin{array}{l}\text { The patient has a short wait in the } \\
\text { waiting room when he comes to the } \\
\text { cancer centre to see the radiation } \\
\text { oncologist for the first time }(1)\end{array}$ & Accessibility & 41 & 44 & 135 \\
\hline $\begin{array}{l}\text { A social worker is available to } \\
\text { provide advice on financial and } \\
\text { social issues arising from the } \\
\text { diagnosis (1) }\end{array}$ & $\begin{array}{l}\text { Comprehensive } \\
\text { ness }\end{array}$ & 43 & 3 & 136 \\
\hline $\begin{array}{l}\text { Someone at the cancer centre gives } \\
\text { the patient information about support } \\
\text { groups in his area for patients and/or } \\
\text { family members (1) }\end{array}$ & $\begin{array}{l}\text { Comprehensive } \\
\text { ness }\end{array}$ & 44 & 1 & 137 \\
\hline $\begin{array}{l}\text { Someone on the healthcare team } \\
\text { other than the radiation oncologist is } \\
\text { available to provide support to the }\end{array}$ & $\begin{array}{l}\text { Comprehensive } \\
\text { ness }\end{array}$ & 45 & 14 & 132 \\
\hline
\end{tabular}




\begin{tabular}{|c|c|c|c|c|}
\hline $\begin{array}{l}\text { patient in making the decision about } \\
\text { treatment (2) }\end{array}$ & & & & \\
\hline $\begin{array}{l}\text { The radiation oncologist reads the } \\
\text { patient's previous medical records } \\
\text { before seeing the patient for the first } \\
\text { time (1) }\end{array}$ & Competence & 46 & 69 & 52 \\
\hline $\begin{array}{l}\text { The patient gets all the help he needs } \\
\text { from the radiation oncologist to } \\
\text { make up his mind about which } \\
\text { treatment to have (2) }\end{array}$ & $\begin{array}{l}\text { Patient } \\
\text { Centeredness }\end{array}$ & 47 & 93 & 22 \\
\hline $\begin{array}{l}\text { The patient is aware that he has a } \\
\text { right to see all the information in his } \\
\text { medical record (5) }\end{array}$ & $\begin{array}{l}\text { Patient } \\
\text { Centeredness }\end{array}$ & 48 & 47 & 101 \\
\hline $\begin{array}{l}\text { The patient gets enough information } \\
\text { from the radiation oncologist to be } \\
\text { able to participate in the decision } \\
\text { about treatment (2) }\end{array}$ & $\begin{array}{l}\text { Patient } \\
\text { Centeredness }\end{array}$ & 49 & 82 & 33 \\
\hline $\begin{array}{l}\text { The radiation oncologist explains to } \\
\text { the patient that he can change his } \\
\text { mind about which treatment to have } \\
\text { as long as he does so before the } \\
\text { treatment starts (2) }\end{array}$ & $\begin{array}{l}\text { Adequacy of } \\
\text { Information } \\
\text { Sharing }\end{array}$ & 50 & 35 & 95 \\
\hline $\begin{array}{l}\text { The radiation oncologist asks the } \\
\text { patient about any other medical } \\
\text { problems he may have (1) }\end{array}$ & Competence & 51 & 62 & 69 \\
\hline $\begin{array}{l}\text { The radiation oncologist is aware of } \\
\text { the test results and has the results } \\
\text { available when seeing the patient for } \\
\text { the first time (1) }\end{array}$ & Competence & 51 & 85 & 14 \\
\hline $\begin{array}{l}\text { The patient is encouraged by the } \\
\text { cancer center to bring a relative or } \\
\text { friend along to the first appointment } \\
\text { with the radiation oncologist (1) }\end{array}$ & $\begin{array}{l}\text { Patient } \\
\text { Centeredness }\end{array}$ & 51 & 32 & 116 \\
\hline $\begin{array}{l}\text { The radiation oncologist explains } \\
\text { what each treatment option involves } \\
\text { (2) }\end{array}$ & $\begin{array}{l}\text { Adequacy of } \\
\text { Information } \\
\text { Sharing }\end{array}$ & 54 & 53 & 56 \\
\hline $\begin{array}{l}\text { The radiation oncologist makes sure } \\
\text { the patient understands the treatment } \\
\text { options before making up his mind } \\
\text { about which treatment to have (2) }\end{array}$ & $\begin{array}{l}\text { Adequacy of } \\
\text { Information } \\
\text { Sharing }\end{array}$ & 54 & 94 & 29 \\
\hline $\begin{array}{l}\text { The radiation oncologist explains the } \\
\text { different forms of treatment that are } \\
\text { available for prostate cancer (1) }\end{array}$ & $\begin{array}{l}\text { Adequacy of } \\
\text { Information } \\
\text { Sharing }\end{array}$ & 56 & 92 & 15 \\
\hline $\begin{array}{l}\text { The radiation oncologist sees the } \\
\text { patient at least once a week during } \\
\text { the course of radiation treatment (4) }\end{array}$ & $\begin{array}{l}\text { Continuity of } \\
\text { care }\end{array}$ & 56 & 18 & 130 \\
\hline
\end{tabular}




\begin{tabular}{|c|c|c|c|c|}
\hline $\begin{array}{l}\text { Someone on the healthcare team } \\
\text { gives the patient written information } \\
\text { about the side effects of each } \\
\text { treatment option }(2)\end{array}$ & $\begin{array}{l}\text { Adequacy of } \\
\text { Information } \\
\text { Sharing }\end{array}$ & 58 & 55 & 66 \\
\hline $\begin{array}{l}\text { Someone on the healthcare team is } \\
\text { always available to answer the } \\
\text { patient's questions and advise on the } \\
\text { management of side effects during } \\
\text { the course of radiation treatment (4) }\end{array}$ & Accessibility & 59 & 76 & 67 \\
\hline $\begin{array}{l}\text { Directions and signs inside and } \\
\text { outside the cancer centre are easy to } \\
\text { understand (5) }\end{array}$ & Convenience & 59 & 23 & 123 \\
\hline $\begin{array}{l}\text { Someone on the healthcare team } \\
\text { explains that radiation treatment } \\
\text { involves the use of high energy rays } \\
\text { directed at the prostate from outside } \\
\text { the body (2) }\end{array}$ & $\begin{array}{l}\text { Adequacy of } \\
\text { Information } \\
\text { Sharing }\end{array}$ & 61 & 63 & 74 \\
\hline $\begin{array}{l}\text { The patient trusts the radiation } \\
\text { oncologist to look after him properly } \\
\text { (5) }\end{array}$ & Competence & 61 & 109 & 3 \\
\hline $\begin{array}{l}\text { The radiation oncologist is } \\
\text { knowledgeable and experienced in } \\
\text { dealing with prostate cancer (5) }\end{array}$ & Competence & 61 & 120 & 1 \\
\hline $\begin{array}{l}\text { Once the treatment starts, someone } \\
\text { on the healthcare team reminds the } \\
\text { patient of the potential side effects to } \\
\text { expect during the course of radiation } \\
\text { treatment (4) }\end{array}$ & $\begin{array}{l}\text { Adequacy of } \\
\text { Information } \\
\text { Sharing }\end{array}$ & 64 & 43 & 115 \\
\hline $\begin{array}{l}\text { The patient can find his way around } \\
\text { the cancer centre easily (5) }\end{array}$ & Convenience & 64 & 28 & 127 \\
\hline $\begin{array}{l}\text { The cancer centre provides resources } \\
\text { to assist the patient in understanding } \\
\text { and dealing with prostate cancer (e.g. } \\
\text { staffed information services, library } \\
\text { of books and DVDs about cancer) } \\
\text { (1) }\end{array}$ & $\begin{array}{l}\text { Comprehensive } \\
\text { ness }\end{array}$ & 66 & 8 & 133 \\
\hline $\begin{array}{l}\text { The patient understands that there is } \\
\text { no immediate rush to make a } \\
\text { decision about treatment although } \\
\text { it's best to make a decision within a } \\
\text { week or two (2) }\end{array}$ & $\begin{array}{l}\text { Adequacy of } \\
\text { Information } \\
\text { Sharing }\end{array}$ & 67 & 81 & 83 \\
\hline $\begin{array}{l}\text { The patient has enough time with the } \\
\text { radiation oncologist to get all of the } \\
\text { information he needs about treatment } \\
\text { options (2) }\end{array}$ & Accessibility & 68 & 83 & 32 \\
\hline The patient has enough time to & Patient & 69 & 90 & 50 \\
\hline
\end{tabular}




\begin{tabular}{|c|c|c|c|c|}
\hline $\begin{array}{l}\text { consider the treatment options before } \\
\text { it is decided how he will be treated } \\
\text { (2) }\end{array}$ & Centeredness & & & \\
\hline $\begin{array}{l}\text { Someone on the healthcare team } \\
\text { explains that radiation treatment can } \\
\text { only be delivered at a few } \\
\text { specialized treatment centers (2) }\end{array}$ & $\begin{array}{l}\text { Adequacy of } \\
\text { Information } \\
\text { Sharing }\end{array}$ & 70 & 22 & 125 \\
\hline $\begin{array}{l}\text { The radiation oncologist describes } \\
\text { and explains all of the treatment } \\
\text { options that are available to the } \\
\text { patient other than radiation treatment } \\
\text { (2) }\end{array}$ & $\begin{array}{l}\text { Adequacy of } \\
\text { Information } \\
\text { Sharing }\end{array}$ & 71 & 70 & 56 \\
\hline $\begin{array}{l}\text { Someone on the healthcare team } \\
\text { explains that radiation treatment is } \\
\text { delivered by the radiation therapists, } \\
\text { not a radiation oncologist (3) }\end{array}$ & $\begin{array}{l}\text { Adequacy of } \\
\text { Information } \\
\text { Sharing }\end{array}$ & 71 & 48 & 120 \\
\hline $\begin{array}{l}\text { The patient is aware of who to } \\
\text { contact with questions about his } \\
\text { prostate cancer and treatment (5) }\end{array}$ & $\begin{array}{l}\text { Continuity of } \\
\text { care }\end{array}$ & 73 & 88 & 16 \\
\hline $\begin{array}{l}\text { The nurses explain things to the } \\
\text { patient in a way that he can } \\
\text { understand (5) }\end{array}$ & $\begin{array}{l}\text { Adequacy of } \\
\text { Information } \\
\text { Sharing }\end{array}$ & 74 & 105 & 36 \\
\hline $\begin{array}{l}\text { Someone on the healthcare team is } \\
\text { available if needed to help explain } \\
\text { the diagnosis to family members (1) }\end{array}$ & $\begin{array}{l}\text { Comprehensive } \\
\text { ness }\end{array}$ & 75 & 37 & 117 \\
\hline $\begin{array}{l}\text { The atmosphere in the waiting room } \\
\text { is relaxing (5) }\end{array}$ & $\begin{array}{l}\text { Acceptability of } \\
\text { Treatment } \\
\text { Environment }\end{array}$ & 76 & 39 & 128 \\
\hline $\begin{array}{l}\text { The cancer centre has a place to stay } \\
\text { overnight if the patient lives far } \\
\text { away }(5)\end{array}$ & Convenience & 77 & 112 & 106 \\
\hline $\begin{array}{l}\text { The radiation oncologist carefully } \\
\text { assesses the patient's suitability for } \\
\text { radiation treatment (1) }\end{array}$ & Competence & 78 & 97 & 24 \\
\hline $\begin{array}{l}\text { The radiation oncologist shows } \\
\text { interest in the patient as a person, not } \\
\text { just as a patient (5) }\end{array}$ & $\begin{array}{l}\text { Patient } \\
\text { Centeredness }\end{array}$ & 79 & 76 & 90 \\
\hline $\begin{array}{l}\text { The nurses show sensitivity to the } \\
\text { patient's feelings and emotional } \\
\text { needs (5) }\end{array}$ & $\begin{array}{l}\text { Empathy and } \\
\text { Respectfulness } \\
\text { of Caregivers }\end{array}$ & 80 & 91 & 89 \\
\hline $\begin{array}{l}\text { The patient is involved as much as } \\
\text { he wants in making the final decision } \\
\text { about which treatment to have (2) }\end{array}$ & $\begin{array}{l}\text { Patient } \\
\text { Centeredness }\end{array}$ & 81 & 107 & 39 \\
\hline $\begin{array}{l}\text { The nurses care about the patient's } \\
\text { well-being (5) }\end{array}$ & $\begin{array}{l}\text { Empathy and } \\
\text { Respectfulness } \\
\text { of Caregivers }\end{array}$ & 82 & 103 & 68 \\
\hline
\end{tabular}




\begin{tabular}{|c|c|c|c|c|}
\hline $\begin{array}{l}\text { The radiation oncologist is honest } \\
\text { with the patient (5) }\end{array}$ & $\begin{array}{l}\text { Adequacy of } \\
\text { Information } \\
\text { Sharing }\end{array}$ & 82 & 129 & 8 \\
\hline $\begin{array}{l}\text { The patient has enough time with a } \\
\text { member of the healthcare team to } \\
\text { discuss the treatment plan (3) }\end{array}$ & Accessibility & 84 & 56 & 97 \\
\hline $\begin{array}{l}\text { The radiation oncologist shows } \\
\text { sensitivity to the patient's feelings } \\
\text { and emotional needs (5) }\end{array}$ & $\begin{array}{l}\text { Empathy and } \\
\text { Respectfulness } \\
\text { of Caregivers }\end{array}$ & 84 & 100 & 63 \\
\hline $\begin{array}{l}\text { Someone on the healthcare team } \\
\text { explains that radiation treatment } \\
\text { often causes urinary symptoms } \\
\text { during treatment (2) }\end{array}$ & $\begin{array}{l}\text { Adequacy of } \\
\text { Information } \\
\text { Sharing }\end{array}$ & 84 & 101 & 59 \\
\hline $\begin{array}{l}\text { The radiation oncologist cares about } \\
\text { the patient's well-being (5) }\end{array}$ & $\begin{array}{l}\text { Empathy and } \\
\text { Respectfulness } \\
\text { of Caregivers }\end{array}$ & 84 & 113 & 30 \\
\hline $\begin{array}{l}\text { The radiation oncologist explains } \\
\text { things to the patient in a way that he } \\
\text { can understand (5) }\end{array}$ & $\begin{array}{l}\text { Adequacy of } \\
\text { Information } \\
\text { Sharing }\end{array}$ & 84 & 118 & 19 \\
\hline $\begin{array}{l}\text { The patient feels that his rights for } \\
\text { privacy are fully protected at the } \\
\text { cancer centre (5) }\end{array}$ & Privacy & 89 & 65 & 79 \\
\hline $\begin{array}{l}\text { The nurses take the time to answer } \\
\text { all of the patient's questions (5) }\end{array}$ & Accessibility & 90 & 106 & 43 \\
\hline $\begin{array}{l}\text { Once an appointment is made for the } \\
\text { patient it is not cancelled or } \\
\text { postponed (5) }\end{array}$ & Convenience & 90 & 71 & 111 \\
\hline $\begin{array}{l}\text { The cancer centre seems to have all } \\
\text { the equipment and facilities needed } \\
\text { to completely care for the patient's } \\
\text { prostate cancer ( } 5 \text { ) }\end{array}$ & $\begin{array}{l}\text { Comprehensive } \\
\text { ness }\end{array}$ & 90 & 121 & 4 \\
\hline $\begin{array}{l}\text { If the patient wants, someone on the } \\
\text { healthcare team is willing to answer } \\
\text { questions about treatment from } \\
\text { family or friends (2) }\end{array}$ & $\begin{array}{l}\text { Patient } \\
\text { Centeredness }\end{array}$ & 93 & 26 & 114 \\
\hline $\begin{array}{l}\text { The nurses are honest with the } \\
\text { patient }(5)\end{array}$ & $\begin{array}{l}\text { Adequacy of } \\
\text { Information } \\
\text { Sharing }\end{array}$ & 94 & 110 & 47 \\
\hline $\begin{array}{l}\text { The patient feels that he can trust the } \\
\text { nurses with confidential information } \\
\text { (5) }\end{array}$ & Privacy & 95 & 84 & 94 \\
\hline $\begin{array}{l}\text { Transportation to/from the cancer } \\
\text { centre is available for the patient if } \\
\text { needed (5) }\end{array}$ & Convenience & 95 & 80 & 112 \\
\hline $\begin{array}{l}\text { Someone on the health care team } \\
\text { offers written information about }\end{array}$ & $\begin{array}{l}\text { Adequacy of } \\
\text { Information }\end{array}$ & 97 & 87 & 70 \\
\hline
\end{tabular}




\begin{tabular}{|c|c|c|c|c|}
\hline $\begin{array}{l}\text { prostate cancer to the patient that he } \\
\text { can take home with him (1) }\end{array}$ & Sharing & & & \\
\hline $\begin{array}{l}\text { Someone on the healthcare team } \\
\text { explains that radiation treatment } \\
\text { often causes bowel symptoms during } \\
\text { treatment (2) }\end{array}$ & $\begin{array}{l}\text { Adequacy of } \\
\text { Information } \\
\text { Sharing }\end{array}$ & 98 & 102 & 65 \\
\hline $\begin{array}{l}\text { The nurses listen carefully to all the } \\
\text { patient's concerns (5) }\end{array}$ & $\begin{array}{l}\text { Adequacy of } \\
\text { Information } \\
\text { Sharing }\end{array}$ & 98 & 111 & 44 \\
\hline $\begin{array}{l}\text { The radiation oncologist takes the } \\
\text { time to answer all of the patient's } \\
\text { questions (5) }\end{array}$ & Accessibility & 98 & 119 & 7 \\
\hline $\begin{array}{l}\text { The radiation oncologist listens } \\
\text { carefully to all the patient's concerns } \\
\text { (5) }\end{array}$ & $\begin{array}{l}\text { Adequacy of } \\
\text { Information } \\
\text { Sharing }\end{array}$ & 98 & 126 & 16 \\
\hline $\begin{array}{l}\text { The radiation oncologist makes the } \\
\text { patient feel like he can ask any } \\
\text { questions he wants to (5) }\end{array}$ & $\begin{array}{l}\text { Empathy and } \\
\text { Respectfulness } \\
\text { of Caregivers }\end{array}$ & 98 & 132 & 11 \\
\hline $\begin{array}{l}\text { The patient has a short wait to start } \\
\text { treatment after the decision was } \\
\text { made to have radiation treatment (4) }\end{array}$ & Accessibility & 103 & 79 & 105 \\
\hline $\begin{array}{l}\text { Appointments are scheduled for a } \\
\text { time that is convenient }(5)\end{array}$ & Convenience & 103 & 72 & 122 \\
\hline $\begin{array}{l}\text { The nurses make the patient feel like } \\
\text { he can ask any questions he wants to } \\
\text { (5) }\end{array}$ & $\begin{array}{l}\text { Empathy and } \\
\text { Respectfulness } \\
\text { of Caregivers }\end{array}$ & 103 & 123 & 44 \\
\hline $\begin{array}{l}\text { The furniture in the waiting room is } \\
\text { comfortable (5) }\end{array}$ & $\begin{array}{l}\text { Acceptability of } \\
\text { Treatment } \\
\text { Environment }\end{array}$ & 106 & 17 & 138 \\
\hline $\begin{array}{l}\text { Someone at the cancer centre is } \\
\text { available to answer the patient's } \\
\text { questions in between appointments } \\
\text { (5) }\end{array}$ & Accessibility & 107 & 67 & 76 \\
\hline $\begin{array}{l}\text { The nurses show interest in the } \\
\text { patient as a person, not just as a } \\
\text { patient (5) }\end{array}$ & $\begin{array}{l}\text { Patient } \\
\text { Centeredness }\end{array}$ & 108 & 99 & 103 \\
\hline $\begin{array}{l}\text { The nurses are knowledgeable and } \\
\text { experienced in dealing with prostate } \\
\text { cancer }(5)\end{array}$ & Competence & 108 & 115 & 13 \\
\hline $\begin{array}{l}\text { During treatment, the radiation } \\
\text { oncologist, nurses and radiation } \\
\text { therapists do everything they can to } \\
\text { help the patient get through } \\
\text { treatment with as few problems as } \\
\text { possible (4) }\end{array}$ & Competence & 110 & 123 & 38 \\
\hline During treatment, the radiation & Accessibility & 110 & 105 & 131 \\
\hline
\end{tabular}




\begin{tabular}{|c|c|c|c|c|}
\hline $\begin{array}{l}\text { therapists make enough time for the } \\
\text { patient (4) }\end{array}$ & & & & \\
\hline $\begin{array}{l}\text { The waiting area and treatment } \\
\text { rooms are quiet (5) }\end{array}$ & $\begin{array}{l}\text { Acceptability of } \\
\text { Treatment } \\
\text { Environment }\end{array}$ & 112 & 45 & 134 \\
\hline $\begin{array}{l}\text { The patient is welcome to bring a } \\
\text { friend or relative with him to his } \\
\text { appointments (5) }\end{array}$ & $\begin{array}{l}\text { Patient } \\
\text { Centeredness }\end{array}$ & 113 & 78 & 118 \\
\hline $\begin{array}{l}\text { There is enough space in the waiting } \\
\text { room that the patient can have a } \\
\text { private conversation with his } \\
\text { companion (5) }\end{array}$ & Privacy & 114 & 10 & 140 \\
\hline $\begin{array}{l}\text { The radiation therapists care about } \\
\text { the patient's well-being ( } 5 \text { ) }\end{array}$ & $\begin{array}{l}\text { Empathy and } \\
\text { Respectfulness } \\
\text { of Caregivers }\end{array}$ & 115 & 139 & 72 \\
\hline $\begin{array}{l}\text { The radiation therapists are polite to } \\
\text { the patient }(5)\end{array}$ & $\begin{array}{l}\text { Empathy and } \\
\text { Respectfulness } \\
\text { of Caregivers }\end{array}$ & 116 & 134 & 85 \\
\hline $\begin{array}{l}\text { The patient trusts the nurses to look } \\
\text { after him properly (5) }\end{array}$ & Competence & 117 & 108 & 46 \\
\hline $\begin{array}{l}\text { The radiation therapists are } \\
\text { knowledgeable and experienced in } \\
\text { dealing with prostate cancer (5) }\end{array}$ & Competence & 117 & 137 & 5 \\
\hline $\begin{array}{l}\text { The radiation therapists explain } \\
\text { things to the patient in a way that he } \\
\text { can understand (5) }\end{array}$ & $\begin{array}{l}\text { Adequacy of } \\
\text { Information } \\
\text { Sharing }\end{array}$ & 117 & 137 & 37 \\
\hline $\begin{array}{l}\text { Someone on the healthcare team } \\
\text { explains that radiation treatment } \\
\text { often causes temporary fatigue ( } 2)\end{array}$ & $\begin{array}{l}\text { Adequacy of } \\
\text { Information } \\
\text { Sharing } \\
\end{array}$ & 120 & 98 & 93 \\
\hline $\begin{array}{l}\text { The nurses are polite to the patient } \\
\text { (5) }\end{array}$ & $\begin{array}{l}\text { Empathy and } \\
\text { Respectfulness } \\
\text { of Caregivers }\end{array}$ & 120 & 114 & 81 \\
\hline $\begin{array}{l}\text { The patient has confidence in his } \\
\text { treatment team that he is treated } \\
\text { correctly every day (4) }\end{array}$ & Competence & 120 & 127 & 23 \\
\hline $\begin{array}{l}\text { Waiting areas are decorated nicely } \\
\text { (5) }\end{array}$ & $\begin{array}{l}\text { Acceptability of } \\
\text { Treatment } \\
\text { Environment } \\
\end{array}$ & 120 & 6 & 142 \\
\hline $\begin{array}{l}\text { The radiation oncologist, nurses and } \\
\text { radiation therapists work well } \\
\text { together when treating the patient for } \\
\text { prostate cancer }(5)\end{array}$ & $\begin{array}{l}\text { Continuity of } \\
\text { care }\end{array}$ & 120 & 142 & 6 \\
\hline $\begin{array}{l}\text { The radiation oncologist treats the } \\
\text { patient with respect (5) }\end{array}$ & $\begin{array}{l}\text { Empathy and } \\
\text { Respectfulness } \\
\text { of Caregivers }\end{array}$ & 120 & 141 & 31 \\
\hline The patient trusts the radiation & Competence & 126 & 124 & 27 \\
\hline
\end{tabular}




\begin{tabular}{|c|c|c|c|c|}
\hline $\begin{array}{l}\text { therapists to look after him properly } \\
\text { (5) }\end{array}$ & & & & \\
\hline $\begin{array}{l}\text { If the patient wants, the radiation } \\
\text { oncologist is willing to answer all } \\
\text { the questions the patient's family and } \\
\text { friends have (5) }\end{array}$ & $\begin{array}{l}\text { Patient } \\
\text { Centeredness }\end{array}$ & 127 & 95 & 110 \\
\hline $\begin{array}{l}\text { The patient feels that he can trust the } \\
\text { radiation therapists with confidential } \\
\text { information (5) }\end{array}$ & Privacy & 128 & 128 & 84 \\
\hline $\begin{array}{l}\text { The patient feels that he can trust the } \\
\text { radiation oncologist with } \\
\text { confidential information (5) }\end{array}$ & Privacy & 129 & 125 & 74 \\
\hline $\begin{array}{l}\text { The radiation therapists listen } \\
\text { carefully to all the patient's concerns } \\
\text { (5) }\end{array}$ & $\begin{array}{l}\text { Adequacy of } \\
\text { Information } \\
\text { Sharing }\end{array}$ & 130 & 117 & 60 \\
\hline $\begin{array}{l}\text { The radiation therapists take the time } \\
\text { to answer all of the patient's } \\
\text { questions (5) }\end{array}$ & Accessibility & 131 & 137 & 58 \\
\hline $\begin{array}{l}\text { The patient sees the same radiation } \\
\text { therapists each time he goes for } \\
\text { radiation treatment (4) }\end{array}$ & $\begin{array}{l}\text { Continuity of } \\
\text { care }\end{array}$ & 132 & 24 & 139 \\
\hline $\begin{array}{l}\text { The nurses treat the patient with } \\
\text { respect }(5)\end{array}$ & $\begin{array}{l}\text { Empathy and } \\
\text { Respectfulness } \\
\text { of Caregivers }\end{array}$ & 133 & 133 & 61 \\
\hline $\begin{array}{l}\text { The radiation oncologist is polite to } \\
\text { the patient (5) }\end{array}$ & $\begin{array}{l}\text { Empathy and } \\
\text { Respectfulness } \\
\text { of Caregivers }\end{array}$ & 133 & 143 & 55 \\
\hline $\begin{array}{l}\text { The radiation therapists show } \\
\text { interest in the patient as a person, not } \\
\text { just as a patient (5) }\end{array}$ & $\begin{array}{l}\text { Patient } \\
\text { Centeredness }\end{array}$ & 135 & 116 & 99 \\
\hline $\begin{array}{l}\text { The radiation therapists are honest } \\
\text { with the patient (5) }\end{array}$ & $\begin{array}{l}\text { Adequacy of } \\
\text { Information } \\
\text { Sharing }\end{array}$ & 135 & 140 & 20 \\
\hline $\begin{array}{l}\text { The radiation therapists make the } \\
\text { patient feel like he can ask any } \\
\text { questions he wants to (5) }\end{array}$ & $\begin{array}{l}\text { Empathy and } \\
\text { Respectfulness } \\
\text { of Caregivers } \\
\end{array}$ & 137 & 131 & 54 \\
\hline $\begin{array}{l}\text { The radiation therapists show } \\
\text { sensitivity to the patient's feelings } \\
\text { and emotional needs (5) }\end{array}$ & $\begin{array}{l}\text { Empathy and } \\
\text { Respectfulness } \\
\text { of Caregivers }\end{array}$ & 137 & 130 & 87 \\
\hline $\begin{array}{l}\text { The radiation therapists treat the } \\
\text { patient with respect (5) }\end{array}$ & $\begin{array}{l}\text { Empathy and } \\
\text { Respectfulness } \\
\text { of Caregivers } \\
\end{array}$ & 139 & 138 & 78 \\
\hline $\begin{array}{l}\text { The patient is treated in the same } \\
\text { treatment room each day (4) }\end{array}$ & $\begin{array}{l}\text { Continuity of } \\
\text { care }\end{array}$ & 139 & 36 & 143 \\
\hline $\begin{array}{l}\text { The radiation oncologist or the nurse } \\
\text { see the patient at least once a week }\end{array}$ & $\begin{array}{l}\text { Continuity of } \\
\text { care }\end{array}$ & 141 & 89 & 121 \\
\hline
\end{tabular}




\begin{tabular}{|l|l|c|c|c|}
\hline $\begin{array}{l}\text { during the course of radiation } \\
\text { treatment (4) }\end{array}$ & Privacy & 142 & 86 & 124 \\
\hline $\begin{array}{l}\text { The patient has enough privacy } \\
\text { during his care (5) }\end{array}$ & $\begin{array}{l}\text { Acceptability of } \\
\text { Treatment } \\
\text { Environment }\end{array}$ & 143 & 7 & 141 \\
\hline $\begin{array}{l}\text { Food and drink facilities are } \\
\text { available in or near the waiting room }\end{array}$ & & & \\
\hline
\end{tabular}

*The number in parentheses indicates the step in the treatment pathway the element refers to: (1) Pretreatment assessment, (2) Treatment decision-making, (3) Treatment planning, (4) Treatment and follow-up, (5) General aspects of care 


\title{
Appendix F
}

\section{Additional Results for the Manuscript Titled, "Measuring the Quality of Personal Care in Patients Undergoing Radiotherapy for Prostate Cancer"}

\author{
Appendix F1: Test-retest Reliability \\ Median positive agreement for quality ratings of the 64 elements in module 3 was $92 \%$ (range \\ $68 \%$ to $100 \%)$. There was only one element of care with $<70 \%$ positive agreement: "There is \\ somewhere convenient to park".
}

\section{Appendix F2: Percentage of elements rated "very good" over time}

We compared the percentage of elements rated "very good" by each patient recruited in the first half of the study to the second half of the study and the differences were not significant (median percentage of elements rated "very good" in the first half of the study to the second half was $78.9 \%$ vs $79.9 \%, \mathrm{p}=0.7)$.

\section{Appendix F3: Sensitivity analyses for ranking methods and missing data}

A secondary analysis in which the elements were ranked based on the percentage rating each element as either "good" or "very good" gave very similar results to the original ranking based on "very good". The Spearman correlation coefficient comparing the overall ranking of elements was $0.92(\mathrm{p}<0.0001)$. The ranking of elements based on the percentage of patients rating each one 
"very good" or "good" identified 7 out of the same 10 elements of care in the bottom 10 as the analysis by "very good" only.

We conducted a sensitivity analysis to assess the impact of missing data on the ranking of elements of care based on ratings of "very good". For each patient, missing responses were coded as less than "very good" and the elements of care were re-ranked based on the percentage of patients rating each one as "very good". The Spearman correlation coefficient comparing the new rank order to the original order was 1.0. Although there were some changes in the elements ranked in the top 10 , there was only only 1 element in the bottom 10 ranked elements of care that differed.

\section{Appendix F4: Assumptions of Generalized Estimating Equations}

This topic was described in Appendix C3 with respect to the analysis of the results of the importance ratings. The same rationale applies to this analysis; we did not use imputation to deal with missing data as it is not necessarily needed with GEE (193) and again, the amount of missing data was relatively low; for each patient, the median percentage of elements missing a quality rating was $6 \%$ (range $0 \%$ to $34 \%$, IQR $3 \%$ to $11 \%$ ). Again, we compared various correlation structures using the QIC for comparison, and again, chose the "exchangeable" structure as we felt it was most appropriate for these data (194).

Table F3-1: QIC values for different GEE correlation structures

\begin{tabular}{|l|l|}
\hline Correlation structure & QIC value \\
\hline Exchangeable & 14787.3 \\
\hline
\end{tabular}




\begin{tabular}{|l|l|}
\hline Autoregressive & 16506.6 \\
\hline Independent & 14787.0 \\
\hline Unstructured & 15279.0 \\
\hline
\end{tabular}

